\title{
Beach stability on a tropical uplifted coral atoll: Niue Island
}

\author{
Teuvirihei Helene Marsters
}

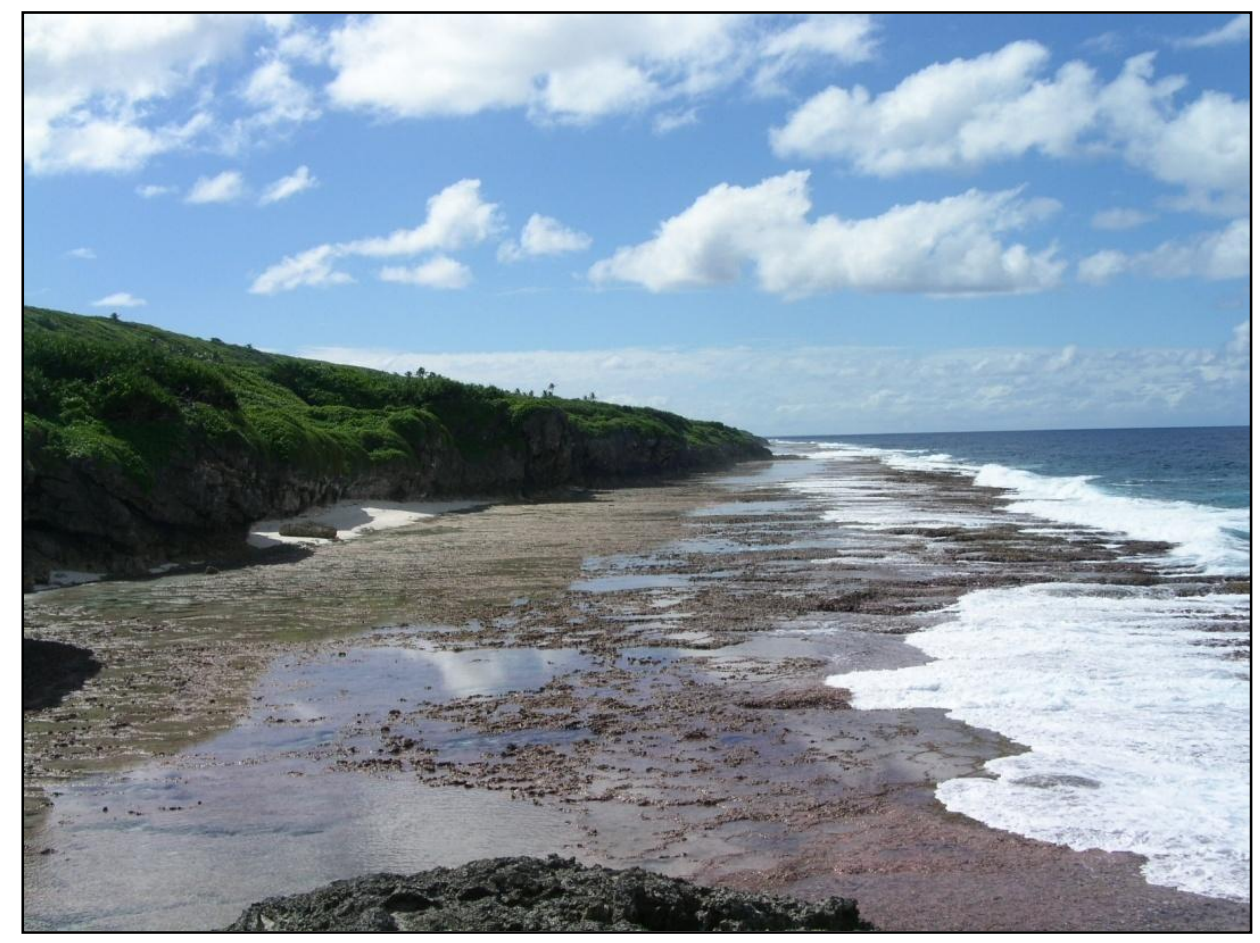

A thesis submitted to Victoria University of Wellington, as partial fulfillment of the requirements for the degree of Master of Science (Hons) in Physical Geography

School of Geography, Environmental and Earth Sciences, Victoria University of Wellington 


\begin{abstract}
Fundamental knowledge about the change and dynamics, and what thresholds drive sediment accumulation in tropical reef settings are poor. Little is also known about how they may respond to the higher and stormier seas that are predicted in an enhanced greenhouse world. Niue's rocky shore setting and the regular occurrence of small isolated pocket-beaches provides an ideal environment to investigate key factors that drive beaches to accumulate or erode within a tropical reef setting.

Niue is the largest uplifted coral atoll in the world, covering an area of $200 \mathrm{~km}^{2}$ and rising to $70 \mathrm{~m}$ above sea level. The island is characterised by a series of Pleistocene reef terraces with distinct platforms forming at the base at approximate mean sea level. Lateral reef growth at sea level is juxtaposed with landward retreat of the limestone cliffs leading to the formation of shore platforms. Geomorphological surveys of 9 sites revealed a combined reef platform width of up to $150 \mathrm{~m}$ with the widest section found on the leeward side of the island on the north western coast and the narrowest $(<30 \mathrm{~m})$ being located on the more exposed south eastern coast. Therefore, their distribution is likely related to the energy environment around the island.
\end{abstract}

Beaches up to $12 \mathrm{~m}$ wide and $50 \mathrm{~m}$ long are only found in protected coves along the shoreline. Their development is determined by platform width, with beaches only occurring in areas where platform width is more than $60 \mathrm{~m}$. While distance from the reef crest played a role in dissipating wave energy across the platform therefore reducing beach erosion, beach stability is reliant the morphology of the underlying ramp on the landward edge of the platform. Beaches increased in width at higher elevations therefore implying that a higher ramp can effectively reduce the amount of wave energy reaching the landward edge of the beach resulting in the accumulation of sediment. Composition analysis of 51 samples reveal that the Niuean beaches are largely composed of unconsolidated bioclastic sand and gravels derived from the surrounding reef platform. They are characterised by an assemblage of chlorozoan carbonates typical of tropical areas, in which coral and coralline algae are prominent $(>50 \%)$ except on the north western platforms (Hio and Tuapa) where foraminifera is the key component.

Radiocarbon dating further indicates the youth of these beaches returning modern ages for reef flat microatolls as well as the beach sand itself. These sedimentary environments on Niue are therefore intrinsically linked to the platform biota and their preservation also dependent on the frequency of cyclones. The fast recovery of the foraminifera-rich north western beaches following Tropical Cyclone Heta (2004) is an indication that the foraminifera community can re-establish quicker after cyclones. This therefore confirms that the beaches are highly dynamic, and build out or erode during alternated calm and stormy conditions. The close links between beach accumulation and their biotic communities will be strongly affected by human-induced climate change, likely leading to the beaches becoming more ephemeral in the future. 


\section{Acknowledgements}

This project would not have been possible without my supervisor Dr. David Kennedy, whose support, encouragement and remarkable patience from the initial to the final stages enabled me to develop an understanding of the subject. One simply could not wish for a better or friendlier supervisor.

I also wish to express my gratitude to the wonderful people of Niue, particularly the Pihigia Family for your warm and welcoming hospitality during our visit. Fakaue Lahi. Thanks to the Niuean High Commissioner, Mrs. Sisilia Talagi for providing us with all the necessary contacts. To the Niue Department of Environment who provided the necessary permits to carry out this research and for the export of sand samples. To the Niue Lands and Survey department for the GIS data. Many thanks also to Ross Arden, Niue Chief of Police, for all your help. A special mention goes out to Haden Talagi (our local tour guide), Gigi Woods and Dr. David Kennedy for assistance and advice in the field.

I would like to acknowledge the University Research Fund who funded this research. Thanks to the many academic staff and students at the School of Geography, Environment and Earth Sciences. To Stewart Bush for the preparation of thin sections, to Andrew Rae for your continuous help in the use of GIS and to Gillian Ruthven for assistance in the library. I am also grateful to the Te Rōpu Āwhina Whānau for all their support from the very beginning of this journey. I cannot thank you enough.

To my office buddies, Katie, Dave and Erin. Cheers for the laughs and the numerous stimulating science discussions we've had over the past 2 years. And to all my friends, thanks a million.

Lastly, I cannot end without thanking my family, in particular my mother, Metua Marsters, on whose constant encouragement and love I have relied on throughout my time at university. 


\section{Table of Contents}

Abstract

Acknowledgements III

List of Figures $\quad$ VII

List of Tables

List of Equations $\quad$ IX

CHAPTER 1: Introduction 1

$\begin{array}{lll}1.1 & \text { Introduction } & 1\end{array}$

1.2 Aims and Objectives 3

1.3 Thesis Structure 4

CHAPTER 2: Literature Review 5

$\begin{array}{lll}2.1 & \text { Introduction } & 5\end{array}$

2.1.1 Historical perspective and evolution 5

2.1.2 Atoll and reef types 6

2.1.3 Holocene reef growth and response to sea level change 8

2.2 Reef morphology and zonation $\quad 11$

2.2.1 Reef zonation 11

$\begin{array}{lll}2.3 & \text { Reef processes } & 12\end{array}$

2.3.1 Carbonate sedimentation and distribution 12

2.3.2 Wave and tide processes 15

$\begin{array}{lll}\text { 2.3.3 Extreme events and disturbances } & 19\end{array}$

2.4 Island and sediment accumulation 20

2.4.1 Reef island sedimentation 20

2.4.2 Sediment accumulation and dynamics on platforms 22

$\begin{array}{lll}2.5 & \text { Summary } & 28\end{array}$

CHAPTER 3: Regional Setting 29

3.1 Introduction $\quad 29$

$\begin{array}{lll}3.2 & \text { Geology } & 30\end{array}$

3.3 Geomorphology $\quad 32$ 
3.3.1 Coastal and reef morphology 32

3.4 Climate 37

3.5 Oceanography 38

3.6 Natural Hazards 39

3.6.1 Tropical cyclones

$\begin{array}{lll}3.6 .2 & \text { Tsunami } & 40\end{array}$

3.6.3 Submarine slope failure 41

3.7 Land use and vegetation $\quad 41$

CHAPTER 4: Methodology 44

4.1 Field data collection 44

4.1.1 Topographic surveying 44

4.1.2 Sediment sample collection 46

$\begin{array}{lll}4.2 & \text { Laboratory Procedures } & 47\end{array}$

4.2.1 Sample Processing $\quad 47$

4.2.2 Laser Diffraction Particle Sizer (LDPS) analysis 47

4.2.3 Composition analysis $\quad 49$

4.3 Radiocarbon dating $\quad 50$

4.3.1 Calibration 50

4.4 Airphoto analysis $\quad 51$

4.4.1 Georeferencing Aerial Photos 52

4.4.2 Beach and platform measurements 54

CHAPTER 5: Results 55

5.1 Introduction $\quad 55$

5.2 Surface Morphology 56

5.2.1 South West Coast 56

5.2.2 West Coast 60

5.2.3 North West Coast 62

5.2.4 East Coast 64

5.3 Sediment texture $\quad 66$

5.3.1 South West Coast 66 
$\begin{array}{lll}\text { 5.3.2 West Coast } & 67\end{array}$

5.3.3 North West Coast 68

5.3.4 East and South East Coast

5.4 Sediment composition $\quad 69$

5.4.1 South West coast $\quad 69$

5.4.2 West Coast 72

5.4.3 North West coast 73

5.4.4 East and South East Coast $\quad 75$

$\begin{array}{lll}5.5 & \text { Surface sediment ages } & 76\end{array}$

CHAPTER 6: Discussion $\quad 79$

6.1 General platform morphology 79

6.2 Linkage between platform reef morphology and sediment composition 83

6.3 Reef platform processes and sediment transportation 89

6.3.1 Wave energy $\quad 89$

6.3.2 Reef energy window and geomorphic implications 91

6.3.3 Surface sediment character in relation to composition and wave processes 94

6.3.4 Relations between component and sediment texture 97

$\begin{array}{lll}6.4 & \text { Beach stability } & 98\end{array}$

6.4.1 Beach accumulation thresholds 98

6.4.2 Application of Bruun or Trenhaile's model to beach stability 100

6.4.3 Beach stability in relation to exposure 103

CHAPTER 7: Conclusion $\quad 105$

$\begin{array}{lll}7.1 & \text { Introduction } & 105\end{array}$

$\begin{array}{lll}7.2 & \text { Reef platform morphology } & 105\end{array}$

$\begin{array}{lll}7.3 & \text { Drivers of sediment accumulation } & 106\end{array}$

$\begin{array}{lll}7.4 & \text { Beach stability } & 107\end{array}$

$\begin{array}{lll}7.5 & \text { Recommendations for future studies } & 108\end{array}$ 


\section{Appendices}

\section{Appendix 1: Grain size results}

\section{Appendix 2: Sediment composition results}

\section{Appendix 3: Sample locations}

Appendix 4: Radiocarbon dating results

\section{List of Figures}

2.1: Island atoll types on the Pacific lithospheric plate $\quad 6$

2.2: Reef growth response to variations in Holocene sea-level change 10

2.3: Coral form responses to various environmental stresses and cross-section of coral forms $\begin{array}{ll}\text { and diversity from sums of stresses } & 12\end{array}$

2.4: Breakdown of reef sediments 14

2.5: Schematic scenarios of reef island accumulation 22

2.6: Beach model assumptions based on the relationship between beach face and platform gradients

3.1: Location Map of Niue $\quad 30$

3.2: Stages in the evolution of Niue Island 31

3.3: Niue cross-section showing the geomorphic features 32

3.4: Coastal morphology of Niue and place names 33

3.5: Mean monthly rainfall and air temperature on Niue 38

3.6: Satellite image of the Niue coastline at the capital Alofi on the West Coast. Waves after $\begin{array}{ll}\text { Tropical Cyclone Heta } & 40\end{array}$

3.7: Vegetation cover of Niue) $\quad 43$

4.1: Surveying in progress at Lakepa beach using the Sokkia SET 4010 EDM 44

4.2: Moated Porites microatolls from the south western site of Tamakautoga 46

4.3: Beckman Coulter Counter Laser Diffraction Analyzer (LDPSA) 48

4.4: Relief displacement in aerial photographs 52

4.5: Before and after aerial photographs illustrating the effect of georeferencing an aerial photograph to the Niue topographic map. 
5.1: Map of Niue, showing locations that are mentioned in this study

5.2: Aerial photo of sites on the south west coast and survey transects

5.4: Survey transect at Avatele Beach, showing general surface morphology

5.5: Sediment accumulation at Avatele Beach

5.6: Topographic profiles at Utuko and Alofi Wharf

5.7: Aerial photo of Utuko and Alofi Wharf with survey transects

5.8: North Western sites of Hio and Tuapa

5.11: Platform and beach morhology at Lakepa and Tautu 66

5.12: Coral gravels on top of storm ridge at Avatele Beach 66

5.13: Sediment characteristics for Utuko

5.14: Bivariate plot of mean and sorting of surficial sediments from all coastal sites in Niue 68

5.15: Total surface composition for the South West coast 70

5.17: Total surface composition on the North West coast 74

5.18: Thin section of the sand sized fraction from Tuapa and Hio 75

5.19: Thin section of the sand sized fraction from Tautu and Togo Chasm 76

5.20: Beach and platform profile at Tamakautoga showing location of microatolls and ages 77

6.1: Well-developed microatolls superimposed on the reef platform at Tamakautoga. 81

6.2: Cliff failure at Makefu South during Cyclone Heta 82

6.4: Utuko at low tide and high tide where the beach is completely inundated

6.5: Relationship between mean grain size and sorting of Niue beach and reef platform sediments.

6.6: Hierarchical cluster analysis of surface sediment texture of samples collected from Niue.96

6.7: Platform width versus Beach width

6.8: Pocket beach at Tautu sitting on top of an abrasion ramp. Note the exposed abrasion ramp as a result of wave refraction within the embayment. 


\section{List of Tables}

2.1: Reef energy window index values and proportion of spring neap tidal cycle gravity wave energy can propagate across reef flat

2.2: Beach face equilibrium gradients between two wave environments

3.1: Terrace ages and rates of long-term uplift of Niue since the emergence of the Mutalau Reef

3.2: Total length, reef platform, width, and beach occurence by coastal unit

4.1: Mean elevation of reef flat microatolls relative to MWL at sites on the South West, West, North West, and Eastern side of the island.

4.2: Root Mean Square error values and order of Polynomial transformation for georeferenced aerial photos of Niue

5.1: Summary of the mean proportion of skeletal components in samples from the East and South East coast.

5.2: Radiocarbon ages and their associated calibrated ages from bulk sand and individual grains from Tamakautoga beach and reef platform.

6.1: Correlation matrix of key sediment components using the Pearson Linear Correlation method. Figures in brackets represent the p-values

6.2: Reef energy window indices for Niue platforms

6.3: Correlation matrix of beach, platform and sediment characteristics using the Pearson Linear Correlation method

\section{List of Equations}

Equation 2.1 


\section{CHAPTER 1: Introduction}

\subsection{Introduction}

The vulnerability of islands formed on coral atolls to environmental and climatic change is the subject of great global concern, especially in atoll nations where they provide the only habitable land (Kench et al., 2005). These islands are particularly susceptible to the effects of sea level rise due to their size, low elevation and limited resources. Coastal erosion is a common problem in most Pacific Island states and this may be exacerbated by the effects of rising sea level (Nunn, 1990). Predicted sea level rise of close to $1 \mathrm{~m}$ by the end of the century will likely erode islands and beaches throughout the tropics most likely causing complete drowning of entire Pacific nations (Nunn, 1990; Woodroffe, 2008).

Beaches on atoll reef islands rely on sustained input of sediment that is sourced from the surrounding reef flats and adjacent cliffs. Degradation of these sediment producing areas, especially the former, from natural and anthropogenic impacts is already causing high rates of beach erosion on many small Pacific Islands (Nunn, 1998). The dominant sediment contributors in most coral reef environments are Halimeda, coral, molluscs, foraminifera and coralline algae (Weber and Woodhead, 1972). Larger benthic foraminifera (LBF) are important carbonate producers in Pacific marine ecosystems and are particularly useful sediment tracers for interpreting coastal processes (Collen and Garton, 2004). Therefore, knowledge of the factors that influence sources of carbonate producers, for example, habitat, mode of transportation and the connection between the production and deposition area are vital for understanding the evolution of beach systems (Hohenegger, 2006).

Many islands within the Pacific also lie in the tropical cyclone belt. Storms are both construction and erosional agents (Woodroffe, 1994) and studies suggesting that episodic storm events and sea level fluctuations can lead to the reworking or the disappearance of existing beaches (Bayliss-Smith, 1988; Kench et al., 2005; Trenhaile, 2004; Woodroffe, 1994). The situation is exacerbated when sediment availability is initially scarce and sediment production and transport is slow, particularly in areas with a rocky foundation which limits beach development (Trenhaile, 2004). 
The dynamics of sediment accumulations on rocky shores is further complicated in that many rocky coasts are inhospitable environments for beach formation. Some rocks break down too slowly to replenish and maintain beaches, while the eroded finer material is lost offshore (Trenhaile, 2004). Little is known on the factors or settings that are favorable for sediment accumulation on rocky surfaces and how they may respond to changing environmental conditions. Models are often used to predict shoreline behavior in response to changes such as rising sea level and increased storminess. While the renowned 'Bruun Rule' is based on the horizontal recession of the shoreline associated with a given rise in sea level (Davidson-Arnott, 2005), mathematical modeling suggests that the nature and formation of beaches is determined by the relationship between platform and beachface gradient as well as sediment availability (Trenhaile, 2004).

Even under present climatic conditions, sand accumulations on most rocky shores are ephemeral features, disappearing and reforming as cyclonic events pass over tropical islands (Woodroffe, 2002). Therefore, sediment accumulations on rocky shores are extremely vulnerable to change, especially as their ongoing stability may also depend on erosion of the surrounding shore as a sediment source for beach and island construction. Fundamental knowledge about what thresholds drive beach accumulation in these settings is therefore poor and little is known about how they may respond to the higher and stormier seas that are predicted in an enhanced greenhouse world. It is therefore critical to discover what the tipping-points are for these systems which may drive them to disappear completely. 


\subsection{Aims and Objectives}

This research principally aims to "Describe the morphology of tropical coral reef beaches and to identify what thresholds exist that allow for sediment build-up in areas with a rocky foundation".

The island of Niue will be used as the study site for this research. The islands rocky shore setting and the regular occurrence of small isolated pocket-beaches provide an environment for investigating thresholds of sediment accumulation in a tropical reef environment. It also provides a basis for developing a conceptual model for the accumulation and dynamics of tropical carbonate beaches in response to environmental changes.

The specific objectives of this study are as follows:

1. Describe the morphology of reef platforms and their association to beach development.

2. Identify the key mechanisms which drive sediment accumulation and erosion within this tropical reef setting.

3. Determine the geomorphic stability of small pocket beaches on Niue. 


\subsection{Thesis Structure}

This research is comprised of seven chapters. Chapter 2 reviews literature relevant to sediment accumulation within tropical reef settings and the various factors and environmental processes that contribute to their development. A number of physical and mathematical models will also be reviewed within this chapter. Chapter 3 will describe the regional setting of the island of Niue, where this research is based. Chapter 4 discusses the methodologies carried out for field data collection, laboratory procedures and sample analysis while Chapter 5 presents results derived from these methods. A discussion of threshold conditions under which sediment accumulation occurs is then presented in Chapter 6. Finally, the conclusions derived from this research are presented in Chapter 7, along with recommendations for future research. 


\section{CHAPTER 2: Literature Review}

\subsection{Introduction}

Coral reefs can be regarded as both robust and fragile geomorphological ecosystems, displaying a complex interaction between physical and biological processes. Due to their dynamic nature, they are continually changing in both space and time as a result of natural disturbance ranging from minor to catastrophic (Woodroffe, 2002). Calcium carbonate $\left(\mathrm{CaCO}_{3}\right)$ derived from the nearby reef accounts for the majority of beach sediment in lower latitude tropical and subtropical regions, such as in the Pacific Islands (Woodroffe, 2008; Woodroffe et al., 1999). The degradation of these sediment producing areas will therefore likely lead to significantly high rates of shoreline erosion. Beach maintenance and change are also reliant on the transport of sediments from the reef source to the island sink and reef-top processes control how sediment is dispersed across the reef flat (Brander et al., 2004). Studies have highlighted the important linkage between reef flat sediment production and reef island formation, maintenance and their response to higher and stormier seas as a result of climate change (e.g. Woodroffe and McLean, 1992). However, very few studies have been carried out of contemporary sediment production on atoll reef flats especially in areas with a rocky foundation where sediment supply is considerably limited.

\subsubsection{Historical perspective and evolution}

In 'The Voyage of the Beagle', Charles Darwin (1842) proposed his theory of coral atoll evolution which is still accepted today. Darwin described how several reef types represented an evolutionary succession related to gradual subsidence of an oceanic volcano on which the reef initially developed in combination with vertical reef growth (Darwin, 1842). As the island begins to subside, the surrounding fringing coral reef is gradually built up through the vertical accumulation marine organisms. While the outer part of the reef maintains itself near sea level, the inner reef section lags behind. This forms ideal conditions for the development of a lagoon. As the volcano subsides below the water, an atoll, which is the final product of this gradual metamorphosis, is formed. The successive stages in the Darwinian sequence (Figure 2.1a, b, d, and e) are evident on several linear 
island chains in the Pacific such as the Hawaiian and Society Islands (Chubb, 1957; Scott and Rotondo, 1983; Woodroffe, 2002).

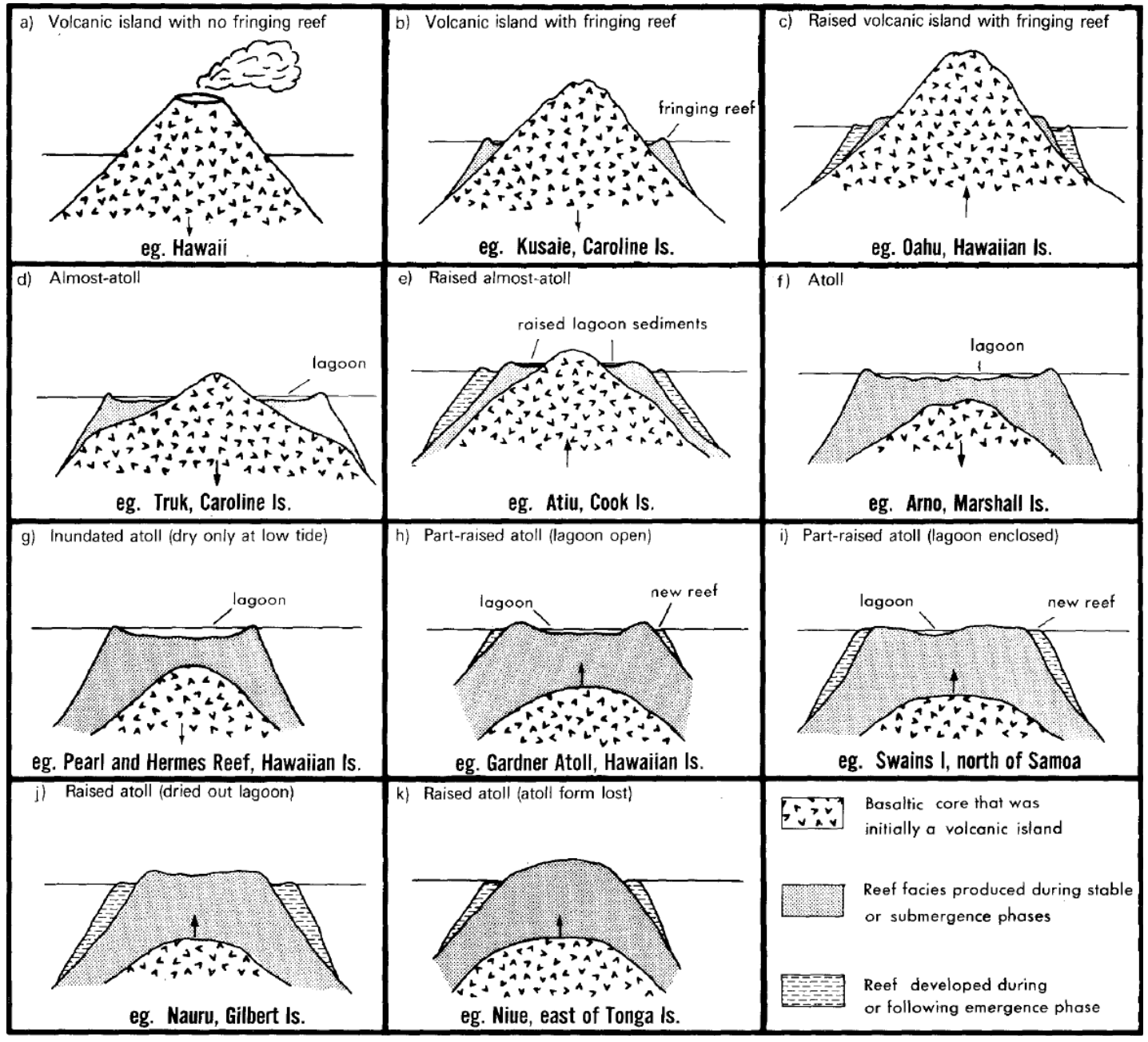

Figure 2.1: Island atoll types on the Pacific lithospheric plate. Arrows indicate relative vertical movement. Source: Scott and Rotonda (1983).

The subsidence theory of atoll formation was conclusively proven in the 1950's and on Enewetak Atoll, where a volcanic rock basement was discovered in boreholes at depths of $1267 \mathrm{~m}$ and $1405 \mathrm{~m}$ (Ladd et al., 1953).

\subsubsection{Atoll and reef types}

Tectonic and climatic factors play key roles in determining the distribution of coral reefs at a global scale and across geological time (Woodroffe, 2002). Most island types on the 
Pacific Plate originated as a volcanic island. Other islands depend on the development of a fringing reef followed by some degree of subsidence or emergence or a combination of the two. These were also driven by sea level change (Scott and Rotondo, 1983). The mode of formation, subsequent geological history of these volcanoes and the overlying reef caps, determine the form of the modern islands. In general terms, the islands can be classified as volcanic high islands, atolls and raised atolls, although numerous intermediate types exist (Figure 2.1) (Scott and Rotondo, 1983). These three islands are discussed in detail below:

1. Volcanic islands are characterised by slow subsidence, are generally high, well vegetated and may have broad coastal plains around river mouths. They typically occur either in arcs parallel to convergent plate boundaries or in chains in intraplate locations. A volcanic island in reef forming areas is rapidly encircled by a fringing reef such as on the island of Hawaii. Corals have established quite rapidly on young lava flows on various sections of the coast, while young volcanic islands are generally surrounded by a fringing reef (for example, Rarotonga, Cook Islands) due to ideal reef growing conditions. On some islands, emergence may have uplifted the original reef above the modern reef (Figure 2a-2c) (Scott and Rotondo, 1983; Woodroffe, 2002).

2. High limestone islands (or makatea islands) are often rising, commonly cliffed with dense vegetation and little lowland close to the shore. Most high limestone islands are either associated with lines of plate convergence or places where flexure of the intraplate lithosphere has taken place (Scott and Rotondo, 1983; Woodroffe, 2002). The sequence of island types in the mid-plate of the Pacific is more complex because there are a range of islands on which Pleistocene reef limestone is exposed above sea level (Figures $2 \mathrm{j}$ and $2 \mathrm{k}$ ). They can result from two main causes. Uplift in the order of tens of metres as a result of lithospheric loading and flexure associated with Pleistocene and Holocene volcanism. This creates a moat around the island and an arch several hundred kilometres away from the volcano leading to the formation of makatea islands. They comprise a deeply eroded volcanic core with a surrounding karstic limestone and dolomite landscape (Gray and Hein, 2005; Scott and Rotondo, 1983; Woodroffe et al., 1991; Woodroffe et al., 1990). The islands of Mauke, Atiu and Mitiaro in the Southern Cook Islands are typical examples that are located relatively close to the young volcanic 
island of Rarotonga (Gray and Hein, 2005; Scott and Rotondo, 1983; Woodroffe et al., 1991; Woodroffe et al., 1990). Raised coral atolls such as Niue are initially formed as the volcano subsides forming an atoll similar to that in Kiribati and Tuvalu (Solomon and Forbes, 1999). Consequently, the volcanic basement on which it sits upon is uplifted as the island moves across a lithospheric bulge. This is associated with plate subduction at ocean trenches, and in the case of Niue, the Tonga trench (Woodroffe, 2002). Characteristics of a raised-atoll like Niue include steep cliffs extending to the water line; narrow to non-existent fringing reefs and limited beach development. Some other common features include a rugged and dry interior and extensive cave networks. Subsequent glacial-interglacial sea level oscillations as well as irregular uplift have led to the development of several terraces at various levels around the outer rim of the island (Solomon and Forbes, 1999; Wheeler and Aharon, 1997).

3. Atoll islands usually rise no more than 3 metres above mean sea level and are made largely from unconsolidated materials accumulated on reef flats. They are mid-ocean reefs with an annular reef rim, surrounding a central lagoon with reef island; either sandy cays or shingle motu on the atoll rim (Barry et al., 2007; McLean and Woodroffe, 1994). They occur in tropical intraplate locations marking the areas where volcanic islands have sunk (Scott and Rotondo, 1983; Woodroffe, 2002). An almost-atoll is formed when the volcano is extinct and its peak deeply eroded. It is almost completely submerged except for several embayed basaltic islands in the middle of the lagoon (for instance, Truk, Caroline Islands) (Scott and Rotondo, 1983; Woodroffe, 2002). Once the volcanic basement subsides below sea level and vertical coral growth is established, an atoll occurs.

\subsubsection{Holocene reef growth and response to sea level change}

Knowledge of coral reef growth patterns during the Holocene has increased significantly in the last 30 years due to the development of drilling capabilities and radiometric dating techniques (Camoin et al., 1997). Reef evolution is influenced by accommodation space which is determined by changes in eustatic sea level and tectonic stability (Kennedy and Woodroffe, 2002, 2004). Reefs grow at a slow rate of $1 \mathrm{~mm} \mathrm{a}^{-1}$ to $10 \mathrm{~mm} \mathrm{a}^{-1}$ in comparison to individual corals which have growth rates of 10-100 $\mathrm{mm} \mathrm{a}^{-1}$ (Woodroffe et al., 2007). It 
is therefore crucial when studying coral reefs to distinguish between the growth rates of individual organisms comprising the reef to framework production and reef accretion (Neumann and Macintyre, 1985).

Modern reefs have evolved in response to Holocene sea-level changes. At least three reefgrowth scenarios have been identified; keep-up, catch-up and give-up (Figure 2.2) (Davies and Montaggioni, 1985; Neumann and Macintyre, 1985). 'Keep-up' reefs are those that are able to maintain vertical growth rate and keep pace with sea-level rise. 'Catch-up' reefs which are dominated by corals which appear to have lagged behind, and later caught up with sea level as the rate of rise become stable or decelerated (Davies and Montaggioni, 1985; Neumann and Macintyre, 1985; Woodroffe et al., 2007). Lateral progradation of coral reefs may also occur especially if the reef has established close to sea level, as has occurred in the Pacific (McLean and Woodroffe, 1994). In doing so, there is very little vertical accommodation space and as a result the reef extends seaward (Kennedy and Woodroffe, 2002). On Mangaia, Cook Islands, reef growth caught up with the sea surface between 4000 and 3400 years BP yet became stranded after a regional fall in sea level. It then began accreting laterally and eventually formed a double reef crest (Kennedy and Woodroffe, 2002; Yonekura et al., 1988). In the Indo-Pacific province, several reefs are emergent due to a regional relative fall of sea level in the mid-late Holocene (Dickinson, 2004). 


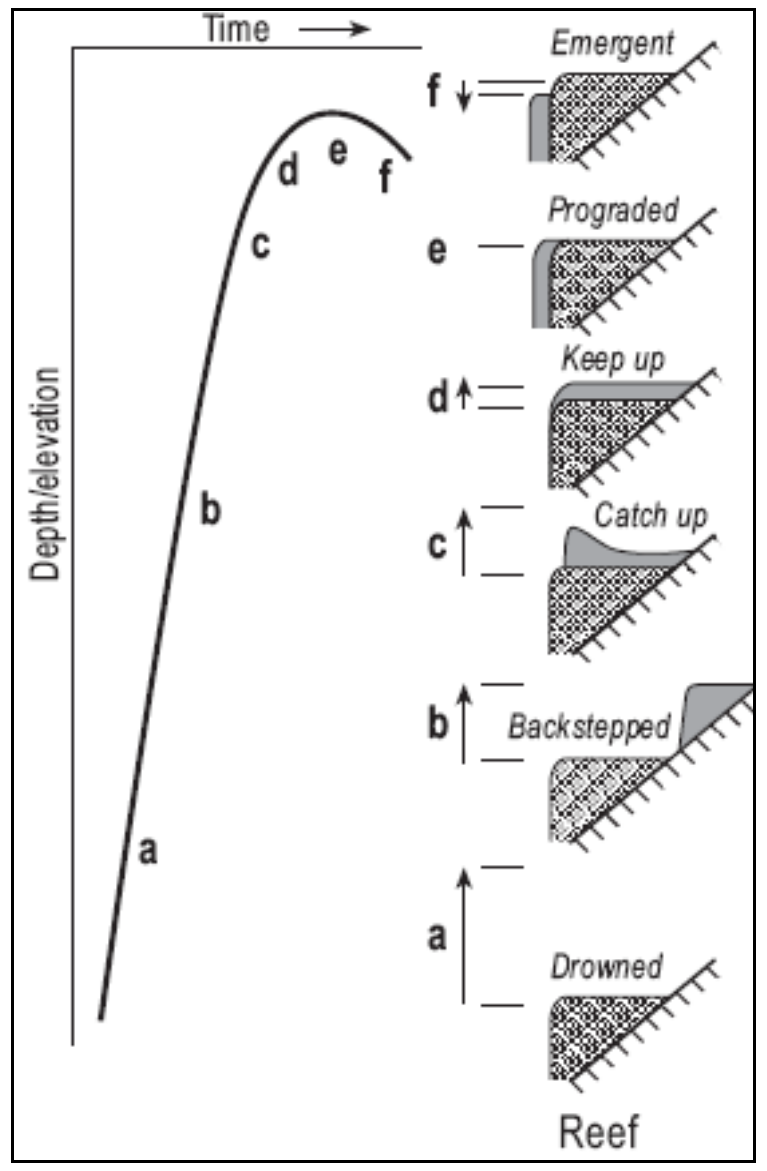

Figure 2.2: Reef growth response to variations in Holocene sea-level change. Source: Woodroffe (2007)

'Give-up' reefs are reefs that cannot maintain growth with the rate of sea level rise and eventually drown (Figure 2.2). This is evident on many of the shelf margins of the Caribbean and the West Atlantic Ocean where they currently persist as terraces at depths of approximately $20 \mathrm{~m}$ (Davies and Montaggioni, 1985; Macintyre, 1988; Neumann and Macintyre, 1985). Factors such as terrestrial freshwater runoff may have contributed to their limited vertical growth (Lighty, 1977).

Despite the fact that the three main modes of reef growth are usually applied to the reef crest, various sections of one reef may react differently to sea-level fluctuations. For example, a reef crest may have kept up with sea level and at the same time growth on the backreef may have been delayed but later caught up while the forereef terrace could have given up (Woodroffe, 2002). This has occurred on Tahiti, where keep-up reefs are found on the windward side and catch-up on the leeward side. Give-up reefs occur in muddy-patchreef settings (Montaggioni, 1988). 


\subsection{Reef morphology and zonation}

\subsubsection{Reef zonation}

Reefs especially those that have reached sea level can be subdivided into three zones namely; reef front, reef crest and backreef (Figure 2.3). The reef front has a steep slope and abundant live coral which joins into the forereef dominated by shore-normal 'spur and groove' structures that are 10-30 m apart and often 30-80 m long (Chappell, 1980; Woodroffe, 2002). They are usually prominent in high wave energy environments (Tracey et al., 1948). The reef crest is characterised by irregular morphology and is a high-energy zone where deepwater waves break. It is dominated by robust coral heads such as Acropora palmata and Millepora sp., or encrusting coralline algae in more vigorous wave energy settings. On many Indo-Pacific reefs, an algal ridge mainly of pink algae is a common feature that extends to about 5-15 $\mathrm{m}$ wide and rising to $0.3 \mathrm{~m}$ above the reef surface (Chappell, 1980; Woodroffe, 2002). However, in some areas (e.g. Tongatapu, Tonga) they can be a metre or higher (Nunn, 1993). Backreefs occur in more sheltered environments. The environments that promote back reefs either includes a reef flat, a roughly horizontal surface that usually extends from the shoreline out some distance to the reef crest, with fairly low and intermittent coral cover and 'ridge and runnel' structures (Blanchon and Jones, 1997) or lagoonal environments (Woodroffe, 2002). 

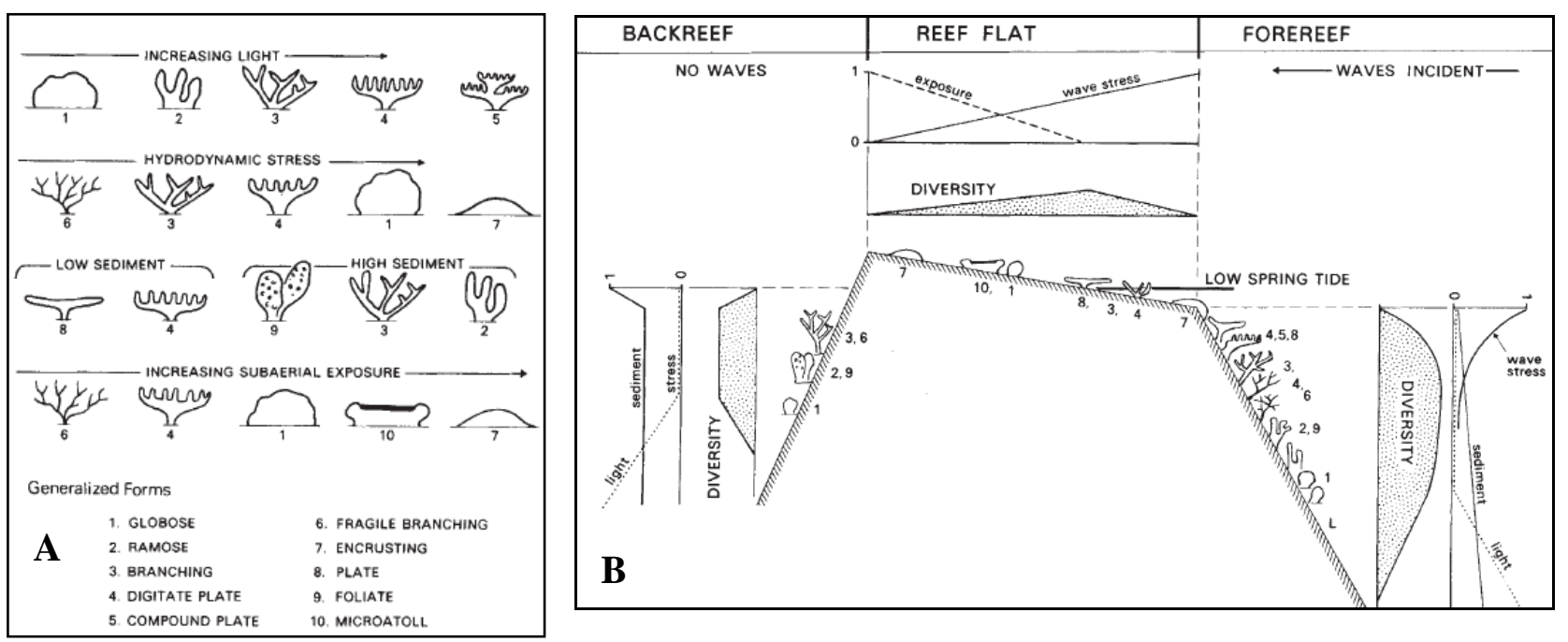

Figure 2.3: A) Coral form responses to various environmental stresses. B) Cross-section of coral forms and diversity from sums of stresses. Numbers correspond to the different coral forms in A. Source: Chappel (1980)

Reef flats can extend to more than a kilometre wide which dries at low tide; and become cemented by coralline algae. Live coral will only exist on the reef flat if there is sufficient water on the reef surface as corals cannot withstand exposure to air for long periods (Woodroffe, 2002). In areas that experience frequent storms, rubble ramparts are evident landward of the algal ridge. Alternatively, in the case of several atolls in the Marshall Islands, a moat may exist between these ridges (Stoddart et al., 1978).

\subsection{Reef processes}

\subsubsection{Carbonate sedimentation and distribution}

The interaction of benthic communities and physical processes such as waves and tides all contribute to the development of the reef complex. Specifically the interaction of these processes contribute to the production, transportation and deposition of sediments on reefs and platforms (Orme, 1973). However, it is difficult to group the various agents according to their relative importance due to the fact that some have multiple roles as producers, disintegrators or sediment transporters (Orme, 1973). Reefs within similar settings can be dominated by various benthic communities depending on nutrient status or grazing pressures from herbivores. Low nutrient conditions (nitrate $<2.0 \mathrm{umol} 1^{-1}$, phosphate $<0.2$ 
umol $1^{-1}$ ) are favorable for coral, yet high levels of grazing are essential in order to inhibit microalgae growth. Alternating periods of emersion and immersion within the intertidal zone can also determine which organisms can survive (Littler et al., 1991).

Sediment supply increases as the area of productive reef rim increases. Fringing reefs are often backed by reef flats instead of lagoons and so sediment may be carried directly across the flat and towards the shore where it accumulates (Woodroffe, 2002). Large amounts of carbonate sediment are generated through mechanical and biological breakdown of the reef framework. These vary from coral boulders and shingle that can form ramparts to fine gravel comprised of Acropora sticks (Hart and Kench, 2007; Kennedy and Woodroffe, 2002; Woodroffe, 2002); while Halimeda and foraminifera contribute directly to medium sand (Weber and Woodhead, 1972). Coarse stable fragments may also promote further coral colonization whereas fine mobile particles inhibit the growth of inactive reef-builders unless cementation of sediment takes place (Hart and Kench, 2007).

In most coral reef environments the dominant carbonate producers appear to be Halimeda, corals, molluscs, foraminifera and coralline algae. The abundance of carbonate grains from different sources may vary from one reef to another or within a single reef complex depending on population and productivity factors (Orme, 1973; Weber and Woodhead, 1972). For instance, modern beach sands on Tarawa Atoll, Kiribati are dominated by coral and foraminifera (Woodroffe and Morrison, 2001) while Halimeda dominates 70-100\% of sediment contributors on Eniwetok and Bikini Lagoons (Marshall Islands) (Emery et al., 1954; Weber and Woodhead, 1972). In Nusa Dua, Bali and Sesoko Island, Japan, foraminifera is the main component of beach sand, comprising around $90 \%$ of carbonate grains (Hohenegger, 2006). In contrast, foraminifera and Halimeda are less abundant in Fanning Lagoon, Kiribati (Roy, 1970) and the Midway Atolls, Hawaiian Islands (Gross et al., 1969). Molluscs, corals and coralline algae also seem to dominate over foraminifera at Pearl and Hermes Reef in the Hawaiian Islands (Thorp, 1936) as well as in Discovery Bay, Jamaica (Perry, 1996).

The life history of benthic organisms determines the rate of sediment production while its preservation depends on biological and chemical attrition (Woodroffe, 2002). Variations in 
carbonate grain size reflect the different factors involved in the creation of calcareous sediments (Figure 2.4). The composition and texture of sediment is determined by the characteristics of contributing organisms, the structure and micro architecture of their skeleton, its reaction to breakdown mechanism or its durability properties, and sediment transport (Orme, 1973; Spencer and Viles, 2002). For example, reef rock and skeletal components (coral, encrusting algae and molluscs) are relatively resistant to mechanical breakdown (Orme, 1973). Coral is highly durable due to its skeletal architecture and breaks down into joints (-6Ф) and grit (-2 $\Phi)$ and so conversion rates to sediment is low while the green algae, Halimeda on the other hand is highly productive yet easily breaks down to fine dust (10 $\Phi)$ due to its aragonite crystallography (Hart and Kench, 2007; Scoffin, 1992). Grains that pass through the intermediate stages of breakdown will also appear in a wider grain size distribution than those that breakdown into discrete size classes. The breakdown of sediments into certain size fractions is therefore a function of its structural characteristics, and this is referred to as the Sorby principle (Orme, 1977). For instance, Folk and Robles (1964) identified two size grades that Halimeda was concentrated at on Yucatan beaches, namely $0 \Phi$ and $10 \Phi$ the latter being the final disintegration size of aragonite crystals. The breakdown stages of Halimeda is however not entirely the result of structural characteristics but partly due to the sorting potential of a given environment (Chave, 1964; Scoffin, 1987). The initial size of foraminifer tests controls their grain size, with very large foraminifers such as Marginopora contributing to the gravel fraction while smaller Amphistegina adds to reef sands (Flugel, 2004; Fujita et al., 2009; Scoffin, 1987).

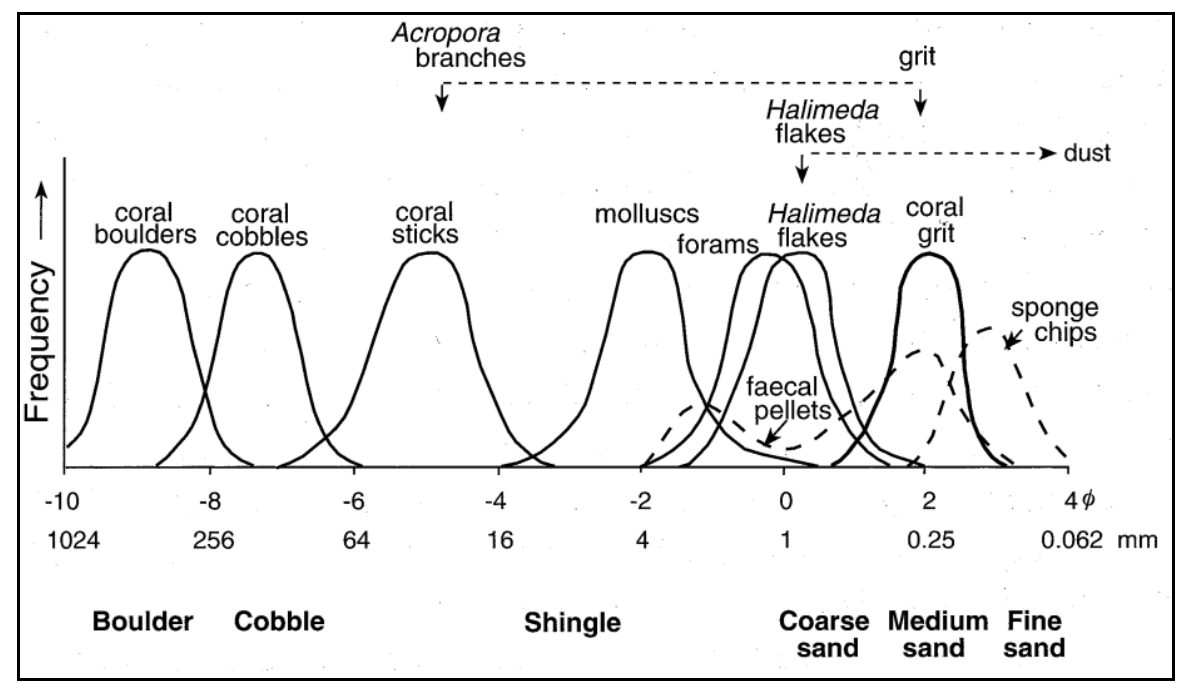

Figure 2.4: Breakdown of reef sediments via a series of discrete size classes depending on biological characteristics and physical processes. Source: Folk and Robles (1964) and Scoffin (1987.) 
Biological and mechanical processes make materials more susceptible to erosion through the weakening of skeletal structures (Orme, 1977). Once they are broken down to a size where they are easily transported, sediment may be subject to further size reduction due to abrasion. Resistance of skeletal material to mechanical erosion depends on the microstructure as well as the nature of its organic matrix. Tumbling barrel experiments by Chave (1964) found that echinoderms and coralline algae were the least durable forms relative to Acropora, Porites and mollusc fragments. The skeletons of certain organism have high durability implying slower conversion rates which leads to a reduction in sediment component makeup as opposed to the less resistant grains. For instance, coral is highly productive but its high durability reduces its potential to be converted into sediment in comparison to Halimeda which has high turnover rates and is less resistant (Orme, 1977; Hart and Kench, 2007). Nevertheless, major storm events can completely change long-term grain size distribution patterns in reefs and platforms within hours (Flugel, 2004).

Bioerosion is accomplished by a suite of organisms ranging from microborers (algae and bacteria) that bore into living and dead corals, to macroborers such as bivalves or sponges that contribute to mud fractions on many reefs. Grazers (parrot fish, echinoids and gastropods) feed on micro and macroborers as well as remove part of the substrate, breaking down material to smaller grains and transporting it across the reef (Spencer, 1992; Spencer and Viles, 2002). Mechanical erosion due to the hydraulic action of waves and tides subsequently erodes, sorts and entrains sediment (Marrack, 1989). For example, annual production of sediment on a fringing reef in western Barbados is approximately 10.7 $\mathrm{kg} \mathrm{m} \mathrm{m}^{-1}$, with sea urchins and parrotfish accounting for about half of this $\left(5.3 \mathrm{~kg} \mathrm{~m}^{2} \mathrm{a}^{-1}\right)$ (Stearn et al., 1977). This also occurs on St Croix, where about $60 \%$ of the reef is removed through bioerosion and any remaining sediment is eventually lost offshore due to storms (Hubbard, 1992; Hubbard et al., 1990).

\subsubsection{Wave and tide processes}

Windward margins are favourable environments for reef growth, especially those in tradewind settings where wave energy and nutrient supply is greatest (Woodroffe, 2002). These margins of the reef are where wave and current activity are highest and burial by 
mobile sediment is least likely (Reading, 1996). For example on the Cocos (Keeling) Islands (Kench, 1997; Kench, 1998a, b; Smithers, 1994). Reef flats are well developed on the windward margin extending $1500 \mathrm{~m}$ in width on the south side as opposed to $<100 \mathrm{~m}$ on the east and west. Incident waves have shorter wave periods with variable wave directions. These are found to be the important components of waves on some reefs, such as that on a sand cay in Torres Strait, Australia (Samosorn and Woodroffe, 2008).

Wave characteristics and the extent of energy dissipation across a reef are influenced by abrupt changes in morphology (i.e. elevation, reef slope, and reef flat width), variable roughness and relative water depth at the reef edge (Kench and Brander, 2006; Kench et al., 2006; Samosorn and Woodroffe, 2008). Five different hydrodynamic zones have been identified across reef platforms (Gourlay, 1996b; Gourlay and Colleter, 2005). These include (i) outer slopes where waves propagate over, (ii) reef edge where waves break, (iii) reef rim, where waves surge after breaking, (iv) flats where waves reform, and (v) beaches where reformed waves will break again. On Grand Cayman Island in the West Indies (Roberts et al., 1975) and the Great Barrier Reef (Hopley, 1982; Wolanski, 1994), reefs on the windward side reduce open-water wave energy by 70-90\%. The spacing of spur and groove patterns at the reef edge also determine how incident wave energy is distributed (Kench et al., 2006). Factors such as the magnitude and characteristics of residual energy following wave breaking across the reef edge affect processes that occur on the reef. Residual energy activates geomorphic processes such as sediment entrainment and deposition and contributes to reef island construction, distribution, sedimentary character and beach morphology (Brander et al., 2004; Kench and Brander, 2006; Kench et al., 2006; Kench and McLean, 2004). In actual fact, very little research has been done on sediment movement patterns and the mode of energy dissipation across shallow lagoons and reef flats. Wave refraction may contribute to sediment distribution within the backreef zones (Gourlay, 1996) and this may explain why sand cays are concentrated on the leeward side of platform reefs in the Great Barrier Reef (Hopley, 1981).

The 'reef energy window index' ( $\Psi$ ) (Kench and Brander, 2006) signifies the ratio of reef flat water depth at MHWS to reef width (Equation 2.1). It is an important quantitative 
indicator to determine the effectiveness of waves to activate the geomorphic processes on reef tops.

$\underline{\Psi=\text { Reef platform depth at MHWS }}$

Equation 2.1

Reef width

High index values $(>0.05)$ indicate narrow active reefs with high relative water depth, while low values $(<0.01)$ represent wide and shallow reefs that are inactive and more effective at filtering and dissipating wave energy over the reef flat (Kench and Brander, 2006). For instance, the reef south of Cocos Island is broad measuring $1100 \mathrm{~m}$ in width with a mean water depth of only $0.55 \mathrm{~m}$, therefore resulting in a low index value (0.0005) (Table 2.1). In contrast, the reef east of Cocos Island has higher values (0.015) indicating narrower reefs at lower elevations allowing for the activation of sediment transport. The amount of gravity wave energy on reef flats is generally determined by water depth; however, reef width is also important in how energy is distributed, with wider reefs dissipating more wave energy (Kench and Brander, 2006). Yet, in some cases shoreward reduction in wave energy ends $1200 \mathrm{~m}$ from the reef edge and there is actually a relative increase in wave energy further landward, as have occurred on Warraber Island (Kench and Brander, 2006). On the island it is the local generation of high frequency wind waves on the reef flat at high tide that drives sediment transport (Brander et al, 2004).

Kennedy and Woodroffe (2002) also pointed out that the different modes of reef development determine the type of sediment deposited. Beach gradient and grain size tend to be inversely related to the width of the adjacent fringing reef. Where the reef is narrow, steep gravel beaches exist whereas sandier beaches usually develop on wider reefs (Kench and Brander, 2006). 
Table 2.1: Reef energy window index values and proportion of spring neap tidal cycle gravity wave energy can propagate across reef flat. Source: Kench and Brander (2006)

\begin{tabular}{|lcccc|}
\hline Location & $\begin{array}{c}\text { Mean Water Depth } \\
\text { across Reef Flat at } \\
\text { Spring High Tide } \\
(d, \mathrm{~m})\end{array}$ & $\begin{array}{c}\text { Reef } \\
\text { Width } \\
(R w, \mathrm{~m})\end{array}$ & $\begin{array}{c}\text { Reef Energy } \\
\text { Window } \\
\text { Index } \\
(d / R w=\Psi)\end{array}$ & $\begin{array}{c}\text { Time of Spring- } \\
\text { Neap Cycle } \\
\text { Critical Reef Flat } \\
\text { Water Depth } \\
\text { Exceeded }(\%)\end{array}$ \\
\hline Cocos east & 1.05 & & & 76 \\
Cocos south & 0.55 & 1100 & 0.0005 & 16.2 \\
Warraber & 1.95 & 2700 & 0.00072 & 21 \\
LEI* east & 2.75 & 400 & 0.007 & 38 \\
LEI* west & 3 & 58 & 0.052 & 74 \\
\hline *LEI= Lady Elliot Island & & & \\
\hline
\end{tabular}

Lady Elliot Island is a coral shingle cay located on a kidney-shaped platform. The high and low index values on the east (windward) and west (leeward) reef flats are possibly due to the differences in wave energy and shoreline morphology. Beaches along the narrow reef flat on the leeward side are composed of coarse sediment (-2.0 phi) and are narrow $(15 \mathrm{~m})$ and steep ( $\tan \beta=0.15$ ), while behind the windward reef flats, beaches are wider $(23 \mathrm{~m})$ and composed of finer sediment $(-0.3$ phi) with a lower beach gradient $(\tan \beta=0.12)$. Variations in grain size and beach morphology are likely related to different modes of sediment production which is controlled by the various wave energy windows on the east and west sides of the island. This suggests that despite reef flats and island shorelines on the leeward side being exposed to less vigorous wave energy conditions, they are more geomorphologically active, forming steeper and reflective beach slopes composed of coarse coral shingle compared to the eastern windward side of the island (Kench and Brander, 2006).

High energy events are often required for significant change to take place, though the sediment transport system is limited if there is insufficient sediment supply (Brander et al., 2004; Scoffin, 1993). Although episodes of extreme events may be geomorphically important, wave energy processes under normal environmental conditions are more than capable of generating sediment transport across some reef flats e.g. Cocos (Keeling) Islands (Kench and McLean, 2004). Carbonate sands and gravel have skeletal and buoyancy 
characteristics therefore making some of them easily transported during non-storm energy conditions (Kench and McLean, 1996, 1997). For instance, the mean energy processes on the narrow eastern reef flat in the Cocos Islands are capable of transporting sediments and due to the limited sediment; transport rate is unaffected during storm events (Kench and McLean, 2004). However, the broader southern reef was less geomorphically inactive under mean energy conditions relative to the eastern reefs. Transport pulses often took place during higher-energy events when water depth and wave energy across the reef increased. This suggests that reef energy window index values can help determine the characteristics of sediment transport systems and shoreline sensitivity during extreme events. Low values indicate high reliance on storms while high values signify dependence on mean energy processes (Kench and Brander, 2006).

\subsubsection{Extreme events and disturbances}

Reefs are extremely dynamic and diverse and they subject to major disturbances such as tropical cyclones, floods, earthquakes, predator outbreaks, pathogens, and coral bleaching as a result of increased sea-surface temperatures (Brown, 1997). Many reefs are often subjected to frequent if not continuous disturbance, or are recovering from an earlier event. Due to frequent disruptions, some reefs may also build a resistance or become adapted to such disturbances such that they generally depend on the disturbance for the maintenance of its productivity and species diversity (Hughes and Connell, 1999; Stoddart, 1985).

Tropical cyclones occur between $7^{\circ}$ to $25^{\circ}$ north and south of the equator and the reefs that are situated within this belt are affected by periodic damage from these high energy events (Scoffin, 1993). The magnitude and duration of the event as well as the vulnerability of the system determines how effective the impact will be. Generally, significant damage is associated with the more severe storms; however, not all cyclones have the same effect on a reef (Woodroffe, 2002; Scoffin, 1993). For example, Hurricane Andrew (1992) had wind speeds up to $250 \mathrm{~km} \mathrm{~h}^{-1}$ but had very little impact on the reef in north-eastern Great Bahama Bank which it passed over (Boss and Neumann, 1993). A storm may be so intense that all debris is washed over the reef and into the lagoon leaving no intertidal storm ridge. Furthermore, a high intensity cyclone may cause relatively less damage if there is no source of debris due to the activity of an earlier event from which the coast had not fully recovered 
(e.g. Hurricanes Betsy (1965) after Donna (1960) on Florida Keys) (Scoffin, 1993). Large amounts of coarse sediments from reefs are usually carried on to reef flats to form storm ridges of shingle and rubble zones which are later modified by subsequent normal wave action (Bayliss-Smith, 1988). Past storm conditions can be determined by factors such as coral assemblage, occurrence and shapes of microatolls, characteristics of reef framework structure and the presence of storm ridges (Scoffin, 1993).

The area of greatest wave impact, as well as the elevation above mean tide level that storm surge may reach, is influenced by tides. In the event of a storm, deposition is often the dominant process during low tide while erosion occurs during high tide (Scoffin, 1993). Also, the extent of damage on reefs is determined by the availability of sediment required for abrasion on the reef top. Some of this sediment is derived from broken live branching corals such as Acropora or Porites depending on the size or age of the coral, length of time since the last storm event or disturbance, and recovery rate of the species in that setting (Harmelin-Vivien and Laboute, 1986). The greater the damage to the reef, the longer it takes for it to return to its pre-hurricane conditions. It may take anywhere between 5 and 40 years depending on storm frequency (Scoffin, 1993) and threshold conditions beyond which effects of a storm are likely to be prolonged (Bayliss-Smith, 1988; Stoddart, 1985).

\subsection{Island and sediment accumulation}

\subsubsection{Reef island sedimentation}

Recent coral reef studies have identified the need to incorporate sediment dynamics into sediment budgets (Harney and Fletcher, 2003; Kench and Cowell, 2000; Kench and McLean, 2004; Yamano et al., 2000). However, sediment transportation processes are inherently nonlinear and unstable to model over long time-periods. The difficulty with modelling sediment transport processes is exacerbated by the uncertainty in attempts to quantify sediment production, components of sediment production that contribute to reefisland building, and sediment mobilisation in the reef environment (Barry et al., 2007). 
Due to limited studies, the contemporary dynamics of reef islands are difficult to ascertain. Since the formation of the underlying reef flat or platform in the last 3000-4000 years, reef islands on atolls may have accumulated in several ways (Woodroffe et al., 1999). Variations in the gradual build-up of sediments on reef-islands, range from oceanward progradation, to roll-over, to lagoonward accretion (Barry et al., 2007; Woodroffe et al., 1999). The central core, oceanward accretion, and lagoonward accretion scenarios assumes that the dominant mode of accretion is horizontal, however the islands may accrete vertically (Figure 2.5). Rollover may take place when sediment eroded from the oceanward side is deposited on the lagoonward shore with subsequent migration into the lagoon (Woodroffe et al., 1999). On the western margin of the Cocos (Keeling) Islands, the central core or oceanward accretion scenario appears to be the most appropriate model for the evolution of West Island. During a period of gradual sea-level, it appears that the island accumulated primarily through oceanward accretion and to a lesser degree through lagoonward accretion, with the former scenario most likely to be ongoing (Woodroffe et al., 1999). Nevertheless, due to varied settings some scenarios are more likely than others or islands may possess more than one of the scenarios (Woodroffe, 1999). For that reason the depositional history between islands or around the atoll rim may differ from island to island and observations on one reef platform may perhaps not apply to other islands (Barry et al., 2007; Woodroffe et al., 1999). 


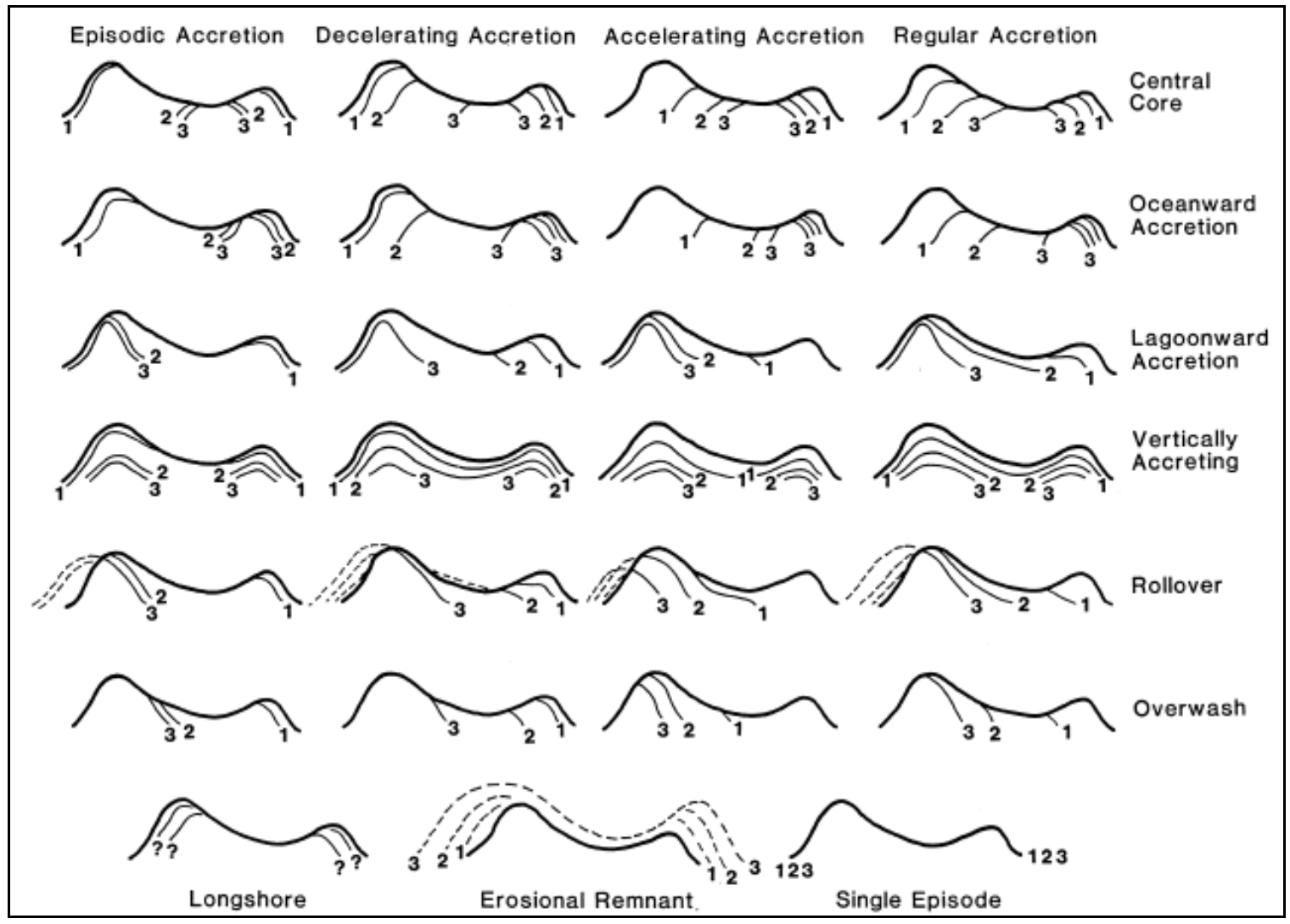

Figure 2.5: Schematic scenarios of reef island accumulation distinguished by the patterns of isochrones representing deposition, with oceanward shore to left and lagoonward to right. Source: Woodroffe et al., (1999).

\subsubsection{Sediment accumulation and dynamics on platforms}

Various models have been developed in order to predict how shorelines may respond to steady sea level rise and changing environmental conditions. The conceptual model put forward by Bruun (1962), termed the 'Bruun Rule', is used to predict the horizontal translation of the shoreline associated to a given rise in sea level (Davidson-Arnott, 2005). It assumes that the beach profile maintains equilibrium through sediment being eroded from the upper portion of the beach and deposited further offshore (Davidson-Arnott, 2005). However, there has been increasing questioning of the Bruun Rule and its applicability to various systems such as barrier islands (Woodroffe, 1993) or rocky coasts (Walkden and Dickson, 2008). It also assumes that the shore profile is entirely beach yet this is not the case on several coastlines and that the beach is only a surface deposit with an underlying a rocky ramp (Walkden and Dickson, 2008). In addition, the response of sedimentary coasts to sea level rise differs from that of rocky coasts. 
Rocky coasts act primarily as sediment sources for nearby beaches, tidal flats or estuaries. The low sediment volume on these platforms in comparison to sandy coasts makes these beaches highly sensitive to rising sea level and are easily modified by increasing storm frequency and intensity (Trenhaile, 2004; Trenhaile, 2005). In some reef settings beaches can develop on erosional terraces therefore Trenhaile's model (2004) is being used seeing that Niue has erosional surfaces rather than accretional flats as in other tropical reef settings. Their development on platforms is related to the shape and gradient of the platform profile, sediment character, tidal range, and wave type (Trenhaile, 2004). When modelling beach development, various assumptions must take place. Firstly, the beach face gradient at its seaward edge must be greater than the platform gradient (Figure 2.6a). If beach gradient at the foot of the beach is less than the platform gradient a beach cannot develop (Figure 2.6b). Given that the last assumption is satisfied, and there is adequate sediment, the beach may move landwards over parts of the platform that have higher gradients than the beach (Figure 2.6c) (Trenhaile, 2004). 


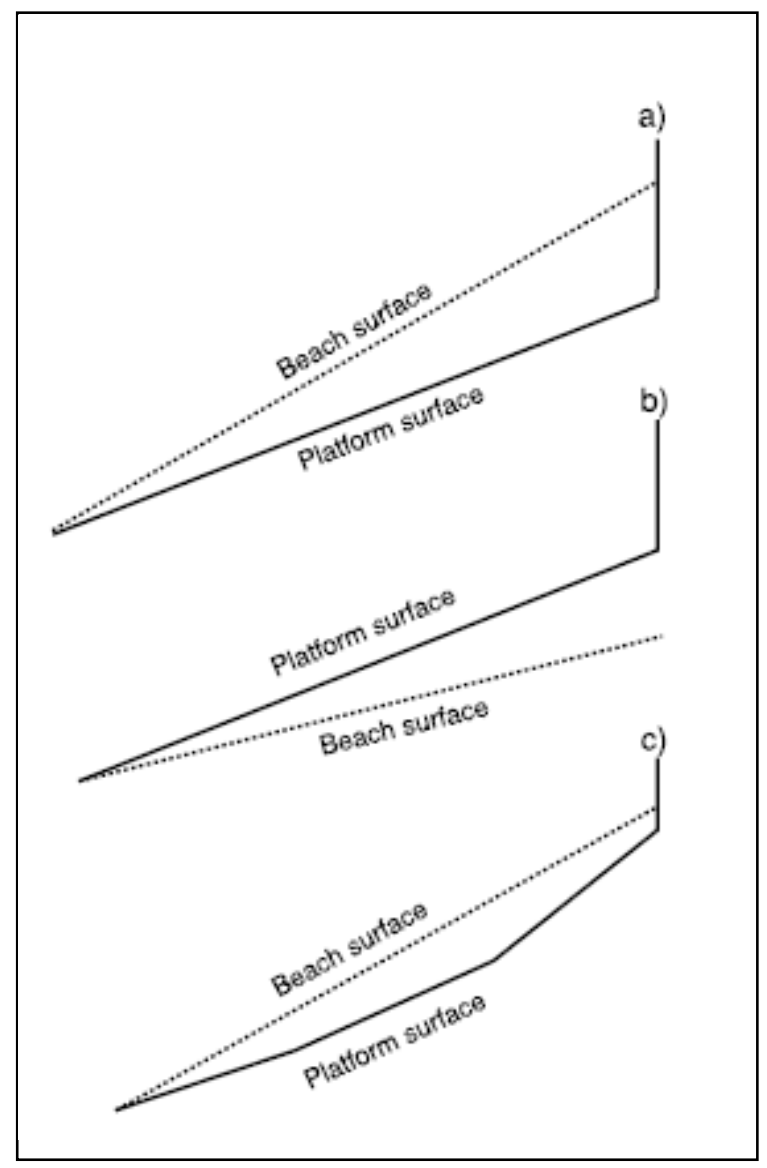

Figure 2.6: Beach model assumptions based on the relationship between beach face and platform gradients: (a) beach development occurs if it's gradient at the beach toe is greater than platform gradient; (b) if platform gradient is greater than beach gradient a beach cannot develop; (c) if there is adequate sediment, the beach may extend landwards over parts of the platform with higher gradients relative to beach gradient. Source: Trenhaile (2004).

As platform gradient is increased, first fine sand, then coarse sand; and eventually pebble beaches are unable to develop. The response of beach deposits also varied with changing wave conditions, particularly when breaker height was increased and wave period decreased (Table 2.2) (Trenhaile, 2004). Due to the fact that beachface and platform gradients are key factors in sediment accumulation, the shape of platform profiles is therefore important in determining whether or not beaches can develop (Trenhaile, 2004). 
Table 2.2: Beach face equilibrium gradients between two wave environments. Wave numbers 1 to 5 increase with increasing deep water wave height. Source: Trenhaile (2004).

\begin{tabular}{llccccc}
\hline & \multirow{2}{*}{ Grain size } & \multicolumn{5}{c}{ Beachface gradient $\left(^{\circ}\right)$} \\
\cline { 3 - 6 } Storm waves & & Wave 1 & Wave 2 & Wave 3 & Wave 4 & Wave 5 \\
\hline Cornwall) & Fine sand & 3.1 & 2.24 & 1.94 & 1.77 & 1.63 \\
& Coarse sand & 4.01 & 2.9 & 2.51 & 2.29 & 2.11 \\
& Pebble & 10.33 & 7.5 & 6.51 & 5.94 & 5.47 \\
& & & & & & \\
Swell waves & & & & & & \\
$($ Galicia) & Fine sand & 3.1 & 2.52 & 2.24 & 2.07 & 1.94 \\
& Coarse sand & 4.01 & 3.25 & 2.9 & 2.67 & 2.51 \\
& Pebble & 10.33 & 8.41 & 7.5 & 6.92 & 6.51 \\
\hline
\end{tabular}

If all assumptions are satisfied, a beach will initially develop in the most landward position and extend towards the gentler seaward edge of a concave profile. With enough sediment, these beaches deepen and gradually migrate landwards or seawards in areas where the platform gradient is greater relative to the beachface gradient (Figure 2.7). The steep seaward gradient of a convex profile also means that sediment accumulation rarely takes place, unless beachface gradient is greater than platform gradient and given that there was adequate sediment (Trenhaile, 2004). Only pebble beaches could develop on such high gradients of both concave and convex profiles. However, this may not apply to Niue since all profiles are linear in shape.

Storm intensity and frequency also play an important role in the morphology of beaches on platforms. Trenhaile's model suggests that the slow erosion on the rocky platform can help determine the locality, as well as the amount of sediment that can be deposited during calmer conditions or removed during storms. Furthermore, beachfaces become more gently sloping during storms, due to the fact that sediment is carried offshore, and in some cases beaches will completely disappear when shoreface gradient is less than the platform gradient. This usually occurs on fine grained beaches (Trenhaile, 2004). Storms often have very little impact on sediment losses and beach thickness on coarse-grained beaches, especially when beachface gradient is greater relative to platform gradient and there is adequate sediment to cover the platform during calm weather conditions. Therefore, despite beachface gradient being reduced during storms, the beach still remains intact (Trenhaile, 
2004). However, these beaches can completely disappear if sediment supply was scarce and the beaches did not cover the entire platform during calm conditions, resulting in reduced beach thickness as sediment encroached seawards (Trenhaile, 2004).

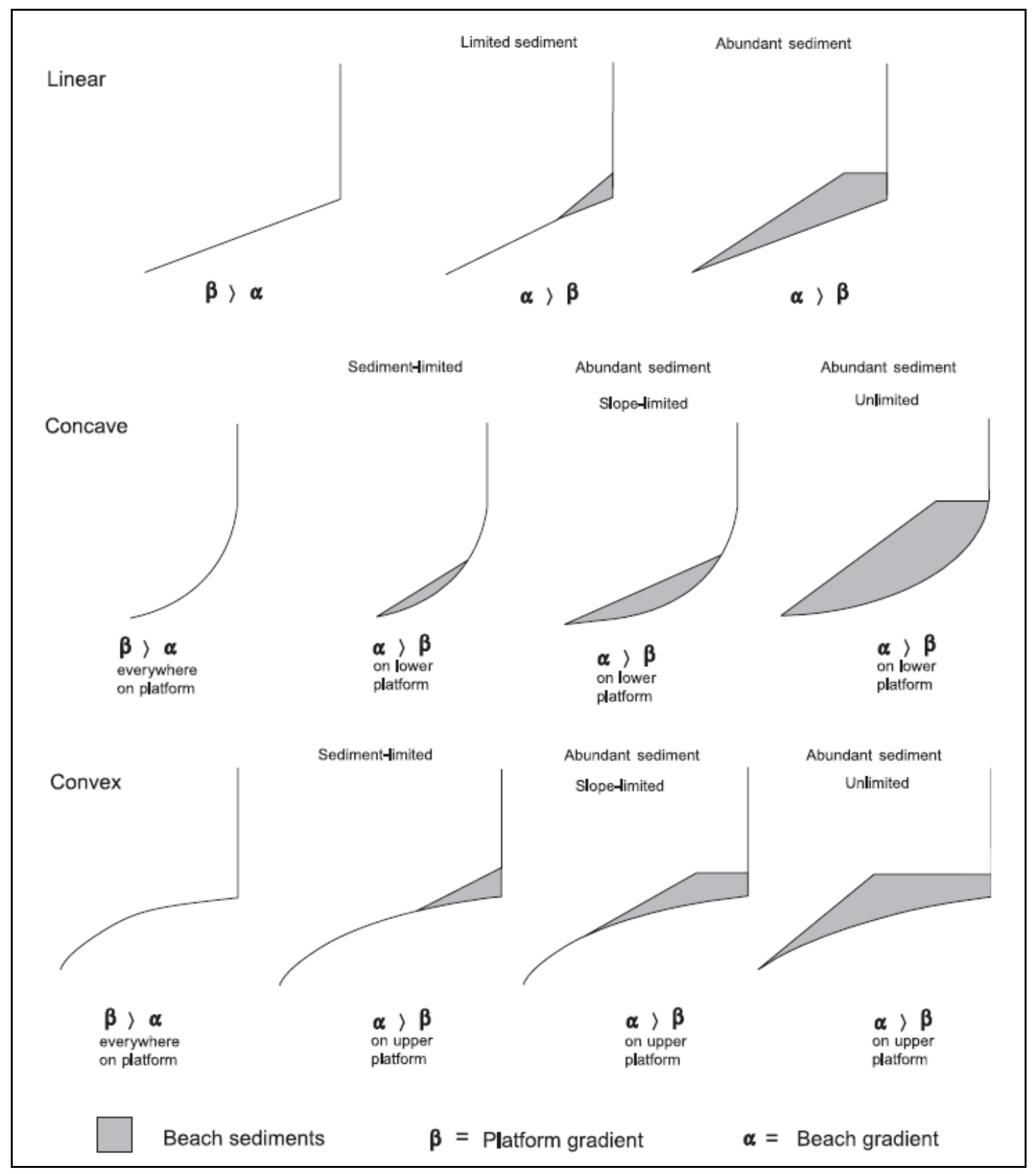

Figure 2.7: Simulated beach development on linear, concave and convex platform surfaces. Source: Trenhaile (2004).

Sediment lost offshore on the gentler slopes of linear and concave platforms can slowly move onshore again during calm phases. However, the time it takes for the beach to change 
depends on its ability to return to its state of equilibrium. This can be influenced by factors such as storm frequency, mobility of beach sediment, and the location and amount of sediment that was not removed from the platform during the storm (Trenhaile, 2004; Trenhaile, 2005). Sediment loss will also increase as platform width and beachface gradient is reduced with sea-level rise. Unlike depositional coasts, the slow eroding cliffs restrict beaches on rocky foundations from migrating landwards. Inundation of gentle sloping areas of concave and convex profiles leads to significant sediment loss in comparison to linear profiles (Trenhaile, 2004). These beaches may eventually disappear if they are displaced landwards where the platform gradient is greater than the beachface gradient. This is usually the case for slope limited beaches (Figure 2.7).

The platforms of Niue and those used by Trenhaile (2004) are similar in that they are both erosional features; however, Trenhaile's model is based on macrotidal platforms while Niue experiences a microtidal regime within a tropical reef setting. Platforms in this study are also fronted by spur and groove structures or a fringing reef which reduces the amount of wave energy reaching the cliff base. As a result, the characteristics of wave energy processes will vary between both environments. Beaches in Niue are also composed of unconsolidated bioclastic sand and gravels derived from the adjacent reef platform while those in Trenhaile's model are possibly sourced from cliff and platform erosion. Differences in sediment character can therefore lead to varied morphology and response to changing environmental conditions. 


\subsection{Summary}

Improved understanding of the depositional history of small pocket beaches and sand transport patterns is essential to better resolve their future stability. Clearly, there is a strong linkage between carbonate beaches in tropical reef settings and the reef platform biota in the immediate area. Their development is dependent on several factors such as the morphology of the underlying substrate, sediment supply and hydrodynamic processes. These beach systems are also dynamic in that they accumulate and erode in alternated calm and stormy conditions. The study site is also located in the tropical cyclone belt therefore beach stability and their ability to recover are dependent on the frequency and magnitude of such exteme events. This research therefore focuses on understanding carbonate beach systems and forecasting how they will adjust to altered environmental conditions such as sea-level change. The literature reviewed in this chapter will provide a context to help with the study of the small pocket beaches featured in this study. 


\section{CHAPTER 3: Regional Setting}

\subsection{Introduction}

The island of Niue $\left(19^{\circ} 00^{\prime} \mathrm{S}, 169^{\circ} 55^{\prime} \mathrm{W}\right)$ is an isolated high carbonate island located in the central South-West Pacific, roughly in the middle of a triangular area bounded by Samoa, Tonga and the Southern Cook Islands (Figure 3.1) (Forbes, 1996). The island is approximately $21 \mathrm{~km}$ along its N-S axis and $17 \mathrm{~km}$ along its E-W axis, occupying an area of $259 \mathrm{~km}^{2}$ (Wheeler and Aharon, 1997). Niue has a maximum elevation of $68 \mathrm{~m}$ above sea level and is considered the largest raised coral atoll in the world (Forbes, 1996; Terry and Nunn, 2003).

There has been limited scientific investigation on beach development and shoreline stability in response to sea level rise on the island. Its rocky shore setting makes it ideal to provide key information on the thresholds of sediment accumulation and their likely response to future climate change and sea level rise. 

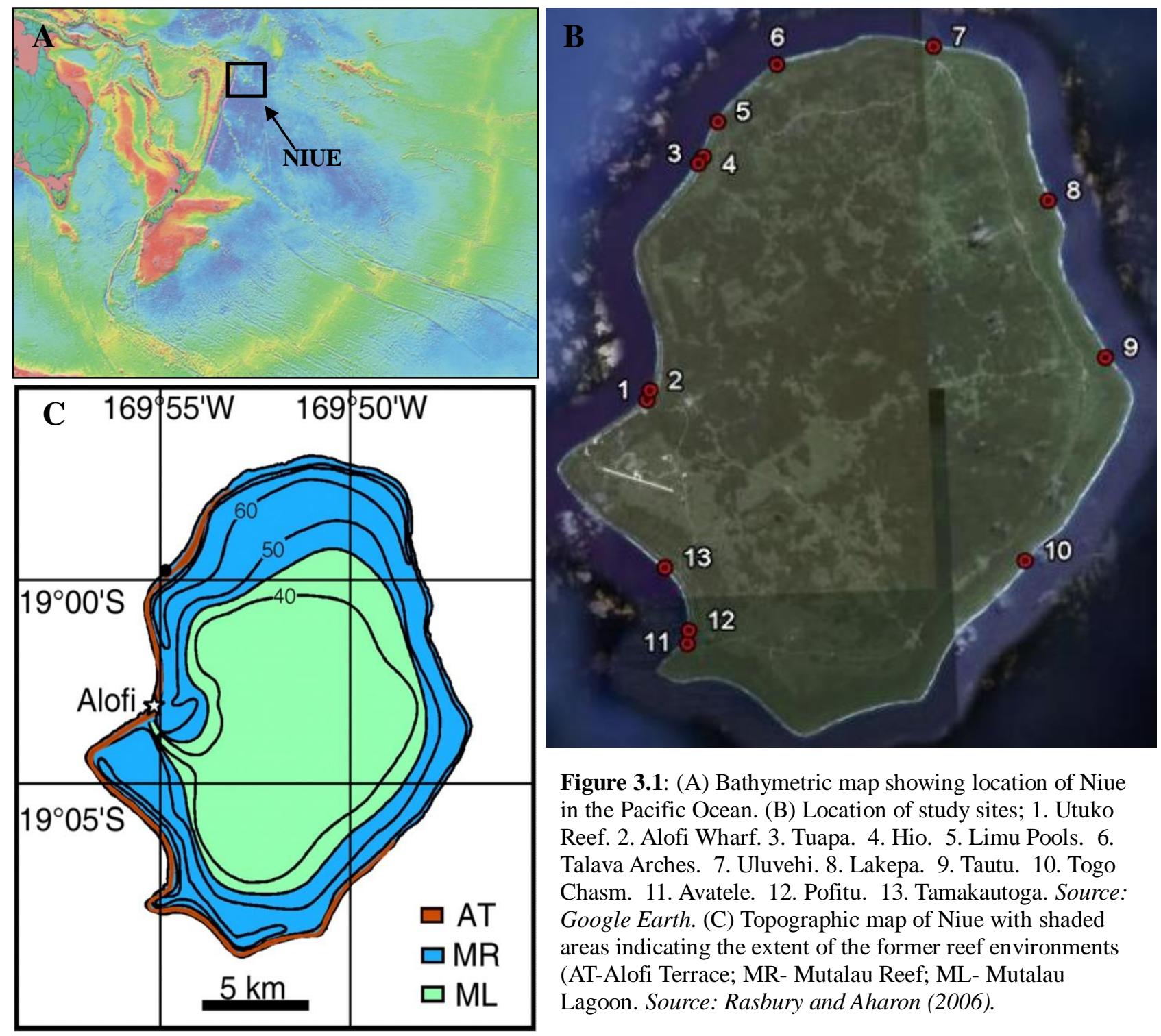

Figure 3.1: (A) Bathymetric map showing location of Niue in the Pacific Ocean. (B) Location of study sites; 1. Utuko Reef. 2. Alofi Wharf. 3. Tuapa. 4. Hio. 5. Limu Pools. 6. Talava Arches. 7. Uluvehi. 8. Lakepa. 9. Tautu. 10. Togo Chasm. 11. Avatele. 12. Pofitu. 13. Tamakautoga. Source: Google Earth. (C) Topographic map of Niue with shaded areas indicating the extent of the former reef environments (AT-Alofi Terrace; MR- Mutalau Reef; ML- Mutalau Lagoon. Source: Rasbury and Aharon (2006).

\subsection{Geology}

The volcanic basement on which Niue sits is uplifting as the island moves across a lithospheric bulge associated with plate subduction at the Tonga Trench, the axis of which lies $270 \mathrm{~km}$ to the west (Forbes, 1996; Nunn, 2004; Terry and Nunn, 2003). Niue is still ascending the lithospheric flexure and is expected to rise an additional $40-70 \mathrm{~m}$. It is assumed that the Pacific Plate is moving at a rate of $12 \mathrm{~cm} /$ year in this area so it is estimated to take half a million years for Niue to reach the crest of the flexure (Forbes, 1996; Nunn, 2004; Terry and Nunn, 2003). It is assumed that the Niue volcano ceased erupting during the late Miocene period, based on the age of fossils in the limestone 
immediately overlying the volcanic rocks (Nunn and Britton, 2004). These volcanic lithologies have however never been sampled so their exact age and character is unknown (Nunn and Britton, 2004).

This volcanic basement is found at a minimum depth of 300-400 $\mathrm{m}$ below sea level in the south-west part of the island (Forbes, 1996; Nunn, 2004; Terry and Nunn, 2003), with the limestone capping developing on only the north and east sides of the volcano. It is postulated that a giant landslide may have removed the south and west parts of the old volcano before the modern limestone cap started to form (Figure 3.2) (Nunn and Britton, 2004). A shelf that is found only off the south west coast of Niue at $3200-4000 \mathrm{~m}$ below sea level provides supporting evidence of such an event occurring (Nunn and Britton, 2004).

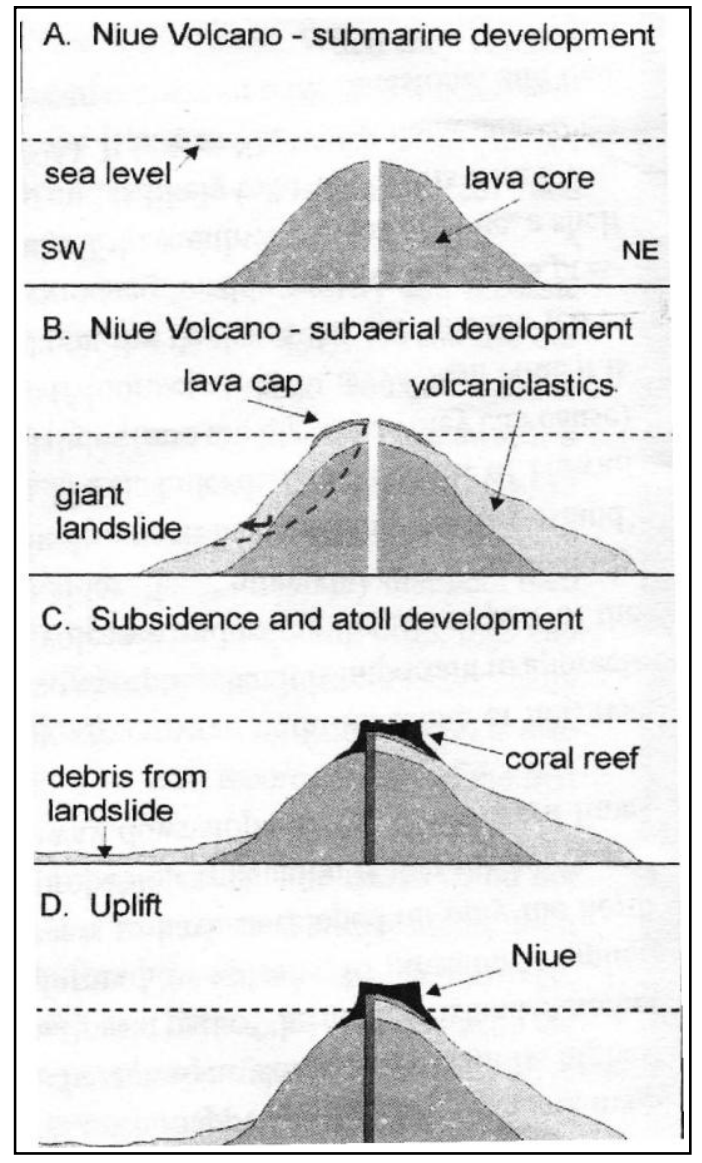

Figure 3.2: Stages in the evolution of Niue Island. Source: Nunn \& Britton (2004)

Coral reefs began to develop as the Niue volcano subsided beneath the ocean surface forming an atoll similar to those that exist in Kiribati or Tuvalu. Consequently, the island 
began to rise about 500,000 years ago as it started to ascend the lithospheric flexure east of the Tonga Trench (Nunn, 2004; Nunn and Britton, 2004; Woodroffe, 2002). As the island was uplifted, emergence of the atoll took place, and it is during this time that the lagoon water became hypersaline and that the limestone became dolomitised (Nunn and Britton, 2004; Schofield, 1959; Terry, 2004). The central basin represents the former lagoon floor which became isolated during uplift. It has an elevation of $35-40 \mathrm{~m}$ above sea level and is referred to as the 'Mutalau Lagoon' (Figure 3.3). Since emergence, reef development has been in the form of fringing reefs, which are themselves uplifted as terraces along the island's coast (Nunn and Britton, 2004; Terry, 2004).

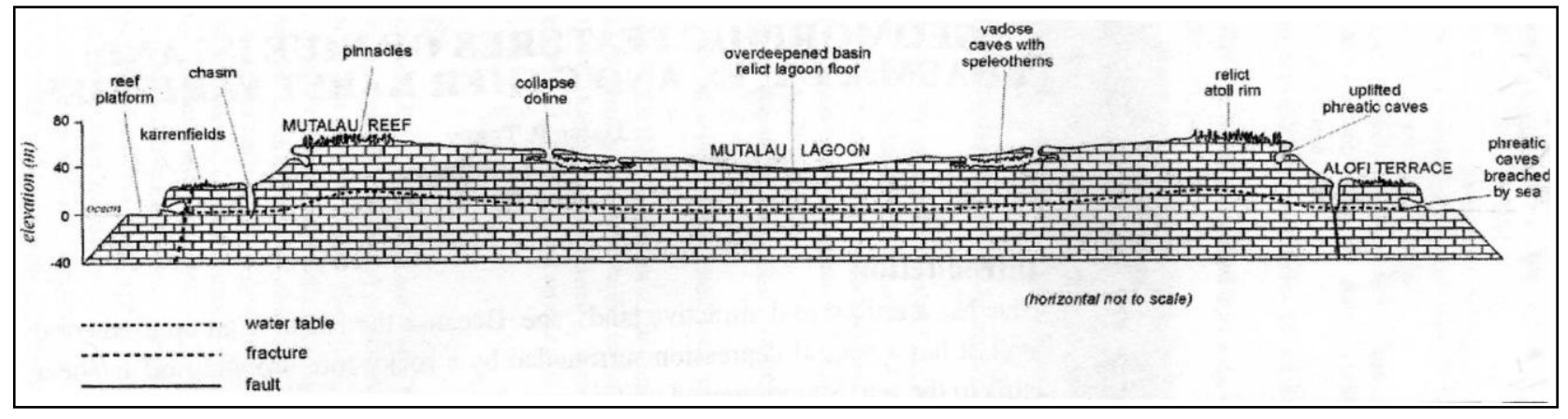

Figure 3.3: Niue cross-section, illustrating the geomorphic features. Source: Terry (2004)

\subsection{Geomorphology}

\subsubsection{Coastal and reef morphology}

Niue's coastline is characterised by sheer limestone cliffs with an active shore platform and fringing reef at their base. The former lagoon, referred to as the 'Mutalau Lagoon' by Schofield (1959) is surrounded by the 'Mutalau Reef', a prominent ridge standing close to $70 \mathrm{~m}$ above sea level representing the reef rim of the former atoll (Figure 3.4) (Nunn and Britton, 2004). This relict reef is broadest $(\sim 1.9 \mathrm{~km})$ in the north around Mutalau and narrowest in the south-west region of the island around the Tamakautoga coast. Schofield (1959) refers to the Mutalau Reef as a large karrenfeld consisting of crevices and razor sharp pinnacles that stand approximately $1.5 \mathrm{~m}$ in height and are formed by the effects of constant sea spray. 


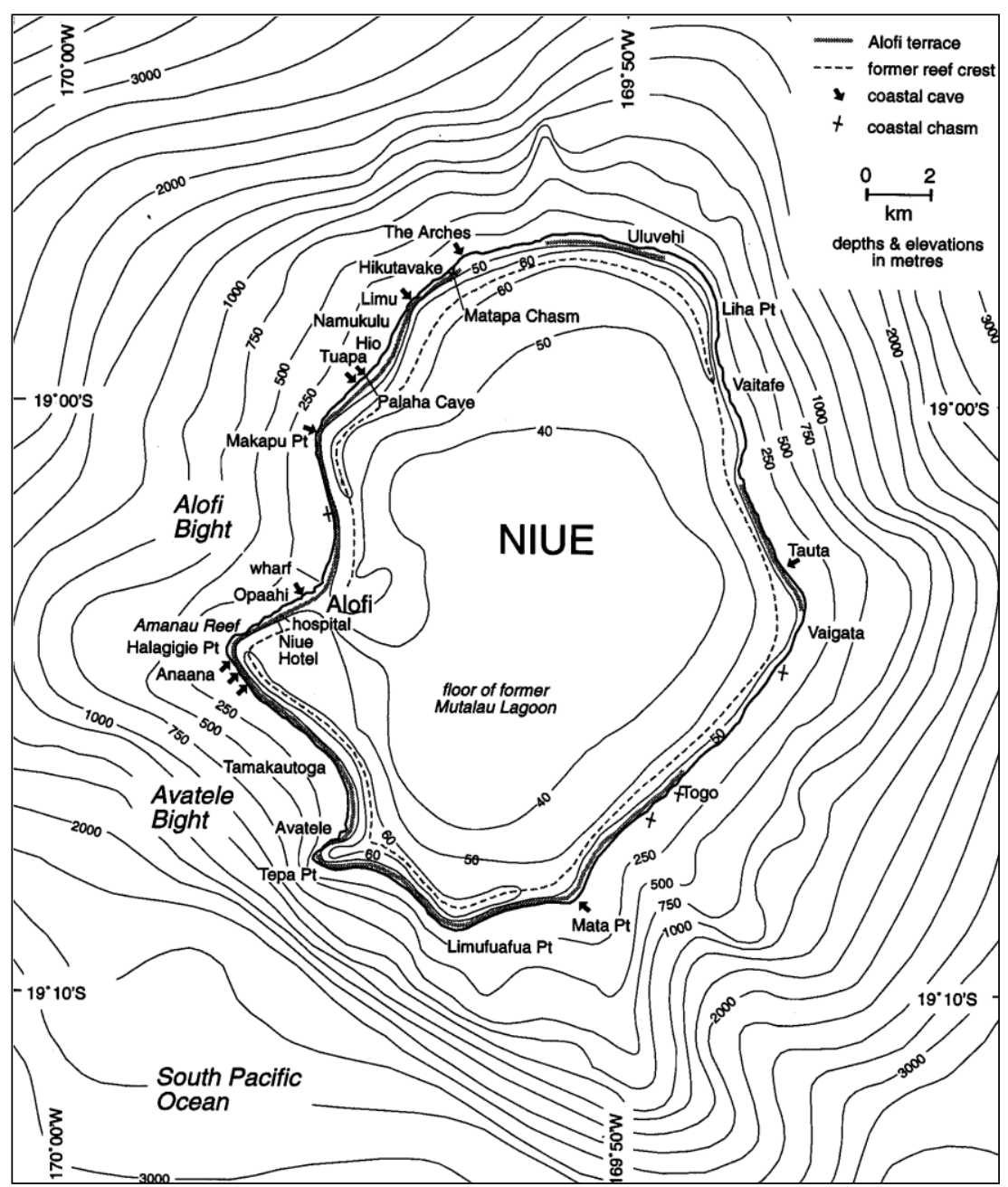

Figure 3.4: Coastal morphology of Niue and place names. Source: Forbes (1996)

The distribution of the Mutalau Reef may reflect the general morphology of the atoll reef approximately 500,000 years ago. Earlier studies of modern atolls in the tradewind belts e.g. Enewetak in the Marshall Islands, have revealed that the widest reefs generally form on the windward sides where wave energy and nutrient supply is greatest and the narrower reefs were found on the leeward side of the island (Forbes, 1996; Nunn and Britton, 2004). If this is the case, then the prevailing winds came from the north east rather than from the south east as it is today (Forbes, 1996; Nunn and Britton, 2004; Terry and Nunn, 2003). Niue may have been located farther north within the north-east tradewind belt relative to today or this belt may have been situated farther south (Schofield, 1959). However, this theory is still somewhat inconclusive and requires more research. The distribution of the Mutalau Reef may also be the result of post-emergence erosion and landslides (Wheeler and Aharon, 1997). The bays of Alofi and Avatele-Tamakautoga and the narrow Mutalau Reef along the Tamakautoga coast may in fact correspond to the scars on the backs of large 
landslides, possibly triggered by tectonic uplift (Nunn and Britton, 2004; Schofield, 1959; Terry and Nunn, 2003).

Much of the periphery of the island is marked by a sequence of reef terraces all found below the Mutalau Reef (Table 3.1). Eight have been identified and they occur from 18-58 $\mathrm{m}$ above sea level, with the main Alofi Terrace, the broadest and best preserved, rising to $\sim 23 \mathrm{~m}$ above the modern reef. The '58 $\mathrm{m}$ terrace' is prominent along the leeward (northern) side of Niue and absent along the windward side of the island, especially between Hakupu and Lakepa. The '52 $\mathrm{m}$ terrace' is evident at only nine locations and is also absent along the Tamakautoga-Avatele Bay which may suggest that it was removed by a landslide before the '34 m terrace' developed (Forbes, 1996; Nunn and Britton, 2004). Other terraces such as the ' $43.5 \mathrm{~m}$ terrace' and the ' $34 \mathrm{~m}$ terrace' have also been identified on the island, with the latter extending up to $200 \mathrm{~m}$ wide in the Hio-Namukulu area. The upper Alofi Terrace sits at a higher level than the main Alofi Terrace at a mean elevation of $\sim 28 \mathrm{~m}$, and is evident along most of the coast except on the western part of the island between Alofi Bay and Hikutavake (Forbes, 1996; Nunn and Britton, 2004). The Alofi Terrace is a well preserved surface $20-25 \mathrm{~m}$ above present sea level and is prominent on the western, southern and south eastern sides of Niue, but also occurs on the northern and eastern coasts. The width of the Alofi Terrace ranging from 200-800 m may have formed as a wave-cut platform since cemented beach conglomerate at $1.5 \mathrm{~m}$ has been found at some places (Nunn and Britton, 2004; Forbes, 1996). In comparison to other terraces, the Alofi Terrace has very limited karstification and height range which implies that it is much younger than the higher terraces. The '18 m terrace' is the lowest emerged terrace and may have formed over a very short period of time. This was removed in several places following its emergence, which may explain its limited distribution around the island. It is found in the Hikutavake and Vaitafe areas and is broadest in the latter reaching to a width of around 20 m (Nunn and Britton, 2004). Many of these terraces have an erosional surface as a result of surface lowering by subaerial erosion as opposed to the more common marine erosion (Nunn and Britton, 2004). 
Table 3.1: Terrace ages and rates of long-term uplift of Niue since the emergence of the Mutalau Reef. Source: Nunn and Britton (2004)

\begin{tabular}{|l|c|c|c|c|c|c|}
\hline \multicolumn{1}{|c|}{ Terrace/reef level } & $\begin{array}{c}\text { Mean } \\
\text { elevation } \\
(\mathbf{m})\end{array}$ & $\begin{array}{c}\text { Suggested } \\
\text { age (years } \\
\mathbf{a g o}\end{array}$ & $\begin{array}{c}\text { Relative } \\
\text { sea level } \\
(\mathbf{m})\end{array}$ & $\begin{array}{c}\text { Surface } \\
\text { lowering } \\
(\mathbf{m})\end{array}$ & $\begin{array}{c}\text { Mean } \\
\text { elevation of } \\
\text { original } \\
\text { surface (m) }\end{array}$ & $\begin{array}{c}\text { Uplift rate } \\
(\mathbf{m m} / \mathbf{y e a r})\end{array}$ \\
\hline The Mutalau Reef & 65 & 700,000 & $? 0$ & 7 & 72 & $? 0.10$ \\
\hline The 58-m terrace & 58 & 658,000 & $? 0$ & 6.58 & 64.58 & $? 0.10$ \\
\hline The 52-m terrace & 52 & 589,000 & $? 0$ & 5.89 & 57.89 & $? 0.10$ \\
\hline The 43.5-m terrace & 43.5 & 521,000 & $? 0$ & 5.21 & 48.71 & $? 0.09$ \\
\hline $\begin{array}{l}\text { The 34-m terrace } \\
\text { The upper Alofi Terrace }\end{array}$ & 28 & 261,500 & -30 & 2.62 & 30.62 & 0.23 \\
\hline $\begin{array}{l}\text { The main Alofi Terrace } \\
\text { The 18-m terrace }\end{array}$ & 18 & 125,000 & +64 & 1.25 & 19.25 & 0.11 \\
\hline $\begin{array}{l}\text { The young reef fringe } \\
\text { on the edge of the main } \\
\text { Alofi Terrace }\end{array}$ & 20 & 120,000 & +9 & 1.20 & 21.2 & 0.10 \\
\hline
\end{tabular}

Niue was last fully submerged during the early Pleistocene and subsequent glacialinterglacial sea level oscillations and have led to the development of two major and six or seven minor terraces (Wheeler and Aharon, 1997). Previous work done by Flint (1948) and Zeuner (1950) cited in Schofield (1959) suggests that the uppermost terrace, the Mutalau Reef, is of antepenultimate interglacial age and the Alofi Terrace, is of last interglacial age.

Niue's coastline is marked by sea cliffs, unlike most typical Pacific Islands that are bounded by sandy beaches. Most cliffs are developed in the Alofi Terrace and are about 18$25 \mathrm{~m}$ high. However, reworking of the outer terrace margin has reduced their heights to 5-10 m (Forbes, 1996; Schofield, 1959). Most cliffs are notched at the base due to the effects of abrasion and solution (Forbes, 1996; Schofield, 1959). Abrasion usually occurs during storms. The presence of silt and small loose shells on top of the cliffs at Tepa Point is an indication of material being carried up over the cliffs by waves. Boulder sized material were also found on top of these 16 m high cliffs after Cyclone Ofa (1990) (Forbes, 1996; Schofield, 1959; Terry and Nunn, 2003). The more exposed coasts where platforms are 
narrow or absent tend to have notches that are developed at higher levels where wave runup and spray extends above the tidal limit. It is therefore difficult to determine earlier sea levels from wave cut notches alone, due to the effects of solution, storm abrasion and degree of coastal protection (Forbes, 1996; Schofield, 1959; Terry and Nunn, 2003).

Near low tide level, an active terrace occurs which consists of a wave-cut platform fringed by a constructional reef which encircles most of the coast of Niue. The combined reefplatform width is up to $150 \mathrm{~m}$; however, in some places on the south and south east coast of the island e.g. Tepa Point, it is less than $30 \mathrm{~m}$ in width or sometimes absent (Forbes, 1996; Schofield, 1959). Platform width generally decreases towards small headlands except in some areas such as Liha Point and the northern coast, where platforms extending to $60 \mathrm{~m}$ are present (Forbes, 1996; Schofield, 1959). A well developed platform is accompanied by a fringing reef and is usually clear of debris, apart from scattered blocks, sand in potholes and small pocket beaches (Schofield, 1959). Schofield (1959) identified two subequal zones on these well developed platforms; the inner zone characterised by $0.6 \mathrm{~m}$ deep and 1 $2 \mathrm{~m}$ wide potholes, and the outer zone which has no potholes and is distinguished by the pink coloration of coralline algae.

Due to the rocky shore setting of Niue, sediment accumulation and beach development is limited. According to a survey conducted by the South Pacific Applied Geoscience Commission (SOPAC), 64\% of Niue's $66 \mathrm{~km}$ shoreline consists of narrow platforms $(<30$ $\mathrm{m}$ wide). Beaches sometimes occur at the cliff base and they account for less than $1 \%$ of the total shore length, with most being less than $1 \mathrm{~m}$ thick (Forbes, 1996). They are mostly found on the south-west coast and are often absent from the south and south-east coast. The majority of the coastal sand is believed to be lost to deep water as well as being trapped on submerged terraces down to approximately $36 \mathrm{~m}$ water depth (Forbes, 1996). 
Table 3.2: Total length, reef platform, width, and beach occurence by coastal unit, conducted by SOPAC.

Source: Forbes (1996)

\begin{tabular}{|c|c|c|c|c|c|c|}
\hline unit & $\begin{array}{c}\text { shore } \\
\text { length } \\
(\mathrm{km})\end{array}$ & $\begin{array}{l}\text { reef- } \\
\text { platform } \\
\%<30 \mathrm{~m}\end{array}$ & $\begin{array}{l}\text { reef- } \\
\text { platform } \\
\%>30 \mathrm{~m}\end{array}$ & $\begin{array}{l}\max \\
\text { width } \\
(\mathrm{m})\end{array}$ & bea & $(\mathrm{km})$ \\
\hline $\begin{array}{l}A \\
B \\
C \\
D \\
E \\
F \\
G\end{array}$ & $\begin{array}{r}9.36 \\
11.64 \\
11.17 \\
8.60 \\
7.70 \\
9.15 \\
8.92\end{array}$ & $\begin{array}{r}100 \\
76 \\
63 \\
64 \\
47 \\
51 \\
38\end{array}$ & $\begin{array}{c}0 \\
24 \\
37 \\
36 \\
53 \\
49 \\
62\end{array}$ & $\begin{array}{r}<30 \\
70 \\
110 \\
120 \\
150 \\
120 \\
90\end{array}$ & $\begin{array}{l}0 \\
0 \\
1 \\
1 \\
1 \\
1 \\
3\end{array}$ & $\begin{array}{l}0.00 \\
0.00 \\
0.06 \\
0.06 \\
0.05 \\
0.07 \\
0.30\end{array}$ \\
\hline TOTAL & 66.5 & 64 & 36 & 150 & 0.8 & 0.54 \\
\hline
\end{tabular}

\subsection{Climate}

Niue has a tropical climate, dominated by the southeast prevailing trade winds and is also influenced by the South Pacific Convergence Zone (SPCZ) (Forbes, 1996; Schofield, 1959; Terry and Nunn, 2003). The island experiences two distinct seasons, a wet summer from November to April (monthly mean rainfall of $307 \mathrm{~mm}$ and an average air temperature of $26^{\circ} \mathrm{C}$ ) and a dry winter from May to October (monthly mean rainfall $84 \mathrm{~mm}$ and average air temperature of $24^{\circ} \mathrm{C}$ ) (Figure 3.5) when trade wind conditions are more prominent (Forbes, 1996; Rasbury and Aharon, 2006). During the wet summer season, the SPCZ is further south; therefore winds from the more northern latitudes bring moist air into the region. From May to October, the SPCZ lies further to the north, and as a result drier southeast trade winds are more dominant (Kreft, 1986).

Niue has a mean temperature of $28.45^{\circ} \mathrm{C}$ and an annual mean precipitation of $2177 \mathrm{~mm}$ (SOPAC, 2007). Most of this rainfall is convective, where it tends to occur frequently during the afternoon or evening when temperatures are high; however, heavy rainfall can also occur during tropical cyclones (see Section 3.6) or during a cold frontal weather system (Forbes, 1996; Kreft, 1986). 


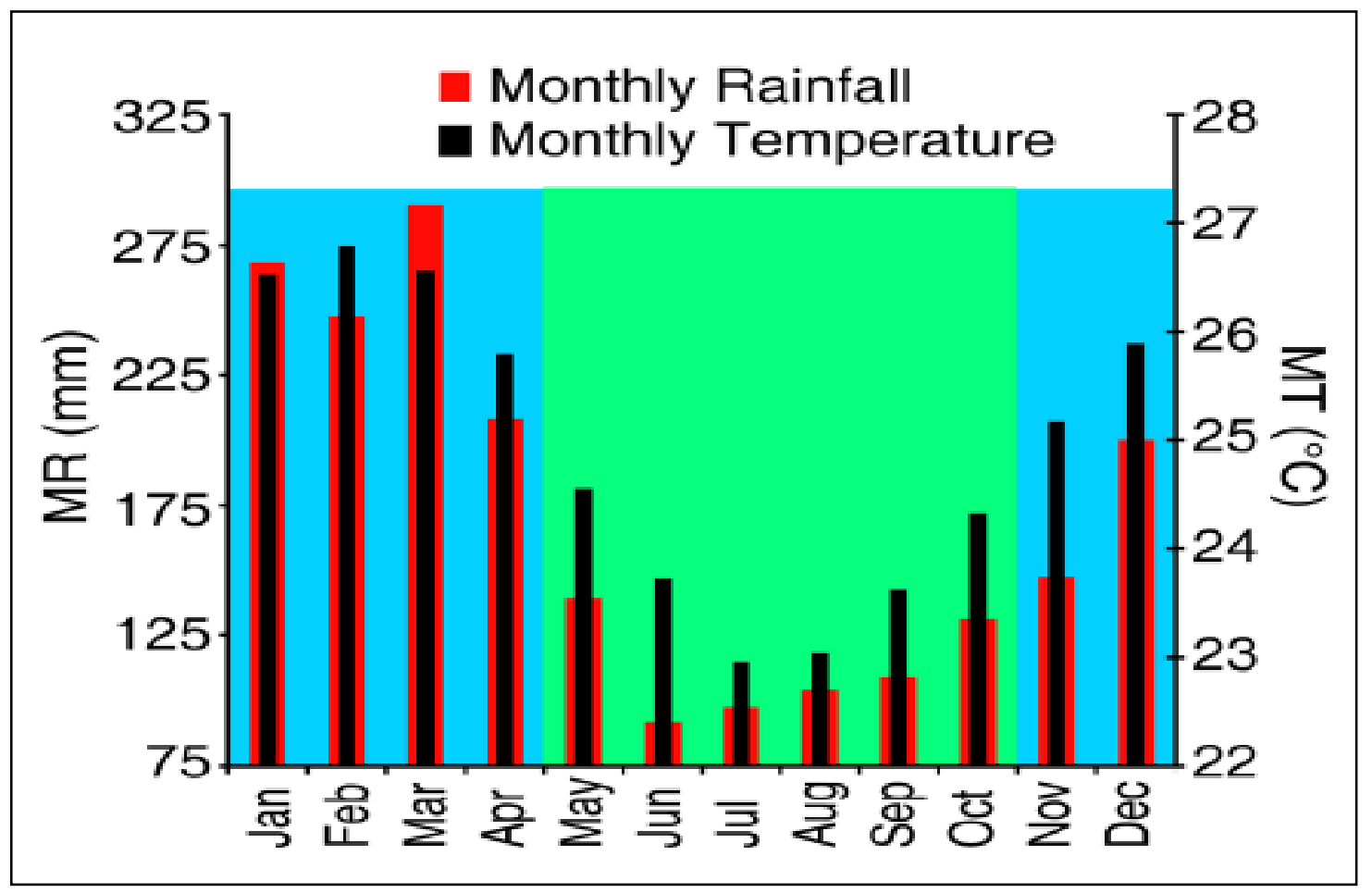

Figure 3.5: Mean monthly rainfall $(\mathrm{mm})$ and air temperature $\left({ }^{\circ} \mathrm{C}\right)$ on Niue based on 92 and 68 years of continuous instrumental observations. The blue shaded area represents the austral summer monsoon season, and the green shaded area represent the austral winter dry season. Source: Rasbury and Aharon (2006)

Despite the fact that Niue's total rainfall is twice as much as some places in New Zealand, (e.g. Auckland), the island experiences on average 1.2 drought events per year, mainly due to its high porosity where rainwater is quickly soaked into the limestone. As such, no surface streams are present on the island (Forbes, 1996; Schofield, 1959; Terry and Nunn, 2003).

\subsection{Oceanography}

Published data on wave climate is not available within the vicinity of Niue; therefore data from nearby islands such as Western Samoa, Tonga, and the Cook Islands are used to represent wave conditions in Niue (Forbes, 1996). According to the GEOSAT altimeter data for 1986-1989, the mean annual significant wave height for Niue is approximately 2.4 $\mathrm{m}$, and increasing to $2.5 \mathrm{~m}$ during summer (Barstow and Haug, 1994; Forbes, 1996). The east coast is exposed to prevailing southeast trade winds which create rougher conditions in comparison to the leeward coast. Sea surface temperature ranges from $24^{\circ} \mathrm{C}$ to $28^{\circ} \mathrm{C}$ being 
consistent with the yearly cycle of mean air temperature, with the latter being generally 1 $2{ }^{\circ} \mathrm{C}$ cooler. The tide at Niue is also semidiurnal, ranging from $0.7 \mathrm{~m}$ during spring tide and 0.5 m during neap tide (Kreft, 1986).

\subsection{Natural Hazards}

\subsubsection{Tropical cyclones}

Niue like most Pacific Islands is situated at the edge of the tropical cyclone belt and in the zone of the southeast trade winds. The island has been subjected to severe cyclones on the average of once a decade with cyclones hitting the island every four years (SOPAC, 2006). The months November to April are known as the tropical cyclone season in the Southwest Pacific (Kreft, 1986). Seventeen tropical cyclones that impacted Niue during from 19051979 (Kreft, 1986). Among several that hit Niue, Cyclone Heta in 2004 was the worst in local living memory. It was a category five tropical cyclone with wind speeds up to 275 $\mathrm{km} / \mathrm{hr}$. Cyclone Heta was the largest tropical cyclone recorded in the Pacific causing widespread devastation to the island on the $5^{\text {th }}$ January 2004 (SOPAC, 2004).

The 20-40 m cliffs were thought to provide protection to coastal inundation, however Cyclone Heta demonstrated that given the correct conditions, waves can ramp up and overtop the cliffs. In 2004, $50 \mathrm{~m}$ waves surged over these cliffs and travelled $200 \mathrm{~m}$ inland causing significant damage to homes, public facilities and infrastructure (Figure 3.6) (SOPAC, 2004; Talagi-Hekesi, 2005). The National Impact Assessment was estimated to be $\$ 37.2$ million and the approximate loss to the environment including crops, marine and terrestrial biodiversity was valued at $\$ 50$ million. Total losses reached $\$ 87.2$ million against the Niue GDP of $\$ 14.2$ million (Liuvaie, 2005; SOPAC, 2004, 2006). As the North West and Western side of the island is more sheltered, most of its population and tourist activities reside here, including their main ship port. But this is also the side facing the path of cyclones (SOPAC, 2006; Tongatule, 2005). 


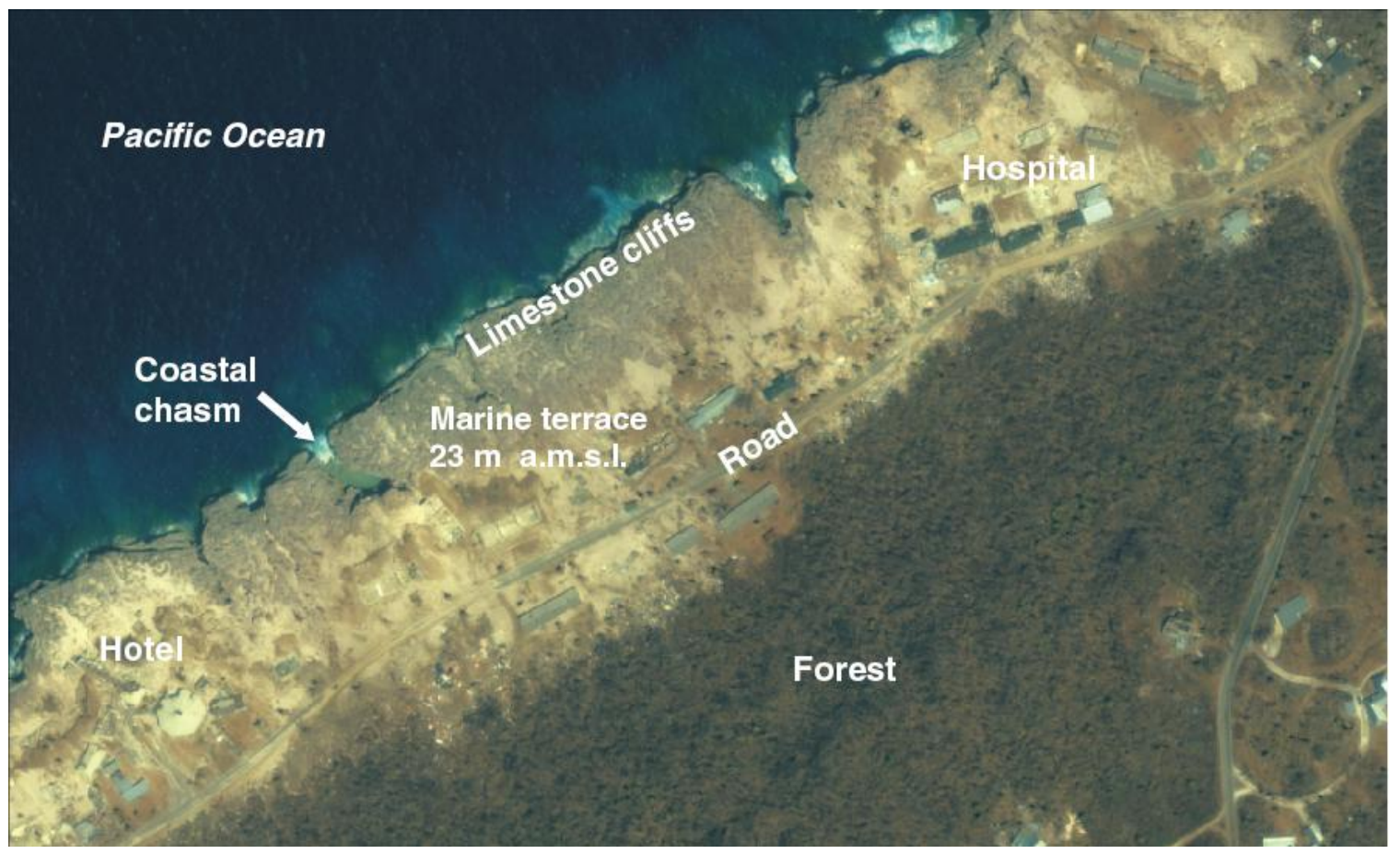

Figure 3.6: Satellite image of the Niue coastline at the capital Alofi on the West Coast. Waves generated by Tropical Cyclone Heta overtopped the 20-40 m high cliffs and travelling $200 \mathrm{~m}$ inland over the $23 \mathrm{~m}$ marine terrace, destroying the hospital and Niue Hotel in its path. Source: NOAA \& Terry (unknown year).

Cyclone Ofa (1990) is the second most destructive cyclone to impact Niue (Prasad, 1990). Extensive damage was sustained on the north-west coast of the island and coastal alignment was believed to be the major contributing factor (Forbes, 1996; Prasad, 1990). Areas such as Hio and Hikutavake suffered severe damage despite broad reefs occurring within the area (Forbes, 1996). Cliff ramps to the south also contributed to wave run-up causing significant effects on adjacent buildings and infrastructure (Forbes, 1996; SOPAC, 2006). The outer margin of the Alofi Terrace is considered a high risk area to storm surges and coastal inundation therefore building regulations have been put into place on the island to reduce future risks (SOPAC, 2006).

\subsubsection{Tsunami}

Niue is located in close proximity to the Tongan Trench, a major source of earthquakes and tsunami. Historical records on tsunami events have indicated that such events have been relatively small, causing little damage in Niue (SOPAC, 2007). The highest event to be recorded was in May 2006 at $21 \mathrm{~cm}$ amplitude with an arrival time of 33 minutes after the 
earthquake (SOPAC, 2007). Niue's high cliffs and bathymetry makes the island less vulnerable to the effects of inundation and shoaling from distant-source tsunamis, however the potential impact of a tsunami event triggered by a magnitude 8.5-9.0 earthquake at the Tongan and Kermadec Trenches may be significant, but is considered to be a rare event (SOPAC, 2007). Locally generated tsunami from submarine failure is also likely to cause extensive devastation to the island (Nunn and Britton, 2004; SOPAC, 2007).

\subsubsection{Submarine slope failure}

The majority of the population of Niue is located on the Alofi Terrace. As $70 \%$ of these are private dwellings, the long term stability of the Alofi Terrace is of concern (Forbes, 1996). The asymmetrical form of the ancient volcano underlying Niue suggests that a large landslide may have occurred on the southern and western slopes of the island. This corresponds to the steep submarine slopes off the southern coast and the coastal embayment's of Avatele Bight and Alofi Bight (Forbes, 1996; Nunn and Britton, 2004; Schofield, 1959). On the Alofi Terrace and around Alofi Bay, a fissure is visible and this could indicate a possible landslide occurring within the area in the future (Nunn and Britton, 2004). It is also possible that movement could occur on the Alofi Terrace and that any future slope failure could cause significant tsunami runup with waves reaching tens of metres. The probability of such events occurring on a human timescale is considerably low and thousands of years may pass before the next landslide event takes place, but the impacts will be immense with very little warning time (Forbes, 1996).

\subsection{Land use and vegetation}

The island supports a population of approximately 1788 people (2001 census) (SOPAC, 2008); however, the country's population continues to decline today with approximately 22,000 Niueans now residing in New Zealand (Jacobson and Hill, 1980; Wheeler and Aharon, 1997). The island is currently experiencing a negative growth of $2 \%$. This is a cause for concern as Jacobson and Hill (1980) consider that a small population is unable to enhance economic and social development in order to maintain a living community. Due to geographical isolation, economic self-sufficiency is quite difficult to achieve in many 
Pacific Island nations including Niue. The economy is generated by subsistence agriculture, a limited amount of commercial export agriculture, and a government sector (Jacobson and Hill, 1980).

The key form of cultivation is rotational cultivation of Taro (Colocasia esculenta). Since much of the surface in the central rural regions is covered by roughly $90 \%$ of limestone outcrop, most commercial and large scale subsistence agriculture is limited to the coast and near villages (McIntyre and Soulsby, 2004; Wright and Westerndorp, 1965). Land use patterns across the island are often determined by these limestone outcrops. For example, patterns of intensive cultivation are found in the central to north part of the island, which corresponds to the more fertile soils where the makatea limestone outcrops are limited (Soulsby, 2004). The lack of suitable areas for pasture due to its rocky terrain and water shortage problems also makes livestock farming only manageable at a very small scale (McIntyre and Soulsby, 2004; Soulsby, 2004; Wright and Westerndorp, 1965). As subsistence cropping is difficult to achieve in approximately two thirds of the island, the other main land cover is the large forested area. Forest cover is quite extensive in Niue, comprising $65 \%$ to $75 \%$ of the land area (Figure 3.7) (Soulsby, 2004). 


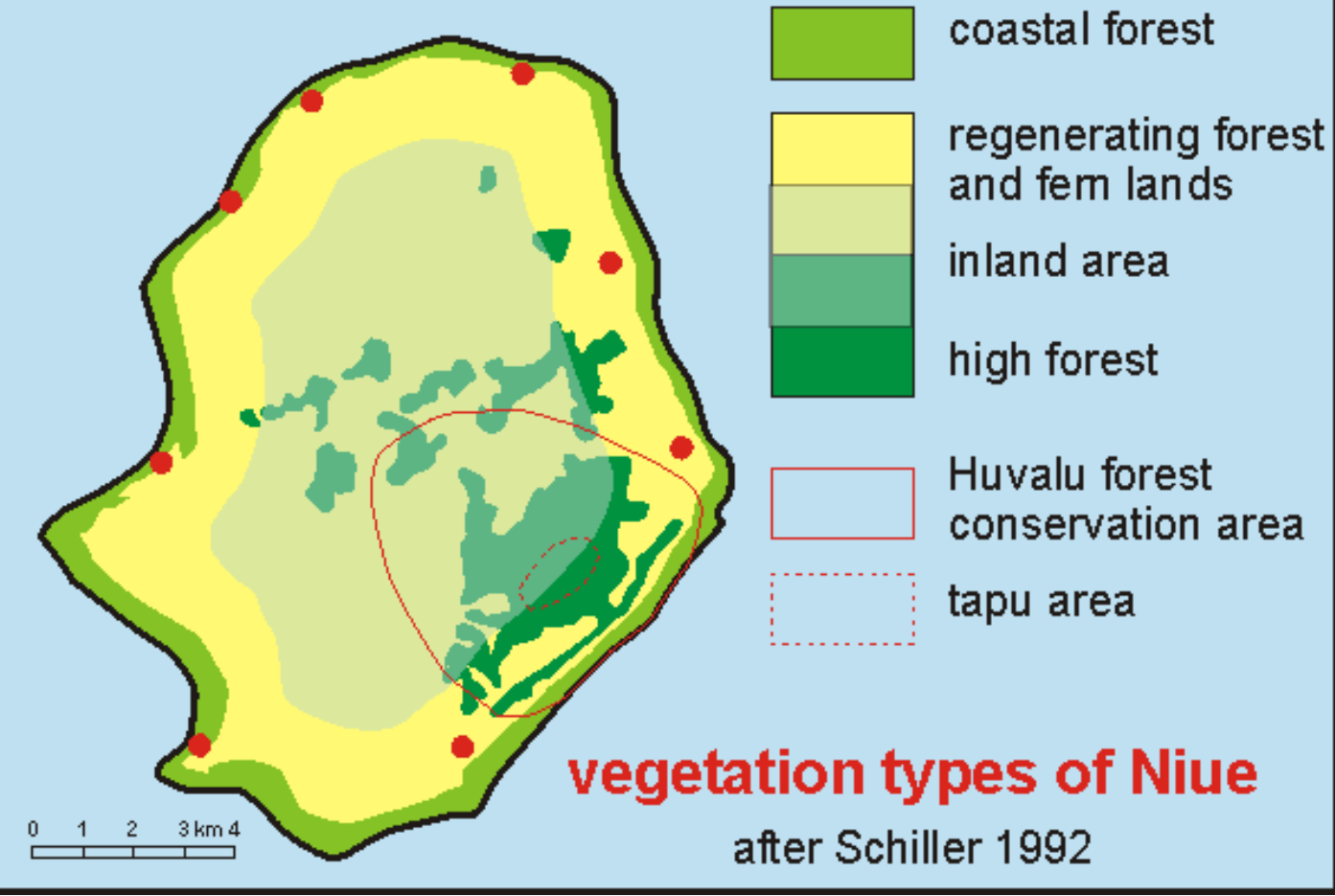

Figure 3.7: Vegetation cover of Niue. Source: Schiller (1992)

The location of Niue's vegetation types (Figure 3.7) distinguishes two zones; the coastal zone and the inland area. The coastal zone extends from the salt spray zone, the coastal forest and coastal fern lands. The inland area covers regenerating forests, fern lands and the high rain forest (Schiller, 1992; Soulsby, 2004). The Huvalu Forest Park consists of both regenerating and original forest that may take several centuries to fully regenerate (McIntyre and Soulsby, 2004; Schiller, 1992; Soulsby, 2004). 


\section{CHAPTER 4: Methodology}

\subsection{Field data collection}

\subsubsection{Topographic surveying}

A total of 32 topographic transects were carried out on representative coastal sites around the island from the cliff top to the seaward edge of the reef, using a Sokkia SET 3030R Electronic Distance Metre (EDM) (Figure 4.1). Profiles at each site were surveyed at regular spaced intervals of about $50 \mathrm{~m}$ to allow for the parameterization of beach and reef platform characteristics. The distance between surveys was also determined by the occurrence of beach development or sediment accumulation along that section of shoreline.

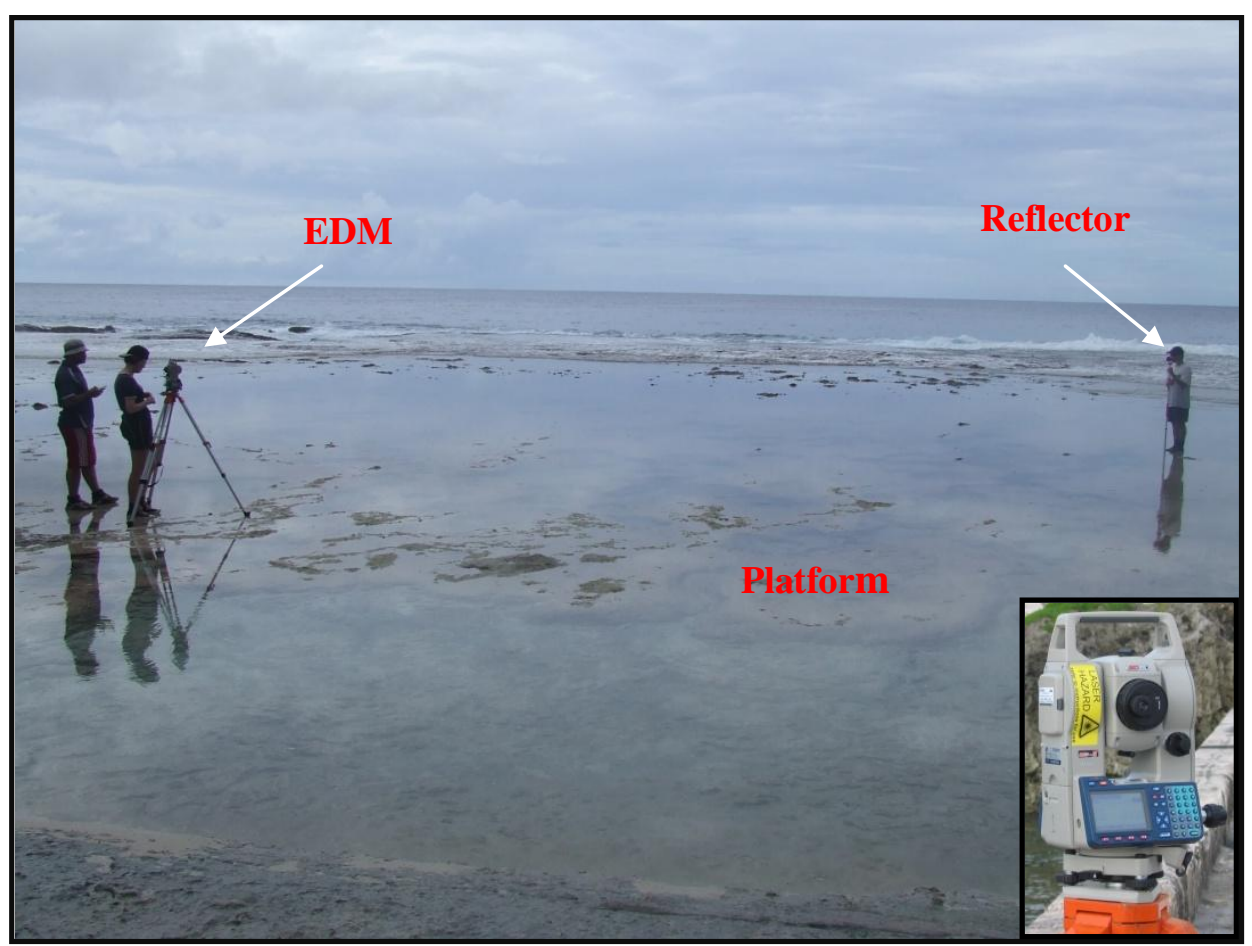

Figure 4.1: Surveying in progress at Lakepa beach using the Sokkia SET 4010 EDM (detailed inset).

A series of temporary benchmarks were used to level surveyed beaches to a single elevation. As there were no accurate benchmarks on the island, all profiles were subsequently corrected to mean water level. In the field, this elevation corresponded to the maximum elevation of Porites microatolls, and these were used as a local datum for these surveys. The use of microatolls as a tidal elevation datum is common as their highest level 
of growth generally corresponds to mean low water (Scoffin et al., 1978; Smithers and Woodroffe, 2000, 2001; Som et al., 2009). Previous studies of microatolls from the Great Barrier Reef indicate that microatolls in free draining reef flat habitats are usually constrained to the mean low water spring tide level (MLWS) while moated microatolls are can grow up to the mean low water neap tide level (MLWN) (McLean et al., 1978). Since the microatolls in Niue are moated their maximum elevation most likely corresponds to the MLWN level. Although, there is still great uncertainty with these elevations since they were based on predicted tidal curves rather than a precise datum and so this reduces survey accuracy (Smithers and Woodroffe, 2000).

In this study, the elevation of 48 Porites microatolls were established from nine localities around Niue and an average was calculated for the South West, West, North West, and Eastern part of the island (Table 4.1). Mean microatoll elevation may however differ significantly between sites depending on whether they occur on reef flats or open water (Smithers and Woodroffe, 2000). Microatolls on reef flats tend to grow $1.1 \mathrm{~m}$ higher than open-water microatolls (Scoffin et al., 1978). However, the microatolls on Niue are all moated and occur within pools on the platform surface therefore variability in mean elevation is minimal (Figure 4.2).

Table 4.1: Mean elevation of reef flat microatolls relative to MWL at sites on the South West, West, North West, and Eastern side of the island.

\begin{tabular}{|l|c|c|}
\hline \multicolumn{1}{|c|}{ Sites } & Mean Elevation (m) & SD (m) \\
\hline South West & -0.05 & 0.15 \\
\hline West & 0.03 & 0.22 \\
\hline North West & 0.14 & 0.30 \\
\hline East & -0.04 & 0.07 \\
\hline
\end{tabular}

Although microatolls are an important source as datums of mean sea level, various factors may lead to errors. For instance: i) storms can moat and re-align corals; ii) coral's response to sea level rise is sometimes delayed; and iii) the dead upper surface of microatolls can undergo erosion, so the record becomes unreliable over time (Scoffin et al., 1978; Smithers 
and Woodroffe, 2000). All of these factors were taken into account on Niue, and only live tops were surveyed.

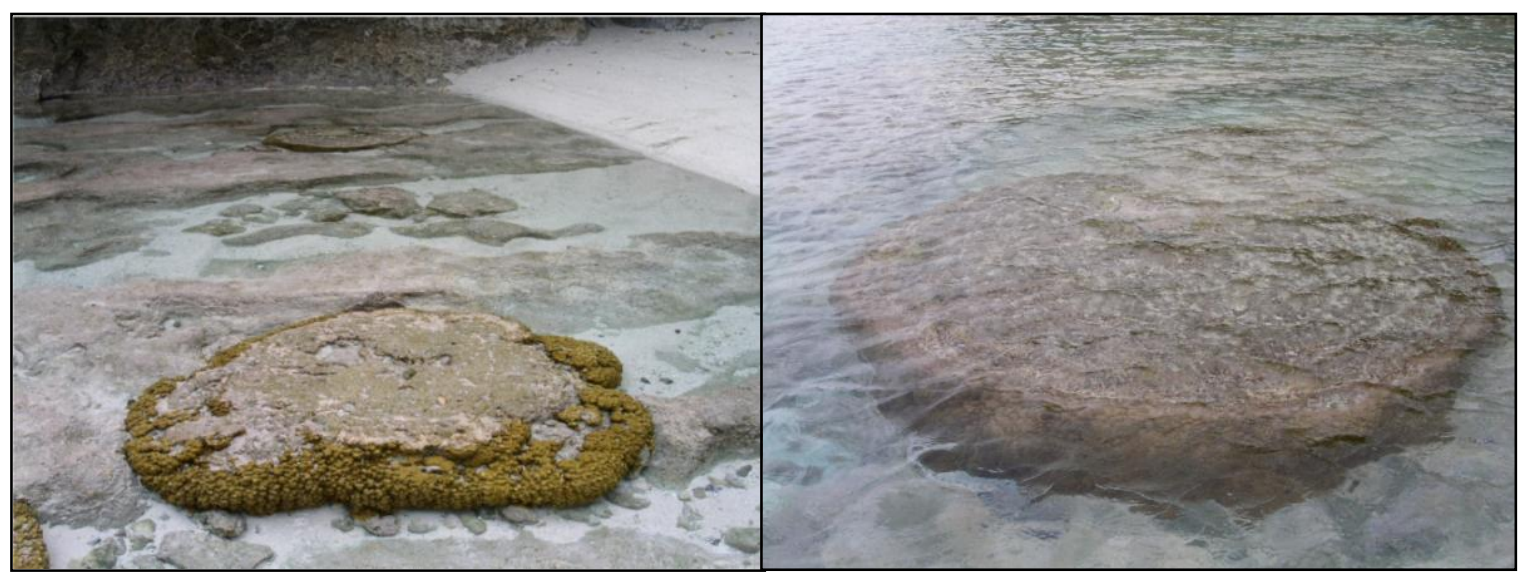

Figure 4.2: Moated Porites microatolls from the south western site of Tamakautoga

In the laboratory, the survey data was transferred from the EDM into the Mapsuite+ software program, to calculate the beach and reef platform profiles, which is then exported to Microsoft EXCEL 2007 to be quantified. Data in EXCEL was then reduced with mean low water at $0 \mathrm{~m}$ elevation, corresponding to the mean height of the microatolls.

\subsubsection{Sediment sample collection}

A total of 51 sediment samples from the platform and adjacent beaches were collected from around the island between May 16 and May 30, 2008. Approximately 100g of sediment was collected per sample and stored in sealed plastic bags for later analysis in the laboratory, with no chemical pre-treatment being undertaken in the field. Samples were collected by hand directly from the upper $10 \mathrm{~cm}$ of the beach and the nearshore platforms. These were taken in each major morphological zone on the reef and platform where sediment was present. 


\subsection{Laboratory Procedures}

\subsubsection{Sample Processing}

All samples were washed thoroughly with fresh water to remove salts and oven dried at $40^{\circ} \mathrm{C}$ for at least 48 hours. These were then split between $40 \mathrm{~g}$ to $50 \mathrm{~g}$ using a riffle box splitter. This is a common method used to mix a relatively large amount of material uniformly and to extract a much smaller amount for sieving. This ensures that the small sample to be measured is representative of the larger population (Pyokari, 1999). Samples were then dry sieved at $-0.5 \Phi$ to separate sand and gravel and weighed for grain size and component analysis. Weights of each fraction were recorded and expressed as a percentage of the initial weight.

\subsubsection{Laser Diffraction Particle Sizer (LDPS) analysis}

Grain size is a fundamental physical property of sediments and as such is a useful descriptive property. It is an important tool as the size and sorting of sediment grains may reflect sedimentation mechanisms, its transport history, provenance and depositional conditions (Pyokari, 1997, 1999; Solohub and Klovan, 1970).

The Laser Diffraction Particle Sizer Analyzer (LDPSA) was used for the analysis of bulk bioclastic (reefal) sediments. Laser diffraction is one of the most widely used techniques for particle size analysis. Instruments employing this technique are considered easy to use and particularly attractive for their capability to analyse over a broad size range in a variety of dispersion media (McCave et al., 1986). It is a non-destructive, non-intrusive method that can be used for either dry or wet samples. Since it derives particle size data using fundamental scientific principles it does not require calibration (Loizeau et al., 1994; McCave et al., 1986). The ability to obtain data rapidly allows many thousand measurements to be averaged when reporting a single result. This, coupled with standardised operating procedures, ensures that the instrument-to-instrument discrepancy is less than $1 \%$, thus allowing for direct comparisons of data from various sites (Loizeau et al., 1994; McCave et al., 1986; Rodriguez and Uriarte, 2009). 
39 sub samples of the sand sized fraction were analysed using the Beckman Coulter Counter Laser Diffraction Analyzer (LDPSA) at the School of Geography, Environment and Earth Sciences, Victoria University of Wellington (Figure 4.3). The measurement time adopted was about $60 \mathrm{sec}$ with $8-12 \%$ obscuration. The size range detected by the machine depends on the focal length of the focussing lens and has a theoretical measuring range of 0.04-2000 $\mu \mathrm{m}$ (McCave et al., 1986; Rodriguez and Uriarte, 2009). However, this measuring range should be taken into account carefully, as previous studies have shown that laser diffraction can report higher particle sizes than what is being analysed (Rodriguez and Uriarte, 2009) e.g (Blott and Pye, 2001). In this study, an upper limit of $1400 \mu \mathrm{m}$ ($0.5 \Phi)$ was used instead to ensure that the coarser particles are measured. The sample quantity required for analysis varies according to grain size distribution. According to Loizeau et al., (1994) 1-2 g of medium sand is needed for the required attenuation of the laser beam by approximately 10\%. For this study, 3-4 grams of sample sand were used. This prevented multiple grains from becoming clustered (McManus, 1988). Once sample analyses were completed, data from the Lasersizer program was exported to Microsoft EXCEL 2007 to be quantified.

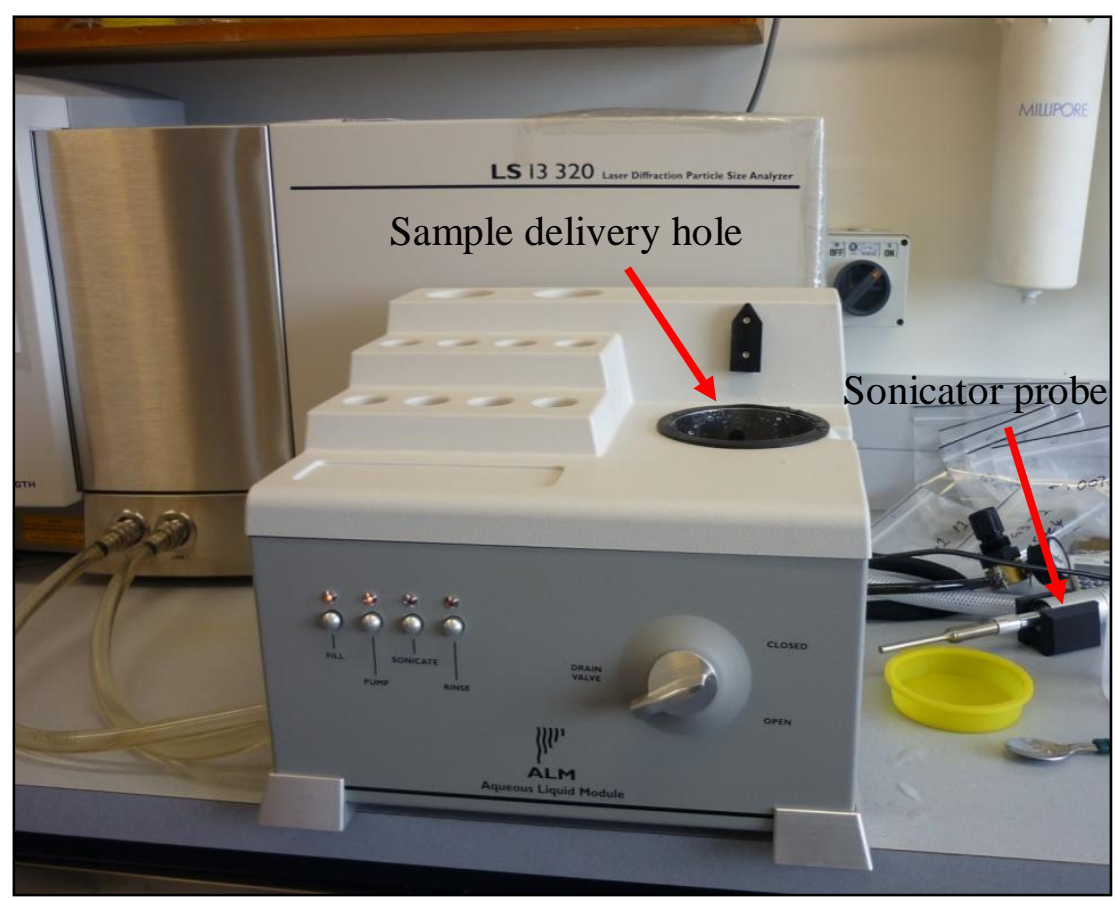

Figure 4.3: Beckman Coulter Counter Laser Diffraction Analyzer (LDPSA) used in this study. Photo shows the Aqueous Liquid Module which pumps sample to laser. 
Even though this method seems rapid and precise, certain errors will arise. Firstly, range of sediment sizes analysed is limited to the sand fraction $(1400 \mu \mathrm{m}$ or $<-0.5 \Phi)$ because of mechanical limitations of the laser diffraction. It may also give false modes in the frequency curve, and that it does not resolve polymodal distributions very accurately (McCave et al., 1986). Furthermore, McCave et al., (1986) reported a standard deviation of the median size of $0.17 \mu \mathrm{m}$ for a laser diffraction instrument. Lastly, problems may arise when analysing sediment within the clay size range or below $0.5 \mu \mathrm{m}$, since the particles do not diffract light in the manner necessary for the application of the Fraunhofer diffraction theory. This is because particle diameter approaches the wave length of light (McCave et al., 1986). However, this does not apply to sediment samples analysed in this study since they are derived from the sand and gravel fraction and no mud was present. In general, laser diffraction may still provide the only option for grain size analysis when more traditional methods are impractical (Rodriguez and Uriarte, 2009).

\subsubsection{Composition analysis}

Thin sections were made for the sand sized fraction of 42 samples. These sub samples were initially dry sieved at $-0.5 \Phi$ to separate the sand and gravel fraction. Most particles above the $-0.5 \Phi$ limit occupy too much volume on each slide making it difficult to count a large number of particles.

Sub samples were then mixed with epoxy resin to make a grain mount, then grounded and polished down to a desired thickness of between 30 and $70 \mu \mathrm{m}$. This allows for the easy identification of various carbonate grains (Flügel, 1982). A Leitz petrographic binocular microscope and Swift Model Counter were utilised to count 42 samples and a grid of approximately 400 grains was counted on each slide and placed into one of nine key categories. Grains were identified based on the classifications of Milliman (1974), Scoffin (1987), and Adams and McKenzie (1998). Every point lying on a grain was counted and larger grains were counted twice as this gives a better representation of grain composition in each sample (Flügel, 1982). The methods used were similar to those carried out around Lord Howe Island by Kennedy (2003), and Kennedy and Woodroffe (2004). Lastly, a broad 
visual compositional estimate was made for the gravel fraction samples especially those with very high gravel content on the basis of Milliman (1974) classifications.

\subsection{Radiocarbon dating}

Conventional radiocarbon ages were obtained on six microatoll samples, and three beach sand samples were radiocarbon-dated by Accelerator Mass Spectrometry (AMS). All samples were obtained from the site of Tamakautoga on the south west side of the island and were processed at Waikato Radiocarbon Dating Laboratory, Hamilton, New Zealand.

All samples were initially washed in freshwater and any encrustation was mechanically removed before being pre-treated in $27 \%$ hydrogen peroxide at $70^{\circ}$ for 12 hours to remove organics. These were then washed again and oven dried at $70^{\circ}$ for at least 24 hours. Conventional dating samples consisted of approximately $30 \mathrm{~g}$ of microatoll samples and roughly $30 \mathrm{mg}$ of foraminifera and mollusc grains were used for single grain AMS dating. Radiocarbon dating of skeletal carbonate records the time of death of the organisms and the time of deposition. However, in order for the latter to be determined rapid transport from source to deposition site with limited reworking must take place (Harney et al., 2000; Maiklem, 1968; Woodroffe and Morrison, 2001). Radiocarbon ages of bulk samples often represent an average radiocarbon content of the aggregate. This is mostly due to the integration of carbonate sediment from different sources, age, and their mixed mineralogy (Harney et al., 2000; Kvenvolden, 1965; Woodroffe and Morrison, 2001).

\subsubsection{Calibration}

The calibration of radiocarbon ages refers to the relationship between the radiocarbon and calendar timescales. The results are Conventional Ages or \% Modern as per Stuiver and Polach (1977) based on the Libby half-life of 5568 years and were corrected for isotopic calibration. All ages were also calibrated using the Marine04 dataset curve (Hughen et al., 2004) in OxCal (Version 3.10). (Stuiver and Polach, 1977). 


\subsection{Airphoto analysis}

1981 aerial photographs of Niue at 1:10,000 scale were obtained from NZ Aerial Mapping Ltd to assess the geographic variability of shore types around the island and measure platform widths and the lengths of individual beaches and adjacent reef platforms, especially in areas that were inaccessible during the field surveys. The photos represent the most recent data available for Niue.

Aerial photographs are the most commonly used data source for the compilation of shoreline mapping. Since 1927 this method has been increasingly utilised to provide topographic information along the coast (Crowell et al., 1991; Moore, 2000). Since air photos are not map projections, several sources of error exist when analysing them (Gibb, 1978). Radial distortion is caused by the imperfections in the lens elements which distorts image points along radial lines from the principal point (Moore, 2000; Thieler and Danforth, 1994). In some cases, taking measurements only from the centre of the photograph may reduce this error (Moore, 2000). Aerial camera tilt and ground relief can also cause objects on the photo image to be displaced from their true ground position. Relief displacement is caused by changes in ground elevation with objects above ground level displaced outward from the centre of the photograph and objects below ground elevation displaced inwards (Figure 4.4). Increasing radial distance from centre of photograph as well as reduced flight altitude increases the severity of relief displacement (Moore, 2000; Stafford, 1971). 


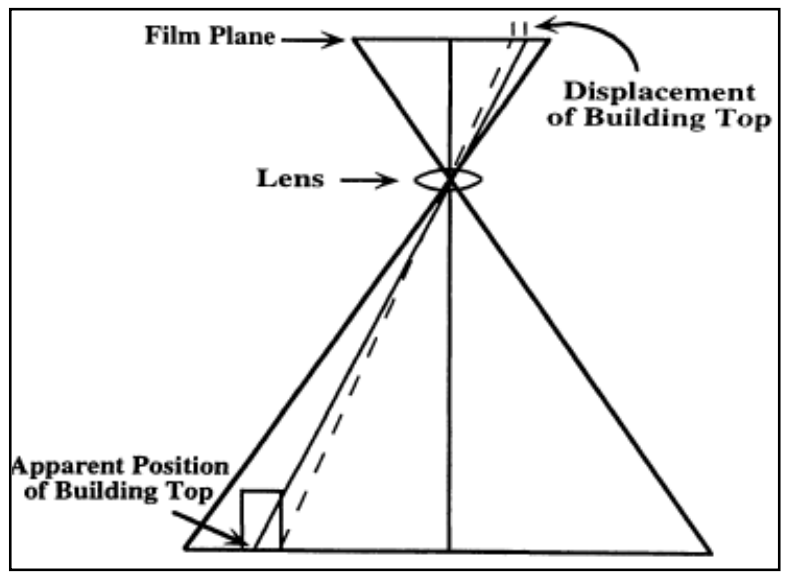

Figure 4.4: Relief displacement causes objects to be displaced towards the outer edges of the photograph. Source: Stafford (1971).

The tilt of the camera can also influence the scale of the image and a tilt of just 1 degree can generate significant displacement (Moore, 2000; Thieler and Danforth, 1994). Geographic Information System (GIS) software (ArcGIS version 9.2) was used in this project to correct or reduce these distortions by georeferencing the images to a published topographic map.

\subsubsection{Georeferencing Aerial Photos}

Aerial photos were initially scanned in colour at photographic quality to $600 \mathrm{DPI}$. These were converted into JPEG format and cropped to remove the frames using Corel PHOTOGRAPH-PAINT X4 software.

The 1:50,000 topographic map of Niue was scanned in two parts and stitched together using CorelDRAW X4 software. This image was then imported into GIS where the latitude and longitude lines that appear on the map are used to register the map to the World Geographic System 1984 UTM Zone 2S. This map was then used as the base against which the 1981 aerial photographs were georeferenced (Figure 4.5). Ground control points were obtained by matching features such as corners of buildings or houses, the wharf, road intersections and coastline shape, with corresponding points in a map projection (Crowell et al., 1991). This allowed the raster image (the aerial photo) to be realigned and stretched to fix as closely with the vector layer as possible (Smith and Cromley, 2006). 


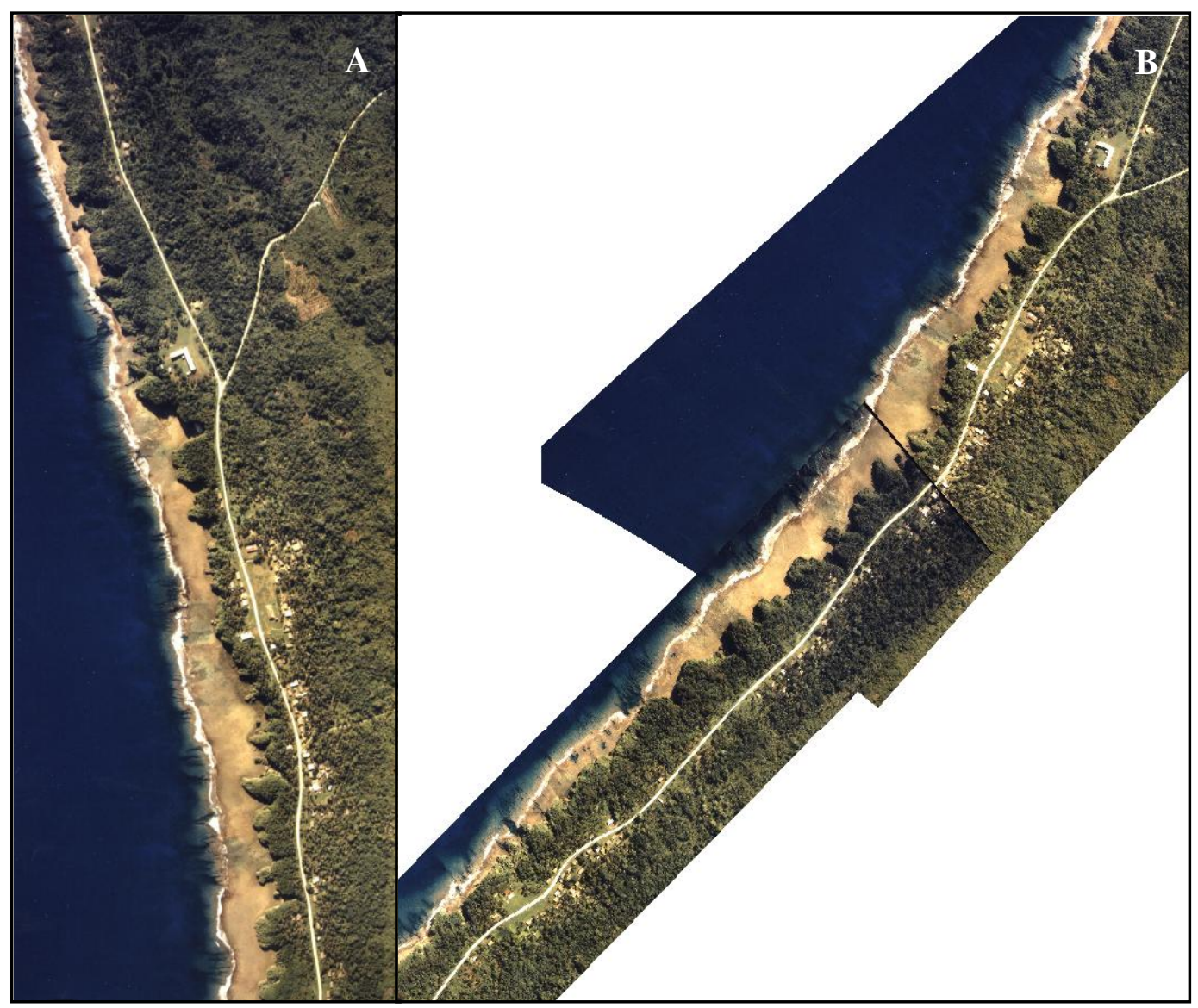

Figure 4.5: Before and after aerial photographs illustrating the effect of georeferencing an aerial photograph to the Niue topographic map. A) 1981 aerial shot of the North West coast at sites Hio and Tuapa (Photograph: NZ Aerial Mapping Ltd 2008). B) Same aerial photo now georeferenced to topographic map.

The more control points added, the lesser the Root Mean Square (RMS) error value and therefore more accurate rectification (Table 4.2). This value gives a standard mean error in pixels and represents the difference between known point locations and their locations after the image has been rectified (Smith and Cromley, 2006). In areas where control points were difficult to establish, less reliable points such as plantation plots or road bends were used; although, this can substantially affect mapping accuracy (Thieler and Danforth, 1994). The calculate RMS error for the georeferenced aerial photos of Niue range up to $21.21 \mathrm{~m}$ and this is due to the lack of ground control points or landmarks in certain areas. The $2^{\text {nd }}$ order polynomial transformation was often used where the image became warped in order to reduce the error of some aerial photos. Despite the large RMS values, this did not affect the results in this study. 
Table 4.2: Root Mean Square error values and order of Polynomial transformation for georeferenced aerial photos of Niue

\begin{tabular}{|c|c|c|}
\hline Aerial Photo ID & $\begin{array}{c}\text { RMS Error Value } \\
(\mathbf{m})\end{array}$ & $\begin{array}{c}\text { Transformation (1st or } \\
\text { 2nd order polynomial) }\end{array}$ \\
\hline A2 & 17.09 & 2 \\
A4 & 16.37 & 1 \\
A6 & 13.14 & 2 \\
A8 & 5.14 & 2 \\
A10 & 19.55 & 2 \\
A12 & 13.15 & 1 \\
B14 & 19.7 & 1 \\
C26 & 12.86 & 1 \\
D22 & 21.21 & 1 \\
E21 & 13.33 & 1 \\
F22 & 11.98 & 2 \\
G2 & 7.93 & 2 \\
G24 & 19.37 & 2 \\
H19 & 13.28 & 1 \\
I22 & 6.59 & 1 \\
J6 & 12.97 & 1 \\
\hline
\end{tabular}

\subsubsection{Beach and platform measurements}

Platform widths and the lengths of individual beaches were obtained using the measurement tool in ArcGIS. The seaward edge of reef platforms is defined on the basis of the change in color between the platform and the water as well as the occurrence of waves breaking. The beach-platform interface is also defined as the boundary between dark colored platform and light sand (beach) while the cliffs define the landward limit of platforms at most sites. To test the accuracy of this analysis, measurements were compared with data derived from EDM surveys, with the field surveys being 5-20\% shorter than those calculated from the photos. Surveying did not extend to the seaward edge of the platform due to rough conditions in some areas and this resulted in field surveys being slightly shorter compared to aerial photo measurements; however, boundaries were ground truthed in the field. Errors may arise when the boundaries between the beach, platform and fringing reef are somewhat difficult to define. According to Li et al., (2001), the identification error of the shoreline from the photo may introduce 1.5 pixels or $1.5 \mathrm{~m}$ with an estimated standard deviation of approximately $2.6 \mathrm{~m}$. Despite of this, the errors during this study are minor and are accounted for in the analysis. 


\section{CHAPTER 5: Results}

\subsection{Introduction}

Rocky coasts are common on uplifting Pacific Islands such as Niue and they tend to be inhospitable environments. Unlike most typical Pacific Islands that are bounded by sandy beaches, the entire coastline of Niue is cliffed and fronted by an erosional platform and fringing reef. There is limited research on beach development in these settings and what thresholds drive them to accumulate For this research the data on fourteen coastal sites will be presented and for the purposes of analysis, the coastline has been subdivided into 5 units, according to the orientation and wave exposure of the island; the North West, West, South West, East, and the South Eastern coast. Surveyed and sample sites of this research are presented in Figure 5.1.

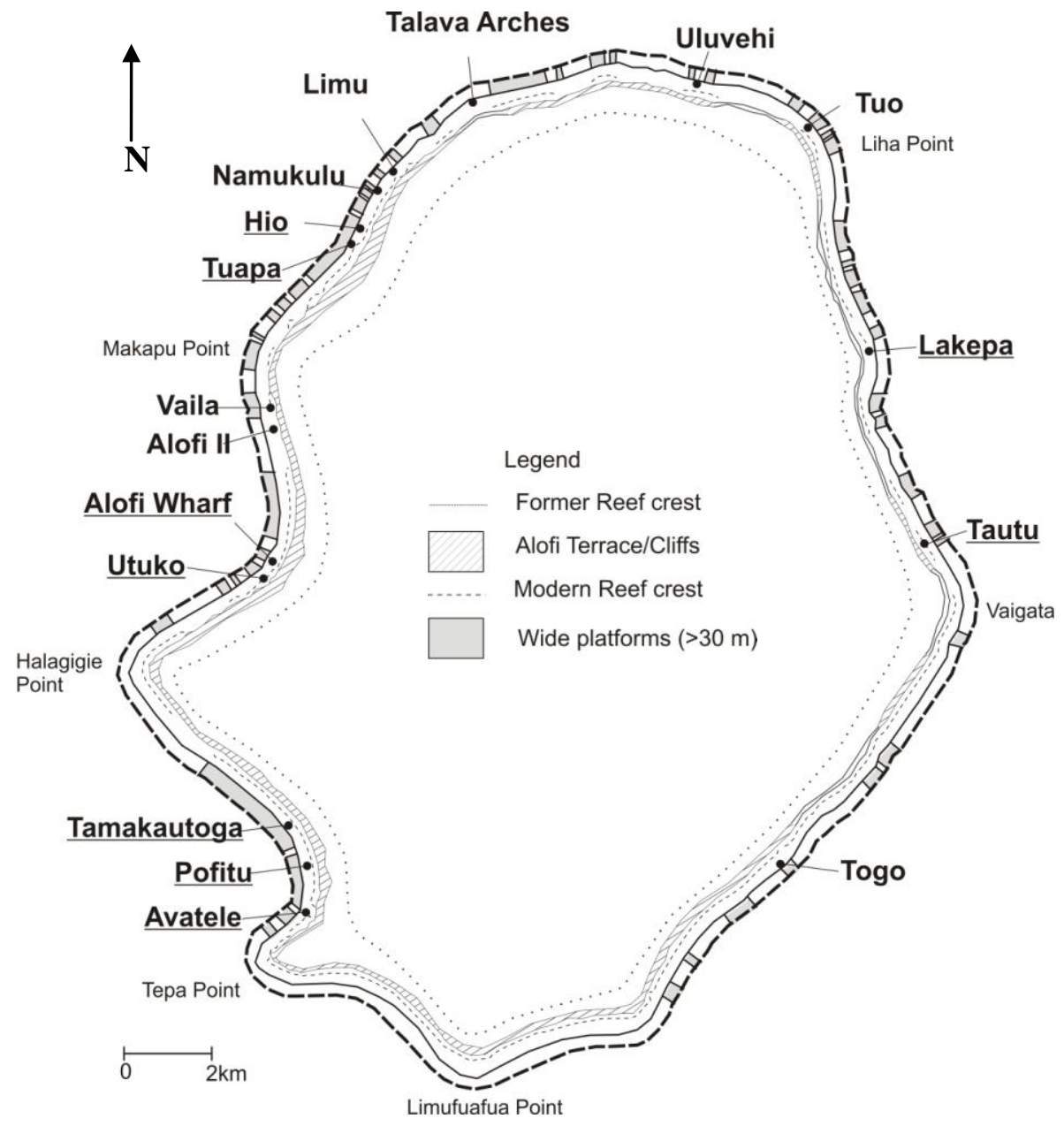

Figure 5.1: Map of Niue, showing locations that are mentioned in this study. Place names underlined represent surveyed sites. 


\subsection{Surface Morphology}

\subsubsection{South West Coast}

The South West Coast, representing Avatele Bight, Tamakautoga, and Pofitu, extends from Halagigie Point to Tepa Point (Figure 5.1 and Figure 5.2) with this part of the shore being protected from the prevailing trade winds by Tepa Point. Platform width ranges from 60-80 $\mathrm{m}$ and this decreases northwestward toward Halagigie Point. Beaches are present at Tamakautoga, Pofitu, and Avatele, the latter being the only covehead beach on the island. A total of 11 transects were surveyed from the cliff base to the seaward edge of the reef platform at the three sites (Figure 5.3A-I).

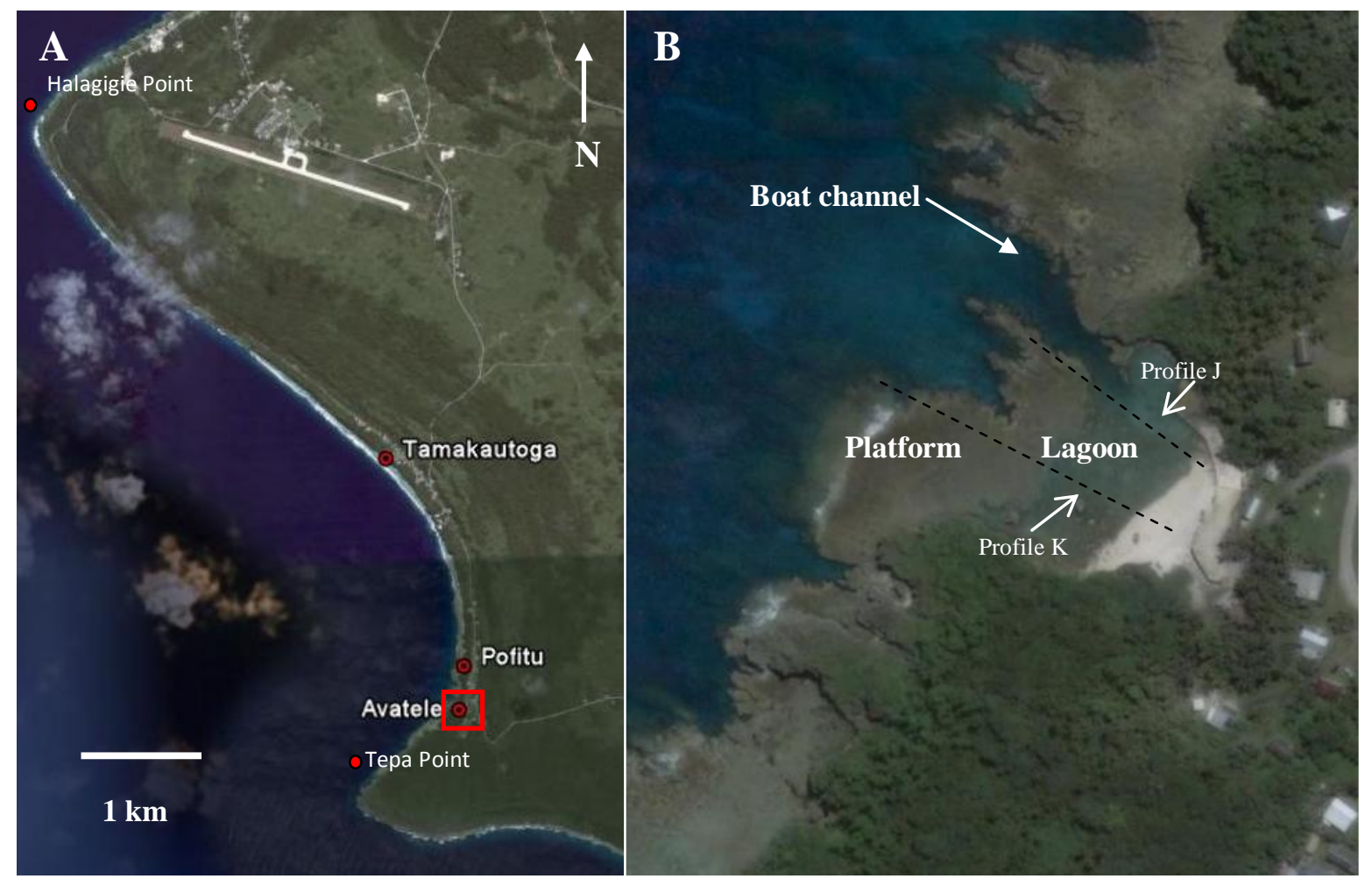

Figure 5.2: (A) Aerial photo of sites on the south west coast (B) Close up of Avatele Beach showing survey transects. Source: Google Earth (2009).

Tamakautoga and Pofitu are small pocket beaches, backed by 6-10 m high cliffs that are notched at the base. These cliffs are formed on Alofi Terrace which slopes gently seaward at its outer edge on this part of the coast, resulting in generally lower cliffs than the rest of the island (Forbes, 1996). The combined reef rim and platform width ranges from 70-100 m with the widest platform $(80 \mathrm{~m}$ ) found immediately north of Tamakautoga Landing and is 
characterised by an algal rim occupying the outer $20 \mathrm{~m}$ of the profile (Profile $\mathrm{G}$ ). The reef platform has a relatively uniform depth and the crest drops sharply beyond each survey to a fore reef slope $\sim 10 \mathrm{~m}$ below mean water level (MWL). This then extends 4-6 m seawards to merge with grooves in the spur and groove zone on the reef front which is dominated by coralline red algae. The platforms in the area are characterised by a surface with heavily dissected grooves and potholes around $0.6 \mathrm{~m}$ deep and 1-2 $\mathrm{m}$ wide being common. They are best developed on the inner parts of the platforms along and occur in association with well-developed microatolls $\sim 1.5 \mathrm{~m}$ diameter occurring near the beach (Profiles $\mathrm{H}$ and I).

The beaches at the rear of the platform range in width from 5-18 $\mathrm{m}$ with a mean slope of $7.4^{\circ} \pm 2$.1. Profiles $\mathrm{A}$ and $\mathrm{G}$ sitting at the highest elevations ( $2-3 \mathrm{~m}$ above MWL) relative to other beaches surveyed which occur at elevations of $<1.5 \mathrm{~m}$ above MWL. Each of the profiles is underlain by a sloping ramp of limestone bedrock. This is often exposed in places with its surface being polished adjacent to the cliff base and becoming more exposed and rugged on the lower beachface, overlain by a thin veneer of sand. Profile $\mathrm{C}$ is distinctly different to the other profiles being near horizontal ( $1.4^{\circ}$ slope $)$ located and not lying on top of a sloping ramp. 
A

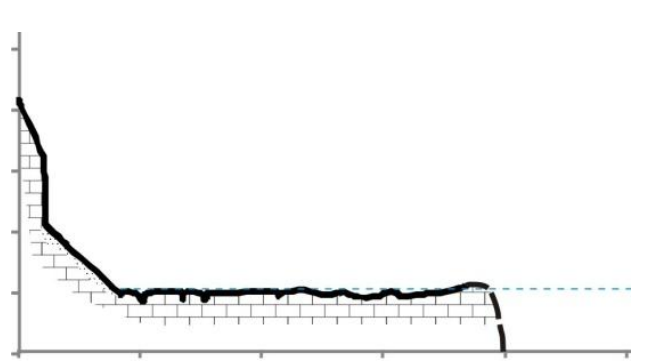

B

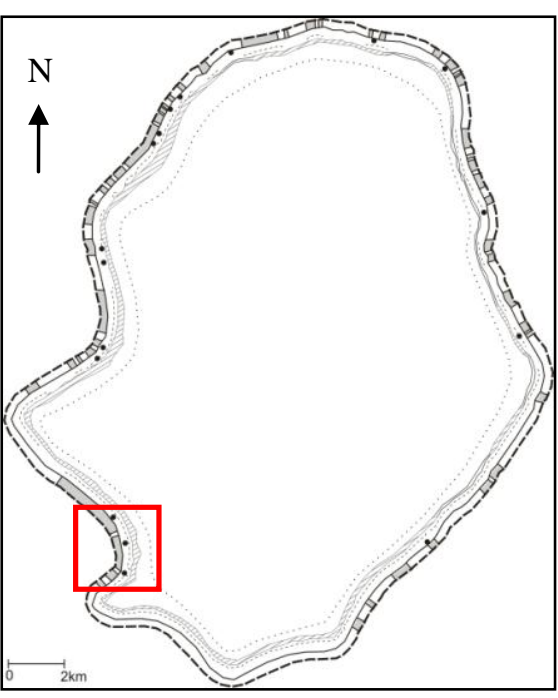

$\mathrm{E}$

C

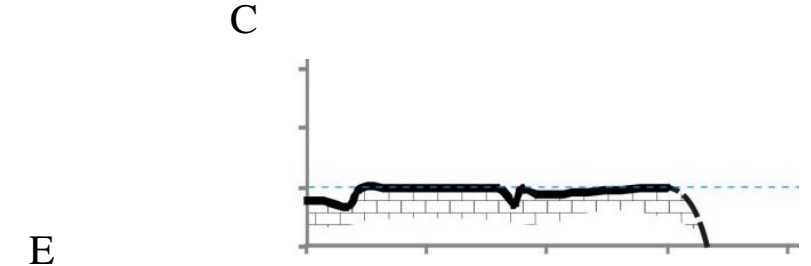

$\mathrm{D}$
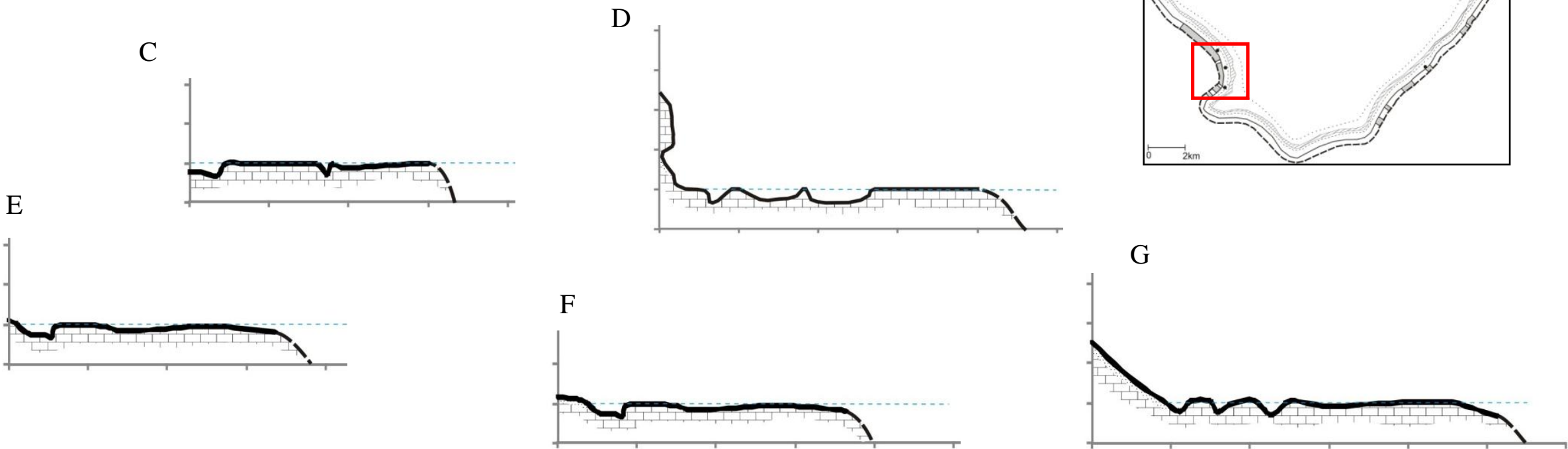

$\mathrm{H}$

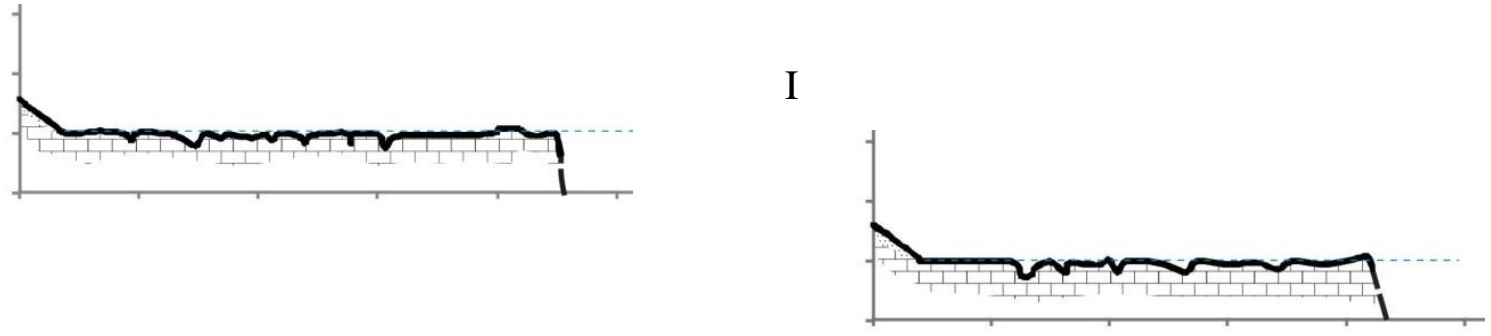

Figure 5.3: Survey transects at Tamakautoga (Profiles A-G) and Pofitu (H and I) showing general surface morphology.

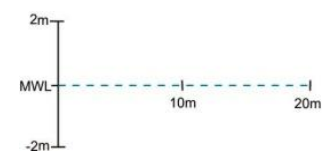

Beach

Limestone platform 
South of Pofitu and Tamakautoga is Avatele Bight facing North West which contains the largest beach on the island. A concrete boat ramp is situated towards the east end of the cove near a channel through the reef (Figures 5.2), with low cliffs bordering this part of the cove and becoming higher towards the west. Two topographic transects were surveyed at Avatele, one from the cliff base and beach junction to the seaward edge of the platform reef, the other from the crest of the beach berm (Figure 5.4J-K). The combined platform and reef rim width is approximately $90 \mathrm{~m}$ with the reef rim rising to $0.46 \mathrm{~m}$ above MWL. Avatele beach is fronted by a 1-2 $\mathrm{m}$ deep lagoon and covered mainly in rubble debris, which locals report to have infilled the lagoon by $0.5-1 \mathrm{~m}$ in the past 20 years. Small patch reefs 1-2 m high are also present with live Porites coral confined to the outer $20-30 \mathrm{~m}$ of the reef.

Avatele beach is composed of coarse gravel and cobble, is $80 \mathrm{~m}$ long and $30 \mathrm{~m}$ wide, covering an area of $2.4 \mathrm{~km}^{2}$. The upper beach reduces from $3.5 \mathrm{~m}$ above MWL in the east (Profile $\mathrm{J}$ ) to $\sim 2 \mathrm{~m}$ in the west (Profile $\mathrm{K}$ ), with the beach slope increasing from $12^{\circ}$ on the lower beach to $15^{\circ}$ on the upper beachface from the high tide berm to the storm ridge. This storm ridge is composed of weathered coral cobbles and accumulates during cyclone events, the most recent being Cyclone Heta in 2004. A distinct high tide berm occurs at $\sim 2 \mathrm{~m}$ above MWL on the eastern transect; while the western transect is more gently sloping with no apparent berm. Beach deposits grade from large boulders at the east end adjacent to the ramp to coarse sand at the cliff base of the western transect. Accumulation of gravel and cobble towards the eastern end of the beach also appear to be recent deposits since this area was characterised by boulders in previous years (Figure 5.5A-B). Sediment is also finer on the lower beachface with a sheet of gravel and pebble visible in places within the swash zone and becoming coarser towards the high tide berm and storm ridge (see Section 5.3). 

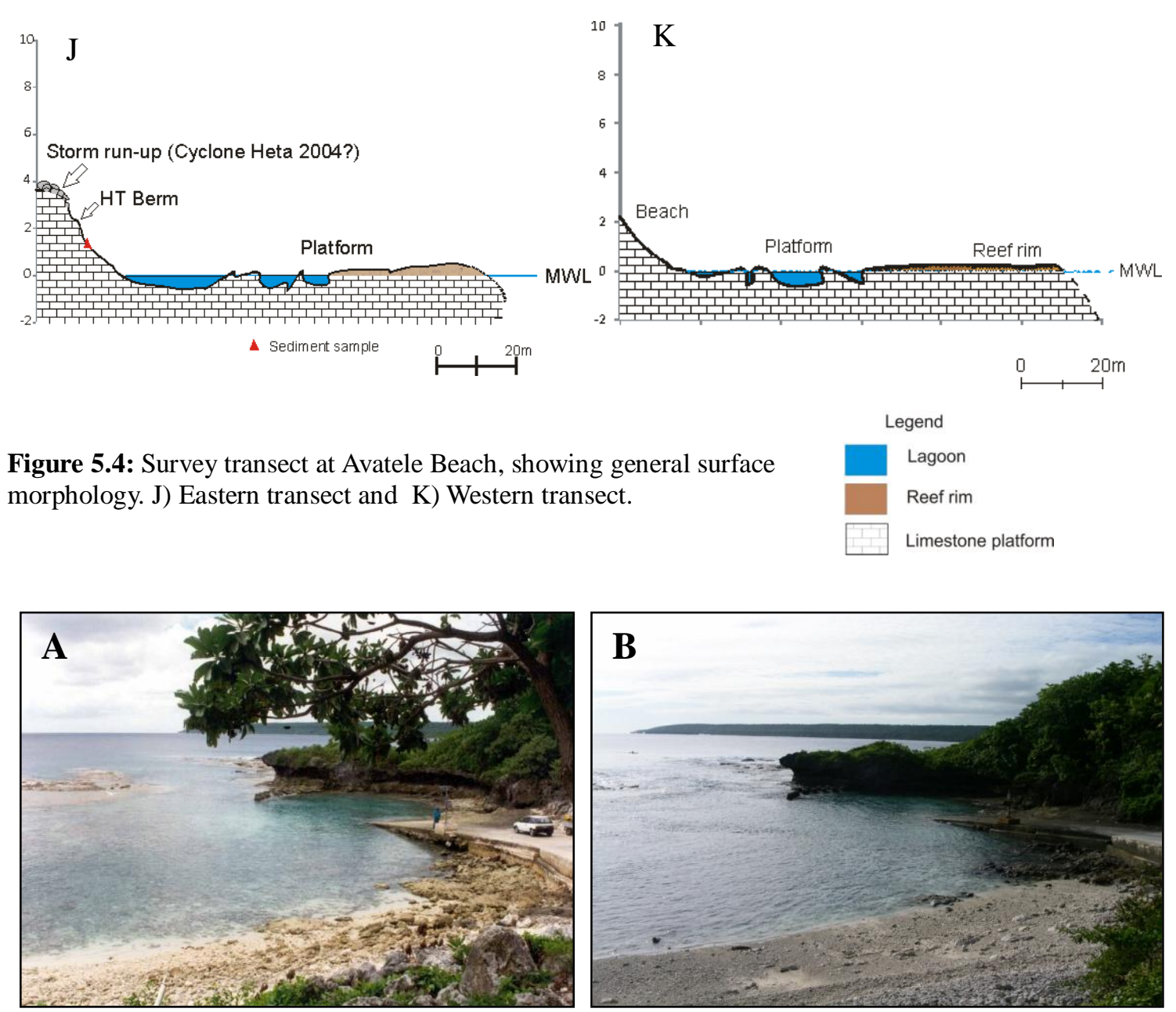

Figure 5.5: Looking down on to Avatele Beach, with boat ramp on the right. A) Photo taken in 1995 by SOPAC. B) More recent photo of the beach in 2008.

\subsubsection{West Coast}

The West Coast representing Alofi Bight extends from Makapu to Halagigie Point and a total of 3 transects were measured at Alofi Wharf and Utuko Reef (Figure 5.6A-C). Platform width ranges from 80-130 m with the reef rim occupying the outer $30 \mathrm{~m}$. This rim rises to $+0.3 \mathrm{~m}$ and $+0.5 \mathrm{~m}$ at Alofi Wharf and Utuko Reef respectively while the crest drops sharply to a fore reef slope $\sim 30 \mathrm{~m}$ below MWL. 5-10 m high cliffs mark the landward limit of the platform north and south of the wharf as well as at Utuko Reef with small gravel beaches occurring on the north and southern sides of the wharf. The lower beachface slope of the southern beach is $7^{\circ}$ increasing to $10^{\circ}$ across the high tide swash and storm berms at $+2.5 \mathrm{~m}$. From this point the beach rises to an elevation of $3.5 \mathrm{~m}$ above MWL; with sediment becoming coarser towards the top of the beach with clasts up to 30 $\mathrm{cm}$ occurring. In contrast, the beach north of the wharf ( 
Figure 5.7) sits at only $0.3 \mathrm{~m}$ above MWL and is gently sloping $\left(2.7^{\circ}\right)$ relative to the southern beach.

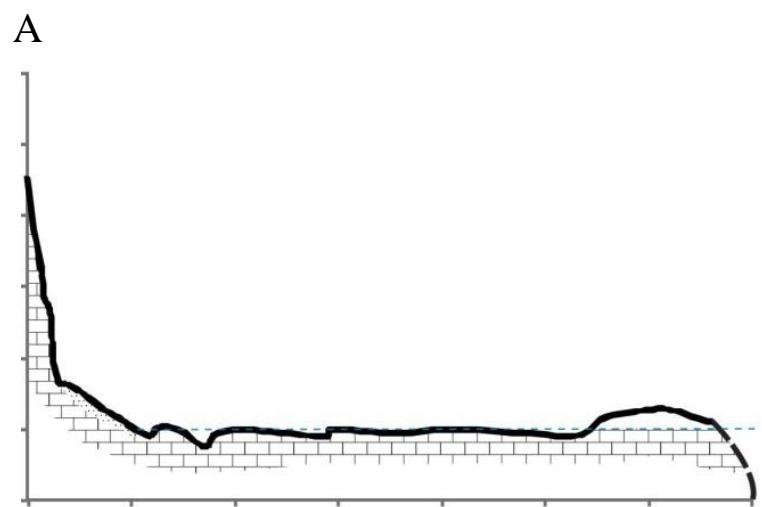

\section{B}
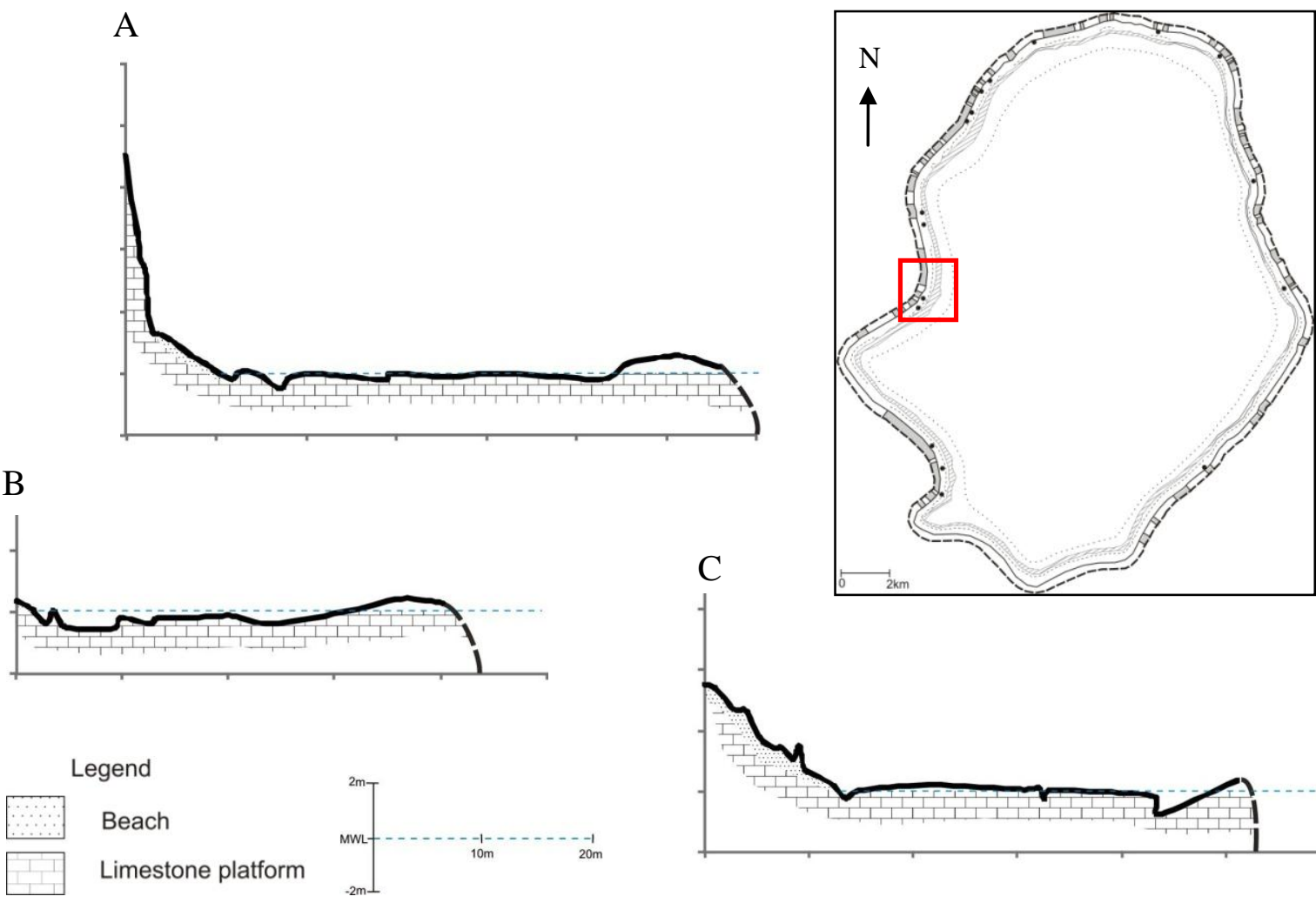

Figure 5.6: Topographic profiles at Utuko (Profile A) and Alofi Wharf (Profile B and C).
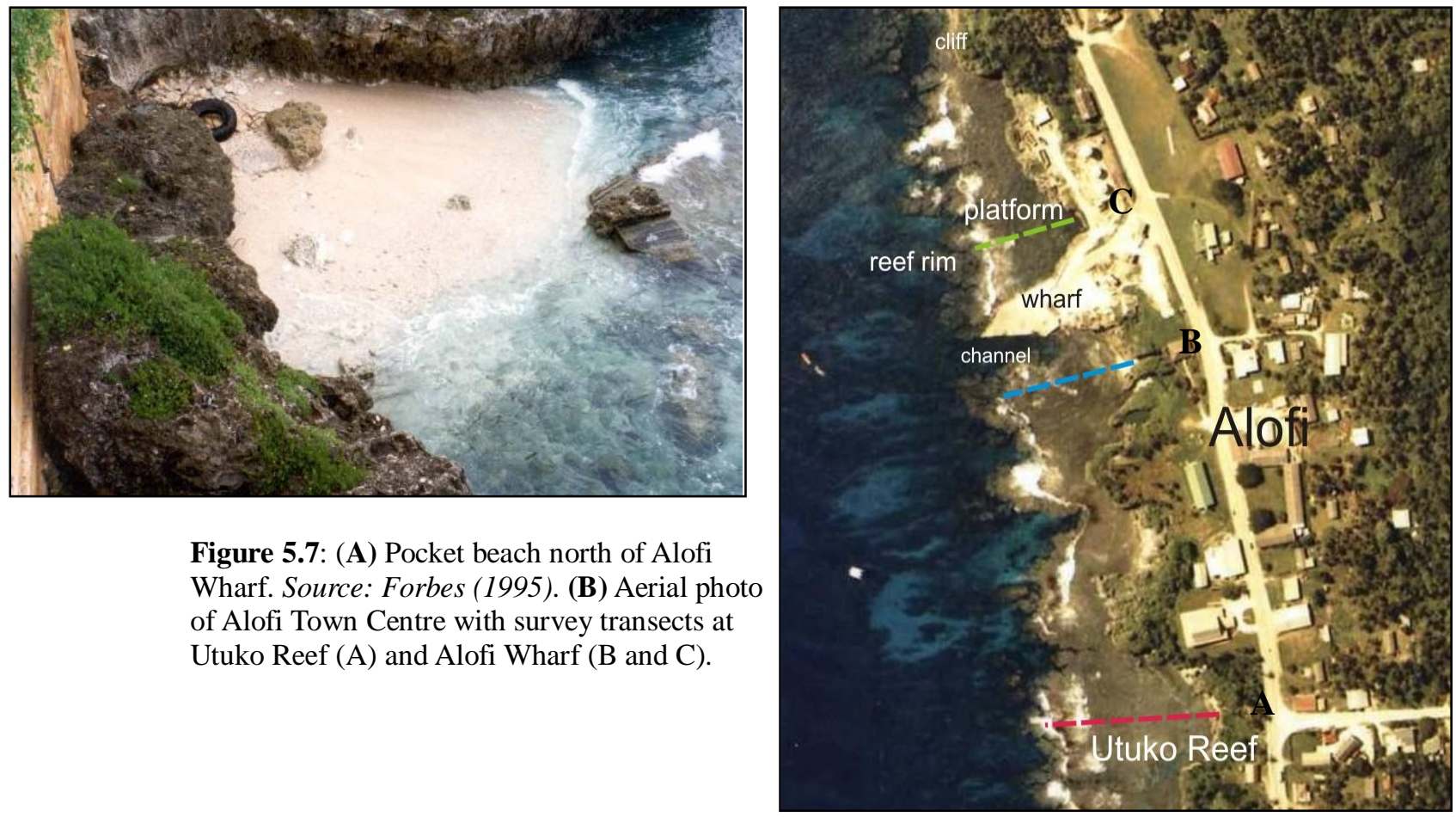

Figure 5.7: (A) Pocket beach north of Alofi Wharf. Source: Forbes (1995). (B) Aerial photo of Alofi Town Centre with survey transects at Utuko Reef (A) and Alofi Wharf (B and C). 
Utuko Reef is located south of Alofi Wharf and is a small cliff base pocket beach behind a relatively wide platform and fringing reef with a combined width of $119 \mathrm{~m}$. Limestone is exposed on the southern half of the beach with only a veneer of sediment cover in most places. Two large boulders 1.5-2 $\mathrm{m}$ high sit across the mid section of the beach which may be a result of cliff failure and subsequently moved to its present location by cyclones. Beach width is $17 \mathrm{~m}$ with a $4.0^{\circ}$ slope occurring at a similar elevation to the gravel beach north of the wharf and is often inundated by waves during high tide.

\subsubsection{North West Coast}

This section of the coast extends from Makapu Point to the Talava Arches and represents the sites of Tuapa and Hio (Figure 5.8 A-B). The widest reef platforms on the island are found within this area where they can reach up to $150 \mathrm{~m}$. The platforms within the area have a mean elevation of $+0.08 \mathrm{~m}$ and $-0.20 \mathrm{~m}$ MWL at Tuapa and Hio respectively. Beaches are backed by steep cliffs that are notched at the base. In addition, a near vertical in the cliffs behind Hio beach extending from the platform to the cliff top (Figure 5.8C). This may be a result of wholesale removal of parts of the outer terrace and indicate that wave quarrying and cliff erosion are ongoing processes.

Two very narrow and thin pocket beaches are present just north of the landing at Tuapa. The northern beach is only $2 \mathrm{~m}$ wide and is less than $0.1 \mathrm{~m}$ thick with a beachface slope of $6^{\circ}$ slightly steeper than that at Hio Beach (A-D). Some potholes and gutters are present on the platform which is covered in an algal turf supporting a dense population of foraminifera especially in the mid-platform area. A cliff base pocket beach is located just north of Tuapa at Hio. The beach is $12 \mathrm{~m}$ wide and thin and a sediment cover of less than $0.1 \mathrm{~m}$ with the underlying ramp being exposed at the cliff base and towards the northern end. 

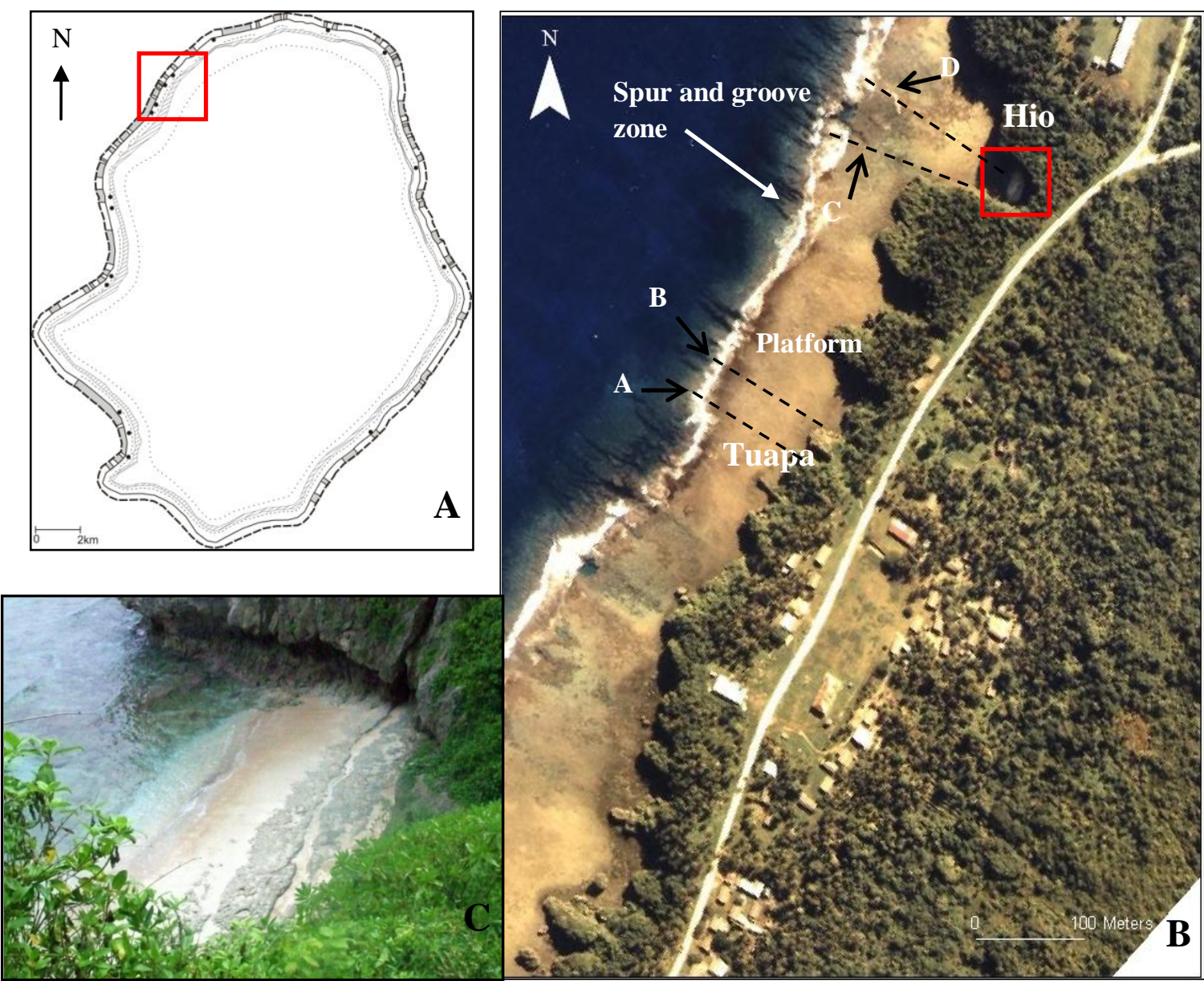

Figure 5.8: (A): Location of North Western sites. (B): Aerial photo of sites Hio and Tuapa showing extensive platform development and prominent spur and groove structures and survey transects. (C): Close up of Hio beach seen from the top of the cliff at mid tide. Note the wave polished limestone ramp at the base of the cliff and steeply dipping fracture at the back of the beach.
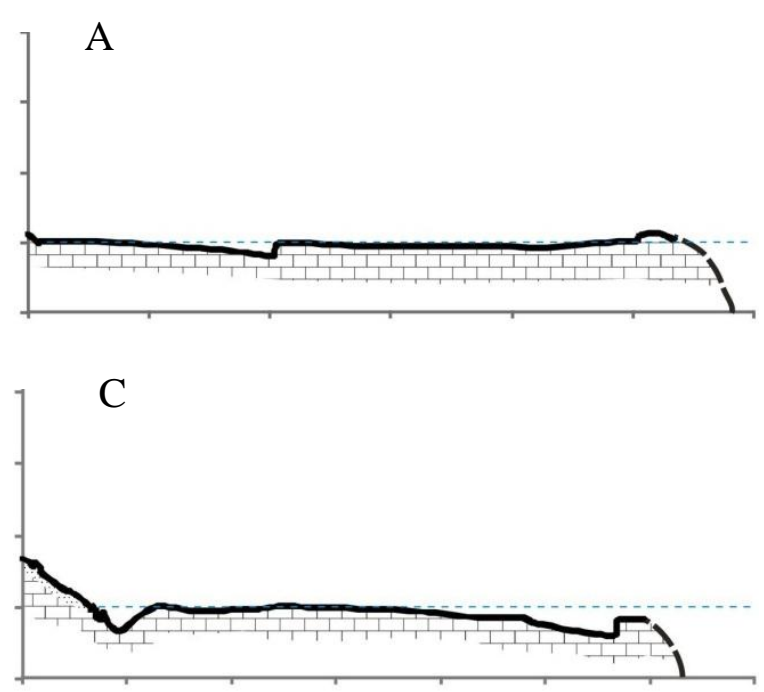

Figure 5.9: Topographic profiles of Tuapa (A and B) and Hio (C and D).
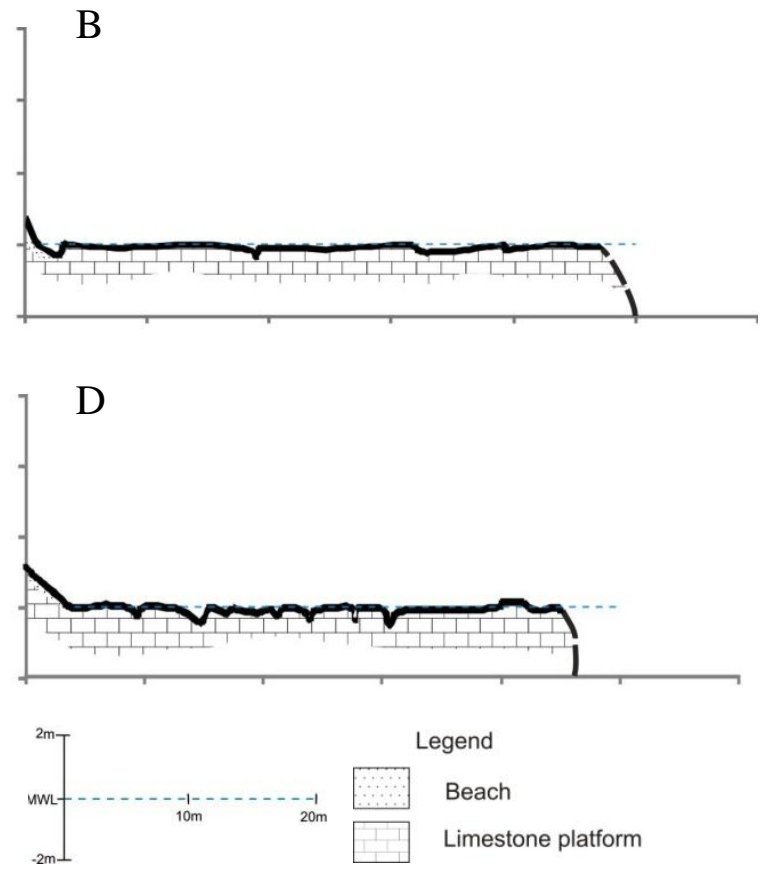
Gravel patches at Hio occur at the base of the western cliff and with mean grain size becoming finer towards the other side of the beach. The beachface is linear in profile with a slope of $5.8^{\circ}$ and lacks a berm (Figure 5.9C-D). Profile $\mathrm{C}$ has a less prominent algal reef crest, with a depth of 0.3-0.5 m below MWL relative to other sites. Several irregular shallow depressions partly filled with wave rippled sand also occur on the inner platform.

\subsubsection{East Coast}

The East Coast extends from Liha Point to Vaigata which includes the sites of Lakepa and Tautu which is exposed to the prevailing southeast trade winds. Combined platform and reef rim width ranges from 50-70 $\mathrm{m}$ with the narrowest platforms found at Tautu (Figure 5.10A-D). The seaward margin of these erosional platforms is often cut by a series of grooves 1-2 m wide with the spurs separating the grooves. Very few microatolls are present here with the inner platform being heavily dissected by potholes. Their size often decreases towards the reef crest, as the platform becomes smoother due to infill by coral and coralline algae (Figure 5.11A). A deep pool with a maximum depth of $0.71 \mathrm{~m}$ below MWL is present on profile $\mathrm{F}$ and is comprised of several branching live corals. Mean platform depth is -0.49 and $-0.27 \mathrm{~m}$ at Lakepa and Tautu respectively with the highest point being $0.14 \mathrm{~m}$ above MWL on Profile H.

Small pocket beaches 3-6 m wide occur in five embayments at the landward edge of the platform (Figure 5.11B). Pocket beaches north of Tautu Landing (Figure 5.11A-C) sit at a slightly higher elevation (+1 $\mathrm{m}$ above MWL), particularly profile A, compared to those on the southern side (profiles D and E) as well as those at Lakepa, where $70 \%$ are being $<1 \mathrm{~m}$ above MWL in elevation. All beaches are thin $(<0.1 \mathrm{~m})$ with a mean slope of $7.0^{\circ}$ with sand often accumulating towards the southern side of the beach in some embayments. A slight difference in slope and elevation is observed on profiles $\mathrm{G}$ and $\mathrm{H}$ at Lakepa, both of which are taken from each end of the beach just south of the seatrack. The abrasion ramp at the rear of the platform on profile $G$ is narrower $(3 \mathrm{~m})$ with a slope of $9.5^{\circ}$ as opposed to the slightly wider $(6 \mathrm{~m})$ and more gently sloping beach $\left(7.0^{\circ}\right)$ on profile H. Despite of this, thickness was greatest towards the narrower and steeper side of the beach. 

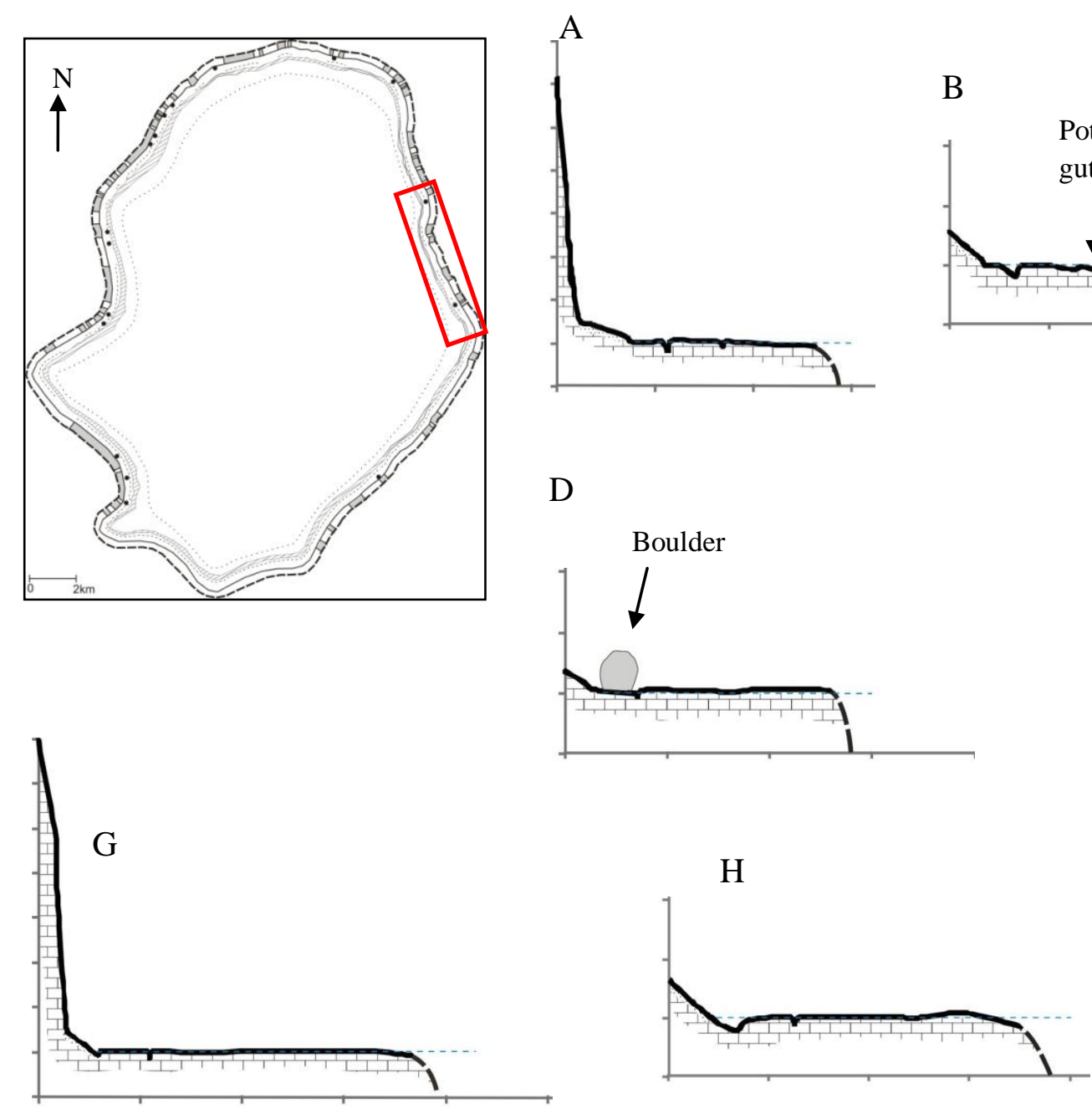

Figure 5.10: Survey transects at Tautu (A-E) and Lakepa (F-I) showing beach and platform morphology.

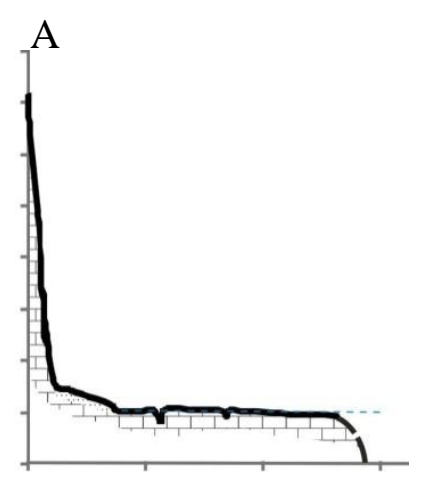

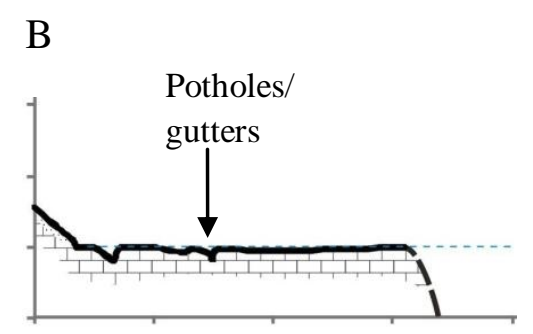
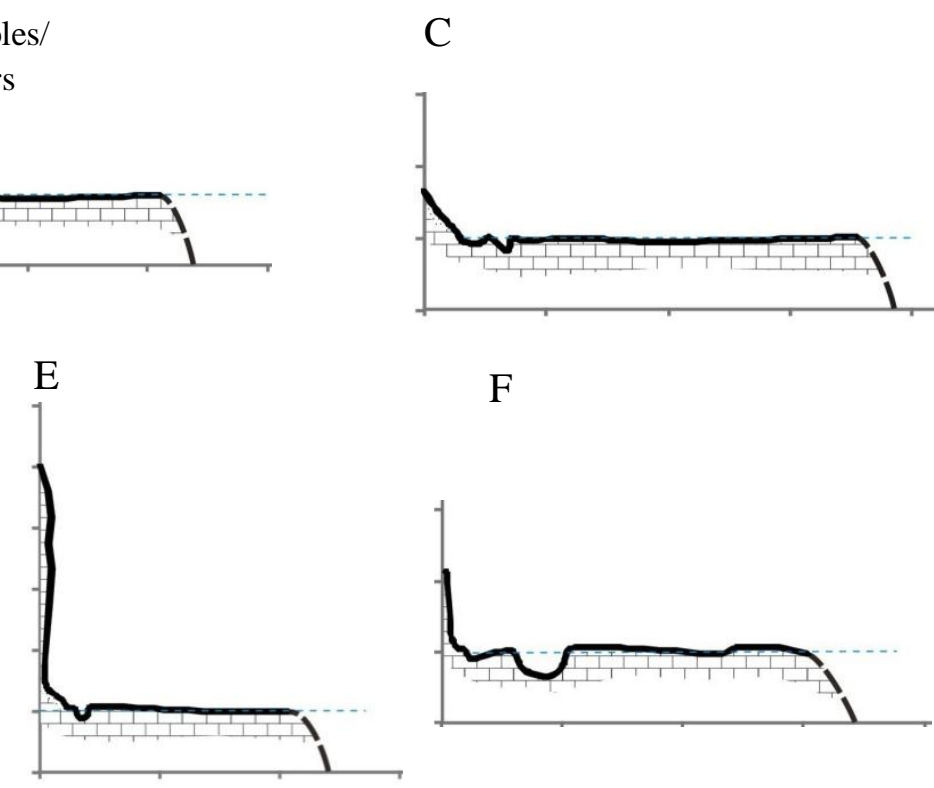

F
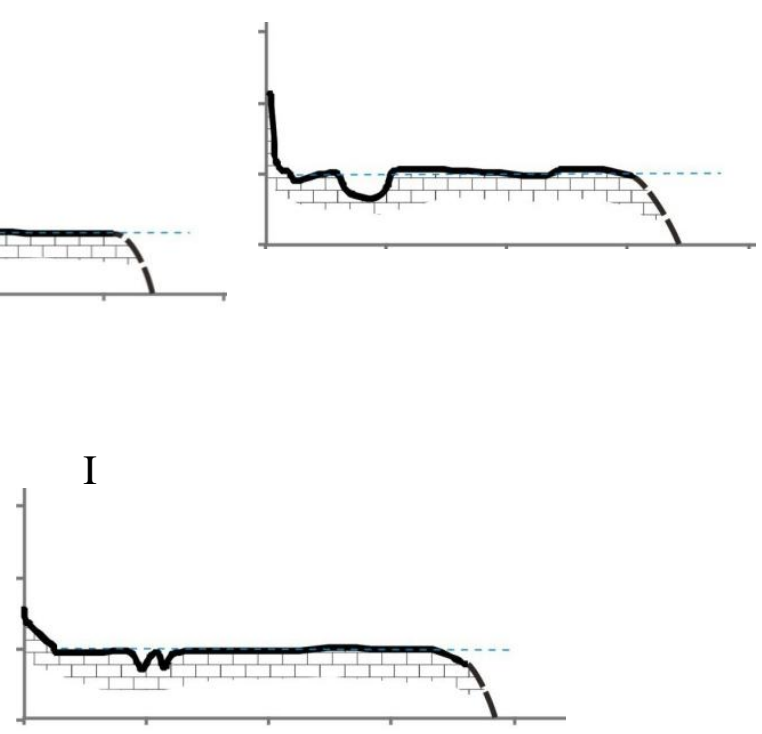

Legend

Beach

Limestone platform

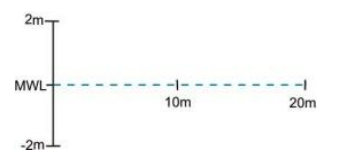




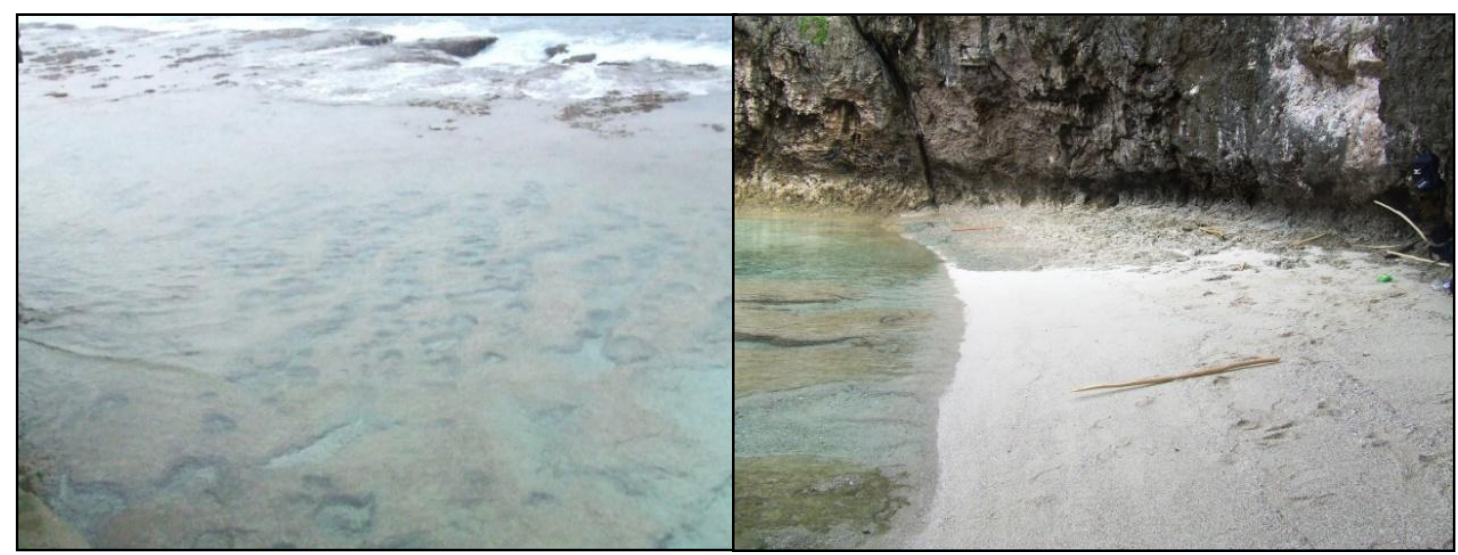

Figure 5.11: (A) Potholes and gutters present on the inner platform at Tautu. (B) Small pocket beach at Lakepa with the ramp exposed towards the southern end.

\subsection{Sediment texture}

\subsubsection{South West Coast}

Surface sediments from the sites of Pofitu and Avatele are composed mostly of gravel $(85.01 \pm 25.96 \%$ and $83.59 \pm 28.42 \%)$, while further north at Tamakautoga, sand is more dominant $(54.97 \pm 45.04 \%)$. At Avatele, surface sediment ranged from cobbles $(-6 \Phi)$ at the top of the storm ridge (Figure 5.12) to moderately well sorted (0.6 $\Phi$ ), very coarse sand ($0.5 \Phi)$ on the mid beach face, while samples from the lower beach face consisted of a mixture of pebble and coarse sand (Ava/3) (refer to Appendix 3). Gravel composition is also generally greatest on the beach toe at other locations (61.9 and 100\% in Tama/4 and Pofi/2 respectively), being composed of fine gravels of coral and coralline algae.

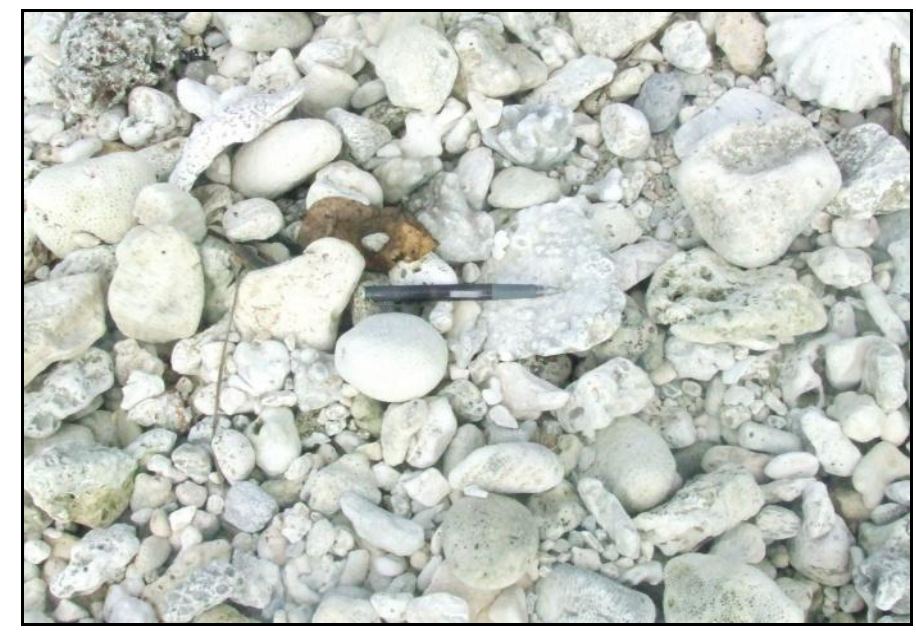

Figure 5.12: Coral gravels on top of storm ridge at Avatele Beach. Pen $(14 \mathrm{~cm})$ for scale. 
The sand fraction at Tamakautoga is composed of very coarse, moderately sorted sand (-0.3 to $-0.9 \Phi)$ with a mean size of $-0.4 \pm 0.3 \Phi$. Similar results were also found at Pofitu. On the other hand, beach toe samples from Tama/6 appeared coarser $(-0.9 \Phi)$ and better sorted $(0.3 \Phi)$. There is very little variation in skewness between most samples at Pofitu, Avatele and Tamakautoga with all being positively skewed apart from the uniform distribution at Tama/7 and negative skewness at Tama/5 (-0.11Ф).

\subsubsection{West Coast}

Beach sediments from Alofi Wharf were entirely gravel while at Utuko Reef, sand was the more dominant component comprising $66 \pm 15.18 \%$ of surface material. Sediment samples were collected from the high tide (Utu/1), mid tide $(\mathrm{Utu} / 2)$, low tide $(\mathrm{Utu} / 3)$ and reef platform (Utu/4) at Utuko Reef and demonstrate a fining of sediment shorewards from the platform $(-0.60 \Phi)$ the top of the beach $(-0.08)$. The sand fraction at Utuko is composed of moderately sorted (mean $0.69 \pm 0.09 \Phi)$, very coarse grained sediment with a mean grain size of $-0.34 \pm 0.26 \Phi$. Sediments from the high tide (Utu/1) and low tide (Utu/2) swash zone exhibit a binomial and strongly positively skewed size distribution that contrasts with the coarser and better sorted low tide and reef flat sediments (Figure 5.13).
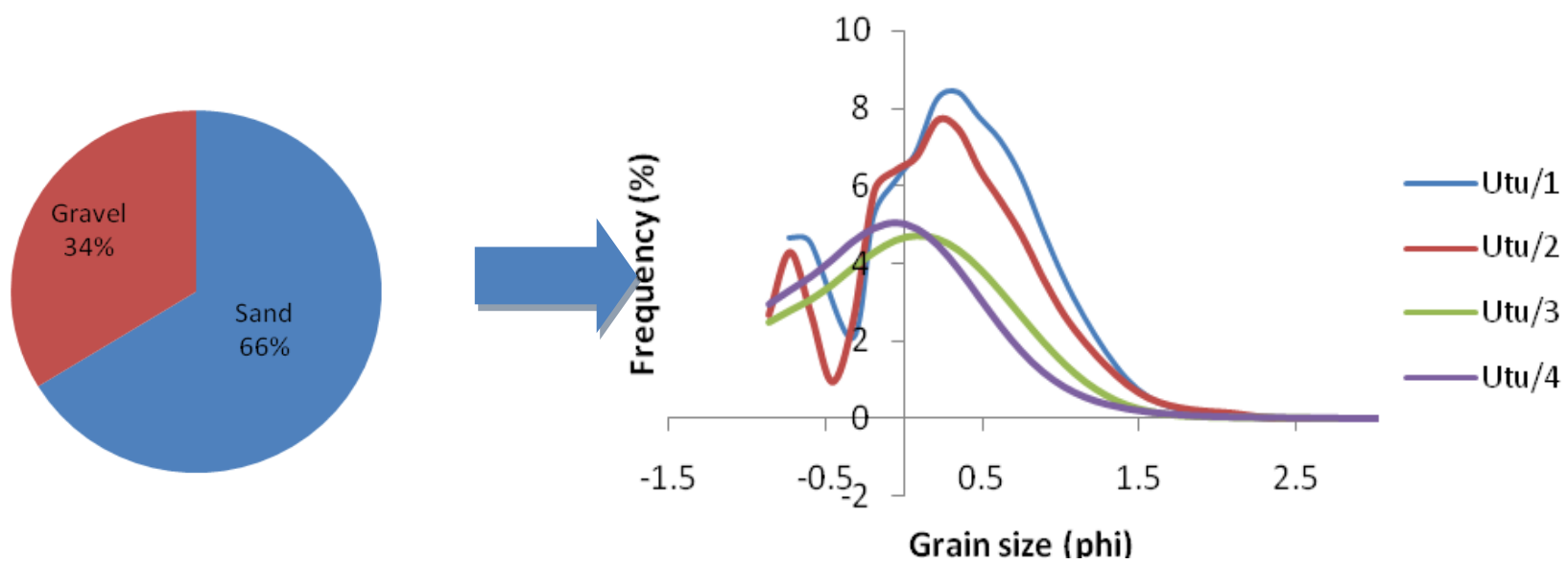

Figure 5.13: A) Pie graph of sand and gravel content at Utuko Reef. B) Surficial sand sized grain character at Utuko Reef. 


\subsubsection{North West Coast}

Surface sediments on the North West Coast are composed of gravelly sand. Sand accounts for $60.1 \pm 39.8 \%$ and $50.8 \pm 49.1 \%$ of sediment at Tuapa and Hio respectively with the highest found at Talava Arches (74.1\%). Samples collected from the mid beach, swash zone and the reef flat at Hio and Tuapa decrease in sand content seawards. The proportion of sand on the beach top (Hio/2) reduced from $93 \%$ to $40 \%$ on the reef flat (Hio/4). A similar pattern was also found on the West Coast at Utuko Reef. The sand fraction is composed of coarse to very coarse grained sand (ranging $-0.78-0.24 \Phi$ ) with the coarsest material found on the reef flat Hio/4 and sand patch at Alof/1, while the finest sand was found on the beach (Hio/2). Samples from Hio and Tuapa are well sorted to moderately well sorted, ranging from $0.45-0.88 \Phi$ with a mean of $0.56 \pm 0.1 \Phi$ (Figure 5.14) for both sites with the degree of sediment sorting increasing towards the reef flat at Hio.

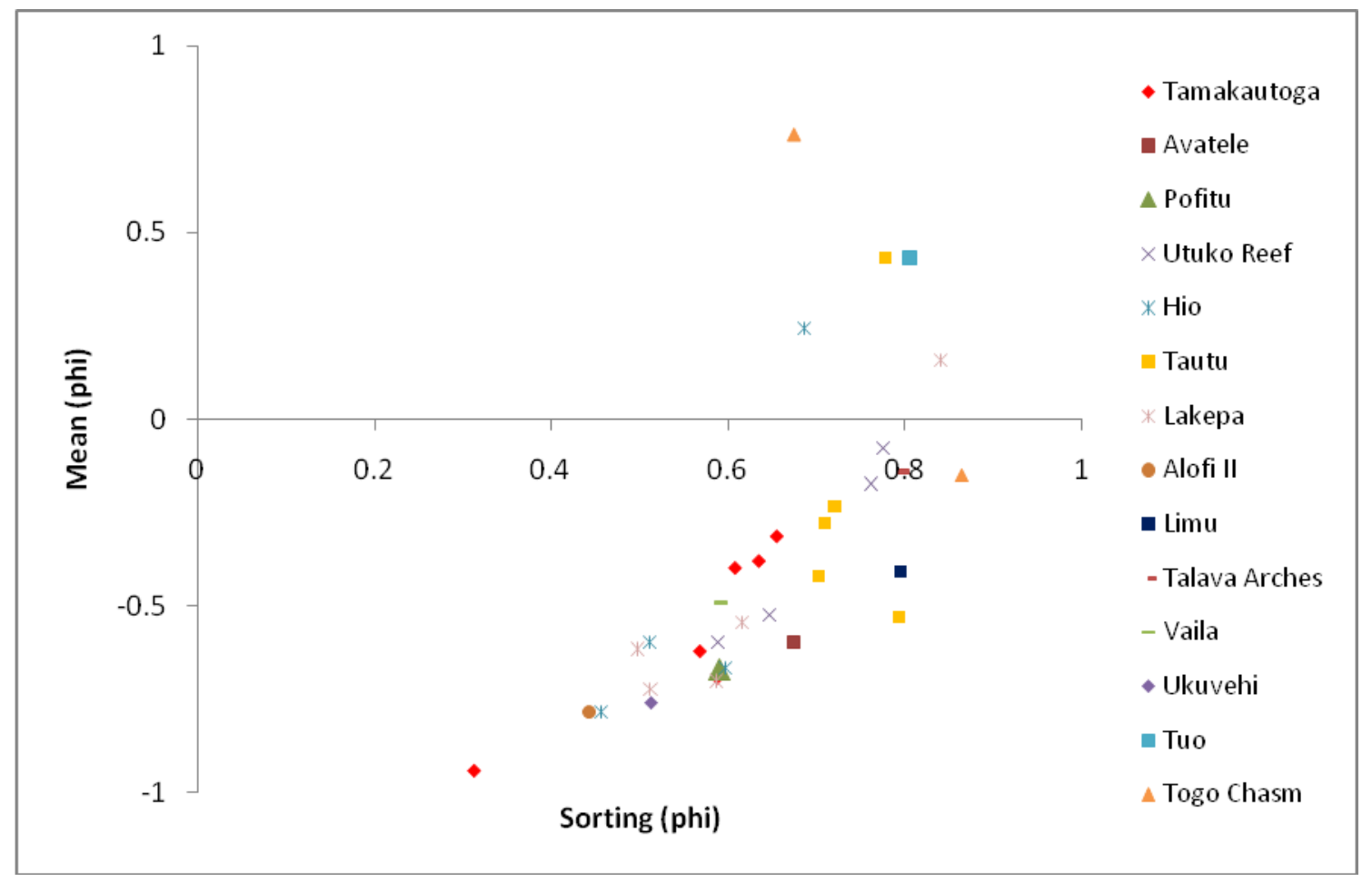

Figure 5.14: Bivariate plot of mean and sorting of surficial sediments collected from all coastal sites in Niue. 


\subsubsection{East and South East Coast}

Very coarse, (mean $-0.23 \pm 0.3 \Phi$ and $-0.4 \pm 0.3 \Phi)$ moderately well sorted sand dominates the two sites on the eastern coast of the island, with gravel accounting for $31.58 \pm 14.73 \%$ and $43.84 \pm 20.03 \%$ of the sediment at Tautu and Lakepa respectively. The beach samples (Taut/1-5) collected from the swash zone are coarser and more positively skewed relative to the north reef platform sample (Taut/6). At Lakepa, sediment was coarser (ranging 0.15 to $0.72 \Phi)$, moderately well sorted (mean $0.60 \pm 0.13 \Phi)$ and more finely skewed $(0.82 \pm$

$0.62 \Phi)$ than Tautu. In rock pools at Lakepa (Lake/4) coarse- grained, negatively skewed sediment occurred which contrasts to the coarser and strongly positive skewed samples derived from adjacent pocket beaches. Samples from Togo chasm, a beach that has accumulated at the landward end of a chasm in the cliffs as a result of stormy sea conditions on the south eastern side of the island are characterized by moderately sorted coarse sand with an average grain size of $0.30 \pm 0.64 \Phi$ and a positive skewness (mean 0.11 $\pm 0.20 \Phi)$.

\subsection{Sediment composition}

Like most tropical carbonate depositional environments, the small pocket beaches in Niue are all composed of a distinctly chlorozoan assemblage primarily of fragments and shells locally supplied from the adjacent reef flats and reef crests. These include corals, coralline algae, molluscs, echinoid, Halimeda, and benthic foraminifers with coral being the dominant constituent at most sites. Foraminifera appear to make up a large proportion of sediment on the North West coast while other components occurred in minor proportions.

\subsubsection{South West coast}

Coral is the main component of the sand-sized sediment accounting for $49.8 \pm 4.1 \%$ of material at Tamakautoga and $64.4 \%$ and $51.5 \%$ at Avatele and Pofitu respectively (Figure 5.15 and Figure 5.16). The next most abundant grain types are coralline algae $(20.2 \pm 1.9 \%)$ and molluscs $(14.7 \pm 4.1 \%)$. Foraminifera $(6.4 \pm 2.6 \%)$ are comprised of the three main species, Amphistegina lobifera, Baculogypsina sp., and Marginopora sp. Traces of Halimeda $(7.3 \pm 2.4 \%)$ and echinoids $(0.9 \pm 0.5 \%)$ are also present at all locations. The 
proportion of foraminifera is slightly higher at Pofitu, accounting for $10.6 \%$ of the sediment relative to that at Tamakautoga with Amphistegina lobifera being the dominant component at both sites. All the grains were fresh with micritisation occurring in very few samples $(0.7$ $\pm 0.7 \%)$.

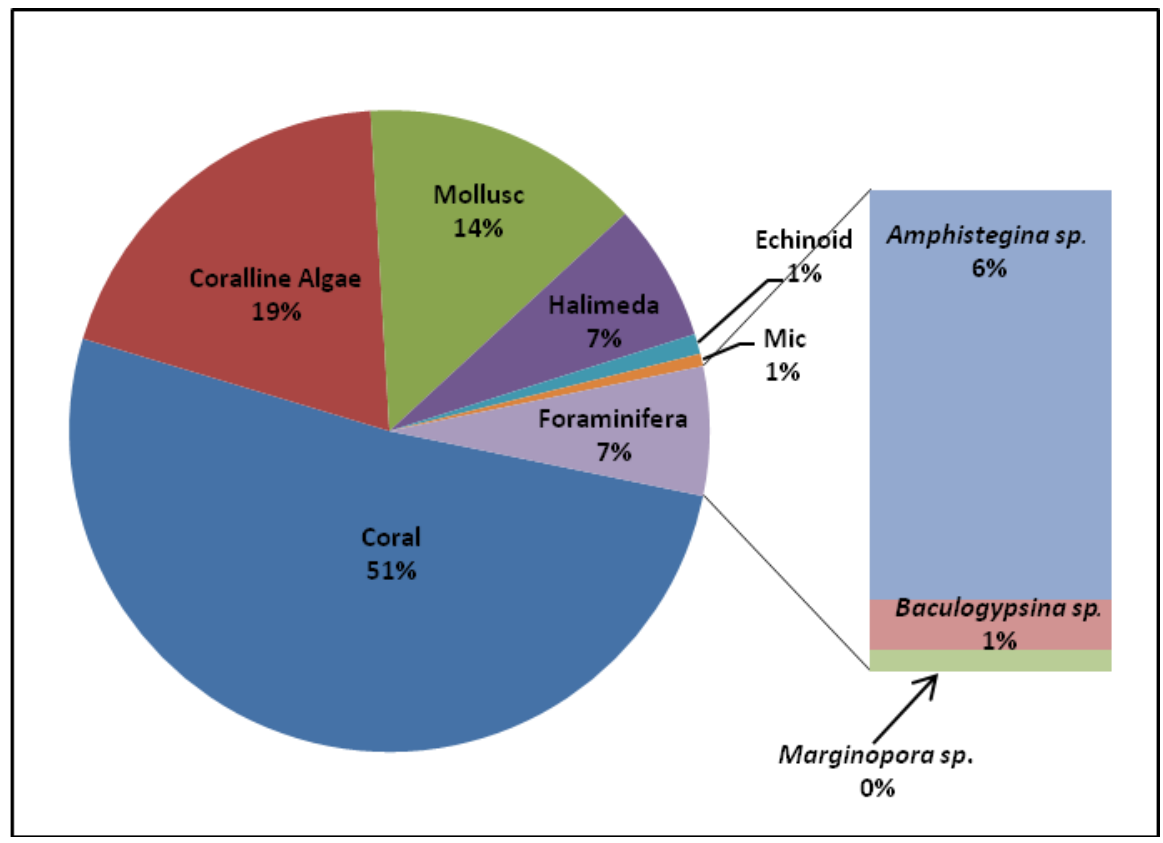

Figure 5.15: Total surface composition for the South West coast 

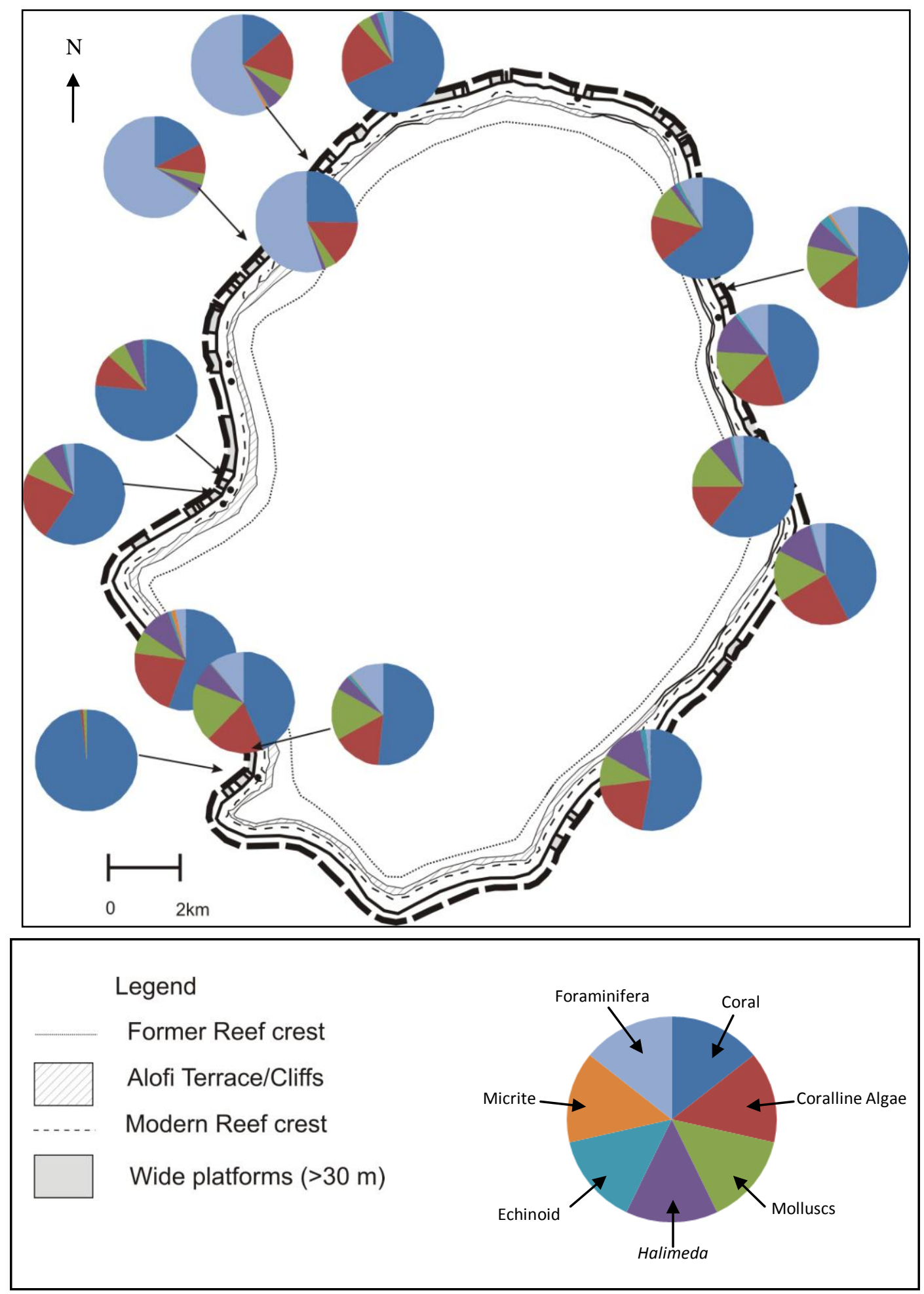

Figure 5.16: Spatial distribution of surface sediment composition on Niue. 
There is very little variation in coral composition between the pocket beaches around Tamakautoga with the highest being $55.5 \%$ on the northernmost beach (Tama/1) and reducing to $43.5 \%$ on the southernmost beach (Tama/7). Coralline algae and mollusc were the next most common fraction comprising $20.2 \pm 1.9 \%$ (range 18.8-22.5\%) and $14.7 \pm$ $4.1 \%(7.3-19.0 \%)$ of the constituents respectively and occurred in equal proportions. Halimeda was less abundant at Tama/6 (2.8\%) yet there was no distinct pattern in its distribution across the six locations at Tamakautoga.

Echinoids and foraminifers (predominantly Amphistegina lobifera) are minor components with the latter more common on the southernmost beach (Tama/7) at $11.0 \%$ and least abundant at Tama/1 (3.3\%). Amphistegina lobifera occurred at all sites suggesting a broader ranger and larger population of this specimen. In contrast, the Baculogypsina sp. which appeared to be significantly abraded in thin section and Marginopora sp. is absent at more than half of the sample locations and only comprise less than $1 \%$ of the total sediment.

\subsubsection{West Coast}

Coral and coralline algae dominate the sand sized component of the surficial sediment, comprising $54.6 \pm 3.8 \%$ and $25.0 \pm 2.1 \%$ respectively with mollusc $(9.2 \pm 2.8 \%)$ and Halimeda $(7.2 \pm 2.8 \%)$ being the next most abundant grains. Foraminifera compositions are low $(3.1 \pm 0.9 \%)$. Echinoids and micritic grains are present in minor amounts $(<1 \%)$ (Figure 5.16).

There is very little spatial variation in coral composition from the top of the beach to the reef platform (59.5- 50.7\%), being slightly higher on the mid beach (Utu/2) than the platform (Utu/4). Similarly, a greater concentration of molluscs occurs on the platform accounting for $11.5 \%$ of the sediment compared to $5.6 \%$ on the beach. The opposite trend occurs for Halimeda which $9.5 \%$ of the sediment on the beach top (Utu/1) reducing to $6.2 \%$ on the platform (Utu/4). There is an equal distribution of coralline algae across the beach and platform (range 22.0- 26.8\%) and there appears to be no significant trend in 
foraminifer's composition except for the Baculogypsina sp. which is more abundant on the platform (3.4\%) and virtually absent on the beach.

\subsubsection{North West coast}

Sediment composition on the North Western coast, especially at Hio and Tuapa varied compared to other sites around the island (Figures 5.16 and Figure 5.17). Foraminifer is the dominant constituent at most sites on the North West coast (35.2 $\pm 23.9 \%$ at Hio) and (64.5 $\pm 11.5 \%$ at Tuapa), the greatest abundance found on the island. Higher abundances also occur at sites Alof/1, Limu/1, Vai/1 and Nama/1 with a total mean $29.1 \pm 3.4 \%$. Baculogypsina sp. makes up a large proportion of foraminifera at Hio and Tuapa $24.2 \pm$ $20.4 \%$ and $33.0 \pm 14.8 \%$ respectively with the highest count found on the reef flat $(44.9 \%$ in Hio/4) and beach toe (47.0\% in Tua/4). Interestingly, Baculogypsina sp. is significantly lower on the reef flats immediately south of Hio (Tua/2) comprising only $12.8 \%$ of the sediment relative to that at Hio/4 and is absent at the Talava Arches (Tala/1-2). The spatial distribution of Amphistegina sp. varies from site to site (range 2.4 - 38.7\%) with the highest proportion found at Tuapa $(28.2 \pm 10.7 \%)$ where Baculogypsina sp. is also abundant. Slightly lower numbers are identified at Hio $(9.9 \pm 3.7 \%)$ and other sample sites on the North West coast. Although Amphistegina sp. appears in smaller quantities relative to the Baculogypsina sp. it is more common at the majority of sites, which suggest that it has a larger population and a broader range. Marginopora sp. appeared in very low quantities (0$5.7 \%$ ) similar to other sites on the South West and Western coast. Foraminifera (predominantly Baculogypsina sp. and Amphistegina sp.) were fresh and less abraded under thin section (Figure 5.18 A-B) particularly in areas where they were abundant e.g. Hio and Tuapa. Coralline algae comprise $26.1 \pm 11.5 \%$ and $10.7 \pm 4.4 \%$ of sediment samples at Hio and Tuapa respectively and equal proportions occur at other north western sites (range 15.5-23.1\%). Molluscs, Halimeda, and echinoid components all accounting for $<10 \%$ on the North West Coast. 


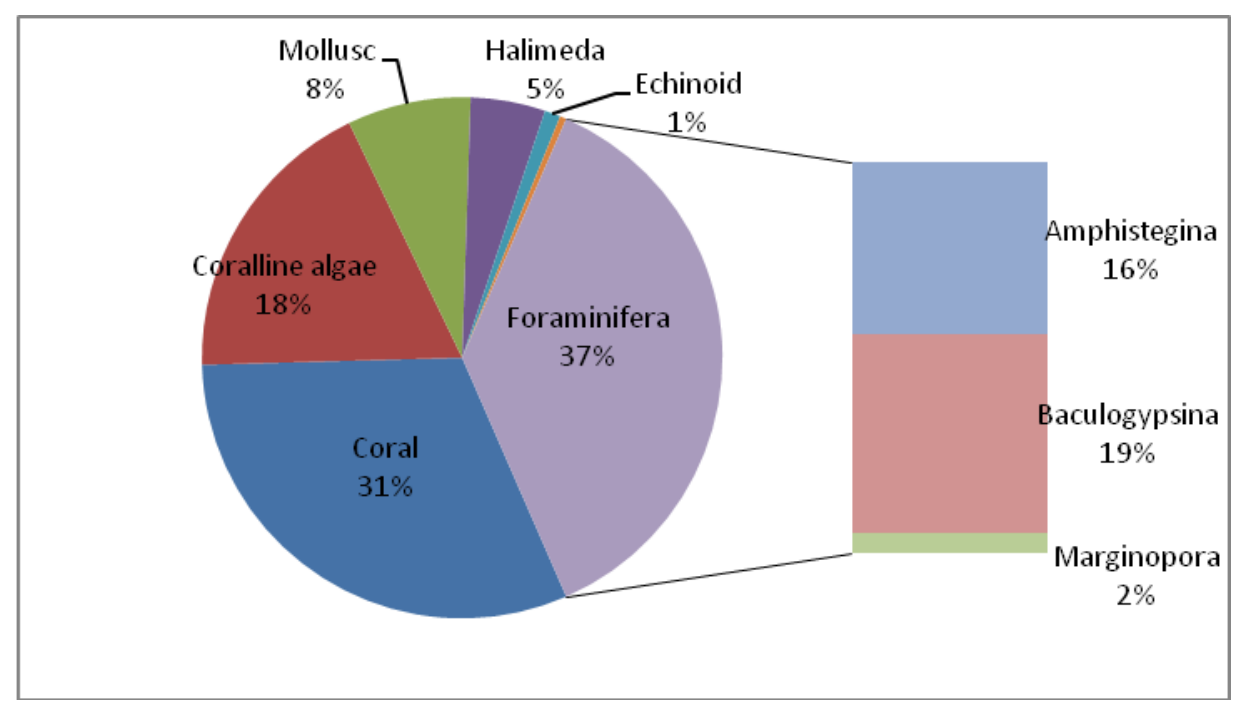

Figure 5.17: Total surface composition on the North West coast

Coral which is usually the dominant constituent at most sites, however, on this part of Niue it comprises $24.9 \pm 12.0 \%$ and $17.3 \pm 7.3 \%$ of the sand sized fraction at Hio and Tuapa respectively. In contrast, notably higher coral counts were observed at sample sites (Tala/1 and Tala/2) further north of Hio and Tuapa with a mean of $65.6 \pm 2.8 \%$. Coral was also present in large proportions at other sites on the North Western coast ranging from 29.5$40 \%$ with the highest proportion found at Limu Pools (Limu/1). There was no apparent trend of coral distribution across the beach and reef platform at Hio (Hio/1-4) with the lowest count occurring on the reef platform (13.8\%), although it was higher on the inner reef flat at Tuapa (25.3\% in Tua/2) just south of Hio. It becomes more abundant on the beach top (Hio/2) and reef channel (Hio/1) at 31.0\% and 38.8\% respectively. 

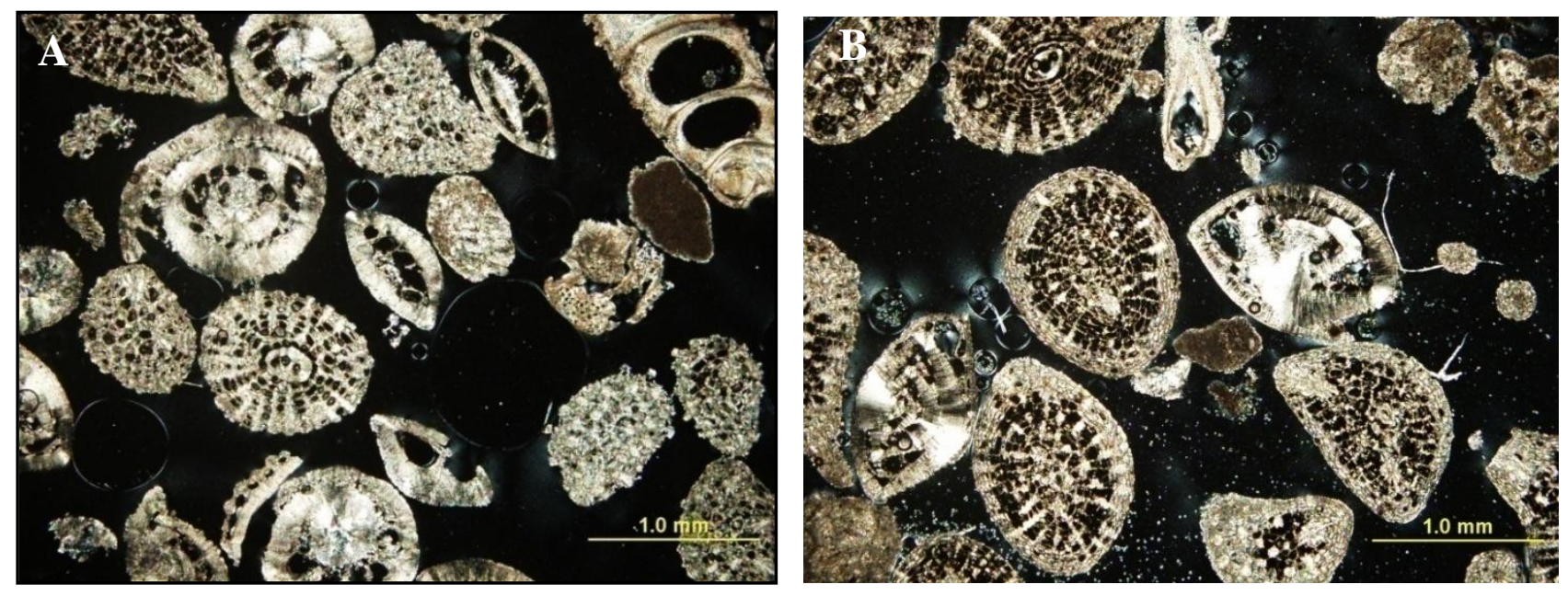

Figure 5.18: Thin section of the sand sized fraction from (A) north beach at Tuapa (Tua/4) and (B) reef flat at Hio (Hio/4), showing whole foraminifera grains in the sample.

\subsubsection{East and South East Coast}

Sediment samples were collected from Tautu and Lakepa on the East Coast and Togo Chasm on the South East coast. The main components, in order of abundance, are coral, coralline algae, Halimeda, mollusc, echinoid, and foraminifera with coral accounting for more than $50 \%$ of the sand sized fraction samples (Table 5.1). Spatial distribution of coral is fairly consistent with the highest counts found on the inner platform at Lake/4 and Taut/6. There is a relatively homogeneous spread of coralline algae, mollusc, and Halimeda. Coralline algae and molluscs have equal distribution between the sites with the highest concentration of molluscs found at Tautu. This is also the second highest percentage of mollusc of all sites on the island $(14.9 \pm 1.9 \%)$.

Foraminifera (predominantly Amphistegina sp.) occur in small proportions at Tautu, the second lowest for the entire island $(3.6 \pm 1.2 \%)$. Amphistegina sp. comprised $<7 \%$ of the sand fraction at all sites, with Baculogypsina sp. found being significantly worn. It is virtually absent at $80 \%$ of sampling sites on this side of the coast. The majority of grains were significantly fragmented although traces of Halimeda had very little abrasion (Figure 5.19). 
Table 5.1: Summary of the mean proportion (\%) of skeletal components in samples from the East and South East coast. Numbers in parentheses represents the standard deviation (S.D.) for each component.

\begin{tabular}{lccc}
\hline & \multicolumn{3}{c}{ Sites } \\
\cline { 2 - 4 } & Tautu & Lakepa & Togo \\
\hline Coral & $52.6(7.2)$ & $52.5(7.3)$ & $52.5(2.2)$ \\
Coralline Algae & $16.8(4.2)$ & $17.1(3.8)$ & $20.3(6.3)$ \\
Mollusc & $14.9(1.9)$ & $12.6(2.4)$ & $10.5(2.3)$ \\
Halimeda & $11.1(4.6)$ & $8.0(4.2)$ & $13.4(4.9)$ \\
Echinoid & $0.9(0.4)$ & $1.9(0.7)$ & $1.7(0.3)$ \\
Misc/ Micritised & $0.1(0.1)$ & $0.3(0.4)$ & - \\
Amphistegina & $2.7(0.9)$ & $6.1(1.9)$ & $1.3(0.8)$ \\
Baculogypsina & $0.0(0.1)$ & $0.3(0.5)$ & - \\
Marginopora & $0.9(0.5)$ & $1.4(1.5)$ & $0.3(0.5)$ \\
\hline
\end{tabular}
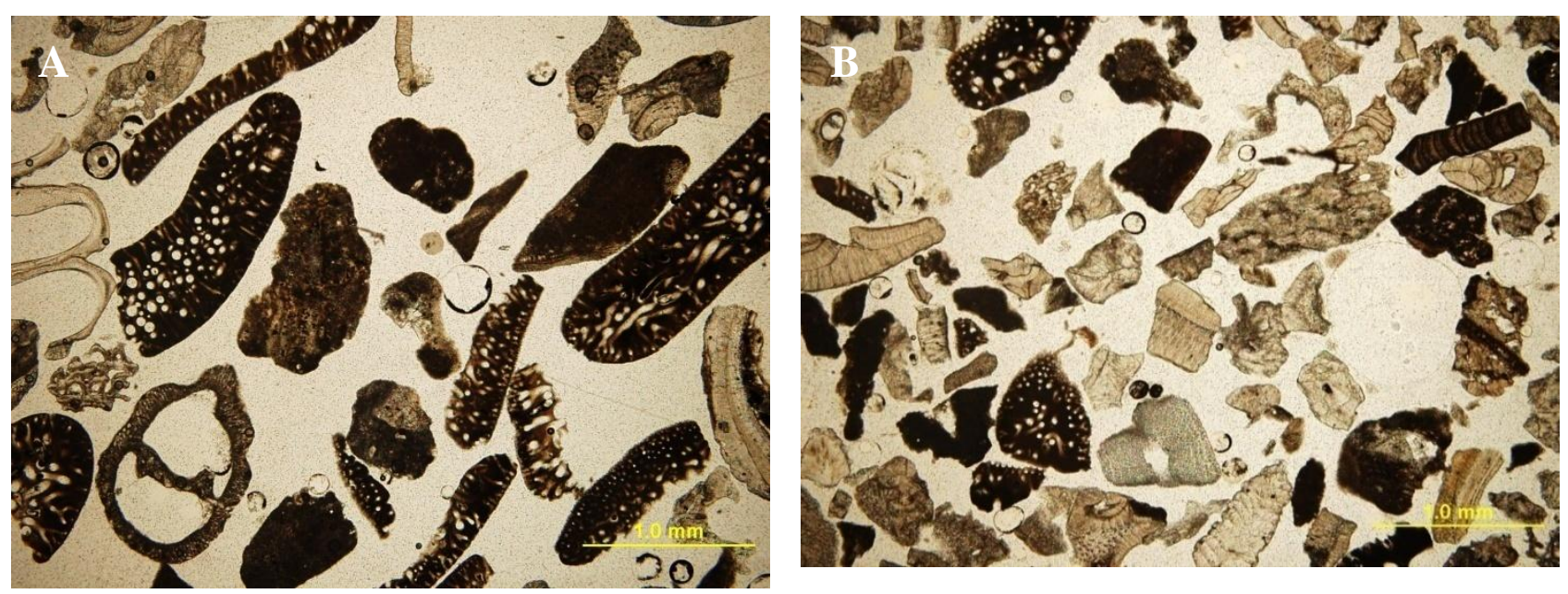

Figure 5.19: Thin section of the sand sized fraction from (A) Tautu/4 and (B)Togo Chasm. Note the large proportion of broken coral and mollusc fragments.

\subsection{Surface sediment ages}

All samples submitted for radiocarbon dating were collected from Tamakautoga on the south west coast. Ten samples were dated, six microatolls, one reef top, and three accelerator mass spectrometry (AMS) of beach sand (Table 5.2, Figure 5.20 and Figure 5.21). All beach sand samples collected from Tama/1-3 returned modern ages as determined by constituent specific AMS dating of Amphistegina and mollusc. Similar results were also obtained for microatolls 1, 3, and 6. Microatolls 2 and 4 date between 360 \pm 45 and $474 \pm 39$ Cal BP respectively, while microatoll 5 has an age of $502 \pm 35 \mathrm{Cal}$ BP 
which is the oldest of all microatoll ages. Samples exhibit a small variability in dates with age differences span a range of around 28-142 years. This implies that all samples derived from the beach and microatolls are therefore all very young and are actively being reworked within this cyclone prone area. The reef platform (Tama/RT) appears to be the oldest of all samples, based on a radiocarbon date of $3681 \pm 40 \mathrm{Cal} \mathrm{BP}$ on a fragment of coralline algae.

Table 5.2: Radiocarbon ages and their associated calibrated ages from bulk sand and individual grains from Tamakautoga beach and reef platform.

\begin{tabular}{llcccc}
\hline $\begin{array}{l}\text { Sample } \\
\text { name }\end{array}$ & $\begin{array}{l}\text { Lab } \\
\text { number }\end{array}$ & Sample location & Material dated & $\begin{array}{c}\text { Conventional } \\
\text { age (years B.P.) }\end{array}$ & $\begin{array}{c}\text { Calibrated age, } \\
\text { probability) } \\
\text { (years B.P.) }\end{array}$ \\
\hline Tama/1 & Wk- 24832 & Beach & Foraminifer & Modern & Modern* \\
Tama/2 & Wk- 24833 & Beach & Bulk sand & Modern & Modern* \\
Tama/3 & Wk- 24834 & Beach & Mollusc & Modern & Modern* \\
Tama/RT & Wk- 24514 & Reef top & Coralline Algae & $3681 \pm 40$ & $3640-3500$ \\
Microatoll 1 & Wk- 24515 & Reef top microatoll & Porites & Modern & Modern* \\
Microatoll 2 & Wk- 24516 & Reef top microatoll & Porites & $360 \pm 45$ & $65-1$ \\
Microatoll 3 & Wk- 24517 & Reef top microatoll & Porites & Modern & Modern* \\
Microatoll 4 & Wk- 24518 & Reef top microatoll & Porites & $474 \pm 39$ & $103-0$ \\
Microatoll 5 & Wk- 24519 & Reef top microatoll & Porites & $502 \pm 35$ & $140-0$ \\
Microatoll 6 & Wk- 24520 & Reef top microatoll & Porites & Modern & Modern* \\
\hline
\end{tabular}

*Modern samples whose radiocarbon ages are out of the range of Marine04 curve

Profile F

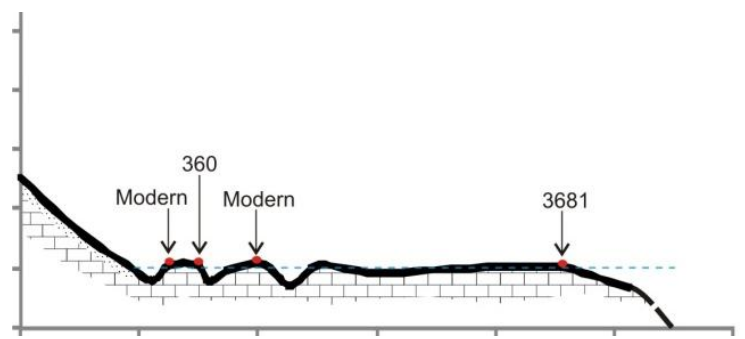

Profile A

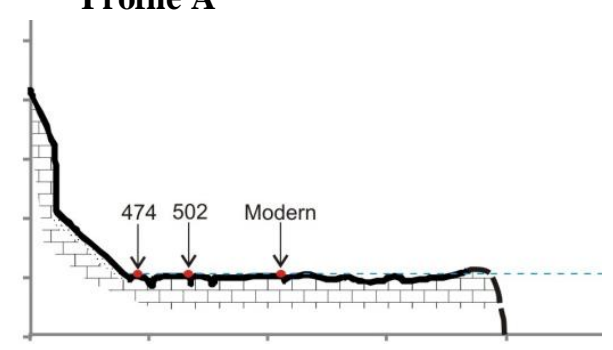

Figure 5.20: Beach and platform profile at Tamakautoga showing location of microatolls and ages (in years Cal BP) on Profile F and Profile A. 

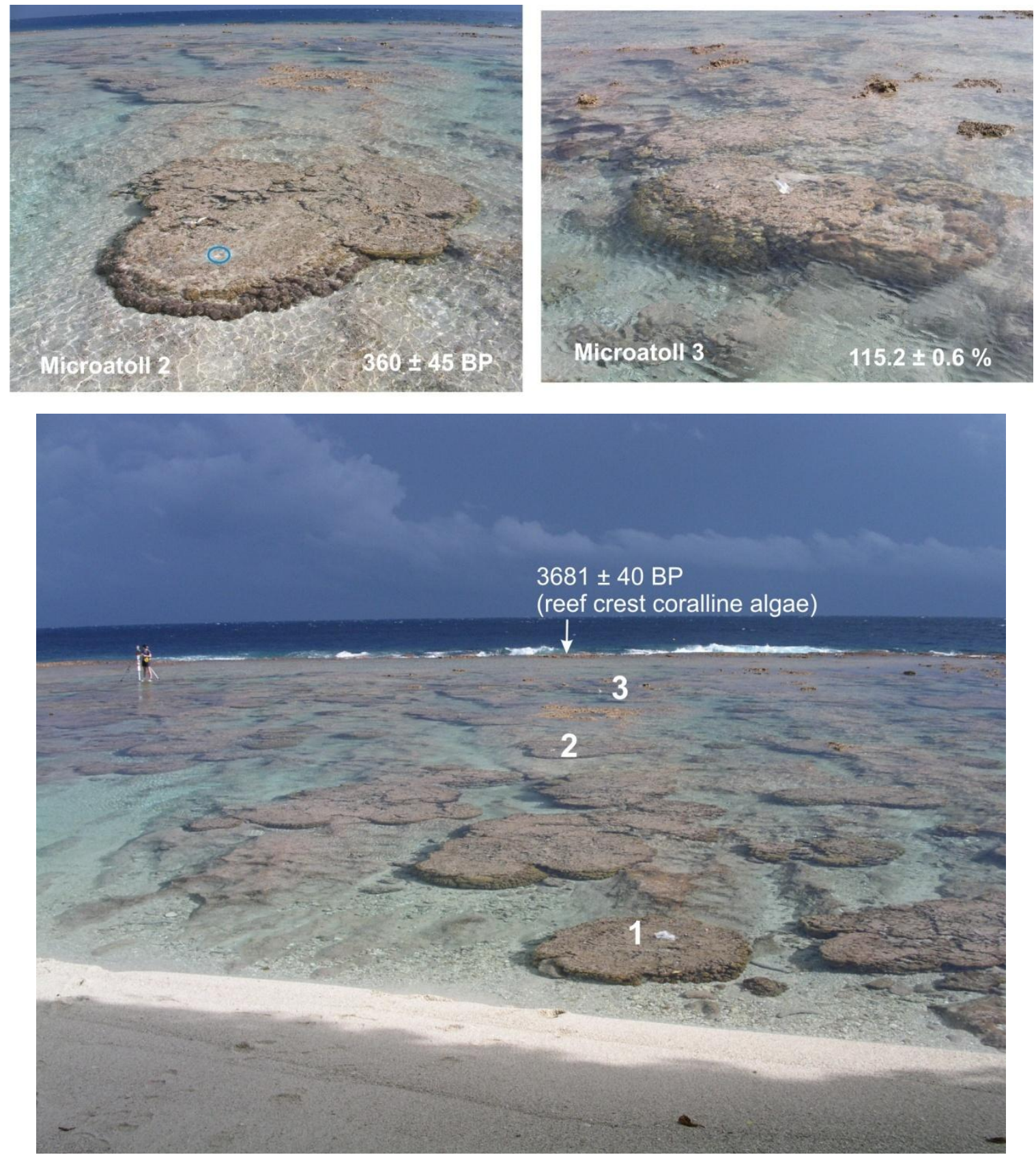

Figure 5.21: Location and age of microatolls 1, 2, and 3 at Tamakautoga. 


\section{CHAPTER 6: Discussion}

\subsection{General platform morphology}

The actively forming terrace around the coast of Niue consists of an erosional platform, fronted by spur and groove structures of a fringing reef at its seaward edge. This reef is up to $30 \mathrm{~m}$ wide and occupies the seaward margin of these erosional platforms especially wherever the platform is wide (>30 m) (Schofield, 1959). This is most evident on the north western coast of the island. The combined reef and platform width in Niue ranges up to 150 $\mathrm{m}$ with the widest platforms occurring on the leeward side of the island on the north western coast at Tuapa, and the narrowest being located on headlands as well as on the south eastern coast. $88 \%$ of platforms on the more exposed south easterly side of the island are $<30 \mathrm{~m}$ wide, while more than $50 \%$ of wide platforms occur on the East, South West, West, and North Western coast. The distribution of platform is likely related to the energy environment around the island with narrow and near absent platforms on the windward coast and the wide platforms on the leeward coast (refer to Section 5.1).

Studies of modern atolls in the tradewind belts e.g. Enewetak in the Marshall Islands, have shown that the widest reefs generally form on the windward sides where wave energy and nutrient supply is greatest. The narrower reefs were found on the leeward side of the island (Ladd et al., 1953; Schofield, 1959). Their surface morphology is generally dependent on their exposure to the prevailing southeasterly winds and the more exposed the reef the greater the surface zonation and reef flat width, as observed in the northern section of the Great Barrier Reef (Hopley, 1982). The important difference between coastlines on Enewetak Atoll in the Marshall Islands and that on Niue is that the former is a true reef flat. On Niue, however, the platforms at sea level are erosional features rather than constructional therefore their response to different energy regimes will vary from those on reef island settings.

On Lord Howe Island, Tasman Sea, the wider calcarenite platforms of about $100 \mathrm{~m}$ in width occur on the open ocean coast while the narrower platforms are found in the lee of 
the fringing reef (Dickson, 2006). Consequently, wider platforms might be expected where wave exposure is higher. Wave energy for the coast of Niue has not been quantified in this study and comparisons between platforms in Niue and those on Lord Howe Island are difficult due to different environmental settings. It is interesting to note that while it is a logical assumption that platform width should be positively related to wave energy, many studies have recorded contrasting width-exposure relationships, and often suggesting that wider platforms sometimes occur within sheltered embayments (Kirk, 1977).

The surface relief of platforms in Niue especially those over $30 \mathrm{~m}$ wide consist of gutters and potholes up to $0.6 \mathrm{~m}$ deep and 1-2 $\mathrm{m}$ wide on the inner platform and the outer consisting of no potholes. This was evident at several sites on the island, particularly at Hio, Tuapa, Tamakautoga, and Tautu where the inner platform was heavily dissected in the uplifted limestone bedrock and progressively becomes smoother towards the seaward edge of the platform. This is due to infill by coral and coralline algae with Holocene reef accretion occurring in some places. In most profiles, the inner platform immediately adjacent to the beach toe has a slightly polished surface indicating abrasion by sand in the wave swash. This section is also deeply scoured, often forming pools and interconnected channels (1-2 m wide and 0.5 m deep) which retain water at low tide. This contrasts with platforms on the uplifting Henderson Island in the eastern Pacific, where heavily scoured $0.5 \mathrm{~m}$ diameter potholes frequently coalesce through abrasion to form shallow channels which extend to the seaward end of the platform (Spencer and Paulay, 1989). This difference is most likely related to the absence of coralline algal ridge on Henderson Island which means infilling of the grooves does not take place. Wave-rippled sand was also observed in several pools adjacent to the beach toe in Niue, which may be responsible for scouring out the beach toe and thereby inhibiting further coral growth in the area (Figure 6.1). Colonies of calcareous algae and coalescent living microatolls up to $1.5 \mathrm{~m}$ in diameter, particularly of Porites spp. can also be found across the platform predominantly on the South Western sites of Tamakautoga and Pofitu (Figure 6.1). 


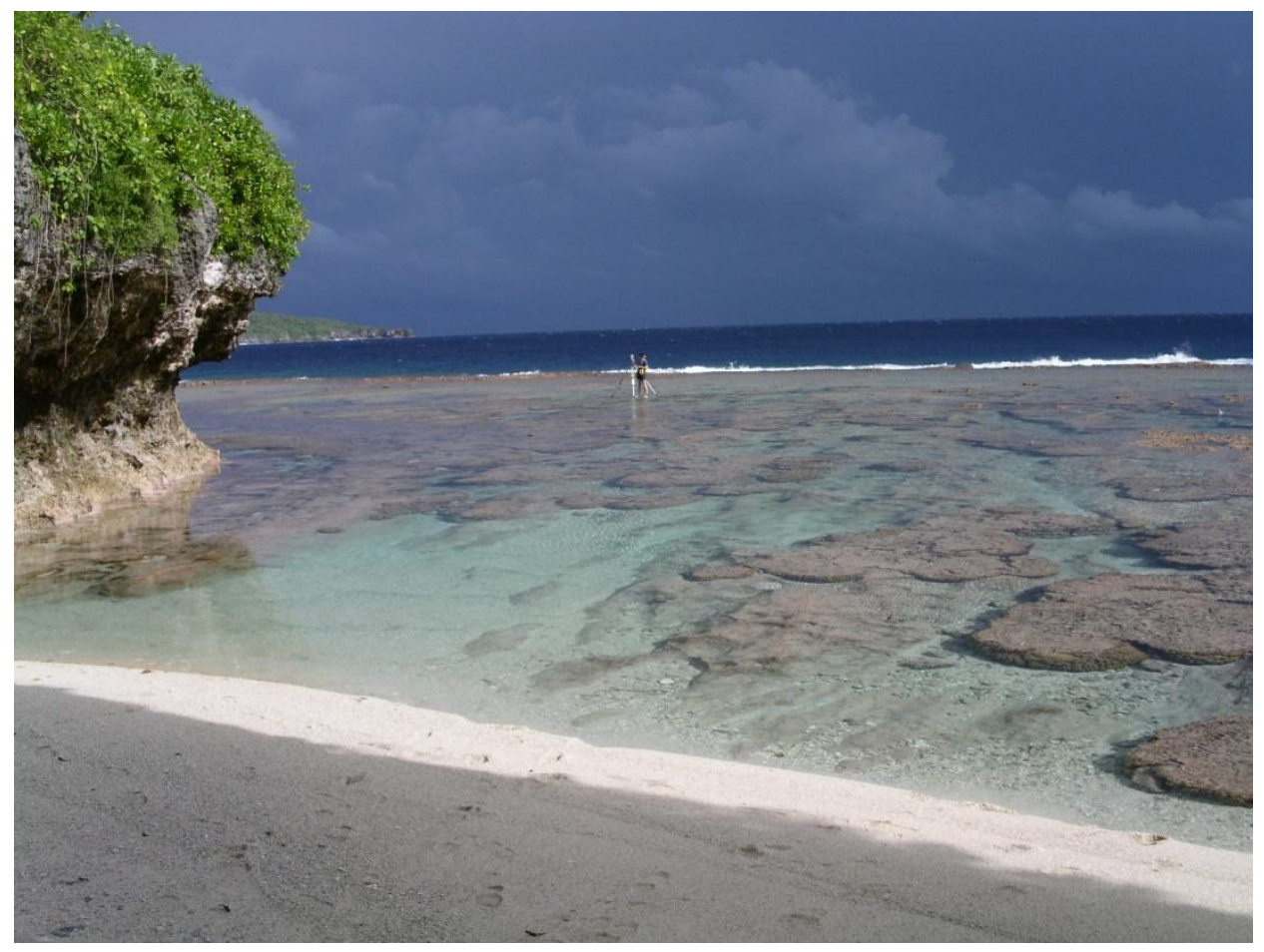

Figure 6.1: Well-developed microatolls superimposed on the reef platform at Tamakautoga.

Pocket beaches sometimes occur on the landward edge of these platforms; yet they are often absent in certain areas, particularly on the windward side of the island. They are typically narrow $(<20 \mathrm{~m})$, steep (mean $7.4^{\circ}$ ) with a mean elevation of $1.4 \mathrm{~m}$ above mean low water (MLW) and composed of an assemblage of chlorozoan carbonates typical of tropical areas that are derived from the adjacent reef flat. These beaches are entirely sandy around the island, except in a small cove (Avatele) on the South West corner of the island where gravel has accumulated.

Fractures have been observed at a number of places such as Anaana, Opaahi, and Hio Beach which corresponds to lines of potential failure and rock fall (SOPAC, 2004). Tropical Cyclone Heta (2004) caused several cliff failures along the N-NW coast with a displacement of $1000 \mathrm{~m}^{3}$ (Figure 6.2). Undercutting of cliffs due to a combination of chemical and mechanical processes leads to the development of notches, and strong wave impact from Cyclone Heta into the cliffs contributed to these failures around the island (SOPAC, 2004). Extreme events such as tropical cyclones can trigger cliff failures that may accelerate erosional processes acting upon these failures and therefore contribute to the supply of large boulders (>2 m high). 


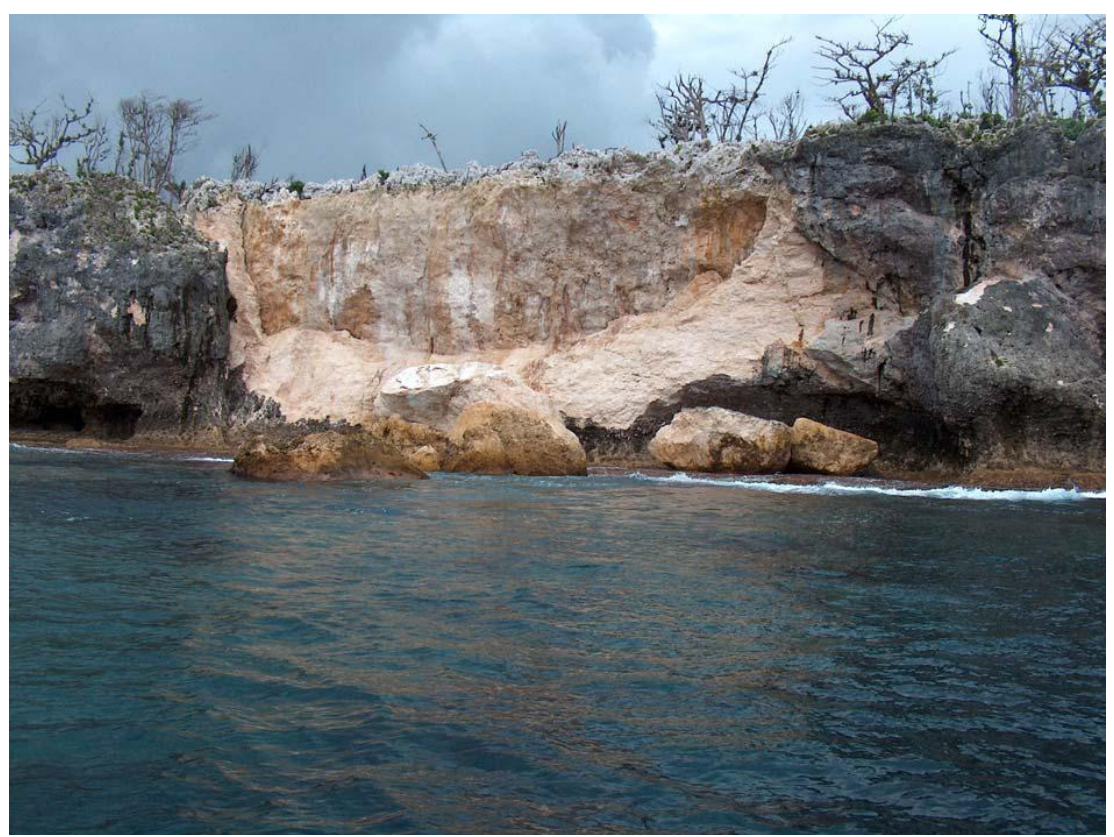

Figure 6.2: Cliff failure at Makefu South during Cyclone Heta. Source: SOPAC (2004).

The seaward margin of Niue's platforms are characterised by a series of grooves 1-2 m wide while the spurs separating the grooves are flattened and covered by massive pink coralline algae. The grooves provide conduits for moving water and sediment onshore and offshore while the spurs act as a buffer in dissipating wave energy. These structures may in fact divert a large proportion of particularly finer sediment offshore and the steep angle of reef slopes consequently prevents sediment lost offshore during cyclone events from being returned on to the reef platform during calmer conditions (Terry, 2007). This therefore limits structural reef damage more effectively as opposed to those in areas of smoother topography. The size and spacing of the grooves and spurs is therefore believed to reflect the average energy of the breaking waves (Terry, 2007) with wave heights of up to 2-3 m have been reduced to $0.3-0.6 \mathrm{~m}$ as they cross the algal ridge in Bikini Atoll, Marshall Islands (Tracey et al., 1948). There are no published data on wave climate in the vicinity of Niue, so measurements are often taken from the nearby islands of Western Samoa, Tonga and the Cook Islands. Mean annual significant wave height is approximately $2.4 \mathrm{~m}$ which then increases to $2.5 \mathrm{~m}$ during the summer season (Barstow and Haug, 1994). Therefore, wave height may be reduced to the same level to that in Bikini Atoll, Marshall Islands. 


\subsection{Linkage between platform reef morphology and sediment composition}

Sediment distribution across the reef platform and beach is related to the spatial variations in source areas, morphology, and wave processes acting on the surface. Beaches on oceanic islands and uplifting atolls such as Niue are maintained through sediment derived from the adjacent reef platform; therefore, reef productivity is the principal control on sediment supply (Calhoun and Field, 2008; Fujita et al., 2009). Niuean beaches are largely composed of unconsolidated bioclastic sand and gravels. They are characterised by an assemblage of chlorozoan carbonates typical of tropical areas, in which coral and coralline algae are prominent $(>50 \%)$ except on the north western platforms (Hio and Tuapa) where foraminifera dominate $(>35 \%)$.

The difference in sedimentary environments around Niue is observable in cluster analysis of all beach components. Two major groups (A and B) can be identified based on the abundance data of sediment components (Figure 6.3). Cluster A is the most distinct and consists of samples from the north western sites Hio and Tuapa. Interestingly, sub group $\mathrm{B}_{1}$ consists of two samples also from the north western coast (Hio). The dominance of coral and coralline algae on the mid beach and platform channel separates these samples from others of this location. In spite of this, a rescaled distance of 15 statistically separates the Hio and Tuapa samples from the other sites. This is related to the high proportion of foraminifera (64.5\%) (particularly Baculogypsina sp.) within the area as opposed to coral and coralline algae which is dominant in all samples in Cluster B. This suggests that Hio and Tuapa provide favourable living conditions for sand production by foraminifera while coral occurred in smaller proportions. This is possibly due to the ability for the foraminifera community to re-establish quicker after cyclones as opposed to coral (Terry, 2007). 


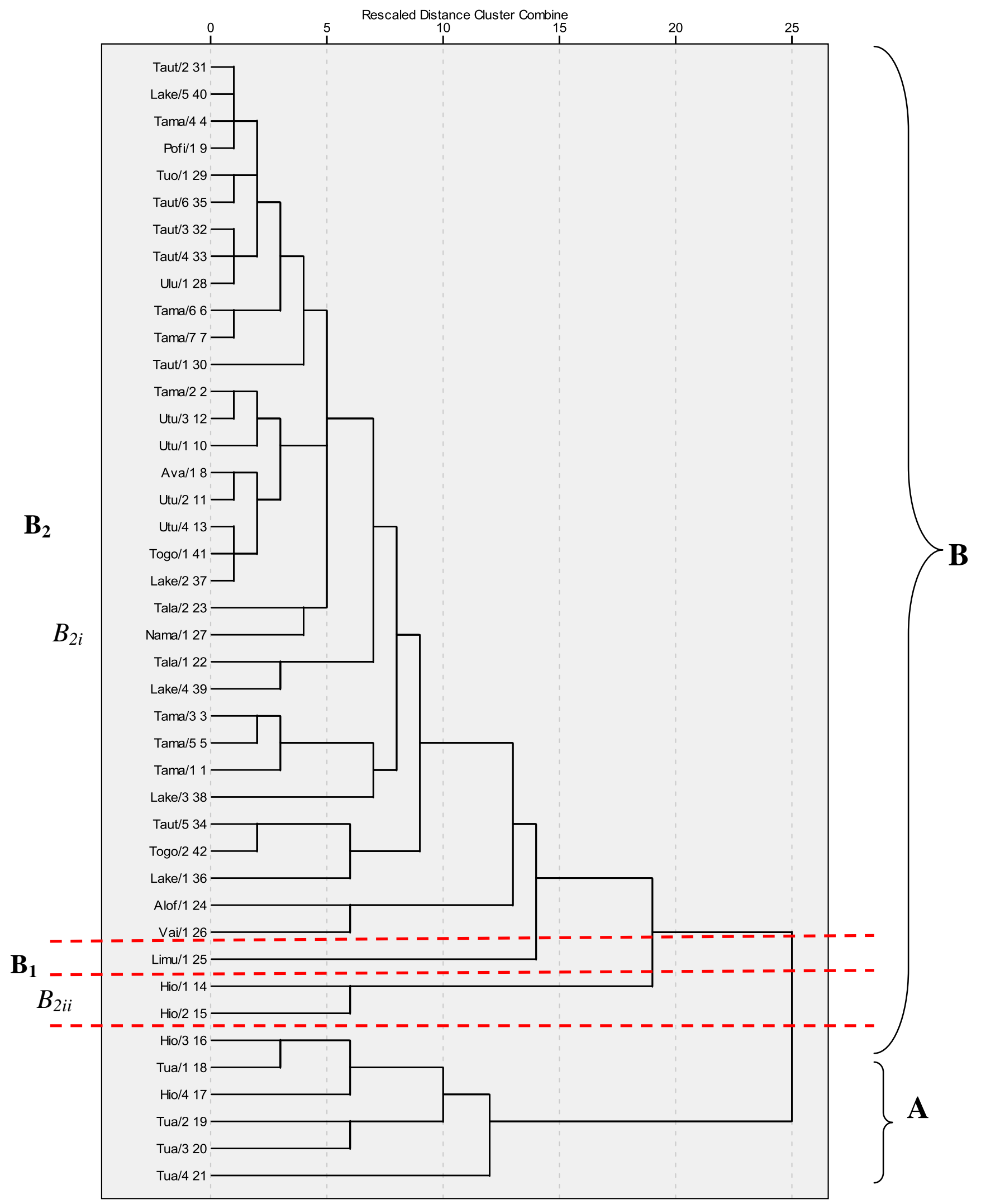

Figure 6.3: Hierarchical cluster analysis showing sediment composition of Niue surface samples. Labels represent locations of sediment samples (refer to Appendix 3). 
Group B is the largest cluster in terms of sample numbers, representing those that have a high coral composition of more than $40 \%$, and coralline algae being the subdominant component. This group is subdivided into 3 clusters $\left(\mathrm{B}_{1}, \mathrm{~B}_{2 \mathrm{i}}\right.$, and $\left.\mathrm{B}_{2 \mathrm{ii}}\right)$, with Subgroup $\mathrm{B}_{2 \mathrm{i}}$ consisting of a single sample from Limu Pools owing to an abundance of foraminifera $(29.2 \%)$ relative to other samples within Cluster $\mathrm{B}_{2}$. Its echinoid content $(3.6 \%)$ is also the highest of any sample on the island. Subgroup $B_{2 i}$ comprises of samples from several sites around the island, particularly the West, South West, and the East coast, where coral often comprises more than $50 \%$ of sediment. In contrast, the proportion of foraminifera is less than $10 \%$ of the majority of sample sites, with Baculogysina sp. being a minor component. This differs significantly to those found on the north western coast.

Survey results also show that there is very little variation in reef or platform elevation in Niue and this may have an effect on sediment composition. Changes in depth have shown to influence coral growth form (Chapelle 1980) and result in spatial differences in components. For example, Avatele Beach is fronted by a lagoon where prolific live coral growth occurs, contributing to the high gravel and coral content within the area. However, the small changes in reef depth imply a similar ecological environment occurs across most platforms in Niue.

Composition of sand grains is a good indicator of source and transport (Orme, 1977). High proportions of foraminifera (predominantly Baculogypsina sp.) on the north western sites of Hio and Tuapa indicate prolific production of these benthic communities. The presence of whole foraminifera grains (refer to Section 5.4.3) imply in situ deposition and suggests that these species are living in very close proximity. At other sites foraminifera rarely reach concentrations greater than $10 \%$ and are significantly abraded and fragmented therefore implying transport and deposition from a more distant source (Kench 1997). A slight variation in sediment composition exists across the Hio platform, with Cluster $\mathrm{B}_{1}$ (Hio/1 and Hio/2) obtained from the beach and platform channel having less abundant foraminifera (8.5 and 21.8\%) compared to that found within the beach swash zone (53\%) and the reef platform (57.6\%). Foraminifera are found on shallow reef flats and they live in association with algal turf on the reef flat which is exposed at low tides (Collen and Garton, 2004; Gischler and Moder, 2009; Yamano et al., 2000). They seldom live on beaches and 
their occurrence in these environments is due to post-mortem transport (Murray, 1973). Foraminiferal tests are the main components of surface sediments on reef flats and lagoons in central and western Pacific atolls such as Kapingamarangi Atoll, Marshall Islands (McKee et al., 1959), Tarawa Atoll, Kiribati (Weber and Woodhead, 1972), and for 90\% of sediment in places on Funafuti, Tuvalu (Collen and Garton, 2004). Foraminiferal assemblages in reef flat sediments are primarily composed of Baculogysina, Amphistegina, Marginopora, and Calcarina sp., although species composition can vary with region, environment, and substratum type (Collen and Garton, 2004; Woodroffe and Morrison, 2001). They are particularly important to carbonate sediment budgets as a result of their size, moderate rates of carbonate production and resistance to abrasion (Kotler et al., 1992). They can act as sediment provenance tracers in sand-enriched beach environments and depending on their source area can indicate transport processes (Haslett et al., 2000; Murray, 1973). Living individuals of large benthic foraminifers occur in large amounts on reef flats (Hallock, 1981; Hohenegger, 2006), and their distribution and abundance are mainly influenced by light, temperature, circulation or energy environment, substratum type, and water quality (Collen and Garton, 2004; Gischler and Moder, 2009; Hohenegger, 2006; Yamano et al., 2000). Foraminifera are abundant on the North West although small proportions do occur in other sites as well. This is consistent with the shallow water preference of these benthic communities (Collen and Garton, 2004) and the lack of pooling on the platform.

The correlation matrix of main sediment components gives further information about the occurrence and distribution of constituent particles (Table 6.1). High correlations exist between coral, mollusc, and Halimeda, while foraminifera which are mostly found on the north western sites showed no correlation with other components. Foraminifera appear to be less common in areas with a high coral content $(>40 \%)$ as suggested by the strong negative correlation with all the other components particularly coral $(\rho=-0.91)$. The $p$ value $<0.05$ also suggests that the distribution of both components is significantly different as illustrated in Figure 6.3 where samples with high foraminifera and low coral content are clustered together. 
Table 6.1: Correlation matrix of key sediment components using the Pearson Linear Correlation method. Figures in brackets represent the p-values, significance at the 5\% level $(\mathrm{P}<0.05)$.

\begin{tabular}{|l|ccccc|}
\cline { 2 - 6 } \multicolumn{1}{c|}{} & Co & CA & Mo & Ha & Fo \\
\hline Coral (Co) & 1 & & & & \\
Coralline Algae (CA) & 0.19 & 1 & & & \\
Mollusc (Mo) & $(0.23)$ & & & & \\
Halimeda (Ha) & 0.33 & -0.01 & 1 & & \\
& $(0.03)$ & $(0.95)$ & & & \\
Foraminifera (Fo) & 0.32 & 0.04 & 0.27 & 1 & \\
& $(0.04)$ & $(0.78)$ & $(0.09)$ & & \\
& -0.91 & -0.45 & -0.51 & -0.49 & \\
\hline
\end{tabular}

Living foraminifers are also abundant on windward reef-flats, implying the distribution of these species may be influenced by the wave energy experienced within a particular habitat (Collen and Garton, 2004). However, the distribution of Amphistegina varied across the windward and leeward reef flats of Majuro Atoll, Marshall Islands occurring in areas with preferably low to moderate water motion. It is apparent that the weakly attached Amphistegina individuals avoided offshore high energy environments and were often found in calm nearshore tide pools (Fujita et al., 2009). Similarly, foraminifera (particularly Calcarina and Baculogypsina) are more prolific on the leeward northern reef flats on Heron Island Reef which is strongly influenced by the physiographic and current patterns while the more exposed southern side is dominated by coral and coralline algae (Maxwell et al., 1961).

The reef platforms at Hio and Tuapa have very limited live coral within the area, samples are therefore composed by the more dominant foraminifera species (predominantly Baculogypsina sp.). The sheltered north western coast is also the side facing the path of tropical cyclones and so extensive coral colonies are continually removed and replaced by algal turf growing on hard coralline algae, which may also explain the low coral composition at Hio (24.9\%) and Tuapa (17.3\%). 
Coral is the most ubiquitous clast type in sediment samples around the island apart from those from the NW coast. The high coral composition ( $>40 \%)$ is represented by Group B with the sites of Avatele (SW) and Alofi Wharf (W) having the highest coral content of 81.5 and $75 \%$ respectively of the total sediment sample. Live coral cover generally increases towards the reef crest as well as within channels where wave energy is highest. Their abundance is also determined by the extensive development of fore-reef communities (Montaggioni and Faure, 1997). The high abundance of coral-derived sediments are often transported by storm waves onto the reef platform and the frequency of tropical cyclones determines the degree of stabilisation of this material, and hence the chances of its preservation (Scoffin 1993). Significant amounts of coral rubble have been observed in the lagoon at Avatele and observations made by locals immediately after Tropical Cyclone Heta in 2004 reported a shallowing of the lagoon by $0.5-1 \mathrm{~m}$ as a result of coral being removed from the reef and deposited in the lagoon. This represents the key source of sediment for the beach.

Similarity in composition within the two environments indicates that sediment exchange does occur between the beach and platform. In addition, the small distance of transport across the reef flat also limits the zonation of components. The coralline algal component is highest at Hio (NW) and Utuko (W) sites. Elsewhere in the Pacific, they are found in the high-energy reef areas where an algal ridge is present (Nunn, 1993; Weber and Woodhead, 1972) as have occurred on the uplifted carbonate island of Makatea, Tuamotus (Montaggioni et al., 1987). Similarly, a prominent algal ridge dominated by the red coralline algae Porolithon onkodes is also found on the platforms on the windward side of Niue. All sediment that source the pocket beaches in Niue is derived from the coral and benthic communities on the reef platform. Cliff erosion was initially thought to provide a small amount of sediment for the beaches; however, all samples appeared fresh and were not recrystalised. Only small proportions of micritised grains $(<3 \%)$ were observed under thin section. This implies that the sediments are recent and not sourced from the cliffs.

Sediment exchange between sand bodies and the beachface could be an important component of beach stability and in some cases can provide quantities of sand for beach replenishment (Bochicchio et al., 2009). The stability of pocket beaches can be determined 
from the age of sediment since radiocarbon dating of skeletal carbonate records the time of death of the organism. The radiometric and AMS dates of bulk sand and individual grains of foraminifera and mollusc at Tamakautoga all yield modern ages (refer to Section 5.5). This implies that the reef platform provides a current source of sediment and a relatively short period of transport before final deposition on the beachface. Very little carbonate material is present on the flat and shallow reef platforms in Niue as a result of low sediment supply and its low capacity for storage. For that reason, sediment produced on the reef flat such as foraminifera are quickly transported and deposited on the beach following death. Previous studies also suggest that foraminifera are the most appropriate component for the determination of sediment depositional chronology for reef islands. This is due to their robust structure and rapid production especially in areas where they are abundant, such as in Makin, Kirbati, and some parts of the Great Barrier Reef (Woodroffe and Morrison, 2001; Yamano et al., 2000). Factors such as the hydraulic properties of carbonate grains as well as the processes acting upon it may contribute to inaccurate dating of sediment (Harney et al., 2000; Kvenvolden, 1965). Porites microatoll samples also yielded radiocarbon dates between modern and 502 years Cal BP, while a sample from the reef top was significantly older.

\subsection{Reef platform processes and sediment transportation}

\subsubsection{Wave energy}

Energy inputs provide the driving forces for coastal systems (Wright and Thom, 1977). Incident wave energy activates geomorphic processes such as sediment entrainment and deposition and contributes to reef island construction, distribution, sedimentary character and beach morphology (Brander et al., 2004; Kench et al., 2006; Kench and McLean, 2004). Sediment on the Niuean beaches is derived from the reef platform; however, it is dependent on wave energy processes and variability in platform morphology in order for them to reach their final depositional place. Wave action is a key formative agent for several reef top sedimentary islands and beaches, and the presence of a reef platform imposes a control on the waves reaching shore (Gourlay, 1996a; Wolanski, 1994). Wave energy dissipation across a reef is influenced by abrupt changes in morphology (i.e. 
elevation, reef slope, and reef flat width), variable roughness, wave exposure and relative water depth at the reef edge (Kench and Brander, 2006; Samosorn and Woodroffe, 2008).

Reef width exerts a significant control on the amount of wave energy that is attenuated across the reef flat (Brander et al., 2004). The capacity of waves to generate sediment entrainment and transport on wide reef platforms is limited. Wider reef flats and platforms such as that on Warraber Island $(2700 \mathrm{~m})$ and Southern reef flat in Cocos Islands $(1100 \mathrm{~m})$ dissipate a greater amount of incident energy since they provide greater frictional resistance waves. Energy loss may be as much as 99\% (Brander et al., 2004; Sheppard et al., 2005), and in the case of Cocos Islands, wave energy dissipation at high tide ranges from $67 \%$ on the outer reef to $99 \%$ on the lagoon sand flat. In contrast, the narrower leeward reef flats of Lady Elliot Island, Great Barrier Reef $(56 \mathrm{~m})$ had $0 \%$ dissipation at high tide between the outer reef and island shoreline due to its lower elevation at the reef edge (Hart and Kench, 2007; Kench and Brander, 2006).

Surface roughness is dependent on the biological and morphological zonation of the platform. For instance, the outer living coral zone of the reef rim can be a region of wave energy dissipation, while the smooth algal pavement located seaward of the reef crest may provide less frictional dissipation (Gourlay, 1996b). The reef platforms in Niue are smooth and of low relief especially towards the seaward edge of the platform. This is due to the infill by coral and coralline algae, thus presenting much less friction to waves. For this reason wave energy is easily propagated across the platform and towards the shore. Friction factors $\left(f_{w}\right)$ were calculated for the reef flats in the Seychelles where 0.1 is smooth and 0.2 is rough with abundant live coral. An $f_{w}=0.1$ was attained where $75-100 \%$ of the reef zone is comprised of a coral pavement or smooth rock and an algal turf (Sheppard et al., 2005). Since much of the platforms in Niue are smooth, it can be assumed that they may have a similar value to some of the reef flats in the Seychelles as data required to calculate the friction factor for Niue is beyond the scope of this study. However, it should be noted that the fringing reefs in the Seychelles and the erosional platforms within this study are two different environments and may influence changes to final energy reaching the shore. 


\subsubsection{Reef energy window and geomorphic implications}

Reef elevation and changes in water depth play a key role on the presence of gravity wave energy on reef flats (Brander et al., 2004; Kench and Brander, 2006). To determine the effectiveness of waves to stimulate geomorphic work across the reef platform, Kench and Brander (2006) introduced the reef energy window index ( $\Psi$ ) (Equation 2.1) which is based on the depth, width and tidal range of the reef. High index values $(>0.05)$ indicate narrow active reefs with high relative water depth, while low values $(<0.01)$ represent wide and shallow reefs that are inactive and more effective at filtering and dissipating wave energy over the reef flat (Kench and Brander, 2006).

Reef energy window indices for Niue (Table 6.2) are low (range 0.0011 to 0.0037) which indicates that the activation of sediment transport processes is relatively limited compared to other reef environments such as Lady Elliot Island (west) and east of Cocos (Keeling) Island. In some cases, a relative increase in wave energy can occur further landward especially on wide reef platforms exceeding $600 \mathrm{~m}$ such as on Warraber Island (Brander et al., 2004). Niue however, only reaches $130 \mathrm{~m}$ in platform width therefore prohibiting the local generation of wind waves.

Table 6.2: Reef energy window indices for Niue platforms

\begin{tabular}{|l|c|c|c|c|c|}
\hline \multicolumn{1}{|c|}{ Site } & $\begin{array}{c}\text { Platform } \\
\text { width } \\
(\mathrm{PW})\end{array}$ & $\begin{array}{c}\text { Mean Water } \\
\text { depth across } \\
\text { platform(d) }\end{array}$ & $\begin{array}{c}\text { Mean water } \\
\text { depth at } \\
\text { Spring HT* }\end{array}$ & $\begin{array}{c}\text { Reef energy } \\
\text { Window Index } \\
(\mathrm{d} / \mathrm{PW})\end{array}$ & $\begin{array}{c}\text { Occurrence of } \\
\text { gravity wave } \\
\text { energy }(\%)\end{array}$ \\
\hline Utuko & 119 & 0.04 & 0.14 & 0.0012 & 27 \\
\hline Alofi Wharf & 70 & 0.08 & 0.18 & 0.0026 & 38 \\
\hline Tamakautoga & 92 & 0.13 & 0.23 & 0.0025 & 37 \\
\hline Tautu & 76 & 0.05 & 0.15 & 0.0020 & 34 \\
\hline Lakepa & 65 & 0.14 & 0.24 & 0.0037 & 35 \\
\hline Avatele & 109 & 0.14 & 0.24 & 0.0022 & 26 \\
\hline Tuapa & 160 & 0.08 & 0.18 & 0.0011 & 35 \\
\hline Hio & 138 & 0.2 & 0.3 & 0.0022 & 41 \\
\hline Pofitu & 70 & 0.13 & 0.23 & 0.0033 & 35 \\
\hline
\end{tabular}

*HT= High Tide 
As demonstrated by Kench and McLean (1996), sediment entrainment, transport and deposition that influence reef island and beach development are activated by gravity wave energy that is propagated across reef platforms. The wide and shallow reef flat on Warraber Island has a low reef energy index (0.00072) which means that geomorphic processes across the reef surface can only be activated over a short space of time (Kench and Brander, 2006). This is further supported by the lack of transportation of sediment from the outer reef flat toward the island, given that the $500 \mathrm{~m}$ raised palaeo-reef surface acts as both a wave dissipater and a source for island beach sediments (Brander et al., 2004; Hart and Kench, 2007). In contrast, the higher indices on the narrow and deeper reefs on Cocos East (0.015) and Lady Elliot Island (west) (0.052) allows for the activation of sediment transport over a longer time period (Kench and Brander, 2006). The spatial and temporal variation in wave energy between the different reef flats reflects the interplay between the incident wave climate and reef platform structure (Kench and Brander, 2006; Kench et al., 2009).

Wave data for Niue was not quantified, although incorporating the reef energy window index for Niue (mean= 0.0023) into Kench and Brander (2006b) regression equation shows that gravity waves in this study occur between $26-42 \%$ of the time over a spring neap tidal cycle (Table 6.2). Although, this seems lower than those calculated for Lady Elliot and Cocos Islands, the index is based on data derived from reef flat environments that vary to the Niuean coastline. It consists of a shallow erosional platform fronted by spur and groove structures or fringing reef causing waves to break and reduce in height at its seaward edge. This could be the contributing factor to which wave energy is dissipated across the platform surface thus resulting in the low reef energy window index for Niue's platforms. Despite of this, wave energy processes across the platforms is still competent for the activation of geomorphic processes, since beaches become completely inundated during high tide as observed at Utuko, Lakepa and Tautu (Figure 6.4) therefore leading to the occurrence of sediment exchange between the platform and the beach. 


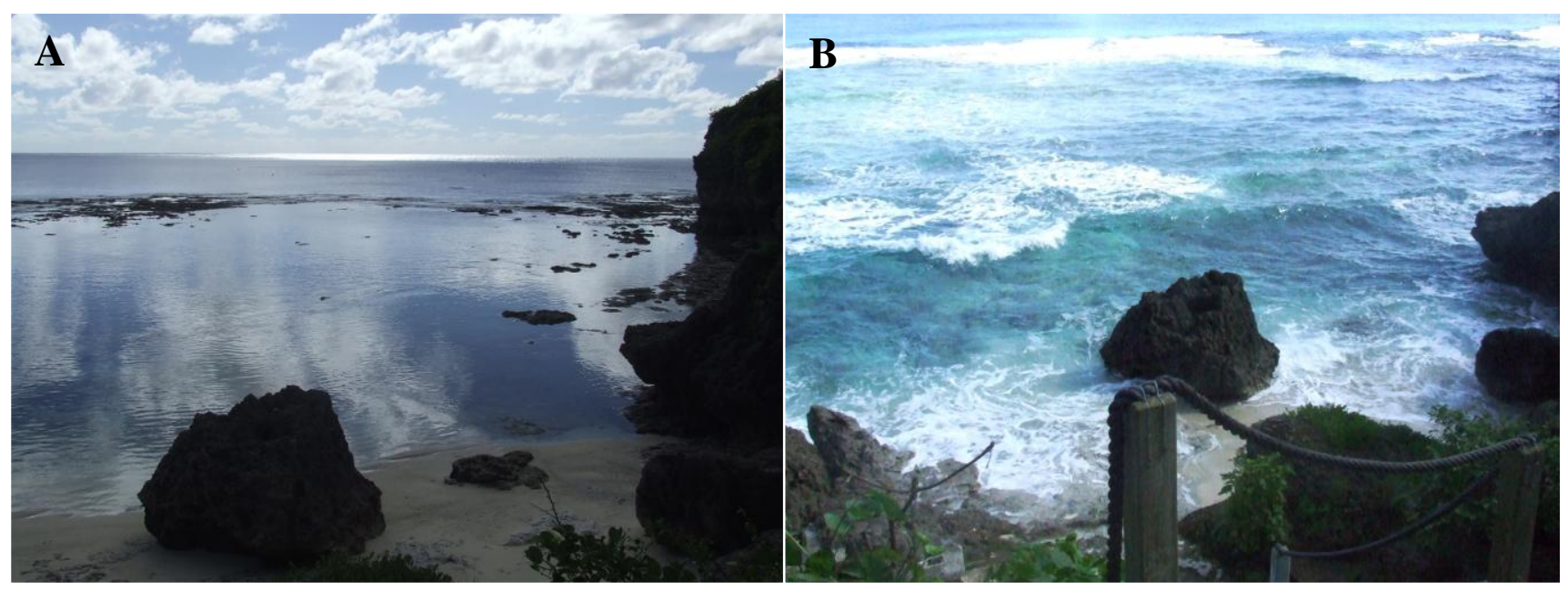

Figure 6.4: Utuko at low tide (A) and high tide (B) where the beach is completely inundated. Note: Large boulder in centre of beach (1.5-2 $\mathrm{m}$ high) for scale.

The highest and lowest index values are found at Lakepa (0.00037) and Tuapa (0.0011) respectively; although, the difference in values is minor, indicating a similarity in wave energy across platforms surveyed around the island. Platform morphology at both sites is similar both in roughness and platform elevation; however platform width varies considerably between the two sites. The widest platforms $(160 \mathrm{~m})$ on the island occur on the North West coast particularly at Tuapa which is more than twice the width of platforms at Lakepa, consequently allowing for the greater dissipation of wave energy across the platform surface. This in turn has significant geomorphological implications for sediment transport across the reef platform to the cliff based beaches. Sediment entrainment decreases landward as wave energy dissipates across the reef platform while transport is likely to be most active under greater depths that are associated with spring high tide conditions or during extreme waves or storm conditions (Brander et al., 2004).

Storm or tropical cyclone events can have significant effects on reef flat conditions (Kench and Brander, 2006). However, mean energy processes appear to be effective in entraining and transporting sediment across the Cocos Island Eastern reef that during extreme events, very little change is experienced in the rate of sediment transport due to the already limited sediment cover on the reef surface (Kench and McLean, 2004). In contrast, the wider and shallower southern reefs on Cocos Island $(\Psi=0.0005)$ rely on higher energy events for the activation of sediment transport (Kench, 1998b; Kench and Brander, 2006). Clearly, low index values indicate a low dependence on extreme events while mean energy processes are 
effective on reef surfaces with high reef energy window indices (Kench and Brander, 2006). Tuapa is located on the leeward side of the island yet this is the side facing the path of tropical cyclones. It has the lowest index value on the island, yet it is still higher relative to that on the reefs south of Cocos Island, implying that platforms in Niue are geomorphically more active as such that they often disappear during tropical cyclone events.

On some reef islands (cays), their development is influenced by the behavior of waves approaching shore. Waves often refract around and converge at a nodal point on the reef platform therefore causing sediment deposition or islet initiation. This is the point where net sediment transfer is zero (Barry et al., 2008; Kench et al., 2009). However, this can only be applied to atoll-islet setting and since the coastline of Niue consists of a narrow erosional platform and fringing reef, it impedes the development of discrete focal points as a result of wave refraction.

\subsubsection{Surface sediment character in relation to composition and wave processes}

Kench and McLean (1996, 1997) demonstrated that skeletal and buoyancy characteristics of carbonate sediment make them easily transported under non-storm energy conditions. The nature and distribution of sedimentary facies on the reef platforms and beaches of Niue essentially reflects the interaction of wave energy on skeletal sediments derived from a range of organisms growing on the platform surface. Much of the sediment obtained from the various sites varies from well sorted to moderately well sorted coarse grained sand, with the exception of the gravel beach at Avatele. There is no distinct pattern in the distribution of sediment between sites irrespective of whether they were collected from the windward or leeward side of the island, although samples from Utuko exhibit an increase in mean grain size from $-0.07 \Phi$ from the beach high tide swash to $-0.60 \Phi$ on the platform. A similar pattern was observed at Hio with a coarsening of sediment from $0.24 \Phi$ on the beach top to $0.78 \Phi$ on the platform. This conforms to models of lagoonal sedimentation which predict a systematic decline in mean grain size with distance from the reef rim and source (Smithers, 1994); however, sediment distribution across the platforms and cliff based beaches is 
unimodal rather than bimodal. The model is developed for lagoonal rather than for a reef flat or platform settings such as in Niue, therefore grain size distribution across the reef flat may differ from those found in lagoonal environments. The coarser sediment on the reef platform at Hio and Utuko have a high degree of sorting relative to the beach samples (Figure 6.5), and this likely reflects the constant wave action along reef edge resulting in the rapid removal of fine detritus.

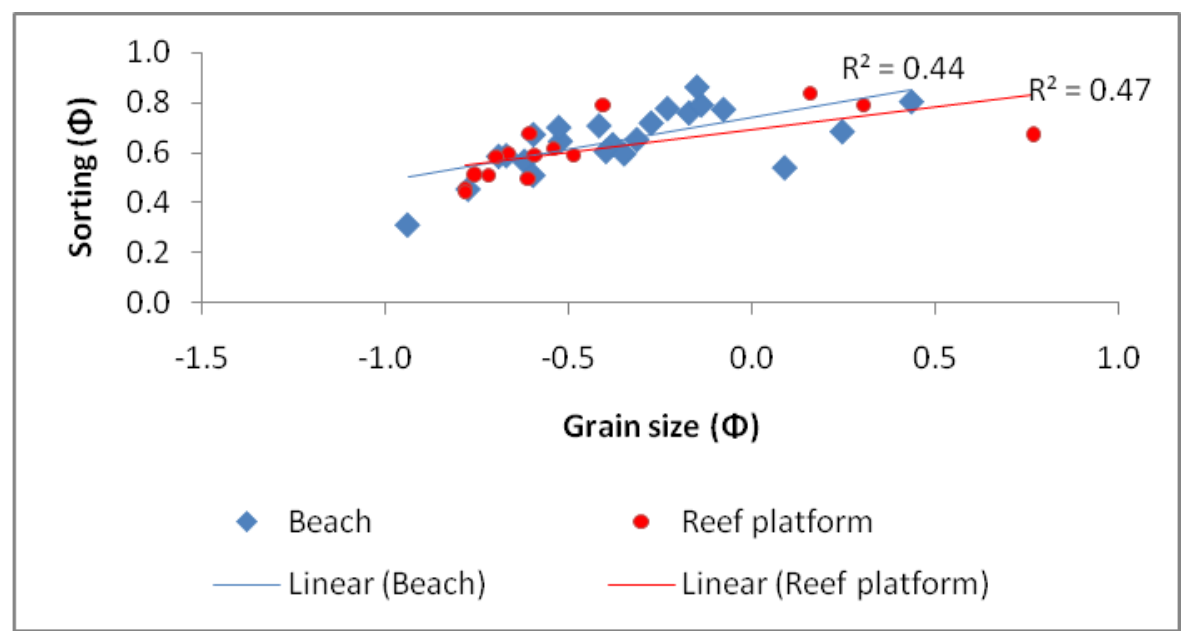

Figure 6.5: Relationship between mean grain size and sorting of Niue beach and reef platform sediments.

The majority of Niue samples are strongly fine to finely skewed, with reef platform samples from Utuko, Hio, and Tuapa exhibiting positive skewness relative to beach samples. This reflects the selective removal of finer grain sizes by wave processes. Based on cluster analysis (Figure 6.6), two textural gradient groups are recognized on the beach and reef platforms. Group A is the largest cluster and comprises very coarse, moderately well sorted sediment from both the windward and leeward side of the island. Samples within the cluster appear to be slightly coarser (range -0.2 to $-0.8 \Phi$ ) and finely skewed relative to the other groups. Reef platform samples make up $48 \%$ of the cluster while beach and swash zone samples occurred in minor proportions. Group B on the other hand consists of less coarse sediment (range -0.4 to $0.4 \Phi$ ) has more than $50 \%$ of its samples derived from the beach while, swash (33\%) and platform (14\%) samples only occur in minor amounts in the cluster. Despite this, the differences are relatively minor which suggests that all samples are well mixed. 


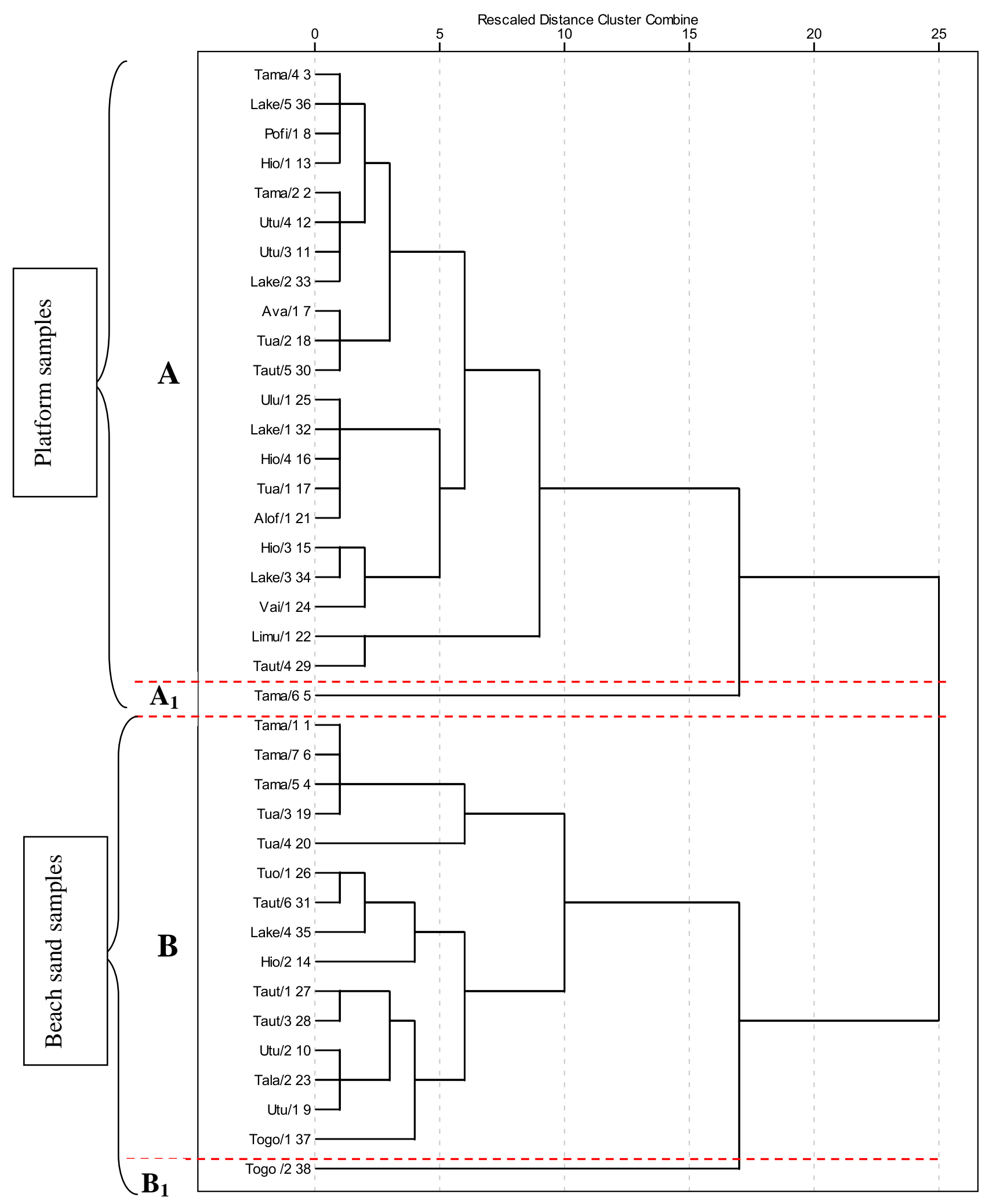

Figure 6.6: Hierarchical cluster analysis of surface sediment texture of samples collected from Niue. 


\subsubsection{Relations between component and sediment texture}

The characteristics of these contributing organisms in turn can be reflected in the texture of surficial sediments or deposits (Orme 1973; Spencer and Viles 2002). They provide an almost continuous spectrum of particle sizes that affect their hydrodynamic properties and the extent to which they will be transported (Kench and McLean, 1997; Orme, 1977). Coral grains are widespread within all the size classes; however, they are best represented in the coarse- to medium-sized populations (Flood and Scoffin, 1978). Foraminifera tests are an important component for several beaches, lagoons and reef flats and their initial size influences their grain size as a sediment particle, with Amphistegina contributing to the sand fraction while Marginopora occurred in the gravel fraction (Collen and Garton, 2004; Flood and Scoffin, 1978; Hohenegger, 2006; Maiklem, 1968).

Very little correlation has been observed between the component and textural types of sediments in Niue, with individual skeletal particles occurring in various textural gradients regardless of inherent differences in shape, size and density. Sediments from the Northern Great Barrier Reef also appear to be primarily influenced by the prevailing energy conditions of waves and tides and secondarily controlled by its skeletal structure (Flood and Scoffin, 1978). The narrowness of the reef platform in Niue also does not appear to allow

for differentiation of sediment sizes and components by the sorting action of wave processes. Furthermore, since both beach and platform sediments exhibit similar grain-size distributions, factors such as low biotic diversity and a simple reef structure yields a relatively restricted range of source materials for sediments in Niue. 


\subsection{Beach stability}

\subsubsection{Beach accumulation thresholds}

Beach elevation is related to the incident wave energy and width of the adjacent reef flat (Brander et al., 2004); however, this does not seem to be the case in Niue since little correlation exist between the two variables ( $p>0.05$ ) (Table 6.3). A strong negative relationship is produced $(r=-0.77, p<0.05)$ between platform width and beach slope, with more gently sloping beaches occurring on wider platforms. Sediment size also exerts a primary control on beach slope. In profile beaches on Niue, are typically narrow and steep $\left(5-8^{\circ}\right)$. Despite a strong correlation between platform width and beach slope, a very weak relationship exist between grain size and platform width $\left(\mathrm{R}^{2}=0.11\right)$. This implies that it has a minor influence on both beach width and sediment size within the area.

Table 6.3: Correlation matrix of beach, platform and sediment characteristics using the Pearson Linear Correlation method. Figures in brackets represent the p-values, significance at the $5 \%$ level $(\mathrm{P}<0.05)$.

\begin{tabular}{|c|c|c|c|c|c|c|}
\hline & Beach elevation & Beach slope & Beach width & Grain size & Platform depth & Platform width \\
\hline Beach elevation & 1 & & & & & \\
\hline & & & & & & \\
\hline \multirow{2}{*}{ Beach slope } & -0.0101 & 1 & & & & \\
\hline & $(0.9810)$ & & & & & \\
\hline \multirow[t]{2}{*}{ Beach width } & 0.8456 & -0.4614 & 1 & & & \\
\hline & $(0.0082)^{*}$ & $(0.2498)$ & & & & \\
\hline \multirow[t]{2}{*}{ Grain size } & -0.2295 & -0.4004 & 0.0000 & 1 & & \\
\hline & $(0.5846)$ & $(0.3257)$ & (1.0000) & & & \\
\hline \multirow[t]{2}{*}{ Platform depth } & 0.2333 & 0.2811 & 0.0932 & 0.4692 & 1 & \\
\hline & $(0.5782)$ & $(0.5001)$ & $(0.8262)$ & $(0.2408)$ & & \\
\hline \multirow[t]{2}{*}{ Platform width } & -0.3198 & -0.7660 & 0.1623 & 0.4354 & -0.0582 & 1 \\
\hline & $(0.4401)$ & $(0.0267)^{*}$ & $(0.7010)$ & $(0.2809)$ & $(0.8912)$ & \\
\hline
\end{tabular}

*p-values significant at $5 \%$ level

Very little relationship has also been established between platform width and beach width $\left(\mathrm{R}^{2}=0.11\right)$. The weak association between platform width and other variables mentioned should not be dismissed completely as it appears that platform width does a minor role for beach occurrence around the island (Figure 6.7). Beaches can only develop where the reef platform is at least $60 \mathrm{~m}$ wide, implying that below the $60 \mathrm{~m}$ width boundary, the ability of sediment to accumulate at the landward edge of these erosional platforms reduces significantly to the point that any sediment present is removed immediately. Interestingly, beaches are absent on some platforms beyond the $60 \mathrm{~m}$ width boundary (marked by arrows 
in Figure 6.7). It is possible that a beach may have been present in the past but was removed in the event of a tropical cyclone and has not recovered since then. Most of these sediment free platforms are also located in the vicinity of the main headlands and this may also be a key factor in determining beach development. The platform marked by a red arrow is quite unusual in that a beach is present despite platform width being $<60 \mathrm{~m}$. It is also located on the windward coast $2 \mathrm{~km}$ south of Togo Chasm where an inland beach is present. It may be possible that sediment is sourced from Togo or that other factors such as the morphology of the underlying abrasion at the cliff base may play a role in determining beach development and stability. However, this cannot be confirmed due to the fact that this specific area was not surveyed, with platform and beach width being derived from aerial photos only.

The role of waves to entrain and transport sediment becomes more effective, since the amount of wave energy arriving at the landward cliff platform junction increases with decreasing platform width. For example, between 93 and $95 \%$ of wave energy is lost in shoaling on the shore platforms of Kaikoura Peninsula, New Zealand, with as little as 4.9 to $6.8 \%$ of wave energy actually reaching the landward cliff foot (Stephenson and Kirk, 2000a). Although, both settings experience a microtidal regime, it should be noted that the shoreline of Kaikoura Peninsula and that on Niue are not directly comparable, with the Kaikoura platforms being of varied geology consisting of a gently sloping profile offshore. In contrast, the platforms in Niue are fronted by spur and groove structures or a narrow fringing reef which plays an important role in the dissipation of wave energy across the platform surface, therefore caution must be exercised when making comparisons with the reef platform setting of Niue. The lack of wave data for the island of Niue also means that a direct relationship between platform width and wave energy is difficult to establish. 


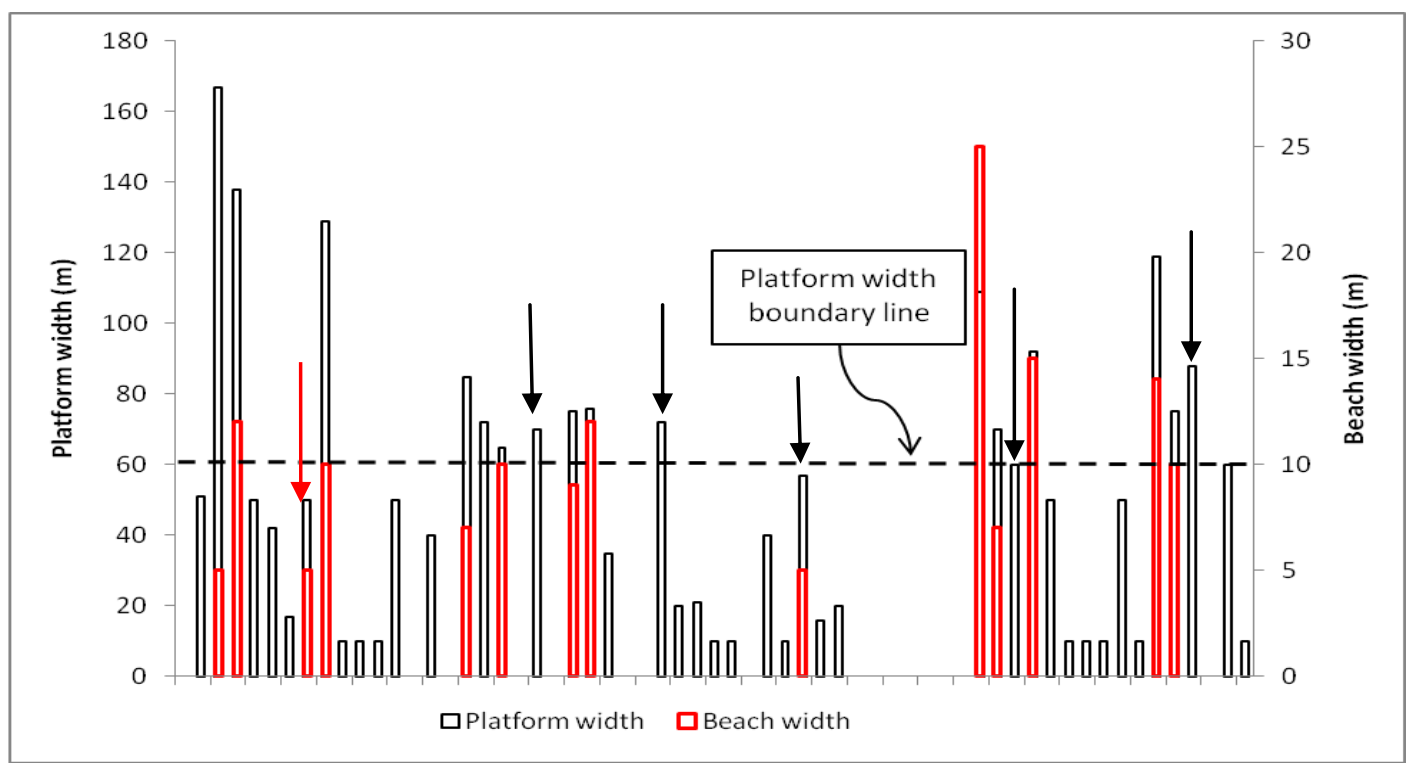

Figure 6.7: Platform width versus Beach width. The black dashed line represents the platform width boundary (> $60 \mathrm{~m}$ ) to which beaches begin to develop. Black arrows mark the platforms $(>60 \mathrm{~m})$ with no beach present while red arrow marks beach occurrence on a platform below the $60 \mathrm{~m}$ boundary.

Beach slope is determined by the permeability of the beach, with coarser sediments forming steeper slopes due to higher permeability (e.g. Avatele Beach), and will only become less steep when attacked by larger waves. Alternatively, the less permeable finer sediments will form low slope beaches that becomes flattened during a storm (Quick, 1991). In Niue, since all pocket beaches are composed mainly of coarse sand sized sediment with the exception of Avatele Beach, their response to various energy regimes is expected to be similar. They tend to build out during fair weather conditions, but are often eroded or completely removed in the event of a tropical cyclone, as have occurred on the north western coast of the island following Cyclone Heta in 2004.

\subsubsection{Application of Bruun or Trenhaile's model to beach stability}

Various models have been developed in order to predict how shorelines may respond to steady sea level rise. The Bruun Rule was devised for sandy shores where beach and nearshore are interconnected and that all net sediment transfers are purely onshore-offshore (Woodroffe et al., 1999). This however does not account for longshore sediment transport, which is a key factor in the response of sandy shores (Davidson-Arnott, 2005; Dickson et al., 2007). The beach profile also maintains equilibrium through erosion of the upper slope 
and deposition of sediment offshore (Cooper and Pilkey, 2004; Woodroffe et al., 1999). Nevertheless, such model is not designed for application on atolls or reef island systems, since it assumes that the shore profile is entirely beach. The lower shoreface of Niue is a solid reef platform which cannot be adjusted or changed over a short timescale (Woodroffe et al., 1999; Woodroffe et al., 2007). The underlying resistant platform also means that the shore profile may adopt a different equilibrium profile to that of sandy shores and may take longer to achieve it (Walkden and Dickson, 2008). The landward migration of sediment under sea level rise is also restricted due to the presence of cliffs behind these pocket beaches and so it is not applicable for the rocky shore system of Niue.

Beaches on rocky coasts will respond to rising sea level differently from those on sedimentary coasts and the response will often depend on the morphology of the rocky foundation. They develop when the beachface gradient at its seaward edge is greater than the platform gradient, assuming there is adequate sediment (Trenhaile, 2004). Beachface gradient either decreased during storms or beaches are completely eroded away as platform gradient exceeded beachface gradient (Trenhaile, 2004). The beaches in Niue sit on a sloping ramp rather than a horizontal surface and are fairly steep (mean $7.4 \pm 1.2^{\circ}$ ) with the relief at the beach base acting as a wave dissipater and store of sand (Figure 6.8). 

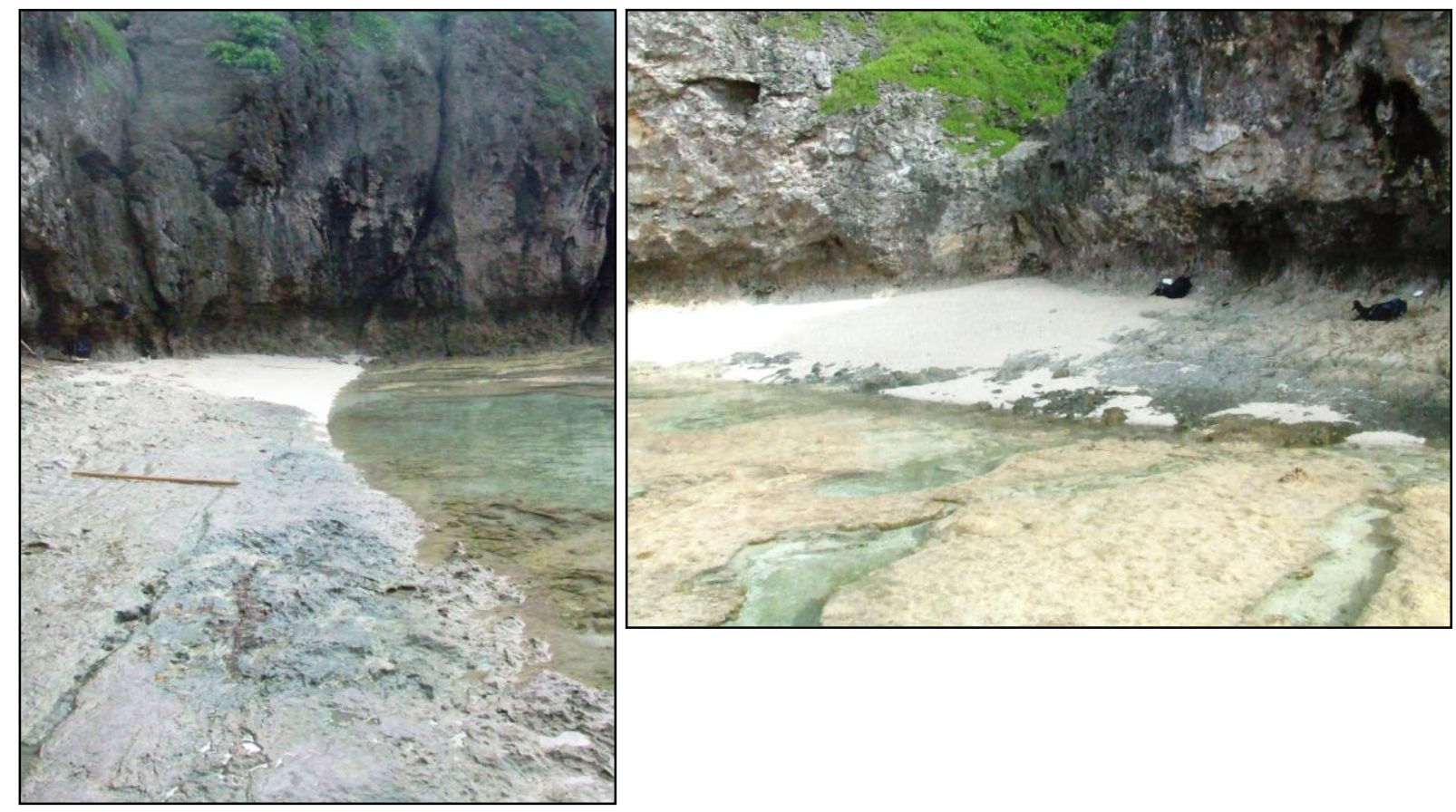

Figure 6.8: Pocket beach at Tautu sitting on top of an abrasion ramp. Note the exposed abrasion ramp as a result of wave refraction within the embayment.

The model also suggests that the underlying rocky foundation plays a key role in determining how sediment is deposited during fair weather conditions, and removed during storms. Therefore, the abrasion ramps that are under the beaches at the rear of platforms may be a significant factor in determining beach stability in Niue. Sediment cover is less than $0.1 \mathrm{~m}$ at most sites with the ramp often exposed in some places (Figure 6.4.3) and so beach elevation and slope is also a representation of the elevation and gradient of the underlying ramp. Beach elevation varies from 0.3-1.9 $\mathrm{m}$ above MWL, while there was very little variation in beach slope ranging from 5.6- $8^{\circ}$. Interestingly, beaches increase in width with higher elevations $(r=0.85)$ significant at the $95 \%$ confidence level. This suggests a higher ramp is able to reduce the amount of wave energy reaching the back of the cliff, therefore allowing for sediment deposition to occur and for the beach to accumulate. The presence of sand stored at the beach toe is evidence of the inability for waves to entrain sediment further landwards. It is possible that over time this ramp may be lowered through abrasion and therefore allowing for waves to reach the rear of the platform more easily and effectively removing any sediment that is present. Clearly, normal wave conditions are capable of transporting sediment across the platform yet it requires high energy events to entirely remove the whole beach from the platform. The lack of sediment supply may have also exacerbated the situation in Niue where several small pocket beaches located on the 
north western coast disappeared after Cyclone Heta. Although platform width is a key factor in dissipating waves across the surface, the narrowest beaches $(<5 \mathrm{~m})$ with a mean elevation of only $0.3 \mathrm{~m}$ above MWL, occur at Tuapa. Despite the widest platforms (160 m) occurring within the area, this implies that the elevation of the ramp at the rear of the platform is critical for beach stability while platform width only plays a secondary role.

\subsubsection{Beach stability in relation to exposure}

The resilience and stability of a shoreline depends on the behaviour of its natural system, as well as other factors such as reef width, frequency and intensity of extreme events, and anthropogenic activities (Woodroffe, 2008). The immediate source of beach sediment in Niue is the adjacent reef flat. This in turn derives its sediment from the breakdown of corals and other carbonate marine organisms such as foraminifera.

At present, of the 37 beaches identified in Niue, $35 \%$ of these occur on the eastern coast and $32 \%$ on the south western side of the island. This may be due to the fact that these sides are protected from the prevailing SE trade winds and experience less damage by tropical cyclones; therefore, they tend to be more stable as opposed to beaches located on the windward and cyclone prone North West and Western region of the island. Beach occurrence on the windward south east coast only accounts for $8 \%$ of total beaches mainly due the lack of platform development along much of the coast. Narrow platforms $(<30 \mathrm{~m})$ are found in some places however the likelihood of sediment accumulating within this high energy setting is minimal. In the Seychelles, beaches predominate on the windward coast with the best-developed occurring on narrow reef coasts while the wider reefs are backed by narrow, coarse-grained beaches. This suggests reef width in conjunction with wave energy regime contributes in the type of beaches found within the area. However, the Seychelles is situated outside the cyclone belt and so its reef and beach structure can only endure the seasonal changes in wave conditions instead of the more extreme cyclone events that several other archipelagos experience (Sheppard et al., 2005).

According to local residents, the impacts of Tropical Cyclone Heta in 2004 caused significant changes to the North Western coastline in particular; numerous small pocket 
beaches were either flattened or eroded away. A comparison between beach surveys in this study to that carried out by SOPAC in 1995 (Pre- Cyclone Heta) (Forbes, 1996) indicate that beach slope at two sites on the North West coast (Hio and Tuapa) have slightly changed following the event. It shows that mean beach slope has decreased from $7.4^{\circ}$ in 1995 to $5.6^{\circ}$ in 2008 when surveying was carried out for this study. Likewise, south of Hio, mean beach slope at Tuapa has reduced from $10.0^{\circ}$ to $6.7^{\circ}$. Interestingly, several of the beaches that were eroded away have started to accumulate again just a few years following the event thus implying a fast recovery rate. Since much of the north western beaches are composed of foraminifera, these organisms are essentially responsible for the rapid production of sand resulting in the fast recovery of these beaches. However, repeated damage of the reef system along this side of the coast from cyclones or changes in environmental conditions may cause a shift in sediment producers. It may also cause fast growing yet delicate species to be selectively removed and replaced by slow growing globular forms of coral and therefore affecting the ability for these beaches to recover more rapidly (Terry, 2007). Consequently, as long as reef flat ecology remains suitable for growth of foraminifera, beaches on the north western coast will continue to thrive.

It is important to emphasise that high sediment connectivity between the reef platform and beach exits, furthermore, these small pocket beaches are subject to continual reworking, possibly by tropical cyclones, as reflected by the modern ages of the majority of sediment. The importance of investigating what may trigger sediment to accumulate and erode on these small pocket beaches is significant both on a short term and long term scale. Lastly, their preservation and ability to return to their pre-storm conditions are determined by the magnitude and frequency of tropical cyclones and are also dependent on benthic communities on reef platforms to maintain and nourish them. 


\section{CHAPTER 7: Conclusion}

\subsection{Introduction}

The coastlines of atoll islands experience pronounced morphological change in response to storms, and sea-level change at a range of time scales. Beaches are maintained by sand produced from the nearby reefs. They are perceived to be more susceptible to global change than other coastal systems particularly in the light of expected future rises in sea level (Woodroffe, 2002). However, there is poor understanding of change and dynamics in atoll environments, mainly the processes of sediment production, entrainment and deposition.

The stated aim for this study is to qualitatively and quantitatively describe the morphology of tropical coral reef beaches and identify what thresholds exist that allow for sediment build-up in areas with a rocky foundation. The island of Niue was specifically selected for this study since it is an ideal environment to investigate key factors that drive beaches to accumulate or erode within a tropical reef setting.

\subsection{Reef platform morphology}

Objective 1: Describe the morphology of reef platforms and its association to beach development.

This study provides the results of field observation, geomorphological surveys, GIS analysis of aerial photographs, and these were utilised to satisfy the first objective of this project. Topographic surveys provide a detailed geomorphic description of the coastline while aerial photographs show the geographic variability of shore types around the island. Much of the coastline of Niue consists of an erosional limestone platform fronted by a fringing reef. It has a combined width of up to $150 \mathrm{~m}$ with the widest section found on the leeward side of the island on the north western coast and the narrowest $(<30 \mathrm{~m})$ being located on the more exposed south eastern coast. The distribution of platforms is therefore likely related to the energy environment around the island. Cliff based pocket beaches 
sometimes develop on the landward edge of the platforms with beaches only occurring on platforms that are at least $60 \mathrm{~m}$ wide. Wider platforms and the presence of spur and groove structures allow for the greater dissipation of incident wave energy across the surface therefore creating favourable conditions for sediment accumulation.

\subsection{Drivers of sediment accumulation}

Objective 2: Identify the key mechanisms which drive sediment accumulation and erosion within a tropical reef setting.

Little is known on the factors that are favourable for sediment accumulation. To meet the second objective of this study, 51 samples were recovered from platforms and the upper 10 $\mathrm{cm}$ of pocket beaches around the island. Composition analysis of beach and platform sediments allowed the source areas from which this material is derived from to be identified. This revealed that beaches in Niue are largely composed of unconsolidated bioclastic sand and gravels of chlorozoan carbonates typical of tropical areas. The key components in order of abundance included coral, coralline algae, mollusc, Halimeda, and benthic foraminifera. The distribution of grain types is attributed to the spatial variation of source areas, platform morphology and hydrodynamic processes. Multivariate analysis of all beach components revealed a difference in sedimentary environments around Niue, with coral generally being the most ubiquitous clast type sediment. The exception are the beaches on the north western coast which are composed largely of foraminifera, particularly Baculogypsina sp. and Amphistegina sp. A minor occurrence of recrystallised grains implies that the sediments are all recent and directly sourced from the adjacent reef platform. Their evolution is therefore intrinsically linked to the productivity of these surrounding carbonate sources. Various factors such as global climate change and anthropogenic impacts may lead to a decrease in the productivity of the adjacent reef platform and possibly causing the loss of the nearby beach systems. Given the beaches erode during cyclones, they can be considered unstable anyway. 
The beach and platform samples exhibit similar grain size distributions. Factors such as low biotic diversity and a simple reef structure yields a relatively restricted range of source materials for sediments in Niue. It is recognised that processes occurring on platform surfaces control sediment dispersal; little is known regarding the specific hydrodynamic controls on sediment entrainment, transport and deposition across reef surfaces that ultimately contribute to the development and stability of island shorelines (Brander et al., 2004). The non dimensional reef energy window index ( $\Psi$ ) introduced by Kench and Brander (2004) for Niue indicate the activation of sediment transport is highest at Lakepa on the East Coast and lowest on the wider platforms at Tuapa. This suggests that platform width is important for beach development; however, the morphology of the underlying abrasion ramp on the landward edge of the platform is a key factor while platform width only plays a secondary role in beach stability.

\subsection{Beach stability}

Objective 3: Determine the geomorphic stability of small pocket beaches on Niue.

The third objective was established through a compilation of sediment and topographic analysis. Nine samples were submitted for radiocarbon dating to determine the age and stability of beaches. All beach samples yielded modern ages, implying that high sediment connectivity exists between the reef platform and beach and are actively being reworked by tropical cyclones and to a lesser extent by normal wave conditions. Pocket beaches in Niue are usually found on the landward edge of erosional platforms. Their stability is determined

primarily by changes in platform morphology, availability of sediment, and relative wave exposure. While distance from the reef crest played a role in dissipating wave energy across the platform therefore reducing beach erosion, beach stability is reliant on the occurrence of tropical cyclones and the elevation of the underlying abrasion ramp. Beaches increased in width at higher elevations therefore implying that a higher ramp can effectively reduce the amount of wave energy reaching the landward edge of the beach resulting in the accumulation of sediment. 
Morphological and sedimentological evidence supports that erosion and the removal of entire beaches occurs on Niue during tropical cyclones. In addition, a comparison of beach surveys done by SOPAC in 1995 (pre-Cyclone Heta) and those in this study (2008) show a decrease in beach slope (up to $4.0^{\circ}$ ) at Hio and Tuapa on the north western coast. This proves that the impacts of Tropical Cyclone Heta are still visible within the area and their stability and capacity to return to their pre-storm conditions is dictated by the frequency and magnitude of subsequent storm events.

Furthermore, sediment is derived directly from the reef platform where benthic communities occur. In general, sediment composition between and within sites in Niue are similar, and textural characteristics of sediment deposits suggest that present conditions have selectively sorted sediment to produce a strong linkage between these sedimentary environments and the platform biota in the immediate area. The fast recovery of the foraminifera-rich north western beaches following Tropical Cyclone Heta is an indication that the foraminifera community can re-establish quicker after cyclones. This therefore confirms that the beaches are highly dynamic, and build out or erode during alternated calm and stormy conditions. However, continuous disruptions or a change in environmental conditions have the potential to increase erosion through decreased sediment supply and therefore leading to the beaches becoming more ephemeral in the future.

\subsection{Recommendations for future studies}

To fully understand the thresholds of sediment accumulation, the physical processes influencing the sedimentation, spatial geomorphic and sedimentological patterns from tropical reef systems must be better understood. A detailed study of the hydrodynamic processes that occur across the platforms to the shoreline on Niue will aid in better establishing the role of waves and tides on sediment transport and beach development. There is limited study of contemporary sediment production on atoll reef flats and its connection with the maintenance of island shorelines. Since these beaches in Niue are intrinsically linked to the platform biota, the distribution patterns and sediment production values of benthic foraminifers and other carbonate producers should be quantified and studied in greater detail. This will provide critical information for evaluating changes in 
production and organism type available for beach development and maintenance and how they may respond to abrupt changes in the environment.

Detailed mapping of the coastal morphology and reef platform ecology of Niue could assist in the classification of shore zones and the geographic variability of shore types around the entire island. More recent aerial photos should be acquired in order to identify and quantify the rate of coastline change and their response to tropical cyclone events. In addition, coastal profiles should be measured every 2-3 years; if possible they should be measured after every tropical cyclone event in order to accurately assess the morphological effects on the coastline of Niue and gain a better understanding of the signature that will be left by such events. 


\section{References}

Barry, S.J., Cowell, P.J. and Woodroffe, C.D. 2007: A morphodynamic model of reefisland development on atolls. Sedimentary Geology 197, 47-63.

Barry, S.J., Cowell, P.J. and Woodroffe, C.D. 2008: Growth-limiting size of atoll-islets: Morphodynamics in nature. Marine Geology 247, 159-177.

Barstow, S.F. and Haug, O. 1994: The wave climate of the southwest Pacific. SOPAC Technical Report 206. 26 pp.

Bayliss-Smith, T.P. 1988: The Role of Hurricanes in the Development of Reef Islands, Ontong Java Atoll, Solomon Islands. The Geographical Journal 154, 377-391.

Blanchon, P. and Jones, B. 1997: Hurricane control on shelf-edge-reef architecture around Grand Cayman. Sedimentology 44, 479-506.

Blott, S.J. and Pye, K. 2001: GRADISTAT: a grain size distribution and statistics package for the analysis of unconsolidated sediments. Earth surface processes and landforms 26, 1237-1248.

Bochicchio, C., Fletcher, C., Dyer, M. and Smith, T. 2009: Reef-Top Sediment Bodies: Windward O'ahu, Hawai'i. Pacific Science 63, 61-82.

Boss, S.K. and Neumann, A.C. 1993: Impacts of Hurricane Andrew on carbonate platform environments, northern Great Bahama Bank. Geology 21, 897-900.

Brander, R.W., Kench, P.S. and Hart, D. 2004: Spatial and temporal variations in wave characteristics across a reef platform, Warraber Island, Torres Strait, Australia. Marine Geology 207, 169-184.

Brown, B.E. 1997: Adaptations of reef corals to physical environmental stress. Advances in Marine Biology, Vol 31, 221-299.

Calhoun, R.S. and Field, M.E. 2008: Sand composition and transport history on a fringing coral reef, Molokai, Hawaii. Journal Of Coastal Research 24, 1151-1160. 
Camoin, G.F., Colonna, M., Montaggioni, L.F., Casanova, J., Faure, G. and Thomassin, B.A. 1997: Holocene sea level changes and reef development in the southwestern Indian Ocean. Coral Reefs 16, 247-259.

Chappell, J. 1980: Coral morphology, diversity and reef growth. Nature 286, 249-252.

Chave, K. 1964: Skeletal durability and preservation. In Imbrie, J. and Newell, N., editors, Approaches to palaeoecology, Sydney, NSW: Wiley, 377-387.

Chubb, L.J. 1957: The pattern of some Pacific Island chains. Geological Magazine, 221228.

Collen, J.D. and Garton, D.W. 2004: Larger foraminifera and sedimentation around Fongafale Island, Funafuti Atoll, Tuvalu. Coral Reefs 23, 445-454.

Cooper, J.A.G. and Pilkey, O.H. 2004: Sea-level rise and shoreline retreat: time to abandon the Bruun Rule. Global And Planetary Change 43, 157-171.

Crowell, M., Leatherman, S.P. and Buckley, M.K. 1991: Historical shoreline change- Error analysis and mapping accuracy. Journal Of Coastal Research 7, 839-852.

Darwin, C.R. 1842: The structure and distribution of Coral Reefs: Smith, Elder and Co, London.

Davidson-Arnott, R.G.D. 2005: Conceptual model of the effects of sea level rise on sandy coasts. Journal Of Coastal Research 21, 1166-1172.

Davies, P.J. and Montaggioni, L. 1985: Reef growth and sea-level change: The environmental signature. Proceedings of the Fifth International Coral Reef Congress, Tahiti.

Dickinson, W.R. 2004: Impacts of eustasy and hydro-isostasy on the evolution and landforms of Pacific atolls. Palaeogeography Palaeoclimatology Palaeoecology 213, 251-269.

Dickson, M.E. 2006: Shore platform development around Lord Howe Island, southwest Pacific. Geomorphology 76, 295-315. 
Dickson, M.E., Walkden, M.J.A. and Hall, J.W. 2007: Systemic impacts of climate change on an eroding coastal region over the twenty-first century. Climatic Change 84, 141-166.

Emery, K.O., Tracey, J.I. and Ladd, H.S. 1954: Geology of Bikini and nearby atolls. United States Geological Survey Professional Paper 260-A, 1-265.

Flood, P.G. and Scoffin, T.P. 1978: Reefal Sediments of the Northern Great Barrier Reef. Philosophical Transactions of the Royal Society of London. Series A, Mathematical and Physical Sciences 291, 55-68.

Flugel, E. 2004: Microfacies of Carbonate Rocks. Analysis, Interpretation and Application: Springer-Verlag, Heidelberg.

Flügel, E. 1982: Microfacies analysis of limestones.: Springer-Verlag, Heidelberg, 633 pp.

Forbes, D.L. 1996: Coastal geology and hazards of Niue. SOPAC, 97 pp.

Fujita, K., Osawa, Y., Kayanne, H., Ide, Y. and Yamano, H. 2009: Distribution and sediment production of large benthic foraminifers on reef flats of the Majuro Atoll, Marshall Islands. Coral Reefs 28, 29-45.

Gibb, J.G. 1978: Rates of coastal erosion and accretion in New Zealand. New Zealand Journal of Marine and Freshwater Research 12, 429-456.

Gischler, E. and Moder, A. 2009: Modern benthic foraminifera on Banco Chinchorro, Quintana Roo, Mexico. Facies 55, 27-35.

Gourlay, M.R. 1996a: Wave set-up on coral reefs .1. Set-up and wave-generated flow on an idealised two dimensional horizontal reef. Coastal Engineering 27, 161-193.

Gourlay, M.R. 1996b: Wave set-up on coral reefs .2. Set-up on reefs with various profiles. Coastal Engineering 28, 17-55.

Gourlay, M.R. and Colleter, G. 2005: Wave-generated flow on coral reefs - an analysis for two-dimensional horizontal reef-tops with steep faces. Coastal Engineering 52, 353-387. 
Gray, S.C. and Hein, J.R. 2005: Lagoonal reef accretion and Holocene sea-level history from three atolls in the Cook Islands, Central South Pacific. Journal Of Coastal Research, 253-264.

Gross, M.G., Milliman, J.D., Tracey, J.I. and Ladd, H.S. 1969: Marine geology of Kure and MidwayA tolls, Hawall: a prelimminary report. Pacific Science 23, 17-25.

Hallock, P. 1981: Production of carbonate sediments by selected large benthic foraminifera on two Pacific coral reefs. Journal Of Sedimentary Research 51, 467-474.

Harmelin-Vivien, M.L. and Laboute, P. 1986: Catastrophic impact of hurricanes on atoll outer reef slopes in the Tuamotu (French Polynesia). Coral Reefs 5, 55-62.

Harney, J.N. and Fletcher, C.H. 2003: A budget of carbonate framework and sediment production, Kailua Bay, Oahu, Hawaii. Journal Of Sedimentary Research 73, 856-868.

Harney, J.N., Richmond, E.E. and Fletcher, C.H. 2000: Age and composition of carbonate shore face sediments, Kailua Bay, Oahu, Hawaii. Coral Reefs 19, 141-154.

Hart, D.E. and Kench, P.S. 2007: Carbonate production of an emergent reef platform, Warraber Island, Torres Strait, Australia. Coral Reefs 26, 53-68.

Haslett, S.K., Bryant, E.A. and Curr, R.H. 2000: Tracing Beach Sand Provenance and Transport using Foraminifera: Preliminary Examples from Northwest Europe and Southeast Australia. In Foster, D.L., editor, Tracers in Geomorphology: Wiley, 437-452.

Hohenegger, J. 2006: The importance of symbiont-bearing benthic foraminifera for West Pacific carbonate beach environments. Marine Micropaleontology 61, 4-39.

Hopley, D. 1982: The Geomorphology of the Great Barrier Reef. New York: Wiley Interscience.

Hubbard, D.K. 1992: Hurrican-induced sediment transport in open-shelf tropical systemsAn example from St. Croix, U.S. Virgin Islands. Journal of Sedimentary Petrology 62, 946-960.

Hubbard, D.K., Miller, A.I. and Scaturo, D. 1990: Production and cycling of calcium carbonate in shelf-edge reef systems (St Croix, U.S. Virgin Islands): applications 
to the nature of reef systems in the fossil record. Journal of Sedimentary Petrology 60, 335-360.

Hughen, K.A., Baillie, M.G.L., Bard, E., Beck, J.W., Bertrand, C.J.H., Blackwell, P.G., Buck, C.E., Burr, G.S., Cutler, K.B., Damon, P.E., Edwards, R.L., Fairbanks, R.G., Friedrich, M., Guilderson, T.P., Kromer, B., McCormac, G., Manning, S., Ramsey, C.B., Reimer, P.J., Reimer, R.W., Remmele, S., Southon, J.R., Stuiver, M., Talamo, S., Taylor, F.W., van der Plicht, J. and Weyhenmeyer, C.E. 2004: Marine04 marine radiocarbon age calibration, 0-26 cal kyr BP. Radiocarbon 46, 1059-1086.

Hughes, T.P. and Connell, J.H. 1999: Multiple stressors on coral reefs: a long term perspective. Limnology and Oceanography 44, 932-940.

Jacobson, G. and Hill, P.J. 1980: Hydrogeology of a raised coral atoll - Niue Island, South Pacific Ocean. Journal of Australian Geology and Geophysics 5, 271-278.

Kench, P.S. 1997: Contemporary sedimentation in the Cocos (Keeling) Islands, Indian Ocean: interpretation using settling velocity analysis. Sedimentary Geology 114, 109-130.

Kench, P.S. 1998a: Physical controls on development of lagoon sand deposits and lagoon infilling in an Indian ocean atoll. Journal Of Coastal Research 14, 1014-1024.

Kench, P.S. 1998b: Physical processes in an Indian Ocean atoll. Coral Reefs 17, 155-168.

Kench, P.S. and Brander, R.W. 2006: Wave processes on coral reef flats: Implications for reef geomorphology using Australian case studies. Journal Of Coastal Research 22, 209-223.

Kench, P.S., Brander, R.W., Parnell, K.E. and McLean, R.F. 2006: Wave energy gradients across a Maldivian atoll: Implications for island geomorphology. Geomorphology $81,1-17$.

Kench, P.S., Brander, R.W., Parnell, K.E. and O'Callaghan, J.M. 2009: Seasonal variations in wave characteristics around a coral reef island, South Maalhosmadulu atoll, Maldives. Marine Geology 262, 116-129.

Kench, P.S. and Cowell, P.J. 2000: Variations in sediment production and implications for atoll island stability under rising sea level. Internation Coral Reef Symposium, Bali, Indonesia, 1181-1186. 
Kench, P.S. and McLean, R.F. 1997: A comparison of settling and sieve techniques for the analysis of bioclastic sediments. Sedimentary Geology 109, 111-119.

Kench, P.S. and McLean, R.F. 2004: Hydrodynamics and sediment flux of hoa in an Indian Ocean atoll. Earth surface processes and landforms 29, 933-953.

Kench, P.S., McLean, R.F. and Nichol, S.L. 2005: New model of reef-island evolution: Maldives, Indian Ocean. Geology 33, 145-148.

Kennedy, D.M. and Woodroffe, C.D. 2002: Fringing reef growth and morphology: a review. Earth-Science Reviews 57, 255-277.

Kennedy, D.M. and Woodroffe, C.D. 2004: Carbonate sediments of Elizabeth and Middleton Reefs close to the southern limits of reef growth in the southwest Pacific. Australian Journal of Earth Sciences 51, 847-857.

Kirk, R.M. 1977: Rates and forms of erosion on intertidal platforms at Kaikoura Peninsula, South Island, New Zealand. New Zealand Journal Of Geology And Geophysics 20, 571-613.

Kotler, E., Martin, R.E. and Lidell, W.D. 1992: Experimental analysis of abrasion and dissolution of modern reef-dwelling foraminifera: implications for the preservation of biogenic carbonate. Palaios 7, 244-276.

Kreft, C.S. 1986: The Climate and Weather of Niue. New Zealand Meterological Service, Wellington, New Zealand, 24 pp.

Kvenvolden, K.A. 1965: Radiocarbon dating of size fractions of a sample of Bahama carbonate sediment. Journal of Sedimentary Petrology 34, 874-876.

Ladd, H.S., Ingerson, E., Townsend, R.C., Russel, M. and Stephenson, H.K. 1953: Drilling on Eniwetok Atoll, Marshall Islands. American Association of Petroleum Geologists Bulletin 37, 2251-2280.

Lighty, R.G. 1977: Relict shelf-edge Holocene coral: southeast coast of Florida. Proceedings of the Third International Coral Reef Symposium, Miami: Rosenstiel School of Marine and Atmospheric Sciences, University of Miami, 215-221.

Littler, M.M., Littler, D.S. and Titlyanov, E.A. 1991: Comparisons of N- and P-limited productivity between high granitic islands versus low carbonate atolls in the 
Seychelles Archipelago: a test of the relative-dominance paradigm. Coral Reefs 10, 199-209.

Liuvaie, S. 2005: Economic Vulnerability. PowerPoint Presentation to the Side Event at the Inter-Regional Small Island States (SIDS)/ BPoA+10 preparatory meeting, Mauritius: Economic Planning and Development Unit, Niue.

Loizeau, J.L., Arboutlle, D., Santiago, S. and Vernet, J.P. 1994: Evaluation of a wide range laser diffraction grain size analyser for use with sediments. Sedimentology 41, 353-361.

Macintyre, I.G. 1988: Modern coral reefs of Western Atlantic: new geological perspective. American Association of Petroleum Geologists Bulletin 72, 1360-1369.

Maiklem, W.R. 1968: Some hydraulic properties of bioclastic carbonate grains. Sedimentology 10, 101-109.

Marrack, E.C. 1989: Patterns of carbonate sediment production and distribution on patch reefs in San Salvador, Bahamas. Second Keck Research Symposium in Geology, Colorado.

Maxwell, W.G.H., Day, R.W. and Fleming, P.J.G. 1961: Carbonate sedimentation on the Heron Island Reef, Great Barrier Reef. Journal of Sedimentary Petrology 31, 215-230.

McCave, I.N., Bryant, R.J., Cook, H.F. and Coughanowr, C.A. 1986: Evaluation of a laserdiffraction-size analyzer for use with natural sediments. Journal Of Sedimentary Research 56, 561-564.

McIntyre, M. and Soulsby, J.A. 2004: Land Use and Land Degradation on Niue. In Murray, W.E. and Terry, J.P., editors, Niue Island: Geographical Perspectives on the Rock of Polynesia, Paris: Insula.

McKee, E.D., Chroni, J. and Leopold, E.B. 1959: Sedimentary belts in lagoon of Kapingamarangi Atoll. Bulletin American Association Petrolium Geologist 43, 501-562.

McLean, R.F., Stoddart, D.R., Hopley, D. and Polach, H. 1978: Sea-level change in Holocene on Northern Great-Barrier Reef. Philosophical Transactions of the Royal Society of London Series a-Mathematical Physical and Engineering Sciences 291, 167-\&. 
McLean, R.F. and Woodroffe, C.D. 1994: Coral Atolls. In Carter, R.W.G. and Woodroffe, C.D., editors, Coastal Evolution: Late quaternary shorelines morphodynamics: Cambridge University Press, 517 pp.

McManus, J. 1988: Grain size determination and interpretation. In Tucker, M., editor, Techniques in Sedimentology: Blackwell, Oxford, 63-85.

Montaggioni, L.F. 1988: Holocene reef growth history in mid-plate high volcanic islands., Proceedings Sixth International Coral Reef Symposium, Townsville: Sixth Coral Reef Symposium Executive Committee, 455-460.

Montaggioni, L.F. and Faure, G. 1997: Response of reef coral communities to sea-level rise: a Holocene model from Mauritius (Western Indian Ocean). Sedimentology 44, 1053-1070.

Montaggioni, L.F., Gabrie, C. and Naim, O. 1987: The seaward margin of Makatea, an uplifted carbonate island (Tuamotus, Central Pacific). Atoll Research Bulletin: The Smithsonian Instituion, Washington, D.C, 38 pp.

Moore, L.J. 2000: Shoreline Mapping Techniques. Journal Of Coastal Research 16, 111124.

Murray, J.W. 1973: Distribution and Ecology of Living Benthic Foraminiferids: Heinemann, London.

Neumann, A.C. and Macintyre, I.G. 1985: Reef response to sea level rise: Keep-up, catchup or give-up. Proceedings of the fifth International Coral Reef Symposium, Tahiti, 105-110.

Nunn, P.D. 1990: Coastal processes and landforms of Fiji- Their bearing on Holocene sealevel changes in the South Pacific. Journal Of Coastal Research 6, 279-310.

Nunn, P.D. 1993: Role of Porolithon Algal-Ridge Growth in the Development of the Windward Coast of Tongatapu Island, Tonga, South-Pacific. Earth surface processes and landforms 18, 427-439.

Nunn, P.D. 1998: Consequences of sea-level change during the Holocene in the Pacific Basin: Introduction. Journal Of Coastal Research 14, 1-2.

Nunn, P.D. 2004: Myths and the formation of Niue island, central South pacific. Journal Of Pacific History 39, 99-108. 
Nunn, P.D. and Britton, J.M.R. 2004: The long-term evolution of Niue Island. In Terry, J.P. and Murray, W.E., editors, Niue Island : geographical perspectives on the rock of Polynesia, Paris: Insula.

Orme, G.R. 1973: Aspects of sedimentation in the coral reef environment. In Jones, O.A. and Endean, R., editors, The Geology and Biology of Coral Reefs, 129-182.

Orme, G.R. 1977: Aspects of sedimentation in the coral reef environment. In Jones, O.A. and Endean, R., editors, The Geology and Biology of Coral Reefs, 129-182.

Perry, C.T. 1996: The rapid response of reef sediments to changes in community composition: Implications for time averaging and sediment accumulation. Journal Of Sedimentary Research 66, 459-467.

Prasad, R. 1990: Cyclone Ofa. Tropical Cyclone Report 90/4: Fiji Meteorological Service (Nadi), 13 pp.

Pyokari, M. 1997: The provenance of beach sediments on Rhodes, southeastern Greece, indicated by sediment texture, composition and roundness. Geomorphology 18, 315-332.

Pyokari, M. 1999: Beach sediments of Crete: Texture, composition, roundness, source and transport. Journal Of Coastal Research 15, 537-553.

Quick, M.C. 1991: Onshore offshore sediment transport on beaches. Coastal Engineering $15,313-332$.

Rasbury, M. and Aharon, P. 2006: ENSO-controlled rainfall variability records archived in tropical stalagmites from the mid-ocean island of Niue, South Pacific. Geochemistry Geophysics Geosystems 7, 15 pp.

Roberts, H.H., Murray, S.P. and Suhayda, J.N. 1975: Physical processes in a fringing reef system. Journal of Marine Research 33, 233-260.

Rodriguez, J.G. and Uriarte, A. 2009: Laser diffraction and dry-sieving grain size analyses undetaken on fine- and medium-grained sandy marine sediments: A note Journal Of Coastal Research 25, 257-264.

Roy, K.J. 1970: Sedimentation and reef development inturbid-water areas of Fanning Lagoon. Bulletin American Association Petrolium Geologist 54, 867 pp. 
Samosorn, B. and Woodroffe, C.D. 2008: Nearshore wave environments around a sandy cay on a platform reef, Torres Strait, Australia. Continental Shelf Research 28, 2257-2274.

Schiller, C. 1992: Assessment of the status of the coconut crab Birgus latro on Niue Island. A report for the FAO: www.fao.org/docrep/field/003/AC281E/AC281E00.htm.

Schofield, J.C. 1959: The Geology and Hydrology of Niue Island, South Pacific. New Zealand Geological Survey Bulletin, $28 \mathrm{pp}$.

Scoffin, T.P. 1987: An Introduction to Carbonate Sediments and Rocks. Blackie, London, $274 \mathrm{pp}$.

Scoffin, T.P. 1992: Taphonomy of coral reefs: a review. Coral Reefs 11, 57-77.

Scoffin, T.P. 1993: The geological effecs of hurricanes on coral-reefs and the interpretation of storm deposits. Coral Reefs 12, 203-221.

Scoffin, T.P., Stoddart, D.R. and Rosen, B.R. 1978: The Nature and Significance of Microatolls. Philosophical Transactions of the Royal Society of London. Series B, Biological Sciences 284, 99-122.

Scott, G.A. and Rotondo, G.M. 1983: A Model to Explain the Differences Between Pacific Plate Island-Atoll Types. Coral Reefs 1, 139-150.

Sheppard, C., Dixon, D.J., Gourlay, M., Sheppard, A. and Payet, R. 2005: Coral mortality increases wave energy reaching shores protected by reef flats: Examples from the Seychelles. Estuarine Coastal and Shelf Science 64, 223-234.

Smith, M.J. and Cromley, R.G. 2006: Coastal Survey Maps: From Historical Documents to Digital Databases. UCCGIA Papers and Proceedings No.1. Storrs. University of Connecticut Center for Geographic Information and Analysis and MAGIC.

Smithers, S.G. 1994: Sediment facies of the Cocos (Keeling) Islands Lagoon. Atoll Research Bulletin 407, Washington D.C: National Museum of Natural History, Smithsonian Institution, $35 \mathrm{pp}$.

Smithers, S.G. and Woodroffe, C.D. 2000: Microatolls as sea-level indicators on a midocean atoll. Marine Geology 168, 61-78. 
Smithers, S.G. and Woodroffe, C.D. 2001: Coral microatolls and 20th century sea level in the eastern Indian Ocean. Earth and Planetary Science Letters 191, 173-184.

Solohub, J.T. and Klovan, J.E. 1970: Evaluation of grain-size parameters in lacustrin environments. Journal of Sedimentary Petrology 40, 81 pp.

Solomon, S.M. and Forbes, D.L. 1999: Coastal hazards and associated management issues on South Pacific Islands. Ocean \& Coastal Management 42, 523-554.

Som, S.K., Shivgotra, V. and Saha, A. 2009: Coral microatoll as geodetic tool in North Andaman and Little Andaman, India. Journal of Earth System Science 118, 157162.

SOPAC 2004: Reducing Vulnerability of Pacific ACP States. Niue- Country Mission Report. 12 pp.

SOPAC 2006: Reducing vulnerability of Pacific ACP states. Pacific Islands Applied Geoscience Commission.

SOPAC 2007: Inventory of Geospatial data available and options for Tsunami inundation and Risk Modelling. SOPAC Miscellaneous Report 652. 57 pp.

SOPAC 2008: Country Profile of Niue.

Soulsby, J.A. 2004: The soils of Niue. In Terry, J.P. and Murray, W.E., editors, Niue Island : geographical perspectives on the rock of Polynesia, Paris: Insula.

Spencer, T. 1992: Bioerosion and biogeomorphology. In John, D.M., Hawkins, S.J. and Price, J.H., editors, Plant-Animal Interactions in the Marine Benthos., Oxford: Clarendon Press, 493-509.

Spencer, T. and Paulay, G. 1989: Geology and Geomorphology of Henderson Island. Atoll Research Bulletin, Washington D.C: National Museum of Natural History, Smithsonian Institution, $51 \mathrm{pp}$.

Spencer, T. and Viles, H. 2002: Bioconstruction, bioerosion and disturbance on tropical coasts:coral reefs and rocky limestone shores. Geomorphology 48, 23-50. 
Stafford, D.B. 1971: An Aerial Photographic Technique for Beach Erosion Surveys in North Carolina. U.S. Army Corps of Engineers, Coastal Engineering Research Center, Technical Memorandum, 115 pp.

Stearn, C.W., Scoffin, T.P. and Martindale, W. 1977: Calcium carbonate budget of a fringing reef on the west coast of Barbados. Bulletin of Marine Science 27, 479510.

Stephenson, W.J. and Kirk, R.M. 2000a: Development of shore platforms on Kaikoura Peninsula, South Island, New Zealand. Part 1: The role of waves.

Geomorphology 32, 21-41.

Stoddart, D.R. 1985: Hurricane effects on coral reefs: conclusions., Proceedings of the Fifth International Coral Reef Congress, Antenne Museum-Ephe. Moorea, French Polynesia, 349-350.

Stoddart, D.R., McLean, R.F., Scoffin, T.P., Thom, B.G. and Hopley, D. 1978: Evolution on Reefs and Islands, Northern Great Barrier Reef- Sythesis and Interpretation Philosophical Transactions of the Royal Society of London Series B-Biological Sciences 284, 149-159.

Stuiver, M. and Polach, H.A. 1977: Discussion: reporting of 14C data. Radiocarbon 19, 355-363.

Talagi-Hekesi, I. 2005: Building Resilience Niue. PowerPoint Presentation to the Side Event at the Inter-Regional Small Island States (SIDS) preparatory meeting, Mauritius: Niue Tourism Office, Niue.

Terry, J.P. 2004: Geomorphic features of Niue Island: Chasm, caves and other karst varieties. In Terry, J.P. and Murray, W.E., editors, Niue Island : geographical perspectives on the rock of Polynesia, Paris: Insula, 75-88.

Terry, J.P. 2007: Tropical Cyclones: Climatology and Impacts in the South Pacific Springer, New York.

Terry, J.P. and Nunn, P.D. 2003: Interpreting features of carbonate geomorphology on Niue Island, a raised coral atoll. Zeitschrift fur Geomorphologie 131, 43-57.

Thieler, E.R. and Danforth, W.W. 1994: Historical Shoreline Mapping (I): Improving Techniques and Reducing Positioning Errors. Journal Of Coastal Research 10, 549-563. 
Thorp, E.M. 1936: The sediments of the Pearl and Hermes Reef. Journal of Sedimentary Petrology 6, 109-118.

Tongatule, S. 2005: Environment Recovery. Niue PowerPoint Presentation to the Side Event at the Inter-Regional Small Island States (SIDS)/ BPoA+10 preparatory meeting, Mauritius: Department of Environment, Niue.

Tracey, J.I.J., Ladd, H.S. and Hoffmeister, J.E. 1948: Reefs of Bikini, Marshall Islands. Geological Society of America Bulletin 59, 861-878.

Trenhaile, A.S. 2004: Modeling the accumulation and dynamics of beaches on shore platforms. Marine Geology 206, 55-72.

Trenhaile, A.S. 2005: Modelling the effect of waves, weathering and beach development on shore platform development. Earth surface processes and landforms 30, 613-634.

Walkden, M. and Dickson, M. 2008: Equilibrium erosion of soft rock shores with a shallow or absent beach under increased sea level rise. Marine Geology 251, 75-84.

Weber, J.N. and Woodhead, P.M.J. 1972: Carbonate lagoon and sediments of Tarawa atoll, Gilbert Islands. Atoll Research Bulletin 157.

Wheeler, C. and Aharon, P. 1997: Geology and Hydrogeology of Niue. In Vacher, H.L. and Quinn, T., editors, Geology and Hydrogeology of Carbonate Islands: Elsevier Science B.V, 537-564.

Wolanski, E. 1994: Physical Oceanographic Processes of the Great Barrier Reef. Boca Raton: CRC Press.

Woodroffe, C. 1994: Sea-level. Progress in Physical Geography 18, 436-451.

Woodroffe, C.D. 2002: Coasts : form, process, and evolution: New York : Cambridge University Press.

Woodroffe, C.D. 2008: Reef-island topography and the vulnerability of atolls to sea-level rise. Global And Planetary Change 62, 77-96.

Woodroffe, C.D., McLean, R.F., Smithers, S.G. and Lawson, E.M. 1999: Atoll reef-island formation and response to sea-level change: West Island, Cocos (Keeling) Islands. Marine Geology 160, 85-104. 
Woodroffe, C.D. and Morrison, R.J. 2001: Reef-island accretion and soil development on Makin, Kiribati, central Pacific. Catena 44, 245-261.

Woodroffe, C.D., Samosorn, B., Hua, Q. and Hart, D.E. 2007: Incremental accretion of a sandy reef island over the past 3000 years indicated by component-specific radiocarbon dating. Geophysical Research Letters 34.

Woodroffe, C.D., Short, S.A., Stoddart, D.R., Spencer, T. and Harmon, R.S. 1991: Stratigraphy And Chronology Of Late Pleistocene Reefs In The Southern-CookIslands, South-Pacific. Quaternary Research 35, 246-263.

Woodroffe, C.D., Stoddart, D.R., Spencer, T., Scoffin, T.P. and Tudhope, A.W. 1990: Holocene Emergence In The Cook Islands, South-Pacific. Coral Reefs 9, 31-39.

Wright, A.C.S. and Westerndorp, F.J.v. 1965: Soils and agriculture of Niue Island. Soil Bureau Bulletin 17: New Zealand Department of Scientific and Industrial Research (Wellington), $80 \mathrm{pp}$.

Wright, L.D. and Thom, B.G. 1977: Coastal depositional landforms: a morphodynamic approach. Progress in Physical Geography 1, 412-459.

Yamano, H., Miyajima, T. and Koike, I. 2000: Importance of foraminifera for the formation and maintenance of a coral sand cay: Green Island, Australia. Coral Reefs 19, 5158.

Yonekura, N., Ishii, T., Saito, Y., Maeda, Y., Matsushima, Y., Matsumoto, E. and Kayanne, H. 1988: Holocene Fringing Reefs And Sea-Level Change In Mangaia-Island, Southern Cook-Islands. Palaeogeography Palaeoclimatology Palaeoecology 68, 177-188. 
APPENDIX 1: Grain size results 


\section{Grain size analysis:}

\begin{tabular}{|c|c|c|c|c|c|c|c|c|c|c|c|c|c|c|c|c|c|c|c|c|c|c|c|c|c|c|c|c|}
\hline \multirow[b]{2}{*}{ Sample } & \multicolumn{2}{|c|}{ Sample sieving (\%) } & \multicolumn{23}{|c|}{ Grain size: \% frequency } & \multicolumn{3}{|c|}{ Sediment texture (phi) } \\
\hline & Sand & Gravel & -0.9 & -0.7 & -0.6 & -0.5 & -0.3 & -0.2 & -0.1 & 0.1 & 0.2 & 0.3 & 0.5 & 0.6 & 0.7 & 0.9 & 1.0 & 1.2 & 1.3 & 1.4 & 1.6 & 1.7 & 1.8 & 2.0 & 2.1 & Mean & $\begin{array}{l}\text { Std } \\
\text { dev }\end{array}$ & Skew \\
\hline Tama/1 & 72.4 & 27.6 & 3.9 & 4.3 & 4.8 & 5.4 & 6.1 & 6.6 & 6.9 & 6.9 & 6.5 & 5.7 & 4.7 & 3.6 & 2.6 & 1.7 & 1.0 & 0.6 & 0.3 & 0.2 & 0.1 & 0.1 & 0.1 & 0.1 & 0.0 & -0.4 & 0.6 & 0.1 \\
\hline Tama/2 & 52.5 & 47.6 & 3.4 & 3.7 & 4.0 & 4.3 & 4.6 & 4.8 & 4.9 & 4.7 & 4.3 & 3.7 & 3.0 & 2.3 & 1.7 & 1.1 & 0.7 & 0.4 & 0.2 & 0.1 & 0.1 & 0.1 & 0.0 & 0.0 & 0.0 & -0.6 & 0.6 & 1.1 \\
\hline Tama/3 & 88.2 & 11.8 & \multicolumn{23}{|c|}{ N/A- Limited sand sized fraction } & \multicolumn{3}{|c|}{$\mathrm{N} / \mathrm{A}$} \\
\hline Tama/4 & 38.0 & 62.0 & 2.0 & 2.2 & 2.4 & 2.5 & 2.8 & 2.9 & 3.1 & 3.1 & 3.0 & 2.8 & 2.5 & 2.1 & 1.8 & 1.4 & 1.1 & 0.8 & 0.6 & 0.4 & 0.2 & 0.1 & 0.1 & 0.1 & 0.0 & -0.7 & 0.6 & 1.5 \\
\hline Tama/5 & 78.2 & 21.8 & 3.6 & 4.1 & 4.7 & 5.4 & 6.2 & 6.9 & 7.5 & 7.6 & 7.4 & 6.7 & 5.7 & 4.5 & 3.2 & 2.1 & 1.3 & 0.6 & 0.3 & 0.1 & 0.1 & 0.1 & 0.1 & 0.1 & 0.1 & -0.3 & 0.7 & -0.1 \\
\hline Tama/6 & 40.1 & 59.9 & 4.2 & 4.4 & 4.4 & 4.5 & 4.4 & 4.2 & 3.8 & 3.3 & 2.6 & 1.9 & 1.2 & 0.7 & 0.3 & 0.1 & 0.0 & 0.0 & 0.0 & 0.0 & 0.0 & 0.0 & 0.0 & 0.0 & 0.0 & -0.9 & 0.3 & 1.0 \\
\hline Tama/7 & 70.2 & 29.8 & 3.3 & 3.9 & 4.4 & 5.2 & 6.0 & 6.7 & 7.2 & 7.2 & 6.8 & 5.9 & 4.8 & 3.5 & 2.3 & 1.3 & 0.7 & 0.3 & 0.1 & 0.1 & 0.1 & 0.1 & 0.1 & 0.1 & 0.0 & -0.4 & 0.6 & 0.1 \\
\hline Tama/8 & 0.0 & 100.0 & \multicolumn{23}{|c|}{ N/A- Limited sand sized fraction } & \multicolumn{3}{|c|}{ N/A } \\
\hline Ava/1 & 49.2 & 50.8 & 1.5 & 1.8 & 2.2 & 2.6 & 3.2 & 3.7 & 4.1 & 4.3 & 4.4 & 4.2 & 3.9 & 3.4 & 2.8 & 2.3 & 1.7 & 1.2 & 0.8 & 0.5 & 0.3 & 0.1 & 0.1 & 0.1 & 0.0 & -0.6 & 0.7 & 1.8 \\
\hline Ava/2 & 0.0 & 100.0 & \multicolumn{23}{|c|}{ N/A- Limited sand sized fraction } & \multicolumn{3}{|c|}{ N/A } \\
\hline Ava/3 & 0.0 & 100.0 & \multicolumn{23}{|c|}{ N/A- Limited sand sized fraction } & \multicolumn{3}{|c|}{ N/A } \\
\hline Pofi/1 & 45.0 & 55.0 & 2.9 & 3.3 & 3.7 & 4.1 & 4.6 & 4.9 & 5.0 & 4.9 & 4.5 & 3.8 & 3.1 & 2.4 & 1.7 & 1.2 & 0.8 & 0.6 & 0.4 & 0.3 & 0.2 & 0.1 & 0.1 & 0.1 & 0.0 & -0.7 & 0.6 & 1.6 \\
\hline Pofi $/ 2$ & 0.0 & 100.0 & \multicolumn{23}{|c|}{ N/A- Limited sand sized fraction } & \multicolumn{3}{|c|}{ N/A } \\
\hline Pofi $/ 3$ & 0.0 & 100.0 & \multicolumn{23}{|c|}{ N/A- Limited sand sized fraction } & \multicolumn{3}{|c|}{$\mathrm{N} / \mathrm{A}$} \\
\hline Utu/1 & 82.5 & 17.5 & 0.0 & 4.7 & 4.5 & 0.0 & 2.1 & 5.2 & 6.1 & 6.9 & 8.2 & 8.4 & 7.8 & 7.2 & 6.2 & 4.9 & 3.6 & 2.6 & 1.7 & 1.0 & 0.6 & 0.3 & 0.2 & 0.2 & 0.1 & -0.1 & 0.8 & -0.7 \\
\hline Utu/2 & 75.8 & 24.2 & 2.7 & 4.3 & 2.7 & 0.9 & 2.5 & 5.9 & 6.4 & 6.7 & 7.7 & 7.4 & 6.4 & 5.6 & 4.7 & 3.6 & 2.7 & 1.9 & 1.4 & 0.9 & 0.5 & 0.3 & 0.2 & 0.2 & 0.1 & -0.2 & 0.8 & -0.3 \\
\hline Utu/3 & 53.8 & 46.2 & 2.5 & 2.8 & 3.1 & 3.4 & 3.9 & 4.3 & 4.6 & 4.7 & 4.6 & 4.3 & 3.9 & 3.3 & 2.6 & 2.0 & 1.4 & 1.0 & 0.6 & 0.3 & 0.2 & 0.1 & 0.1 & 0.0 & 0.0 & -0.5 & 0.6 & 1.1 \\
\hline Utu/4 & 52.8 & 47.2 & 2.9 & 3.3 & 3.7 & 4.1 & 4.6 & 4.9 & 5.0 & 4.9 & 4.5 & 3.8 & 3.1 & 2.4 & 1.7 & 1.2 & 0.8 & 0.6 & 0.4 & 0.3 & 0.2 & 0.1 & 0.1 & 0.1 & 0.0 & -0.6 & 0.6 & 1.1 \\
\hline AlofW & 0.0 & 100.0 & \multicolumn{23}{|c|}{ N/A- Limited sand sized fraction } & \multicolumn{3}{|c|}{$\mathrm{N} / \mathrm{A}$} \\
\hline $\mathrm{Hio} / 1$ & 49.5 & 50.5 & 3.2 & 3.1 & 2.5 & 2.4 & 3.8 & 5.2 & 5.0 & 4.6 & 4.4 & 3.7 & 2.9 & 2.3 & 1.8 & 1.4 & 1.0 & 0.7 & 0.5 & 0.3 & 0.2 & 0.1 & 0.1 & 0.1 & 0.1 & -0.7 & 0.6 & 1.5 \\
\hline $\mathrm{Hio} / 2$ & 93.8 & 6.2 & 0.6 & 1.2 & 2.1 & 3.2 & 4.6 & 6.0 & 7.3 & 8.2 & 8.7 & 8.7 & 8.2 & 7.4 & 6.4 & 5.3 & 4.2 & 3.3 & 2.5 & 1.8 & 1.3 & 0.9 & 0.6 & 0.4 & 0.2 & 0.2 & 0.7 & -0.1 \\
\hline $\mathrm{Hio} / 3$ & 56.9 & 43.1 & 3.5 & 3.9 & 4.4 & 5.1 & 5.8 & 6.4 & 6.6 & 6.2 & 5.4 & 4.2 & 2.8 & 1.6 & 0.8 & 0.2 & 0.0 & 0.0 & 0.0 & 0.0 & 0.0 & 0.0 & 0.0 & 0.0 & 0.0 & -0.6 & 0.5 & 0.7 \\
\hline $\mathrm{Hio} / 4$ & 40.4 & 59.6 & 5.0 & 4.3 & 2.6 & 2.0 & 3.7 & 5.3 & 4.5 & 3.4 & 2.7 & 1.7 & 1.0 & 0.8 & 0.7 & 0.5 & 0.4 & 0.4 & 0.3 & 0.2 & 0.2 & 0.1 & 0.1 & 0.1 & 0.1 & -0.8 & 0.5 & 1.3 \\
\hline Tua/1 & 33.5 & 66.5 & 2.5 & 1.8 & 1.3 & 1.9 & 3.3 & 4.5 & 4.4 & 3.9 & 3.3 & 2.5 & 1.6 & 1.0 & 0.6 & 0.3 & 0.2 & 0.1 & 0.1 & 0.1 & 0.0 & 0.0 & 0.0 & 0.0 & 0.0 & -0.8 & 0.5 & 1.3 \\
\hline Tua/2 & 47.6 & 52.4 & 1.7 & 2.1 & 1.8 & 1.7 & 3.1 & 4.7 & 4.8 & 4.5 & 4.2 & 3.6 & 2.9 & 2.3 & 1.9 & 1.6 & 1.3 & 1.1 & 0.9 & 0.7 & 0.5 & 0.4 & 0.3 & 0.3 & 0.2 & -0.6 & 0.7 & 1.6 \\
\hline Tua/3 & 80.4 & 19.6 & 3.1 & 3.8 & 4.7 & 5.8 & 7.2 & 8.4 & 9.2 & 9.3 & 8.7 & 7.4 & 5.6 & 3.8 & 2.1 & 0.9 & 0.2 & 0.0 & 0.0 & 0.0 & 0.0 & 0.0 & 0.0 & 0.0 & 0.0 & -0.3 & 0.6 & -0.3 \\
\hline Tua/4 & 92.9 & 7.1 & 0.1 & 0.8 & 2.1 & 3.7 & 5.7 & 7.7 & 9.6 & 10.9 & 11.4 & 10.8 & 9.4 & 7.4 & 5.3 & 3.4 & 1.9 & 0.9 & 0.4 & 0.3 & 0.2 & 0.2 & 0.2 & 0.2 & 0.1 & 0.1 & 0.5 & -0.2 \\
\hline Tua/5 & 0.0 & 100.0 & & & & & & & & & & mited s & nd siz & ed frac & & & & & & & & & & & & & V/A & \\
\hline Tala/1 & 0.0 & 100.0 & & & & & & & & & $\mathrm{~N} / \mathrm{A}-\mathrm{L}$ & miteds & nd siz & ed frac & tion & & & & & & & & & & & & V/A & \\
\hline Tala/2 & 74.2 & 25.8 & 1.4 & 1.8 & 2.3 & 3.0 & 3.9 & 4.7 & 5.6 & 6.2 & 6.6 & 6.7 & 6.5 & 5.9 & 5.1 & 4.1 & 3.2 & 2.3 & 1.5 & 1.0 & 0.6 & 0.4 & 0.3 & 0.2 & 0.2 & -0.1 & 0.8 & -0.3 \\
\hline
\end{tabular}




\begin{tabular}{|c|c|c|c|c|c|c|c|c|c|c|c|c|c|c|c|c|c|c|c|c|c|c|c|c|c|c|c|c|}
\hline Alof/1 & 37.9 & 62.1 & 2.6 & 3.0 & 3.3 & 3.6 & 4.0 & 4.2 & 4.2 & 3.9 & 3.3 & 2.5 & 1.7 & 1.0 & 0.5 & 0.1 & 0.0 & 0.0 & 0.0 & 0.0 & 0.0 & 0.0 & 0.0 & 0.0 & 0.0 & -0.8 & 0.4 & 1.3 \\
\hline \multirow[b]{2}{*}{ Sample } & \multicolumn{2}{|c|}{ Sample sieving (\%) } & \multicolumn{23}{|c|}{ Grain size: \% frequency } & \multicolumn{3}{|c|}{ Sediment texture (phi) } \\
\hline & Sand & Gravel & -0.9 & -0.7 & -0.6 & -0.5 & -0.3 & -0.2 & -0.1 & 0.1 & 0.2 & 0.3 & 0.5 & 0.6 & 0.7 & 0.9 & 1.0 & 1.2 & 1.3 & 1.4 & 1.6 & 1.7 & 1.8 & 2.0 & 2.1 & Mean & $\begin{array}{l}\text { Std } \\
\text { dev }\end{array}$ & Skew \\
\hline Vai/1 & 61.7 & 38.3 & 3.3 & 3.8 & 4.3 & 4.9 & 5.6 & 6.0 & 6.2 & 6.0 & 5.4 & 4.6 & 3.6 & 2.6 & 1.8 & 1.2 & 0.7 & 0.4 & 0.3 & 0.2 & 0.1 & 0.1 & 0.1 & 0.0 & 0.0 & -0.5 & 0.6 & 0.5 \\
\hline Nama/1 & 24.7 & 75.3 & \multicolumn{23}{|c|}{ N/A- Limited sand sized fraction } & \multicolumn{3}{|c|}{ N/A } \\
\hline
\end{tabular}

\begin{tabular}{|c|c|c|c|c|c|c|c|c|c|c|c|c|c|c|c|c|c|c|c|c|c|c|c|c|c|c|c|c|}
\hline Ulu/1 & 29.6 & 70.4 & 1.4 & 1.6 & 1.8 & 2.0 & 2.3 & 2.5 & 2.6 & 2.6 & 2.5 & 2.2 & 1.9 & 1.5 & 1.2 & 0.9 & 0.7 & 0.5 & 0.4 & 0.3 & 0.2 & 0.1 & 0.1 & 0.1 & 0.1 & -0.8 & 0.5 & 1.3 \\
\hline Tuo/1 & 87.9 & 12.1 & 0.5 & 0.7 & 1.0 & 1.4 & 2.0 & 2.6 & 3.4 & 4.2 & 5.1 & 6.0 & 6.8 & 7.5 & 7.8 & 7.8 & 7.4 & 6.6 & 5.5 & 4.2 & 2.9 & 1.9 & 1.1 & 0.5 & 0.2 & 0.4 & 0.8 & -0.5 \\
\hline
\end{tabular}

\begin{tabular}{|c|c|c|c|c|c|c|c|c|c|c|c|c|c|c|c|c|c|c|c|c|c|c|c|c|c|c|c|c|}
\hline Taut/1 & 68.2 & 31.8 & 2.3 & 2.6 & 3.0 & 3.5 & 4.0 & 4.6 & 5.1 & 5.4 & 5.5 & 5.4 & 5.1 & 4.6 & 4.0 & 3.4 & 2.7 & 2.1 & 1.5 & 1.1 & 0.7 & 0.4 & 0.3 & 0.2 & 0.1 & -0.2 & 0.8 & 0.2 \\
\hline Taut/3 & 73.5 & 26.5 & 2.9 & 3.3 & 3.8 & 4.5 & 5.2 & 5.9 & 6.4 & 6.6 & 6.5 & 6.0 & 5.3 & 4.4 & 3.5 & 2.6 & 1.9 & 1.4 & 1.0 & 0.7 & 0.4 & 0.3 & 0.2 & 0.2 & 0.1 & -0.3 & 0.7 & 0.0 \\
\hline Taut/4 & 58.6 & 41.4 & 2.7 & 3.0 & 3.3 & 3.6 & 4.0 & 4.4 & 4.6 & 4.7 & 4.6 & 4.3 & 3.9 & 3.4 & 2.9 & 2.4 & 1.9 & 1.5 & 1.1 & 0.8 & 0.5 & 0.3 & 0.2 & 0.1 & 0.1 & -0.4 & 0.7 & 0.8 \\
\hline Taut/5 & 51.8 & 48.3 & 2.5 & 2.8 & 2.9 & 3.2 & 3.5 & 3.7 & 3.9 & 3.9 & 3.8 & 3.6 & 3.3 & 3.0 & 2.6 & 2.2 & 1.8 & 1.4 & 1.1 & 0.8 & 0.6 & 0.4 & 0.2 & 0.1 & 0.1 & -0.5 & 0.7 & 1.4 \\
\hline Taut/6 & 90.0 & 10.0 & 1.1 & 1.5 & 2.0 & 2.6 & 3.4 & 4.3 & 5.1 & 5.9 & 6.6 & 7.0 & 7.2 & 7.2 & 6.8 & 6.2 & 5.5 & 4.6 & 3.7 & 2.8 & 2.0 & 1.4 & 0.9 & 0.6 & 0.4 & 0.3 & 0.8 & -0.2 \\
\hline Lake/1 & 48.1 & 51.9 & 4.0 & 4.2 & 4.3 & 4.5 & 4.6 & 4.6 & 4.4 & 4.0 & 3.5 & 2.9 & 2.3 & 1.6 & 1.1 & 0.7 & 0.5 & 0.3 & 0.2 & 0.1 & 0.1 & 0.1 & 0.0 & 0.0 & 0.0 & -0.7 & 0.5 & 1.3 \\
\hline Lake/2 & 56.2 & 43.8 & 3.5 & 3.8 & 4.0 & 4.3 & 4.7 & 4.9 & 4.9 & 4.8 & 4.4 & 3.9 & 3.3 & 2.6 & 2.0 & 1.5 & 1.1 & 0.8 & 0.5 & 0.3 & 0.2 & 0.1 & 0.1 & 0.1 & 0.0 & -0.5 & 0.6 & 0.9 \\
\hline Lake/3 & 59.4 & 40.6 & 5.0 & 5.4 & 5.7 & 6.0 & 6.3 & 6.3 & 6.1 & 5.5 & 4.6 & 3.5 & 2.5 & 1.5 & 0.8 & 0.3 & 0.1 & 0.0 & 0.0 & 0.0 & 0.0 & 0.0 & 0.0 & 0.0 & 0.0 & -0.6 & 0.5 & 0.7 \\
\hline Lake/4 & 86.1 & 13.9 & 0.8 & 1.3 & 2.0 & 2.8 & 3.8 & 4.9 & 5.9 & 6.7 & 7.2 & 7.4 & 7.1 & 6.6 & 5.9 & 5.0 & 4.1 & 3.3 & 2.5 & 1.9 & 1.5 & 1.1 & 0.9 & 0.7 & 0.6 & 0.2 & 0.8 & -0.2 \\
\hline Lake/5 & 31.0 & 69.0 & 1.1 & 1.3 & 1.5 & 1.7 & 2.0 & 2.2 & 2.4 & 2.5 & 2.5 & 2.4 & 2.3 & 2.0 & 1.7 & 1.4 & 1.1 & 0.9 & 0.6 & 0.4 & 0.3 & 0.2 & 0.1 & 0.1 & 0.1 & -0.7 & 0.6 & 1.4 \\
\hline Lake/6 & 0.0 & 100.0 & \multicolumn{23}{|c|}{ N/A- Limited sand sized fraction } & \multicolumn{3}{|c|}{ N/A } \\
\hline Lake/7 & 0.0 & 100.0 & \multicolumn{23}{|c|}{ N/A- Limited sand sized fraction } & \multicolumn{3}{|c|}{ N/A } \\
\hline
\end{tabular}

\begin{tabular}{|c|c|c|c|c|c|c|c|c|c|c|c|c|c|c|c|c|c|c|c|c|c|c|c|c|c|c|c|c|}
\hline Togo/1 & 64.9 & 35.1 & 1.1 & 1.5 & 2.0 & 2.6 & 3.3 & 4.0 & 4.5 & 4.8 & 4.9 & 4.9 & 4.7 & 4.4 & 4.1 & 3.7 & 3.2 & 2.7 & 2.1 & 1.6 & 1.2 & 0.8 & 0.6 & 0.4 & 0.3 & -0.2 & 0.9 & 0.3 \\
\hline Togo/2 & 97.3 & 2.7 & 0.0 & 0.1 & 0.4 & 0.9 & 1.5 & 2.3 & 3.2 & 4.1 & 5.0 & 6.0 & 6.8 & 7.5 & 8.0 & 8.1 & 7.9 & 7.3 & 6.5 & 5.5 & 4.4 & 3.4 & 2.5 & 1.8 & 1.2 & 0.8 & 0.7 & 0.0 \\
\hline
\end{tabular}


APPENDIX 2: Sediment Composition 
Surficial sediment composition (\%): sand sized fraction ( $\leq-0.5 \Phi)$

\begin{tabular}{|c|c|c|c|c|c|c|c|c|c|c|c|}
\hline Location & Sample & Coral & Coralline Algae & Mollusc & Halimeda & Echinoid & Misc./ Micrite & Amphistegina sp. & Baculogypsina sp. & Marginopora sp. & Foram Total \\
\hline \multirow{14}{*}{ SW Coast } & Tama/1 & 55.5 & 21.5 & 7.3 & 10.0 & 1.0 & 1.5 & 2.5 & 0.5 & 0.3 & 3.3 \\
\hline & Tama/2 & 48.3 & 22.5 & 12.8 & 9.3 & 0.5 & 0.3 & 6.5 & 0.0 & 0.0 & 6.5 \\
\hline & Tama/3 & 52.8 & 20.5 & 13.3 & 6.0 & 1.3 & 1.8 & 4.5 & 0.0 & 0.0 & 4.5 \\
\hline & Tama/4 & 48.3 & 17.5 & 17.3 & 8.5 & 1.3 & 0.0 & 6.3 & 0.0 & 1.0 & 7.3 \\
\hline & Tama/5 & 52.8 & 18.8 & 14.5 & 6.8 & 1.8 & 1.0 & 4.5 & 0.0 & 0.0 & 4.5 \\
\hline & Tama/6 & 47.8 & 21.8 & 19.0 & 2.8 & 0.5 & 0.3 & 6.5 & 1.5 & 0.0 & 8.0 \\
\hline & Tama/7 & 43.5 & 18.8 & 18.8 & 7.5 & 0.3 & 0.3 & 9.0 & 1.3 & 0.8 & 11.0 \\
\hline & Tama/8 & 54.0 & 20.0 & 15.0 & 5.0 & 1.0 & 0.0 & - & - & - & 5.0 \\
\hline & Ava/1 & 64.4 & 17.1 & 7.1 & 6.8 & 1.5 & 0.3 & 2.1 & 0.9 & 0.0 & 3.0 \\
\hline & Ava/2 & 98.0 & 1.0 & 1.0 & 0.0 & 0.0 & 0.0 & - & - & - & 0.0 \\
\hline & Ava/3 & 82.0 & 10.0 & 5.0 & 0.5 & 1.0 & 0.0 & - & - & - & 0.0 \\
\hline & Pofi/1 & 51.5 & 15.3 & 16.5 & 4.7 & 1.2 & 0.3 & 7.6 & 2.4 & 0.6 & 10.6 \\
\hline & Pofi/2 & 52.5 & 16.5 & 20.5 & 3.0 & 2.0 & 0.0 & - & - & - & 5.5 \\
\hline & Pofi/3 & 57.0 & 17.0 & 16.0 & 2.5 & 3.0 & 0.0 & - & - & - & 4.5 \\
\hline
\end{tabular}

\begin{tabular}{|c|c|c|c|c|c|c|c|c|c|c|c|}
\hline \multirow[t]{5}{*}{ W Coast } & Utu/1 & 55.4 & 26.8 & 5.6 & 9.5 & 0.5 & 0.0 & 2.2 & 0.0 & 0.0 & 2.2 \\
\hline & Utu/2 & 59.5 & 22.0 & 8.3 & 6.6 & 1.0 & 0.0 & 2.7 & 0.0 & 0.0 & 2.7 \\
\hline & Utu/3 & 52.6 & 25.8 & 11.3 & 6.3 & 0.3 & 0.3 & 2.9 & 0.5 & 0.0 & 3.4 \\
\hline & Utu/4 & 50.7 & 25.4 & 11.5 & 6.2 & 1.7 & 0.3 & 0.8 & 3.4 & 0.0 & 4.2 \\
\hline & Alofw & 75.0 & 10.0 & 6.0 & 6.0 & 1.0 & 0.0 & - & - & - & 0.0 \\
\hline
\end{tabular}

\begin{tabular}{|c|c|c|c|c|c|c|c|c|c|c|c|}
\hline \multirow[t]{11}{*}{ NW Coast } & Hio/1 & 38.8 & 40.5 & 7.5 & 1.8 & 1.0 & 2.0 & 4.5 & 4.0 & 0.0 & 8.5 \\
\hline & $\mathrm{Hio} / 2$ & 31.0 & 30.0 & 8.0 & 6.8 & 1.0 & 1.5 & 10.8 & 9.5 & 1.5 & 21.8 \\
\hline & $\mathrm{Hio} / 3$ & 16.0 & 17.8 & 7.5 & 4.5 & 1.3 & 0.0 & 12.3 & 38.3 & 2.5 & 53.0 \\
\hline & $\mathrm{Hio} / 4$ & 13.8 & 16.0 & 6.3 & 5.0 & 0.3 & 1.0 & 12.3 & 44.9 & 0.5 & 57.6 \\
\hline & Tua/1 & 18.9 & 13.2 & 6.8 & 3.5 & 0.0 & 0.2 & 13.7 & 40.3 & 3.3 & 57.3 \\
\hline & Tua/2 & 25.3 & 14.9 & 3.5 & 1.3 & 0.0 & 0.0 & 38.7 & 12.8 & 3.5 & 54.9 \\
\hline & Tua/3 & 17.4 & 9.7 & 3.7 & 2.7 & 0.7 & 0.2 & 32.8 & 31.8 & 0.7 & 65.4 \\
\hline & Tua/4 & 7.7 & 5.0 & 4.7 & 1.7 & 0.2 & 0.2 & 27.6 & 47.0 & 5.7 & 80.3 \\
\hline & Tua/5 & 20.0 & 5.0 & 4.0 & 2.0 & 0.0 & 0.0 & - & - & - & 69.0 \\
\hline & Tala/1 & 67.6 & 20.5 & 4.1 & 2.4 & 1.9 & 0.0 & 2.4 & 0.0 & 0.8 & 3.2 \\
\hline & Tala/2 & 63.6 & 14.5 & 6.9 & 9.8 & 0.7 & 0.0 & 9.8 & 0.0 & 1.7 & 11.4 \\
\hline
\end{tabular}




\begin{tabular}{|c|c|c|c|c|c|c|c|c|c|c|c|}
\hline & Alof/1 & 31.4 & 19.4 & 15.0 & 4.4 & 0.6 & 0.0 & 25.3 & 3.1 & 0.8 & 29.2 \\
\hline Location & Sample & Coral & Coralline Algae & Mollusc & Halimeda & Echinoid & Misc./ Micrite & Amphistegina sp. & Baculogypsina sp. & Marginopora sp. & Foram Total \\
\hline \multirow[t]{3}{*}{ NW Coast } & Limu/1 & 40.0 & 23.1 & 11.9 & 6.9 & 3.6 & 0.3 & 6.7 & 4.4 & 3.1 & 14.2 \\
\hline & Vai/1 & 29.5 & 15.5 & 12.6 & 3.9 & 1.8 & 0.0 & 29.7 & 3.4 & 3.4 & 36.6 \\
\hline & Nama/1 & 37.6 & 16.6 & 10.0 & 10.0 & 1.1 & 0.0 & 7.6 & 16.3 & 0.8 & 24.7 \\
\hline
\end{tabular}

\begin{tabular}{|c|c|c|c|c|c|c|c|c|c|c|c|}
\hline Location & Sample & Coral & Coralline Algae & Mollusc & Halimeda & Echinoid & Misc./ Micrite & Amphistegina sp. & Baculogypsina sp. & Marginopora sp. & Foram Total \\
\hline \multirow[t]{2}{*}{ N Coast } & Ulu/1 & 51.6 & 16.8 & 16.1 & 9.5 & 0.8 & 0.5 & 3.9 & 0.5 & 0.3 & 4.7 \\
\hline & Tuo/1 & 59.7 & 18.4 & 11.9 & 4.6 & 0.8 & 0.0 & 3.5 & 0.5 & 0.5 & 4.6 \\
\hline
\end{tabular}

\begin{tabular}{|c|c|c|c|c|c|c|c|c|c|c|c|}
\hline \multirow[t]{13}{*}{ E Coast } & Taut/1 & 42.6 & 23.6 & 16.3 & 12.6 & 0.5 & 0.0 & 3.4 & 0.0 & 1.0 & 4.4 \\
\hline & Taut/2 & 56.1 & 17.3 & 15.8 & 6.7 & 1.5 & 0.3 & 1.5 & 0.0 & 0.9 & 2.4 \\
\hline & Taut/3 & 57.9 & 11.2 & 17.3 & 10.3 & 0.9 & 0.0 & 1.8 & 0.0 & 0.6 & 2.4 \\
\hline & Taut/4 & 53.3 & 15.6 & 14.7 & 10.6 & 0.6 & 0.0 & 3.9 & 0.0 & 1.4 & 5.3 \\
\hline & Taut/5 & 45.3 & 18.7 & 11.8 & 19.2 & 1.1 & 0.3 & 2.4 & 0.0 & 1.3 & 3.7 \\
\hline & Taut/6 & 60.7 & 14.3 & 13.8 & 7.0 & 1.0 & 0.0 & 2.9 & 0.3 & 0.0 & 3.1 \\
\hline & Lake/1 & 44.7 & 17.6 & 13.7 & 12.9 & 1.3 & 0.0 & 5.5 & 0.3 & 3.9 & 9.7 \\
\hline & Lake/2 & 48.9 & 23.4 & 9.5 & 10.3 & 1.8 & 0.3 & 3.7 & 1.1 & 1.1 & 5.8 \\
\hline & Lake/3 & 50.3 & 13.7 & 14.6 & 8.6 & 3.1 & 0.9 & 8.9 & 0.0 & 0.0 & 8.9 \\
\hline & Lake/4 & 64.1 & 14.8 & 10.6 & 1.8 & 1.3 & 0.3 & 6.3 & 0.0 & 0.8 & 7.1 \\
\hline & Lake/5 & 54.2 & 15.8 & 14.5 & 6.6 & 1.8 & 0.0 & 6.1 & 0.0 & 1.1 & 7.1 \\
\hline & Lake/6 & 60.0 & 13.0 & 15.0 & 5.0 & 0.5 & 0.0 & - & - & - & 6.5 \\
\hline & Lake/7 & 50.0 & 16.0 & 15.0 & 10.0 & 1.0 & 0.0 & - & - & - & 8.0 \\
\hline \multirow[t]{2}{*}{ SE Coast } & Togo/1 & 51.0 & 24.8 & 12.1 & 10.0 & 1.5 & 0.0 & 0.7 & 0.0 & 0.0 & 0.7 \\
\hline & Togo/2 & 54.1 & 15.8 & 8.8 & 16.9 & 1.9 & 0.0 & 1.9 & 0.0 & 0.7 & 2.6 \\
\hline
\end{tabular}

Note: Highlighted cells signify samples that were not observed under thin section. A broad visual observation of components and an overall count of foraminifera were carried out instead. 

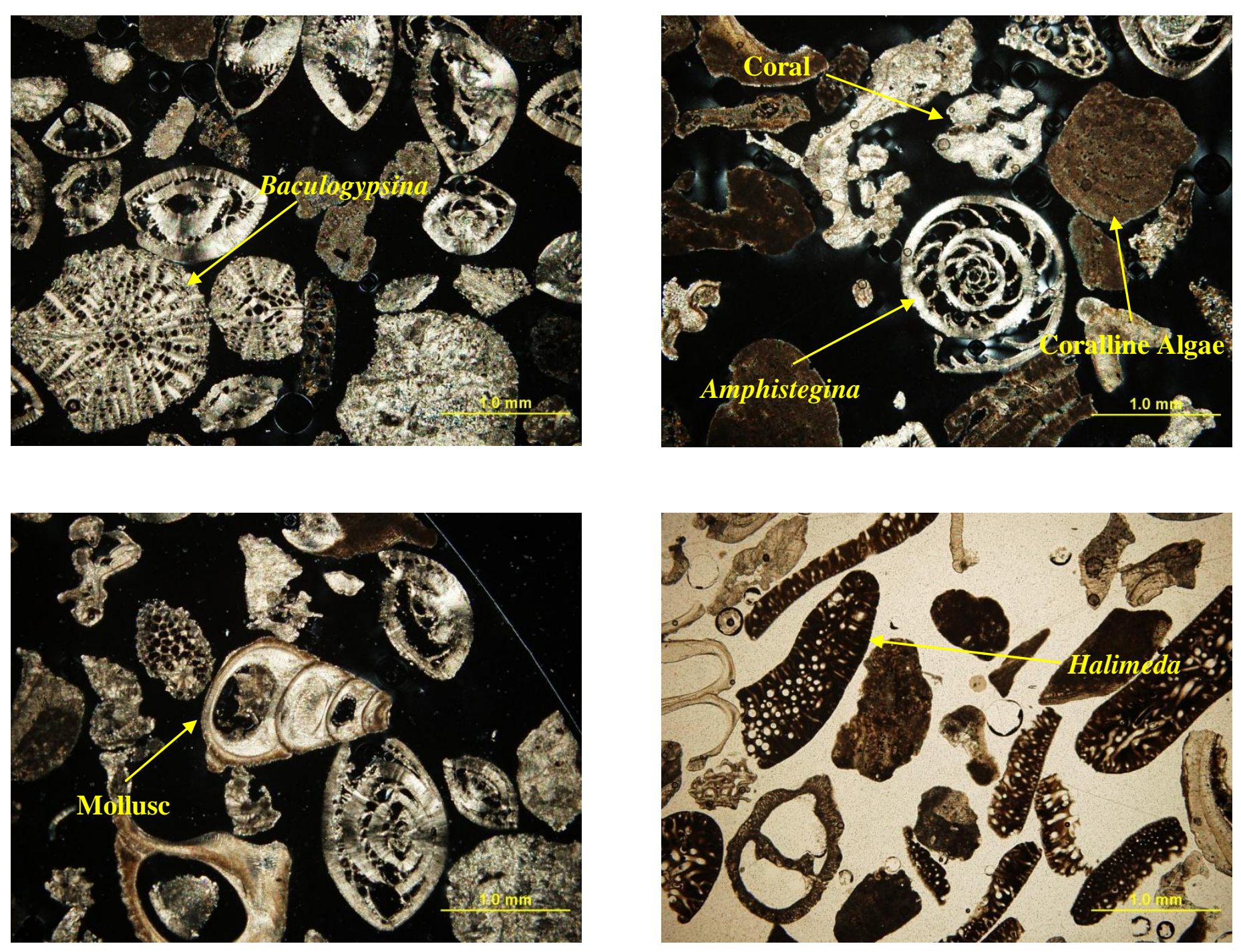

Note: Key sediment components observed under thin section for the beaches in Niue. 
APPENDIX 3: Sample locations 


\section{Sediment sample sites:}

\begin{tabular}{|l|l|l|l|}
\hline \multicolumn{2}{|c|}{ Location } & Sample & \multicolumn{1}{c|}{ Site } \\
\hline \multirow{4}{*}{ SW Coast } & \multirow{4}{*}{ Tamakautoga } & Tama/1 & Nth beach \\
\cline { 3 - 4 } & & Tama/2 & mid beach \\
\cline { 3 - 4 } & Tama/3 & HT swash \\
\cline { 3 - 4 } & Tama/4 & Sth beach 1 \\
\cline { 3 - 4 } & Tama/5 & Sth beach 2 \\
\cline { 3 - 4 } & Tama/6 & Sth beach 3 \\
\cline { 3 - 4 } & Tama/7 & Sth beach 4 \\
\cline { 3 - 4 } & Avatele & Tama/8 & Stairs-beach base \\
\cline { 3 - 4 } & Ava/1 & mid beach \\
\cline { 3 - 4 } & Ava/2 & HT berm \\
\cline { 3 - 4 } & Ava/3 & LT berm \\
\cline { 2 - 3 } & Pofitu & Pofi/1 & mid beach \\
\cline { 3 - 4 } & Pofi/2 & LT swash \\
\cline { 3 - 4 } & Pofi/3 & beach top \\
\hline
\end{tabular}

\begin{tabular}{|l|l|l|l|}
\hline \multicolumn{2}{|c|}{ Location } & Sample & \multicolumn{1}{c|}{ Site } \\
\hline \multirow{3}{*}{ W Coast } & \multirow{2}{*}{ Utuko } & Utu/1 & HT swash \\
\cline { 3 - 4 } & & Utu/2 & MT swash \\
\cline { 3 - 4 } & Utu/3 & LT swash \\
\cline { 3 - 4 } & Utu/4 & platform channel \\
\cline { 3 - 4 } & Alofi Wharf & AlofW & Sth profile-mid beach \\
\hline
\end{tabular}

\begin{tabular}{|l|l|l|l|}
\hline \multirow{2}{*}{ N Coast } & Uluvehi & Ulu/1 & platform pool \\
\cline { 2 - 4 } & Tuo & Tuo/1 & LT swash \\
\hline
\end{tabular}

\begin{tabular}{|l|l|l|l|}
\hline SE Coast & \multirow{2}{*}{ Togo } & Togo/1 & beach \\
\cline { 3 - 4 } & & Togo $/ 2$ & cave pool \\
\hline
\end{tabular}

\begin{tabular}{|c|c|c|c|}
\hline \multicolumn{2}{|c|}{ Location } & Sample & Site \\
\hline \multirow[t]{15}{*}{ NW Coast } & \multirow[t]{4}{*}{ Hio } & $\mathrm{Hio} / 1$ & platform channel \\
\hline & & $\mathrm{Hio} / 2$ & mid beach \\
\hline & & $\mathrm{Hio} / 3$ & swash \\
\hline & & $\mathrm{Hio} / 4$ & reef flat \\
\hline & \multirow[t]{5}{*}{ Tuapa } & Tua/1 & Sth beach \\
\hline & & Tua/2 & reef flat hole \\
\hline & & Tua/3 & Nth 2 beach \\
\hline & & Tua/4 & Nth1 beach-LT swash \\
\hline & & Tua/5 & Sth beach 1 (platform) \\
\hline & \multirow[t]{2}{*}{$\begin{array}{l}\text { Talava } \\
\text { Arches }\end{array}$} & Tala/1 & cave pool \\
\hline & & Tala/2 & beach \\
\hline & Alofi Tokelau & Alof/1 & pool \\
\hline & Limu & Limu/1 & pool \\
\hline & Vaila & Vai/1 & cave pool \\
\hline & Namakulu & Nama/1 & beach \\
\hline
\end{tabular}

Note: HT- high tide; MT- mid tide; LT- low tide

\begin{tabular}{|c|c|c|c|}
\hline \multirow[t]{12}{*}{ E Coast } & \multirow[t]{5}{*}{ Tautu } & Taut/1 & Sth 1 swash \\
\hline & & Taut/3 & Sth 2 swash \\
\hline & & Taut/4 & Nth 1 swash \\
\hline & & Taut/5 & Nth 2 swash \\
\hline & & Taut/6 & Nth 3 platform \\
\hline & \multirow[t]{7}{*}{ Lakepa } & Lake/1 & Nth 1 sandy patch \\
\hline & & Lake/2 & Sth 1 swash \\
\hline & & Lake/3 & stairs-sand patch \\
\hline & & Lake/4 & stairs-pool \\
\hline & & Lake/5 & Sth 1 rock pool \\
\hline & & Lake/6 & Nth beach 1-rock pool \\
\hline & & Lake/7 & Nth beach 1-gravel side \\
\hline
\end{tabular}


APPENDIX 4: Radiocarbon dating results 


\section{The University of Waikato \\ Radiocarbon Dating Laboratory}

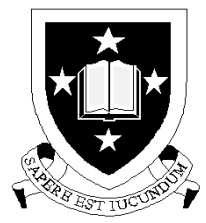

Private Bag 3105

Hamilton,

New Zealand.

Fax +6478384192

$\mathrm{Ph}+6478384278$

email c14@waikato.ac.nz

Head: Dr Alan Hogg

\section{Report on Radiocarbon Age Determination for Wk- 24514}

\author{
Submitter \\ Submitter's Code \\ Site \& Location \\ Sample Material \\ Physical Pretreatment
}

Chemical Pretreatment
D.M Kennedy

Niue-reef top

Tamakautoga Village, Niue

Coralline Algae

Surfaces cleaned. Washed in an ultrasonic bath. Tested for recrystallization: aragonite.

Sample was washed in $2 \mathrm{M} \mathrm{HCl}$ for 100 seconds.
$\delta^{13} \mathrm{C}$ $1.7 \pm 0.2 \%$
$\mathrm{D}^{14} \mathrm{C}$ $-367.6 \pm 3.2 \%$
$\mathrm{F}^{14} \mathrm{C} \%$
$63.2 \pm 0.3 \%$

Result $\quad 3681 \pm 40 \mathrm{BP}$

\section{Comments}

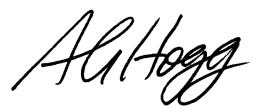

$17 / 12 / 08$

- Result is Conventional Age or \% Modern as per Stuiver and Polach, 1977, Radiocarbon 19, 355-363. This is based on the Libby half-life of $5568 \mathrm{yr}$ with correction for isotopic fractionation applied. This age is normally quoted in publications and must include the appropriate error term and Wk number.

- Quoted errors are 1 standard deviation due to counting statistics multiplied by an experimentally determined Laboratory Error Multiplier.

- The isotopic fractionation, $\delta^{13} C$, is expressed as \%o wrt PDB.

- $\mathrm{F}^{14} \mathrm{C} \%$ is also known as pMC (percent modern carbon). 


\section{The University of Waikato \\ Radiocarbon Dating Laboratory}

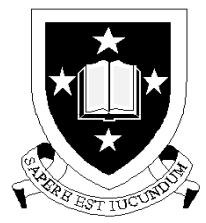

Private Bag 3105

Hamilton,

New Zealand.

Fax +6478384192

$\mathrm{Ph}+6478384278$

email c14@waikato.ac.nz

Head: Dr Alan Hogg

\section{Report on Radiocarbon Age Determination for Wk- 24515}

\author{
Submitter \\ Submitter's Code \\ Site \& Location \\ Sample Material \\ Physical Pretreatment
}

Chemical Pretreatment
D.M Kennedy

Niue1

Tamakautoga Village, Niue

reef top microatoll

Surfaces cleaned. Washed in an ultrasonic bath. Tested for recrystallization: aragonite (salt inhibited staining).

Sample was washed in $2 \mathrm{M} \mathrm{HCl}$ for 100 seconds.
$\delta^{13} \mathrm{C}$ $-1.4 \pm 0.2 \%$
$\mathrm{D}^{14} \mathrm{C}$
$116.8 \pm 4.6 \%$
$\mathrm{F}^{14} \mathrm{C} \%$
$111.7 \pm 0.5 \quad \%$

Result $\quad 111.7 \pm 0.5 \%$

\section{Comments}

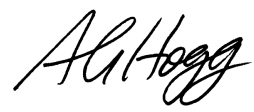

$17 / 12 / 08$

- Result is Conventional Age or \% Modern as per Stuiver and Polach, 1977, Radiocarbon 19, 355-363. This is based on the Libby half-life of $5568 \mathrm{yr}$ with correction for isotopic fractionation applied. This age is normally quoted in publications and must include the appropriate error term and Wk number.

- Quoted errors are 1 standard deviation due to counting statistics multiplied by an experimentally determined Laboratory Error Multiplier.

- The isotopic fractionation, $\delta^{13} C$, is expressed as \%o wrt PDB.

- $\mathrm{F}^{14} \mathrm{C} \%$ is also known as pMC (percent modern carbon). 


\section{The University of Waikato \\ Radiocarbon Dating Laboratory}

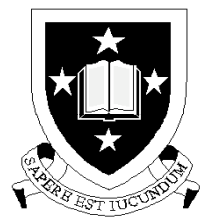

Private Bag 3105

Hamilton,

New Zealand.

Fax +6478384192

$\mathrm{Ph}+6478384278$

email c14@waikato.ac.nz

Head: Dr Alan Hogg

\section{Report on Radiocarbon Age Determination for Wk- 24516}

\author{
Submitter \\ Submitter's Code \\ Site \& Location \\ Sample Material \\ Physical Pretreatment
}

Chemical Pretreatment
D.M Kennedy

Niue2

Tamakautoga Village, Niue

reef top microatoll

Surfaces cleaned. Washed in an ultrasonic bath. Tested for recrystallization: aragonite (salt inhibited staining).

Sample was washed in $2 \mathrm{M} \mathrm{HCl}$ for 100 seconds. $\delta^{13} \mathrm{C}$

$\mathrm{D}^{14} \mathrm{C}$

$\mathrm{F}^{14} \mathrm{C} \%$

Result $\quad 360 \pm 45 \mathrm{BP}$

\section{Comments}

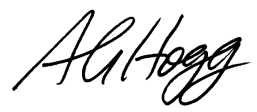

$17 / 12 / 08$

- Result is Conventional Age or \% Modern as per Stuiver and Polach, 1977, Radiocarbon 19, 355-363. This is based on the Libby half-life of $5568 \mathrm{yr}$ with correction for isotopic fractionation applied. This age is normally quoted in publications and must include the appropriate error term and Wk number.

- Quoted errors are 1 standard deviation due to counting statistics multiplied by an experimentally determined Laboratory Error Multiplier.

- The isotopic fractionation, $\delta^{13} C$, is expressed as \%o wrt PDB.

- $\mathrm{F}^{14} \mathrm{C} \%$ is also known as pMC (percent modern carbon). 


\section{The University of Waikato \\ Radiocarbon Dating Laboratory}

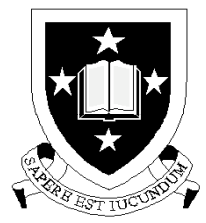

Private Bag 3105

Hamilton,

New Zealand.

Fax +6478384192

$\mathrm{Ph}+6478384278$

email c14@waikato.ac.nz

Head: Dr Alan Hogg

\section{Report on Radiocarbon Age Determination for Wk- 24517}

\author{
Submitter \\ Submitter's Code \\ Site \& Location \\ Sample Material \\ Physical Pretreatment
}

Chemical Pretreatment
D.M Kennedy

Niue3

Tamakautoga Village, Niue

reef top microatoll

Surfaces cleaned. Washed in an ultrasonic bath. Tested for recrystallization: aragonite.

Sample was washed in $2 \mathrm{M} \mathrm{HCl}$ for 100 seconds.
$\delta^{13} \mathrm{C}$
$-1.1 \pm 0.2 \%$
$\mathrm{D}^{14} \mathrm{C}$
$152.3 \pm 5.1 \%$
$\mathrm{F}^{14} \mathrm{C} \%$
$115.2 \pm 0.5 \%$
Result $\quad 115.2 \pm 0.6 \%$

\section{Comments}

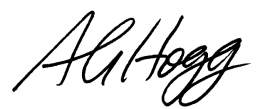

$17 / 12 / 08$

- Result is Conventional Age or \% Modern as per Stuiver and Polach, 1977, Radiocarbon 19, 355-363. This is based on the Libby half-life of $5568 \mathrm{yr}$ with correction for isotopic fractionation applied. This age is normally quoted in publications and must include the appropriate error term and Wk number.

- Quoted errors are 1 standard deviation due to counting statistics multiplied by an experimentally determined Laboratory Error Multiplier.

- The isotopic fractionation, $\delta^{13} C$, is expressed as \%o wrt PDB.

- $\mathrm{F}^{14} \mathrm{C} \%$ is also known as pMC (percent modern carbon). 


\section{The University of Waikato \\ Radiocarbon Dating Laboratory}

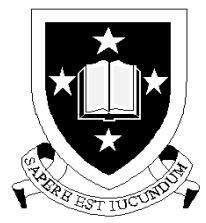

Private Bag 3105

Hamilton,

New Zealand.

Fax +6478384192

$\mathrm{Ph}+6478384278$

email c14@waikato.ac.nz

Head: Dr Alan Hogg

\section{Report on Radiocarbon Age Determination for Wk- 24518}

\author{
Submitter \\ Submitter's Code \\ Site \& Location \\ Sample Material \\ Physical Pretreatment
}

Chemical Pretreatment
D.M Kennedy

Niue4

Tamakautoga Village, Niue

Reef top microatoll

Surfaces cleaned. Washed in an ultrasonic bath. Tested for recrystallization: aragonite (salt inhibited staining).

Sample was washed in $2 \mathrm{M} \mathrm{HCl}$ for 100 seconds.
$\delta{ }^{13} \mathrm{C}$ $-0.6 \pm 0.2 \%$
$\mathrm{D}^{14} \mathrm{C}$
$-57.3 \pm 4.7 \%$
$\mathrm{F}^{14} \mathrm{C} \%$
$94.3 \pm 0.5 \%$

Result $\quad 474 \pm 39$ BP

\section{Comments}

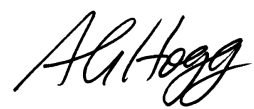

$17 / 12 / 08$

- Result is Conventional Age or \% Modern as per Stuiver and Polach, 1977, Radiocarbon 19, 355-363. This is based on the Libby half-life of $5568 \mathrm{yr}$ with correction for isotopic fractionation applied. This age is normally quoted in publications and must include the appropriate error term and Wk number.

- Quoted errors are 1 standard deviation due to counting statistics multiplied by an experimentally determined Laboratory Error Multiplier.

- The isotopic fractionation, $\delta^{13} C$, is expressed as \%o wrt PDB.

- $\mathrm{F}^{14} \mathrm{C} \%$ is also known as pMC (percent modern carbon). 


\section{The University of Waikato \\ Radiocarbon Dating Laboratory}

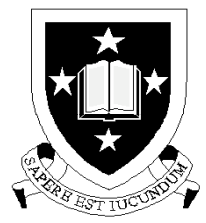

Private Bag 3105

Hamilton,

New Zealand.

Fax +6478384192

$\mathrm{Ph}+6478384278$

email c14@waikato.ac.nz

Head: Dr Alan Hogg

\section{Report on Radiocarbon Age Determination for Wk- 24519}

\author{
Submitter \\ Submitter's Code \\ Site \& Location \\ Sample Material \\ Physical Pretreatment
}

Chemical Pretreatment
D.M Kennedy

Niue5

Tamakautoga Village, Niue

reef top microatoll

Surfaces cleaned. Washed in an ultrasonic bath. Tested for recrystallization: aragonite (salt inhibited staining).

Sample was washed in $2 \mathrm{M} \mathrm{HCl}$ for 100 seconds. $\delta^{13} \mathrm{C}$

$\mathrm{D}^{14} \mathrm{C}$

$\mathrm{F}^{14} \mathrm{C} \%$

Result $\quad 502 \pm 35$ BP

\section{Comments}

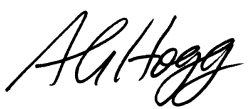

$17 / 12 / 08$

- Result is Conventional Age or \% Modern as per Stuiver and Polach, 1977, Radiocarbon 19, 355-363. This is based on the Libby half-life of $5568 \mathrm{yr}$ with correction for isotopic fractionation applied. This age is normally quoted in publications and must include the appropriate error term and Wk number.

- Quoted errors are 1 standard deviation due to counting statistics multiplied by an experimentally determined Laboratory Error Multiplier.

- The isotopic fractionation, $\delta^{13} C$, is expressed as \%o wrt PDB.

- $\mathrm{F}^{14} \mathrm{C} \%$ is also known as pMC (percent modern carbon). 


\section{The University of Waikato \\ Radiocarbon Dating Laboratory}

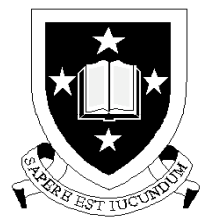

Private Bag 3105

Hamilton,

New Zealand.

Fax +6478384192

$\mathrm{Ph}+6478384278$

email c14@waikato.ac.nz

Head: Dr Alan Hogg

\section{Report on Radiocarbon Age Determination for Wk- 24520}

\author{
Submitter \\ Submitter's Code \\ Site \& Location \\ Sample Material \\ Physical Pretreatment
}

Chemical Pretreatment
D.M Kennedy

Niue6

Tamakautoga Village, Niue

Reef top microatoll

Surfaces cleaned. Washed in an ultrasonic bath. Tested for recrystallization: aragonite (salt inhibited staining).

Sample was washed in $2 \mathrm{M} \mathrm{HCl}$ for 100 seconds.
$\delta{ }^{13} \mathrm{C}$ $-1.1 \pm 0.2 \%$
$\mathrm{D}^{14} \mathrm{C}$
$2.6 \pm 4.9 \%$
$\mathrm{F}^{14} \mathrm{C} \%$
$100.3 \pm 0.5 \%$

Result $\quad 100.3 \pm 0.5 \%$

\section{Comments}

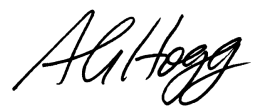

$17 / 12 / 08$

- Result is Conventional Age or \% Modern as per Stuiver and Polach, 1977, Radiocarbon 19, 355-363. This is based on the Libby half-life of $5568 \mathrm{yr}$ with correction for isotopic fractionation applied. This age is normally quoted in publications and must include the appropriate error term and Wk number.

- Quoted errors are 1 standard deviation due to counting statistics multiplied by an experimentally determined Laboratory Error Multiplier.

- The isotopic fractionation, $\delta^{13} C$, is expressed as \%o wrt PDB.

- $\mathrm{F}^{14} \mathrm{C} \%$ is also known as pMC (percent modern carbon). 


\section{The University of Waikato \\ Radiocarbon Dating Laboratory}

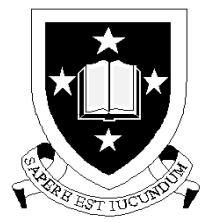

Private Bag 3105

Hamilton,

New Zealand.

Fax +6478384192

$\mathrm{Ph}+6478384278$

emailc14@waikato.ac.nz

Head: Dr Alan Hogg

\section{Report on Radiocarbon Age Determination for Wk- 24832}

( AMS measurement )

\author{
Submitter \\ Submitter's Code \\ Site \& Location \\ Sample Material \\ Physical Pretreatment
}

Chemical Pretreatment
D.M Kennedy

Tamakau 1

Tamakautoga Beach, Niue

foraminifera

Surfaces cleaned. Washed in an ultrasonic bath. Calcitic species.

Sample acid washed using $0.1 \mathrm{~N} \mathrm{HCl}$, rinsed and dried. $\delta^{13} \mathrm{C}$

$\mathrm{D}^{14} \mathrm{C}$

$\mathrm{F}^{14} \mathrm{C} \%$

Result $\quad 108.3 \pm 0.3 \%$

\section{Comments}

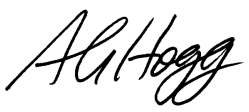

$4 / 2 / 09$

- Result is Conventional Age or \% Modern as per Stuiver and Polach, 1977, Radiocarbon 19, 355-363. This is based on the Libby half-life of $5568 \mathrm{yr}$ with correction for isotopic fractionation applied. This age is normally quoted in publications and must include the appropriate error term and Wk number.

- Quoted errors are 1 standard deviation due to counting statistics multiplied by an experimentally determined Laboratory Error Multiplier.

- The isotopic fractionation, $\delta^{13} C$, is expressed as \%o wrt PDB.

- $\mathrm{F}^{14} \mathrm{C} \%$ is also known as pMC (percent modern carbon). 


\section{The University of Waikato \\ Radiocarbon Dating Laboratory}

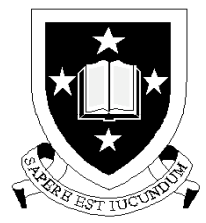

Private Bag 3105

Hamilton,

New Zealand.

Fax +6478384192

$\mathrm{Ph}+6478384278$

email c14@waikato.ac.nz

Head: Dr Alan Hogg

\section{Report on Radiocarbon Age Determination for Wk- 24833}

( AMS measurement)

Submitter

Submitter's Code

Site \& Location

Sample Material

Physical Pretreatment

Chemical Pretreatment
D.M Kennedy

Tamakau 2

Tamakautoga Beach, Niue

Surfaces cleaned. Washed in an ultrasonic bath. Tested for recrystallization: aragonite.

Sample acid washed using $0.1 \mathrm{~N} \mathrm{HCl}$, rinsed and dried.
$\delta^{13} \mathrm{C}$
$-0.7 \pm 0.2 \%$
$\mathrm{D}^{14} \mathrm{C}$
$116.8 \pm 1.5 \%$
$\mathrm{F}^{14} \mathrm{C} \%$
$111.7 \pm 0.2 \%$
Result $\quad 111.7 \pm 0.2 \%$

\section{Comments}

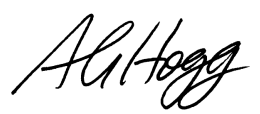

$4 / 2 / 09$

- Result is Conventional Age or \% Modern as per Stuiver and Polach, 1977, Radiocarbon 19, 355-363. This is based on the Libby half-life of $5568 \mathrm{yr}$ with correction for isotopic fractionation applied. This age is normally quoted in publications and must include the appropriate error term and Wk number.

- Quoted errors are 1 standard deviation due to counting statistics multiplied by an experimentally determined Laboratory Error Multiplier.

- The isotopic fractionation, $\delta^{13} C$, is expressed as \%o wrt PDB.

- $\mathrm{F}^{14} \mathrm{C} \%$ is also known as pMC (percent modern carbon). 


\section{The University of Waikato \\ Radiocarbon Dating Laboratory}

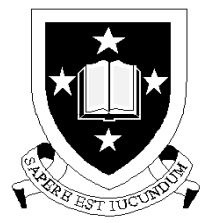

Private Bag 3105

Hamilton,

New Zealand.

Fax +6478384192

$\mathrm{Ph}+6478384278$

email c14@waikato.ac.nz

Head: Dr Alan Hogg

\section{Report on Radiocarbon Age Determination for Wk- 24834}

( AMS measurement )

\author{
Submitter \\ Submitter's Code \\ Site \& Location \\ Sample Material \\ Physical Pretreatment
}

Chemical Pretreatment
D.M Kennedy

Tamakau 3

Tamakautoga Beach, Niue

mollusc

Surfaces cleaned. Washed in an ultrasonic bath. Tested for recrystallization: aragonite.

Sample acid washed using $0.1 \mathrm{~N} \mathrm{HCl}$, rinsed and dried. $\delta^{13} \mathrm{C}$

$\mathrm{D}^{14} \mathrm{C}$

$\mathrm{F}^{14} \mathrm{C} \%$

Result $\quad 109.1 \pm 0.2 \%$

\section{Comments}

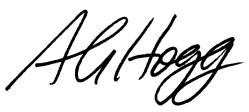

$4 / 2 / 09$

- Result is Conventional Age or \% Modern as per Stuiver and Polach, 1977, Radiocarbon 19, 355-363. This is based on the Libby half-life of $5568 \mathrm{yr}$ with correction for isotopic fractionation applied. This age is normally quoted in publications and must include the appropriate error term and Wk number.

- Quoted errors are 1 standard deviation due to counting statistics multiplied by an experimentally determined Laboratory Error Multiplier.

- The isotopic fractionation, $\delta^{13} C$, is expressed as \%o wrt PDB.

- $\mathrm{F}^{14} \mathrm{C} \%$ is also known as pMC (percent modern carbon). 